UNIVERSIDAD NACIONAL DE LA PLATA

FACULTAD DE CIENCIAS NATURALES Y MUSEO

\title{
PRODUCTIVIDAD EN PASTIZALES SERRANOS A LO LARGO DEL GRADIENTE ALTITUDINAL
}

por

Carolina Alcjandra Pércz.

Director: Dr. Jorge Luis Frangi

Trabajo de Tesis presentado a la Facultad de Ciencias Naturales Y Museo de La Universidad Nacional de La Plata, para optar al Título de Doctor en Ciencias Naturales, Orientación Ecología y Conservación de los Recursos Naturales Renovables. 


\title{
PRODUCTIVIDAD EN PASTIZALES SERRANOS A LO LARGO DEL GRADIENTE ALTITUDINAL
}

\author{
Carolina Alejandra Pérez
}

Trabajo de Tesis presentado a la Facultad de Ciencias Naturales Y Museo de La Universidad Nacional de La Plata, para optar al Título de Doctor en Ciencias Naturales, Orientación Ecología y Conservación de los Recursos Naturales Renovables.

\section{RESUMEN}

\section{Introducción}

El presente es un estudio de la estructura y función de pastizales serranos de las cuencas altas de las Sierras Australes, los cuales adquieren importancia en el control de la erosión y en el mantenimiento de calidad del agua de los arroyos.

Tiene como fin estimar la biomasa y la productividad primaria neta, aérea y subterránea de pastizales de la cuenca alta del Arroyo Sauce Grande y establecer si existen diferencias de comportamiento de esas variables a lo largo de un gradiente complejo: la altitud. En segundo lugar se intenta caracterizar a los ciclos biogeoquímicos del C, N, P, K y Ca en pastizales naturales, a lo largo del mismo gradiente altitudinal.

Las respuestas a las siguientes preguntas constituyen objetivos específicos de este estudio: ¿Cambia la inversión relativa de fotosintatos entre la parte aérea y la parte subterránea a medida que varían los factores ecológicos relacionados con la altitud?

¿Difiere la producción primaria neta total a distintas alturas?

¿Cuál es la tasa de renovación de la biomasa aérea y subterránea? ¿Varía con la altitud? ¿Varían estacionalmente las concentraciones de los nutrientes principales, N, P, K y Ca, en la materia seca?

¿Cómo es la distribución de la biomasa y la asignación de nutrientes hacia los órganos aéreos y subterráneos en estos pastizales?

¿Existen diferencias en el contenido de nutrientes y ciclado de los mismos en los pastizales ubicados a diferente altitud? 


\section{Materiales y métodos}

El estudio se realizó en tres pastizales ubicados sobre una transecta altitudinal, entre los 550 y $1100 \mathrm{~m} \mathrm{sm}$, en la vertiente oriental del cerro El Destierro I, en el Parque provincial Ernesto Tornquist en Sierra de la Ventana (Provincia de Buenos Aires). Los sitios de muestreo se situan a 1025, 850 y $550 \mathrm{~m} \mathrm{sm}$. Los dos primeros corresponden a la comunidad de Sorghastrum pellitum y Stipa filliculmis y el tercero a un pastizal de Piptochaetium hackelii + P. napostaense y Briza subaristata (flechillar) (Frangi y Botino 1995). En cada sitio se instalaron clausuras para evitar el pastoreo de grandes herbívoros. Para la estimación de la materia seca aérea se empleó el método de cosecha (Milner y Hughes 1970), en nueve fechas entre julio de 1988 y julio de 1989. La productividad primaria aérea neta se calculó mediante el método de suma de incrementos de biomasa (Frangi et al. 1980a). La materia seca subterránea se estimó a partir de la extracción de cilindros de suelo hasta los $20 \mathrm{~cm}$ de profundidad, en las mismas fechas en que se realizó la cosecha del material aéreo. La productividad subterránea neta se calculó por diferencias de biomasa aplicando la fórmula de Frangi et al. (1980a). La productividad neta total se estimó como la suma de las productividades aérea + subterránea.

Se realizaron análisis químicos de alícuotas de las muestras obtenidas (biomasa aérea, necromasa aérea, biomasa subterránea, necromasa subterránea). La concentracion de $\mathrm{N}$ fue medida por la técnica de semi-micro Kjeldahl; las concentraciones de $\mathbf{P}, \mathbf{K}$ y $\mathbf{C a}$ fueron determinadas mediante un espectrómetro de emisión de plasma Beckman Spectra Scan. Para obtener el contenido de carbono de la biomasa se multiplicó el valor de materia organica por 0,465 .

Se estimaron: mineralomasa, necronutrientes, almacenajes mineral, nutrientes en los horizontes minerales del suelo y minerales totales.

Se han desarrollado fórmulas específicas de cálculo de los flujos requerimientos, retorno, retención, translocación, descomposición (materia orgánica) o mineralización (nutrientes) y absorción.

Se realizaron los siguientes análisis de los suelos de los pastizales: textura, bases de intercambio, reacción del suelo, concentración del fósforo disponible total, nitrógeno disponible total y porcentaje de carbono. 
Se realizaron modelos de los ciclos de materia seca, materia orgánica, nitrógeno, fósforo, potasio y calcio en los tres pastizales, empleando el lenguaje de energia de Howard T. Odum (1971).

\section{Resultados}

La materia seca total (aérea + subterránea) promedio anual es mayor en el pastizal superior $\left(1507 \pm 63 \mathrm{~g} / \mathrm{m}^{2}\right)$ que en los otros dos pastizales situados más abajo $\left(1208 \pm 70 \mathrm{~g} / \mathrm{m}^{2}\right.$ a 850 $\mathrm{m} \mathrm{sm}$ y $1184 \pm 41 \mathrm{~g} / \mathrm{m}^{2}$ a $550 \mathrm{~m} \mathrm{sm}$ ). En los pastizales más elevados (1025 m sm y $850 \mathrm{~m}$ sm) la materia seca aérea es menor ( $369 \pm 19 \mathrm{~g} / \mathrm{m}^{2}$ y $406 \pm 37 \mathrm{~g} / \mathrm{m}^{2}$ respectivamente) que en el inferior ( $\left.535 \pm 11 \mathrm{~g} / \mathrm{m}^{2}\right)$, a la vez que la materia seca subterránea del pastizal superior $\left(1131 \pm 67 \mathrm{~g} / \mathrm{m}^{2}\right)$, es mayor que la de los otros dos $\left(783 \pm 84 \mathrm{~g} / \mathrm{m}^{2}\right.$ y $642 \pm 49 \mathrm{~g} / \mathrm{m}^{2}$ a 850 y $550 \mathrm{~m}$ sm respectivamente) (test $t$ de Student, $\mathrm{P}<0,05$ ).

La productividad primaria neta total anual es similar en los tres pastizales ubicados a lo largo del gradiente altitudinal $\left(1157 \mathrm{~g} / \mathrm{m}^{2}\right.$.año en el superior, $1280 \mathrm{~g} / \mathrm{m}^{2}$.año a media ladera y $1131 \mathrm{~g} / \mathrm{m}^{2}$.año en el inferior. El pastizal superior se diferencia de los otros dos en que asigna una mayor proporción del crecimiento neto anual a las raíces (67\% 54 y $59 \%$ respectivamente)

Las mayores concentraciones de los nutrientes considerados se encuentran en la biomasa aérea. La concentración de $\mathrm{P}$ y $\mathrm{N}$ es similar entre los compartimientos aéreos vivos y es a su vez mayor que en los muertos, entre los cuales no se detectaron diferencias significativas $(\mathrm{P}<0,05)$. La concentración de $\mathrm{K}$ en los compartimientos aéreos se ordena del siguiente modo: dicotiledóneas $=$ gramíneas $>$ estructuras reproductivas $>>$ seco en pie $>$ hojarasca. La concentración de Ca es mayor en las dicotiledóneas que en la hojarasca y ambas superan a los restantes compartimientos aéreos, los cuales presentan valores similares. En las raíces, las concentraciones de los nutrientes analizados son mayores en las finas muertas, le siguen en orden de importancia las finas vivas, y las gruesas vivas. Las raíces gruesas muertas presentan valores cercanos a los de las finas muertas.

En los tejidos aéreos, las mayores concentraciones de los nutrientes analizados, se observan en el pastizal inferior. En las raíces finas no se detectan diferencias en las concentraciones entre pastizales, mientras que en las raíces gruesas vivas, las concentraciones de $\mathrm{P}, \mathrm{K}$ y $\mathrm{Ca}$ son mayores en el pastizal inferior $(\mathrm{P}<0,05)$. 
Los mayores requerimientos de nutrientes en cuanto a $\mathrm{P}, \mathrm{N}$ y $\mathrm{K}$ corresponden al pastizal inferior, y decrecen con la altitud, en relación con la diferente asignación de la asimilación neta en órganos aéreos y subterráneos en los pastizales situados a diferente altitud. En los tres sitios, el retorno de materia orgánica y nutrientes al suelo desde la vegetación ocurre principalmente a través de la mortalidad de las raíces.

En el texto se detalla la dinámica estacional de los pastizales.

\section{Conclusiones}

En los pastizales serranos la materia seca total es mayor en el sitio cercano a la cumbre con respecto a ubicados a media ladera y en el pie de monte. Se verifica que con la altitud existe una diferente partición de la biomasa entre las estructuras aéreas y subterráneas. La proporción de raíces aumenta, en tanto que la materia seca aérea disminuye desde el pie de monte hacia la cumbre.

La diferente partición de la biomasa y asignación de fotosintatos entre estructuras aéreas y subterráneas en los pastizales de diferente altitud constituye una respuesta adaptativa a las características ambientales asociadas con la altitud, tales como el descenso térmico, la mayor velocidad del viento en la cumbre y la menor profundidad de los suelos de los pastizales ubicados sobre el cerro.

La productividad primaria neta total es similar en los pastizales de diferente altitud. Se verifica, en cambio, que la asignación de fotosintatos hacia los órganos subterráneos aumenta desde la base hacia la cima, a la vez que disminuye la proporción asignada a las estructuras aéreas.

La productividad total semejante tiene que derivar de una combinación distinta del aporte del índice de área foliar y del período de producción, en cada pastizal. En la parte superior de los cerros un mayor período hídricamente favorable se combina con una menor masa fotosintética; en tanto en los basales una mayor alternancia de periodos secos y húmedos del suelo se asocia a una mayor biomasa verde.

La importancia de los períodos inverno-primaveral y estivo-otoñal en cuanto a su contribución a la productividad anual varía altitudinalmente. En los pastizales de mayor altitud, la mayor parte de la producción anual es inverno-primaveral, mientras que en el pie de monte, ambos períodos mencionados son igualmente productivos. 
El patrón de distribución estacional de fotoasimilados entre tejidos aéreos y subterráneos varía altitudinalmente. En el pastizal superior, relativamente más frío y anualmente más isotermo, la mayor parte de la productividad es asignada a la raíces, independientemente de la época del año. En los sitios de menor altitud, con una mayor amplitud térmica estacional, durante el período inverno-primaveral predomina la producción subterránea, y durante el otoño, la producción aérea.

En los pastizales serranos, la renovación de los tejidos aéreos y subterráneos opera a tasas diferentes, siendo menor el tiempo de renovación en los primeros que los últimos. A su vez, las tasas de renovación de la materia seca varían altitudinalmente. El pastizal superior, sometido a condiciones relativamente menos favorables muestra las menores tasas de renovación tanto aéreas como subterráneas.

La productividad del pastizal es sostenida en los aspectos nutricionales por mecanismos de absorción de nutrientes, de dilución de las concentraciones en la biomasa y por retranslocación. Las efíciencias en el uso de los nutrientes aumentan con la menor disponibiliad de los mismos en el suelo.

La partición de la materia seca en tejidos aéreos y subterráneos refleja en gran medida la distribución del almacenajes de $\mathrm{N}$ y $\mathrm{P}$ en la vegetación, pero no ocurre lo mismo con el $\mathrm{K}$ y el Ca.

La variación altitudinal en la distribución de la materia seca tiene importantes implicancias en el presupuesto de nutrientes en los pastizales serranos. En concordancia con el aumento en la proporción de materia seca aérea hacia el pie de monte, la cantidad de nutrientes circulando en la vegetación aumenta en esa dirección.

Desde el punto de vista de su uso, el pastizal de menor altitud, además de ser más accesible para el ganado y presentar mayor disponibilidad de forraje, es de mejor valor nutricional, ya que presenta las mayores concentraciones de nutrientes en los tejidos aéreos.

Las concentraciones y contenidos de los nutrientes en los tres sitios analizados mostraron un patrón similar en su variación estacional. Los períodos primaveral y otoñal tempranos son los más favorables para los herbívoros desde el punto de vista de la concentración de nutrientes en la biomasa aérea.

Las raíces constituyen la principal via de incorporación al suelo de la materia orgánica y de los nutrientes, tanto por ser el principal almacenaje de los mismos en la vegetación como por su rápida incorporación al suelo y descomposición. 
La gran proporción de biomasa y productividad subterráneas es relevante para el suministro de materia orgánica y nutrientes al suelo, mantener su estructura y demás características propias de aquel que junto a la fitomasa aérea ayudan a reducir los riesgos erosivos que puedan causar el agua y el viento.

El manejo de los rodeos deberá considerar el valor protector de las cuencas altas que tiene la vegetación graminosa, capaz de restaurarse en pocos años luego de disturbios agudos como el fuego o los años secos, ya que el sobrepastoreo crónico provoca cambios más profundos que comprometen la recuperación de la estructura del pastizal y su función protectora.

En concordancia con el punto anterior, las cuencas altas serranas incluídas en Reservas Naturales con pastadores exóticos, tales como los caballos del Parque Provincial Ernesto Tornquist, carentes de control humano poblacional comprometen seriamente la función protectora de los pastizales naturales.

En esta zona, las razones de protección y conservación de los recursos naturales que son el objeto mismo de los Parques y Reservas, adquieren significado específico y concreto, ya que no sólo se conserva la biodiversidad nativa en sus distintas escalas, sino que se ayuda a preservar la calidad de los recursos hídricos que, procedentes de estas altas cuencas son embalsados en Paso de Piedras para su potabilización y consumo en Bahía Blanca. 


\section{AGRADECIMIENTOS}

Quiero expresar mi gratitud a todas las personas que han contribuído a la realización de este trabajo:

Al Dr. Jorge Frangi, por haberme confiado la realización de este trabajo, por su tolerancia y especialmente por brindarme la oportunidad de aprender bajo su criteriosa guía.

A la Comisión de Investigaciones Científicas de la Provincia de Buenos Aires y a la Cooperadora del Parque Provincial Ernesto Tornquist por la financiación de este trabajo.

A la Universidad Nacional de La Plata y a la Comisión de Investigaciones Científicas de la Provincia de Buenos Aires por las becas otorgadas.

A Mary Jean Sánchez y al Instituto Internacional de Dasonomía Tropical del departamento de Agricultura de los Estados Unidos por la realización de los análisis químicos de la vegetación.

Al Laboratorio de Investigaciones de Sistemas Ecológicos y Ambientales (LISEA) por el lugar de trabajo y en especial a Juan, Juanjo, Marcelito, Marcelo y Pablo por su amabilidad y compañerismo.

A Alberto, Gabriela, Marcela, María Laura, María Julia, Martha, Nora, Susana y Susanita por el trabajo compartido, por el apoyo y el afecto que siempre recibo de ellos.

A la Dra Amelia Torres por las consultas realizadas sobre las gramíneas encontradas y por la amabilidad con que siempre me ha recibido.

A la Dra. Marta Cabello por los análisis de micorrizas y por su asesoramiento en el tema.

Al Ingeniero Agr. Lanfranco, por su asesoramiento en la interpretación de los análisis de suelos. 
Al Ingeniero Ftal. Pablo Yapura por la digitalización y compaginación de figuras.

Al Lic. Marcelo Arturi y al Ingeniero Ftal. Cristian Carranza (Pirson) por ayudarme a resolver el tratamiento estadístico de los datos.

A Ramiro Filiberto por el ingreso de datos de nutrientes.

A todos aquellos con los que comparti las tareas de campo, a los alumnos de Ecología General, en particular a Gustavo Alarcón, Mariano Bilos y Roberto Repp y a mis compañenos Alberto, Liliana, Guillermo y Marcela por su esfuerzo y por los buenos momentos compartidos.

Al que fuera director del Parque Tornquist, Edgardo Lugones, a su esposa Dina, y a Norberto, por su hospitalidad y por tratar siempre de facilitarnos los trabajos de campo.

A mis padres que siempre me han respaldado y alentado en mi trabajo y en todo momento están a mi lado.

A mis suegros por su incondicional apoyo.

Quiero agraceder especialmente a Walter, mi esposo, que me ha acompañado en todo momento, me ha ayudado y alentado constantemente. A él, a Emilio y a Mauri, por el tiempo que no les dí y por todo el amor que ellos me brindan. 
INTRODUCCION

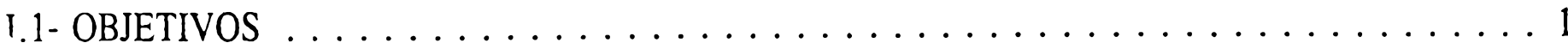

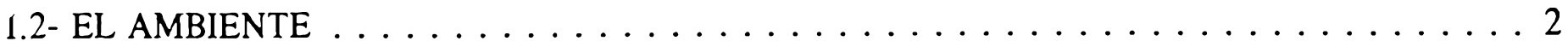

.. MATERIALES Y METODOS

II.1- UBICACION DEL AREA DE ESTUDIO Y CARACTERISTICAS DE LOS SITIOS $\ldots \ldots \ldots 7$

1I.2- CARACTERISTICAS PLUVIOMETRICAS DEL PERIODO

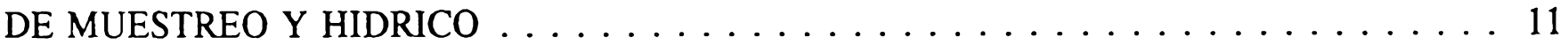

'I.3- METODOLOGIA

3.1- LA PRODUCTIVIDAD PRIMARIA NETA Y SU ESTIMACION . . . . . . . . . . 14

3.2- PRODUCTIVIDAD PRIMARIA AEREA NETA $\ldots \ldots \ldots \ldots \ldots \ldots \ldots \ldots$

3.3- PRODUCTIVIDAD SUBTERRANEA

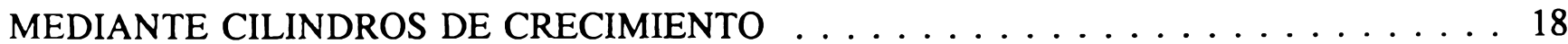

3.4- MASA RADICAL Y PRODUCTIVIDAD PRIMARIA

NETA SUBTERRANEA POR COSECHAS DE BIOMASA . . . . . . . . . . . . . . 19

3.5- ANALISIS DE NUTRIENTES ESTIMACION DE LOS

MINERALES TOTALES Y CALCULOS DE FLUJOS DE NUTRIENTES . . . . . . . . 20

3.6- TRATAMIENTO ESTADISTICO DE LOS TRES PASTIZALES . . . . . . . . . . 24

III. PASTIZAL SUPERIOR

III.1-RESULTADOS

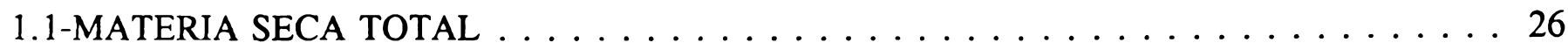

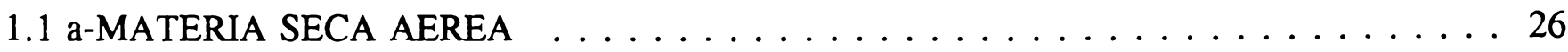

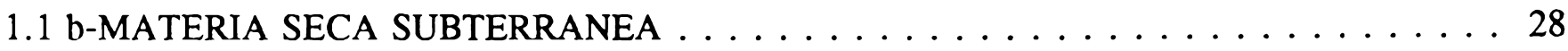

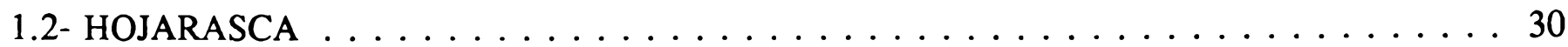

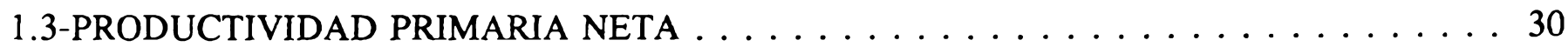

1.3 a-PRODUCTIVIDAD PRIMARIA AEREA NETA $\ldots \ldots \ldots \ldots \ldots \ldots \ldots \ldots$

1.3 b-PRODUCTIVIDAD SUBTERRANEA NETA $\ldots \ldots \ldots \ldots \ldots \ldots \ldots \ldots$

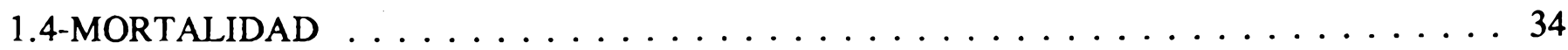

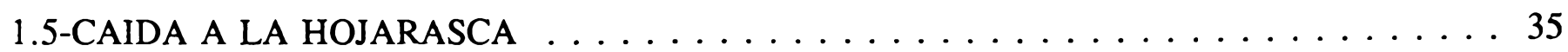

1.6-DESAPARICION DE MATERIA SECA $\ldots \ldots \ldots \ldots \ldots \ldots \ldots \ldots$ 
página

1.7-NUTRIENTES

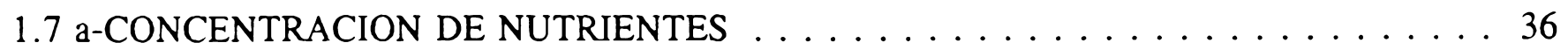

1.7 b-ALMACENAJE MINERAL $\ldots \ldots \ldots \ldots \ldots \ldots \ldots \ldots \ldots$

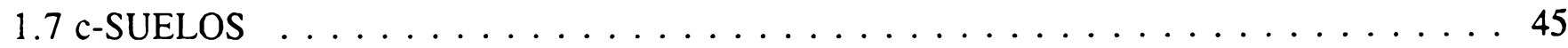

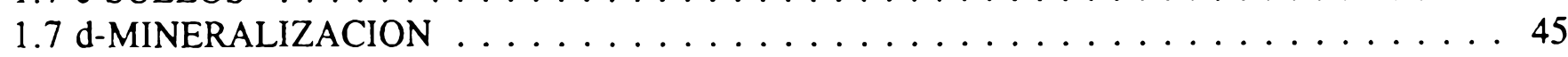

1.7 e-CICLO DE LA MATERIA SECA, MATERIA ORGANICA Y NUTRIENTES

- Ciclo de la materia seca y materia orgánica . . . . . . . . . . . . . . . . 46

-Ciclo del Fosfóro . . . . . . . . . . . . . . . . . . . . . . . . 48

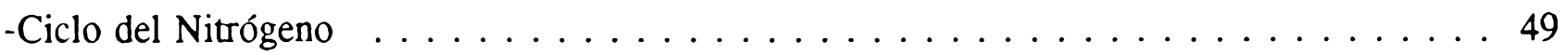

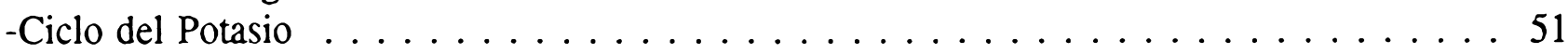

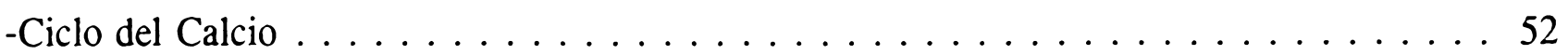

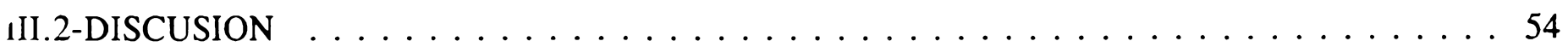

- . PASTIZAL MEDIO

IV.1-RESULTADOS

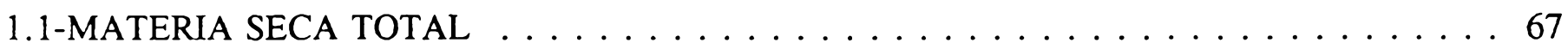

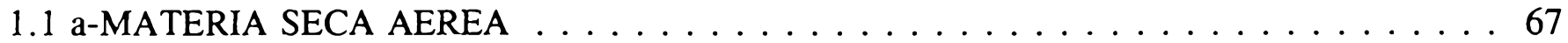

1.1 b-MATERIA SECA SUBTERRANEA $\ldots \ldots \ldots \ldots \ldots \ldots$

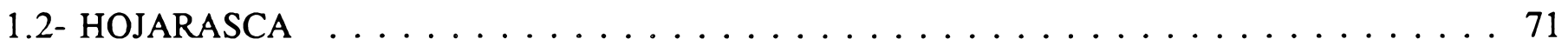

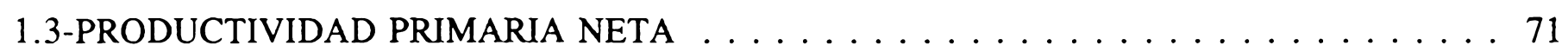

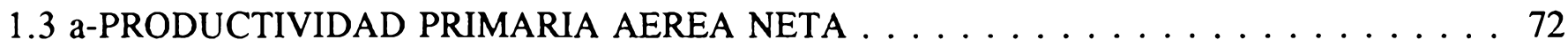

1.3 b-PRODUCTIVIDAD SUBTERRANEA NETA $\ldots \ldots \ldots \ldots \ldots \ldots$

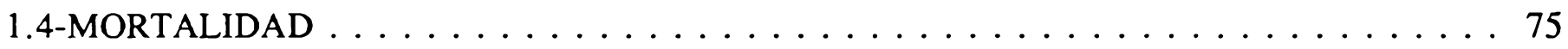

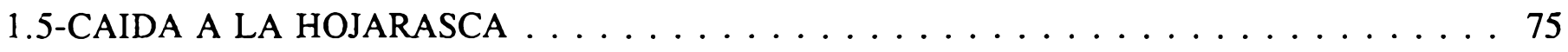

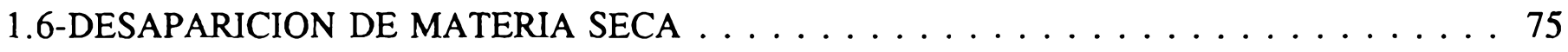

1.7 -NUTRIENTES

1.7 a-CONCENTRACION DE NUTRIENTES $\ldots \ldots \ldots \ldots \ldots \ldots$

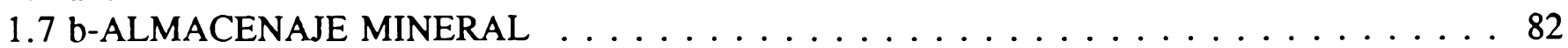

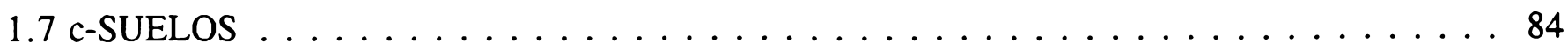

1.7 d-MINERALIZACION $\ldots \ldots \ldots \ldots \ldots \ldots \ldots \ldots \ldots$ 
página

1.7 e-CICLO DE LA MATERIA SECA, MATERIA ORGANICA Y NUTRIENTES

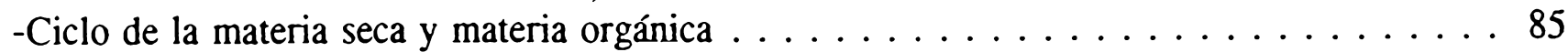

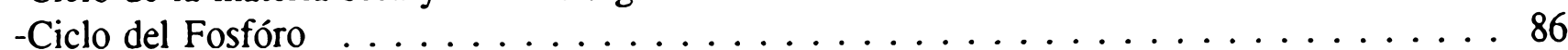

-Ciclo del Nitrógeno . . . . . . . . . . . . . . . . . . . . . . . 87

-Ciclo del Potasio . . . . . . . . . . . . . . . . . . . . . . . . . . 89

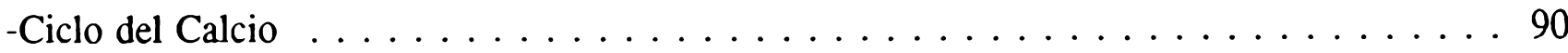

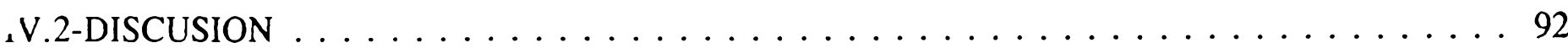

V. PASTIZAL INFERIOR

V.1-RESULTADOS

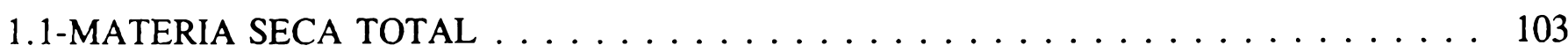

1.1 a-MATERIA SECA AEREA $\ldots \ldots \ldots \ldots \ldots \ldots \ldots \ldots \ldots \ldots \ldots \ldots$

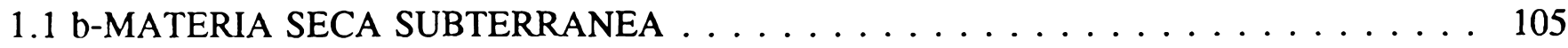

1.2- HOJARASCA . . . . . . . . . . . . . . . . . . . . . . . . . . . . . . . . . 107

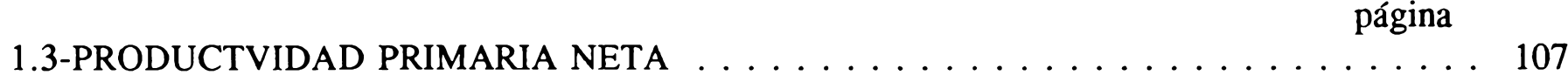

1.3 a-PRODUCTVIDAD PRIMARIA AEREA NETA . . . . . . . . . . . . . . . . . . . 109

$1.3 \mathrm{~b}$-PRODUCTVIDAD SUBTERRANEA NETA $\ldots \ldots \ldots \ldots \ldots \ldots \ldots \ldots \ldots$

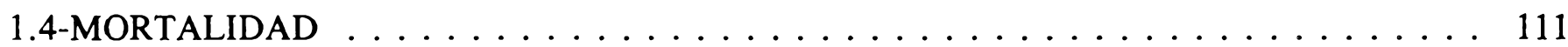

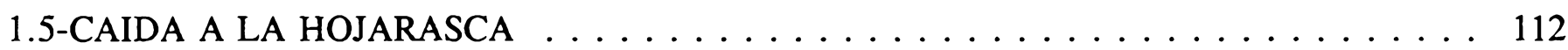

1.6-DESAPARICION DE MATERIA SECA $\ldots \ldots \ldots \ldots \ldots \ldots \ldots \ldots \ldots \ldots$

1.7 -NUTRIENTES

1.7 a-CONCENTRACION DE NUTRIENTES $\ldots \ldots \ldots \ldots \ldots \ldots \ldots \ldots \ldots$

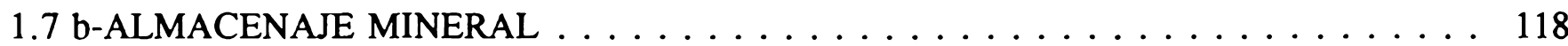

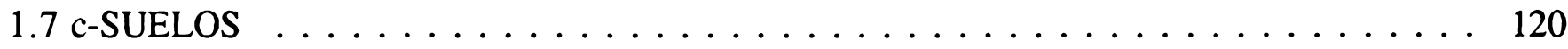

1.7 d- MINERALIZACION . . . . . . . . . . . . . . . . . . 121

1.7 e-CICLO DE LA MATERIA SECA, MATERIA ORGANICA Y NUTRIENTES

-Ciclo de la materia seca y materia orgánica $\ldots \ldots \ldots \ldots \ldots \ldots \ldots \ldots \ldots \ldots$

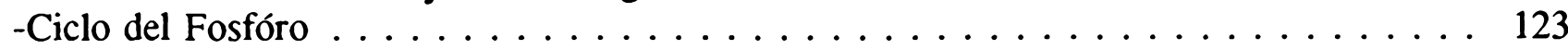

-Ciclo del Nitrógeno . . . . . . . . . . . . . . . . . . . . . . 124

-Ciclo del Potasio . . . . . . . . . . . . . . . . . . . . . . . . . . 125

-Ciclo del Calcio . . . . . . . . . . . . . . . . . . . . . . 126

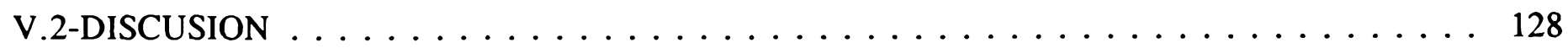




\section{COMPARACION DE LOS TRES PASTIZALES}

\section{VI.1-ALMACENAJES DE MATERIA SECA}

-Materia seca de los pastizales situados a diferente altitud . . . . . . . . . . . . . . . . . . . . 140

-Cociente Raíces/Aéreo . . . . . . . . . . . . . . . . . . . . . . . . . . . . 145

- Distribución de la materia seca en compartimientos, en los pastizales situados a diferente altitud . . . . . . . . . . . . . . . . . . . . . . . . 147

-Asociaciones micorrícicas en los pastizales serranos . . . . . . . . . . . . . . . . . . 150

-El esfuerzo reproductivo en los pastizales serranos . . . . . . . . . . . . . . . . . . 152

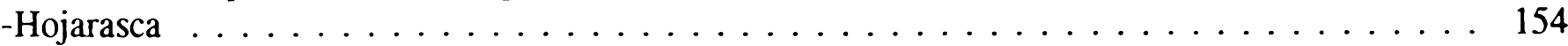

VI.2- TENDENCIAS ESTACIONALES EN LA MATERIA SECA Y HOJARASCA . . . . . . . 155

VI.3- LOS SUELOS SERRANOS Y SU RELACION CON LA BIOMASA VEGETAL . . . . . 157

\section{VI.4-PROCESOS FUNCIONALES EN LOS PASTIZALES SERRANOS}

-Productividad, Mortalidad,

Caída a la hojarasca y Desaparición . . . . . . . . . . . . . . . . . . . . . . . . . . 164

-La productividad primaria neta en los pastizales templados . . . . . . . . . . . . . . . . . 169

-La productividad primaria neta en relación

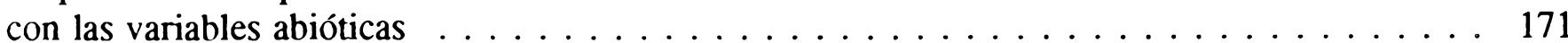

-Estrategias fotosintéticas y eficiencia

en el uso del agua en los pastizales serranos. . . . . . . . . . . . . . . . . . . . . 175

-Tasas de renovación de la biomasa y del material muerto . . . . . . . . . . . . . . . . . . 179

\section{VI.5-LOS CICLOS DE NUTRIENTES EN PASTIZALES DE LAS SIERRAS AUSTRALES}

-Las concentraciones de nutrientes en los pastizales serranos . . . . . . . . . . . . . . . . . 181

-Dinámica estacional de los nutrientes

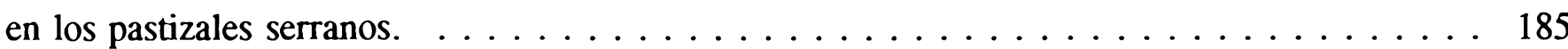

-Los ciclos de nutrientes en los pastizales serranos . . . . . . . . . . . . . . . . . . . 191

VI.6 - EFECTOS DEL FUEGO y PASTOREO EN LOS PASTIZALES SERRANOS ～. . . . . . 198

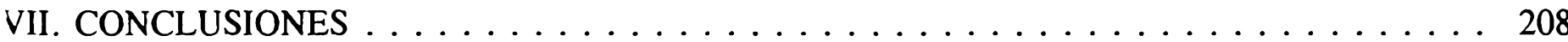

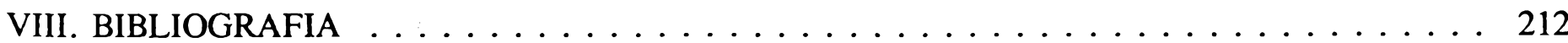


CAPITULO I: INTRODUCCION 


\section{I.1- OBJETIVOS}

Los pastizales constituyen la vegetación dominante del paisaje en las Sierras australes, en los cuales los géneros más frecuentes son Stipa y Piptochaetium (Cabrera 1968). Existe una marcada diferencia entre la flora de la sierra propiamente dicha y la del paisaje de llanura pedemontana y fluvial circundantes (Frangi y Bottino 1995). Estos autores consideran a los tramos medios y superiores de las Sierras Australes como un área de confluencia de especies de diferente origen fitogeográfico, muchas de las cuales no descienden a la zona pedemontana. Por su parte en las sierras los mismos autores destacan que la heterogeneidad de ambientes se asocia con comunidades vegetales que manifiestan distinto grado de afinidad florística, relacionadas con diferentes sustratos, pendientes, exposiciones y fajas altitudinales.

En lo referente a los aspectos funcionales, las variaciones en la biomasa y productividad en los pastizales serranos y pedemontanos pueden vincularse a factores ambientales (disponibilidad de agua, temperaturas, suelos) y a su composición florística formada por una mezcla de géneros micro, meso y megatérmicos que representan diferentes estrategias productivas, de uso de recursos y tolerancia de condiciones (Frangi et al. 1980a-b, Ricci 1992).

Ricci (1992) señala que en el área pampeana austral, la rocosidad y pendiente constituyen los factores más importantes que determinan las áreas de cultivo y pastoreo. Los pastizales naturales en los sistemas serranos australes son de uso pastoril, ya que las condiciones de pedregosidad y rocosidad impiden las tareas agrícolas sobre las Sierras, limitándose estas últimas a los ambientes basales intra y periserranos.

Ricci (1992) enfatiza que en las pendientes de solana, ocupadas por pastizales con Sorghastrum, pese a que la intensidad del pastoreo puede modificar su cobertura, los mismos representan un sistema natural de protección hidrológica. Los pastizales de las cuencas altas resultan de primordial importancia en el control de la erosión y en el mantenimiento de calidad del agua de arroyos, algunos de los cuales, como es el caso del Sauce Grande, son embalsados y entubados para posteriormente proveer agua de consumo (en este caso a Bahía Blanca) (Frangi 1987). 
El objetivo principal de este trabajo consiste en estudiar la variación de la productividad primaria neta, aérea y subterránea de pastizales de la cuenca alta del Arroyo Sauce Grande a lo largo de un gradiente complejo: la altitud.

En segundo lugar se intenta caracterizar a los ciclos biogeoquímicos del C, N, P, K y Ca en pastizales naturales, a lo largo del mismo gradiente altitudinal.

El presente estudio forma parte de un proyecto más amplio, tendiente a comprender de manera integral a los ecosistemas de la cuenca alta y media del arroyo mencionado (Proyecto CIC: Estructura y Funcionamiento de Pastizales Serranos) que ya ha dado como resultado la realización de tres tesis doctorales (Barrera 1991, Kristensen 1992, Ricci 1992). El proyecto mencionado incluye, además el balance hidrológico y de nutrientes de una cuenca experimental de aproximadamente 158 ha en la cual se realiza este trabajo (Dascanio Tesis doctoral en preparación).

La estimación de la productividad de los pastizales serranos no pastoreados registra como antecedentes dos trabajos (Frangi et al. 1980a-b) en los cuales se desarrolla una metodología para el cálculo de la productividad, mortalidad, caída y descomposición en pastizales (Frangi et al. 1980 a); se reconoce la marcha de la productividad a lo largo del año; se advierten los importantes valores que adquiere la productividad primaria aérea neta $\left(700 \mathrm{~g} / \mathrm{m}^{2} a n ̃ o\right)$ en las sierras y se reconoce el impacto en la composición del pastizal y en el comportamiento de la producción durante el primer año de post-quema de un pastizal basal (Frangi et al. 1980 b). Se han realizando otros estudios en tierras pastoreadas serranas, en campos privados (Ricci 1992). En el mismo, se establece que el pastoreo incide sobre las tasas de crecimiento de la biomasa viva -determinando tasas diferentes de acuerdo a su intensidad- y disminuye la cantidad de material seco, afectando los procesos de mortalidad y caída.

Barrera y Frangi (1994) analizaron la estructura de la biomasa de pastizales serranos y pedemontanos y demostraron que en las faldas serranas de solana la biomasa aérea decrece con la altitud, en tanto que la biomasa subterránea se incrementa hacia las cumbres serranas. Este estudio demuestra la importancia que adquieren los pastizales sobre terrenos con alto riesgo de erosión, en las zonas de umbría con fuertes pendientes, que presentan elevados 
valores de cobertura aérea y en las zonas insoladas, con pendientes variables, una gran biomasa subterránea. Sin embargo quedan importantes preguntas por responder:

¿Cambia la inversión relativa de fotosintatos entre la parte aérea y la parte subterránea a medida que varían los factores ecológicos relacionados con la altitud?

¿Difiere la producción primaria neta total a distintas alturas?

¿Cual es la tasa de renovación de la biomasa aérea y subterránea? ¿Varía con la altitud? ¿Varían estacionalmente las concentraciones de los nutrientes principales, $\mathrm{N}$ y $\mathrm{P}$, en la materia seca?

¿Cómo es la distribución de la biomasa y la asignación de nutrientes hacia los órganos aéreos y subterráneos en estos pastizales?

¿Existen diferencias en el contenido de nutrientes y ciclado de los mismos en los pastizales ubicados a diferente altitud?

Las respuestas a estas preguntas constituyen objetivos específicos de este estudio.

\section{I.2- EL AMBIENTE}

Ubicación: Las Sierras Australes, o de Ventania se ubican al SW de la provincia de Buenos Aires, entre los $37^{\circ} 35^{\prime}$ y $38^{\circ} 50^{\prime} \mathrm{S}$ y entre $61^{\circ} 05^{\prime}$ y $62^{\circ} 8^{\prime} \mathrm{W}$. Tienen una longitud de 170 km y un ancho máximo de 65 km (Vargas Gil y Scoppa 1973).

Geología: Desde el punto de vista de su geología este sistema serrano es un sistema altamente plegado, conformado por rocas devónicas pertenecientes a la Serie (Harrington 1947) o Grupo (Suero 1972) Ventana. Dicho Grupo se caracteriza por estar constituído por sedimentos arenosos asociados en su base a escasos materiales conglomerádicos rojos del terciario, y en su parte media y superior a sedimentos cuaternarios arcillosos, loessoides y limos con intercalaciones de tosca (Suero 1972). El Grupo Ventana incluye a las formaciones Bravard, Napostá, Providencia y Lolén (Suero 1972).

Geomorfología y Suelos: Cappannini et al. (1971) distingue distintos ambientes de acuerdo con un enfoque geoedafológico: (1) ambiente serrano; (2) ambiente intraserrano que comprende los valles y depresiones en la región central e interior del ambiente de sierras; (3) 
ambiente periserrano adosado a las sierras, bordeándolas; y (4) ambiente de llanura, que se extiende externamente al ambiente periserrano.

En el ambiente serrano se ubica el eje de la divisoria principal de aguas, de dirección NW-SE sobre la cual se localizan las mayores elevaciones del sistema (Cerro Tres Picos 1243 m sm, Cerro Destierro Primero 1172 m sm, Cerro Ventana 1134 m sm). Sobre las vertientes oriental y occidental de este eje y aproximadamente perpendiculares al mismo, se ubican las divisorias secundarias. Los faldeos occidentales se caracterizan por ser más abruptos que los orientales (Frangi y Bottino 1995).

Los suelos de las Sierras Australes se han formado a partir de los sedimentos loessicos Postlujanense $E_{3}$ y Postplatense $E_{1}$ (Tricart 1968). Estos sedimentos, sólos o mezclados con detritus de roca, son los que otorgan a los suelos sus variadas propiedades.

El espesor de los materiales loessicos varía desde dos metros a pocos centímetros. El primer caso ha dado lugar a suelos con un desarrollo completo, cuyo perfil supera los 100 $\mathrm{cm}$, correspondientes a un Argiudol típico, aunque esta condición está escasamente representada. En el segundo caso (espesores menores), los suelos carecen de uno o más de los horizontes inferiores. Esta condición es la más generalizada, correspondiendo a los suelos Argiudol y Hapludol líticos, desarrollados principalmente sobre los faldeos (Vargas Gil y Scoppa 1973). Perfiles de los suelos serranos han sido descriptos por Capannini et al.(1971), Vargas Gil y Scoppa (1973), Frangi et al. (1980 a-b).

Hidrología: Cappannini et al. (1972) señalan las principales cuencas hidrográficas, por medio de las cuales se realiza el drenaje en las Sierras Australes:

-Cuenca al Atlántico, a través de tres colectores principales, los arroyos Sauce Chico y Napostá Grande y el río Sauce Grande.

-Cuencas endorreicas (hacia la laguna de Chasicó y hacia los arroyos Curamalal Chico y Grande, Hinojo y Sauce corto). 
Rabbasa (1982) estudió la densidad de drenaje (longitud media de los cuerpos de agua por unidad de superficie) de la cuenca del arroyo Sauce Grande. En dicho trabajo se establece que ese parámetro varía entre 0,1 y $6,5 \mathrm{~km} / \mathrm{km}^{2}$ (para unidades superficiales de $4 \mathrm{~km}^{2}$ ), de acuerdo a parámetros fisiográficos y geomorfológicos, correspondiendo los mayores valores a áreas que incluyen colinas y serranías.

Clima: Burgos (1969) en su descripción del clima de la provincia de Buenos Aires destaca que este se caracteriza por su oceanidad. En este marco, los sistemas orográficos bonaerenses, perpendiculares al eje NE-SW de circulación general del la atmósfera, resultan poco efectivos como condensadores de la humedad atmósferica, debido a su mediana altura. Pero sí resulta evidente el efecto de enfriamiento que dichos sistemas producen en el sur de la provincia. Los vientos predominantes en el área serrana son los provenientes del $\mathrm{N}$, siguiendo en importancia los del cuadrante S, SW y W, siendo los del E los menos frecuentes.

El efecto de enfriamiento provocado por las Sierras de Ventana resulta más marcado durante el invierno, con heladas frecuentes que se prolongan hacia la primavera avanzada. Esta estación resulta más fría que el otoño (método de la marcha de las temperaturas relativas de Conrad 1942, según Burgos 1969). En la localidad de Sierra de la Ventana, la temperatura media estival es de $20,7^{\circ} \mathrm{C}$ y la invernal, $8,5^{\circ} \mathrm{C}(\mathrm{n}=15$ 1961-1976, SMN $)$.

Las precipitaciones, respondiendo a la circulación general de la atmósfera, presentan en las Sierras Australes una tendencia decreciente en dirección NE-SW, aunque existen diferencias locales, siendo las áreas intraserranas más húmedas (Frangi y Bottino 1995). La precipitación promedio de 70 años (1916-1986, Estadísticas pluviométricas SMN) de la localidad de Sierra de la Ventana es $715 \mathrm{~mm}$ anuales (rango 1336-439 mm/año). Existen períodos relativamente secos, como el observado en la década del '30 (rango 722-439 $\mathrm{mm} / \mathrm{año}$ ), y otros relativamente lluviosos, tal como el registrado entre 1945 y 1960 (rango 1366-513 mm/año). El $70 \%$ de las lluvias se distribuyen de octubre a abril (los meses más cálidos). La variabilidad anual en las precipitaciones es de aproximadamente el $50 \%$ en más o en menos del promedio y también mensual, ya sea en meses de la misma estación o entre los mismos meses en diferentes años (Cappannini et al. 1971). Existe un problema adicional causado por el desconocimiento de la varición local de las lluvias, ya que no existen series 
de datos paralelos entre la zona intraserrana y la sierra propiamente dicha. Consecuentemente las comparaciones que se efectúan entre datos del Servicio Meteorológico Nacional, provenientes de la localidad de Sierra de la Ventana y los medidos en la zona de estudio presentan entre sí no sólo una variación temporal de las lluvias, sino también posiblemente una variación espacial de las mismas, ignorándose su magnitud para series normales de datos.

A nivel local, Kristensen (1992) ha demostrado que la topografía serrana resulta un elemento generador de heterogeneidad climática, determinando la existencia de diferentes mesoclimas en la región que se vinculan con distintas comunidades vegetales tanto en sustratos de rocas como edáficos.

Vegetación: Desde el punto de vista fitogeográfico las Sierras Australes pertenecen al distrito Austral dentro de la provincia Pampeana (Cabrera 1968). Frangi y Bottino (1995) en sus estudios fitosociológicos de las Sierras de la Ventana reconocen veinticuatro comunidades. La fisonomía dominante es de pastizal, con algunas comunidades arbustivas y escasos bosquecillos de sauces sobre las márgenes de los arroyos y de chañar (Geoffroea decorticans) en las zonas más secas y arenosas. 
CAPITULO II: MATERIALES Y METODOS 


\section{II.1- UBICACION DEL AREA DE ESTUDIO Y CARACTERISTICAS DE LOS SITIOS}

El estudio se realizó en tres pastizales ubicados sobre una transecta altitudinal entre $\mathbf{5 5 0}$ y $1100 \mathrm{~m} \mathrm{sm}$. Los mismos se encuentran ubicados a 550, 850 y $1025 \mathrm{~m}$ sm sobre el eje de una divisoria secundaria de la vertiente oriental del cerro El Destierro I (1172 msm), situado en la reserva La Blanqueada perteneciente al Parque Provincial Ernesto Tornquist (Sierra de la Ventana) (Gráfico II.1).

Los pastizales corresponden a las comunidades denominadas por Frangi y Bottino (1995) de la siguiente manera:

(A) Pastizal bajo con Sorghastrum pellitum y Stipa filiculmis.

(B) Pastizal bajo con Piptochaetium hackelii $+P$. napostaense y Briza subaristata.

A 850 y a $1025 \mathrm{~m}$ sm se encuentra la comunidad A denominándose en el presente trabajo Pastizal medio y Pastizal superior, respectivamente. Frangi y Bottino (1995) destacan que esta comunidad es la más difundida en el ambiente serrano, ocupando la mayor parte de las crestas y laderas de divisorias secundarias, laderas de divisorias primarias y pampas de altura. Presenta un estrato de $40-50 \mathrm{~cm}$ de alto, con una cobertura superior al $80 \%$. Kristensen y Frangi (1995) destacan que esta comunidad se asocia con distintos climas locales.

La comunidad B se sitúa a $550 \mathrm{~m}$ sm y se la denominará en adelante Pastizal inferior. Se encuentra próxima al pie de monte, entre los pastizales de Sorghastrum pellitum y Stipa filiculmis, a mayor altitud, y los de Stipa caudata o Paspalum quadrifarium, a igual o menor altitud (Frangi y Bottino 1995). Estos autores señalan que es un pastizal con un estrato de 50 - $60 \mathrm{~cm}$ de altura. Recibe el nombre de "flechillar", por su riqueza en especies de los géneros Stipa y Piptochaetium ("flechillas"). Suele ser pastoreado. 
El pastizal superior se sitúa próximo a las crestas serranas. Kristensen y Frangi (1995) caracterizan a las cumbres, desde el punto de vista mesoclimático, como el sitio más frío de la sierra, el más isotermo (diaria y anualmente), con iluminación reducida durante el invierno por la frecuente nubosidad. Es un sitio húmedo, con bajo déficit de saturación, que además varía poco a lo largo del día en los meses más fríos. Cuando el déficit de saturación se eleva, el viento incrementa la evaporación, resultando durante el verano el sitio serrano con la mayor tasa evaporativa diaria. La velocidad del viento duplica en la cumbre a la de las áreas basales. Los suelos también son fríos, con pocas variaciones en los primeros centímetros, aunque a mayor profundidad $(-20 \mathrm{~cm})$ son más cálidos que en superficie durante el invierno y más frescos durante el verano. Esta descripción mesoclimática debe considerarse aproximada a las condiciones del sitio ya que éste no se ubica estrictamente en las cumbres, donde predominan los pastizales de altura (Kristensen 1992, Kristensen y Frangi 1995, Frangi y Bottino 1995) sobre suelos diferentes a los del pastizal aqui estudiado.

El pastizal ubicado a media ladera, de acuerdo con Kristensen (1992) y Kristensen y Frangi (1995), es un sitio con condiciones intermedias entre la cumbre y la base. La capacidad evaporante del aire es moderada a baja (en este caso por nubosidad) y se incrementa por la acción del viento. La orientación del faldeo hacia el NE, influye en su insolación, determinando un mayor calentamiento matinal que en los otros sitios, principalmente en otoño. Como en la cumbre, los suelos son los más fríos durante el verano en los niveles más profundos $(-20 \mathrm{~cm})$. En los niveles superficiales, las amplitudes térmicas diarias son elevadas en otoño, produciéndose las máximas más áltas de los sitios serranos.

El pastizal inferior $(550 \mathrm{~m} \mathrm{sm})$ se encuentra topográficamente entre los pastizales situados a media ladera y los pastizales basales, cuyas características mesoclimáticas fueron analizadas por Kristensen (1992) y Kristensen y Frangi (1995). Los pastizales basales con respecto a los de mayor altitud, de acuerdo con dicha autora, son los sitios más secos, con el mayor déficit de saturación del aire. Reciben radiciaón solar directa durante todo el día, con la mayor anisotermia diaria (presentan el mayor calentamiento diurno y el mayor enfriamiento nocturno en dias despejados). En primavera y verano, la superficie del suelo se mantiene relativamente fresca, probablemente por el efecto protector de la vegetación, que es más densa. A partir de $\operatorname{los}-10 \mathrm{~cm}$, los suelos son los más cálidos del área durante todo el año. El pastizal 
inferior, correspondería a una situación probablemente más moderada que la señalada para los pastizales basales. Aunque, con respecto a los pastizales superior y medio, el pastizal inferior correspondería al extremo más cálido de este gradiente altitudinal de condiciones ambientales. Las condiciones de humedad del suelo pueden verse favorecidas por el escurrimiento subsuperficial del agua en el suelo de moderada profundidad sobre roca consolidada (Barrera y Frangi 1994, Frangi y Bottino 1995). 


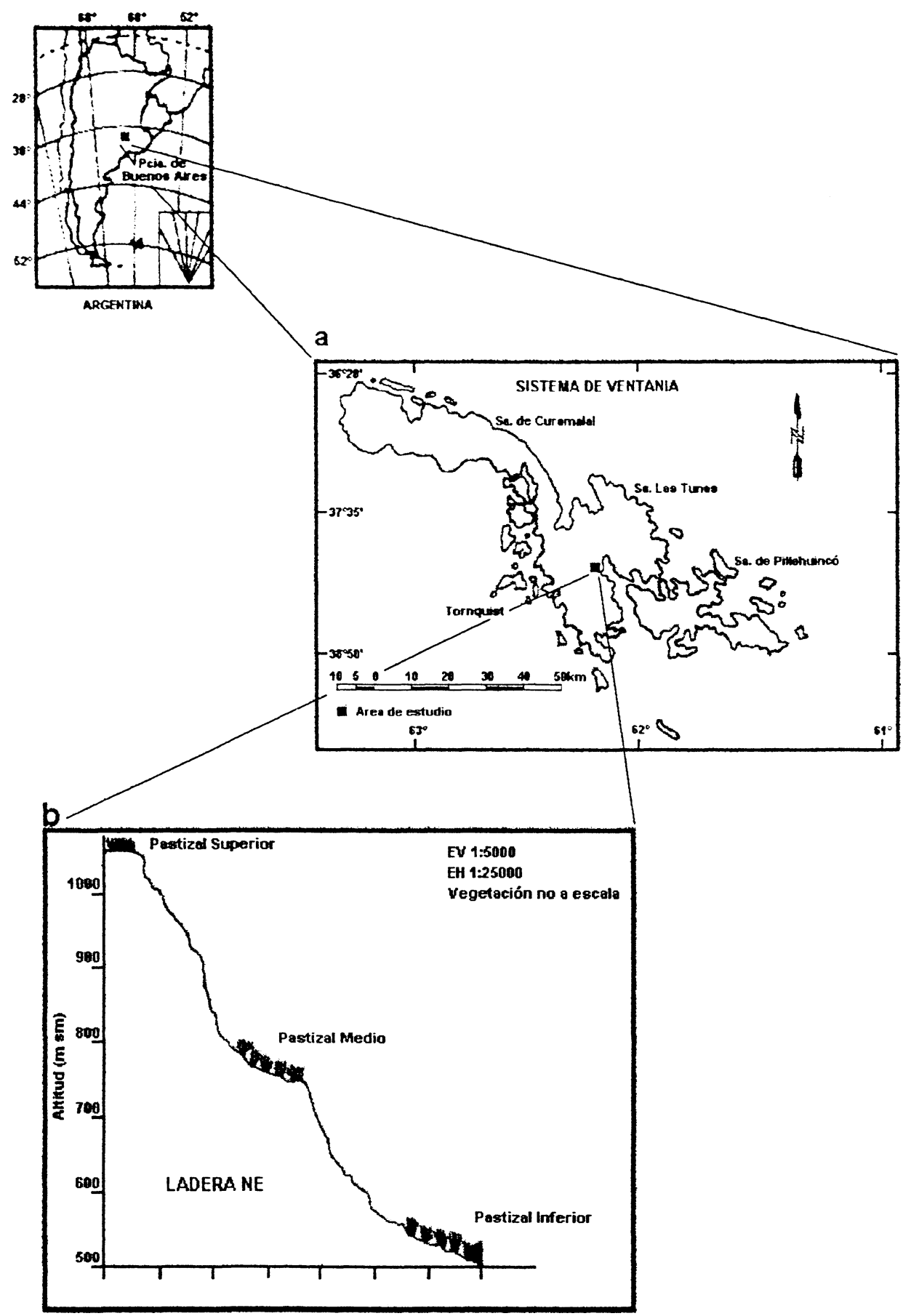

Gráfico II.1: Ubicación gengráfica. a) Sistema de Ventania y área de estudio (Extraido de Mapa Suelos de la Frovincia de Buenos Aires. 1989). b) Sitios muestreados en el perfil topográfico (a partir de la hoja IGM 3963 E-1-39E3 5-2, Sierra de la Ventana-Tornquist.) 


\section{II.2- CARACTERISTICAS PLUVIOMETRICAS DEL PERIODO DE MUESTREO Y BALANCE HIDRICO}

El registro de las lluvias caídas durante el período en que se desarrollo el presente trabajo fue llevado a cabo por Dascanio y Bianchi (inédito) mediante pluviómetros situdados sobre la ladera oriental del cerro El Destierro, a los 1000 y a los $750 \mathrm{~m} \mathrm{sm}$, próximos a los pastizales estudiados, y mediante pluviógrafo a los $530 \mathrm{~m}$ sm. Entre julio de 1988 y julio de 1989, es de destacar la alternancia de períodos prolongados en los que las precipitaciones fueron escasas (de abril a julio, total de dias con lluvias, 8; de los cuales, 3 eventos no superaron los $15 \mathrm{~mm}$ ) con otros de abundantes lluvias (más de $100 \mathrm{~mm}$ en un día) en octubre de 1988 y mayo de 1989 (Dascanio y Bianchi, com. pers.).

Las lluvias en el área serrana, como ya se dijo (pág. 4), presentan una gran variabilidad temporal (intra e inter anual) y espacial (entre la zona serrana y la llanura occidental). A partir de las comparación de las precipitaciones mensuales promedio de 70 años (SMN, 19161986, localidad Sierra de la Ventana) con las del año de muestreo (Dascanio y Bianchi com. pers.), se observa que el invierno y el final de la primavera de 1988 fueron relativamente secos, en cambio en el verano de 1989, el mes de enero fue más lluvioso con respecto al promedio. Las lluvias más abundantes se registraron a mediados de la primavera de 1988 y a fines del otoño de 1989 (Gráfico II.2).

Los balances hídricos de cada uno de los sitios muestreados se construyeron según el método de Thornthwaite (Burgos y Vidal 1951) (Gráfico II.3). La evapotranspiración potencial se calculó a partir de las temperaturas medias mensuales de 15 años (1961-1976) de Sierra de la Ventana (SMN 1981, 1986), considerando que la temperatura desciende 0,5 ${ }^{\circ} \mathrm{C}$ cada $100 \mathrm{~m}$ de altitud. Este gradiente de descenso térmico altitudinal es mencionado por varios autores (Daubenmire 1974, Walter 1977) y en este caso se apoya en los estudios mesoclimaticos realizados por Kristensen (1992), en esos mismos sitios, quien ha hallado que este gradiente podría ser aún mayor, según la época del año $\left(0,7^{\circ} \mathrm{C}\right.$ cada $100 \mathrm{~m}$ de altitud). 


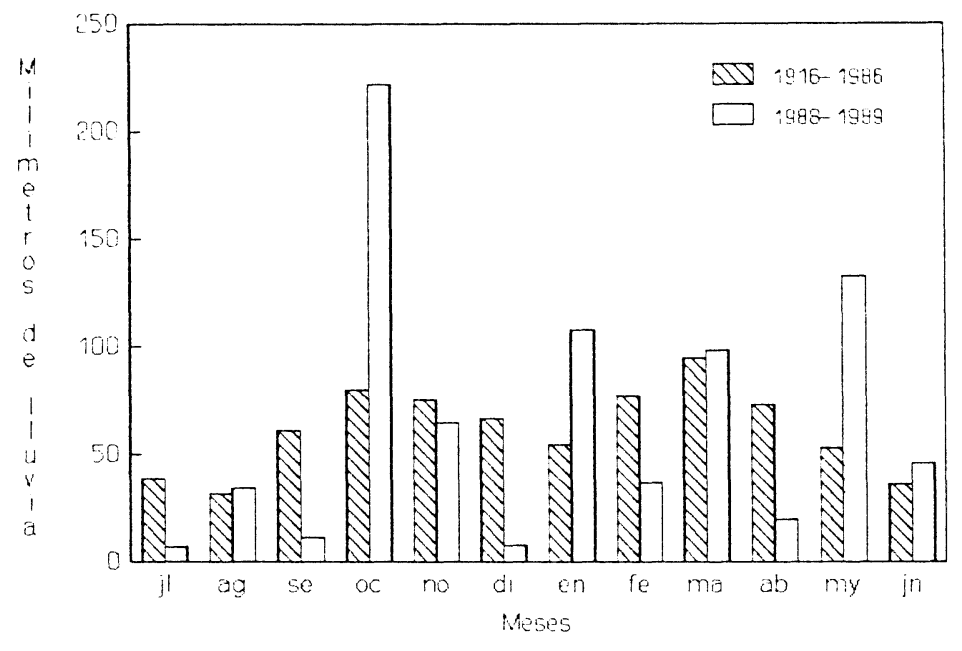

Graflco II.2: Promedio de las lluvlas anuales (en mm, $n=70$ ), en la localidad de sierra de la ventana (SMN) y lluvios caldas durante el periodo jullo dé 1988 -jul10 de 1989 en los sitios de muestreo (Dascanio Y Blanchl, com. pers).

La profundidad del suelo (aproximadamente $20 \mathrm{~cm}$ ) limita la capacidad de retención de agua de estos sitios. Se consideró que esta es de $50 \mathrm{~mm}$ en los sitios de media y alta altitud y de $75 \mathrm{~mm}$, en el pastizal inferior, con suelos algo más profundos de acuerdo con Thornthwaite y Mather (1951).

Durante el invierno, en los tres pastizales hay utilización de agua del suelo. En la primavera, un período breve de déficit hídrico se manifiesta más marcadamente en el pastizal inferior y es menor a medida que se asciende. De esta manera, el pastizal superior resulta una situación más húmeda con respecto a los otros dos. El déficit hídrico característico del verano se prolonga hacia el otoño en el pastizal medio, mientras que en los otros dos en esta época hay recarga y aún exceso de agua en el suelo. A mediados de primavera y del otoño se producen excesos en los tres sitios. 

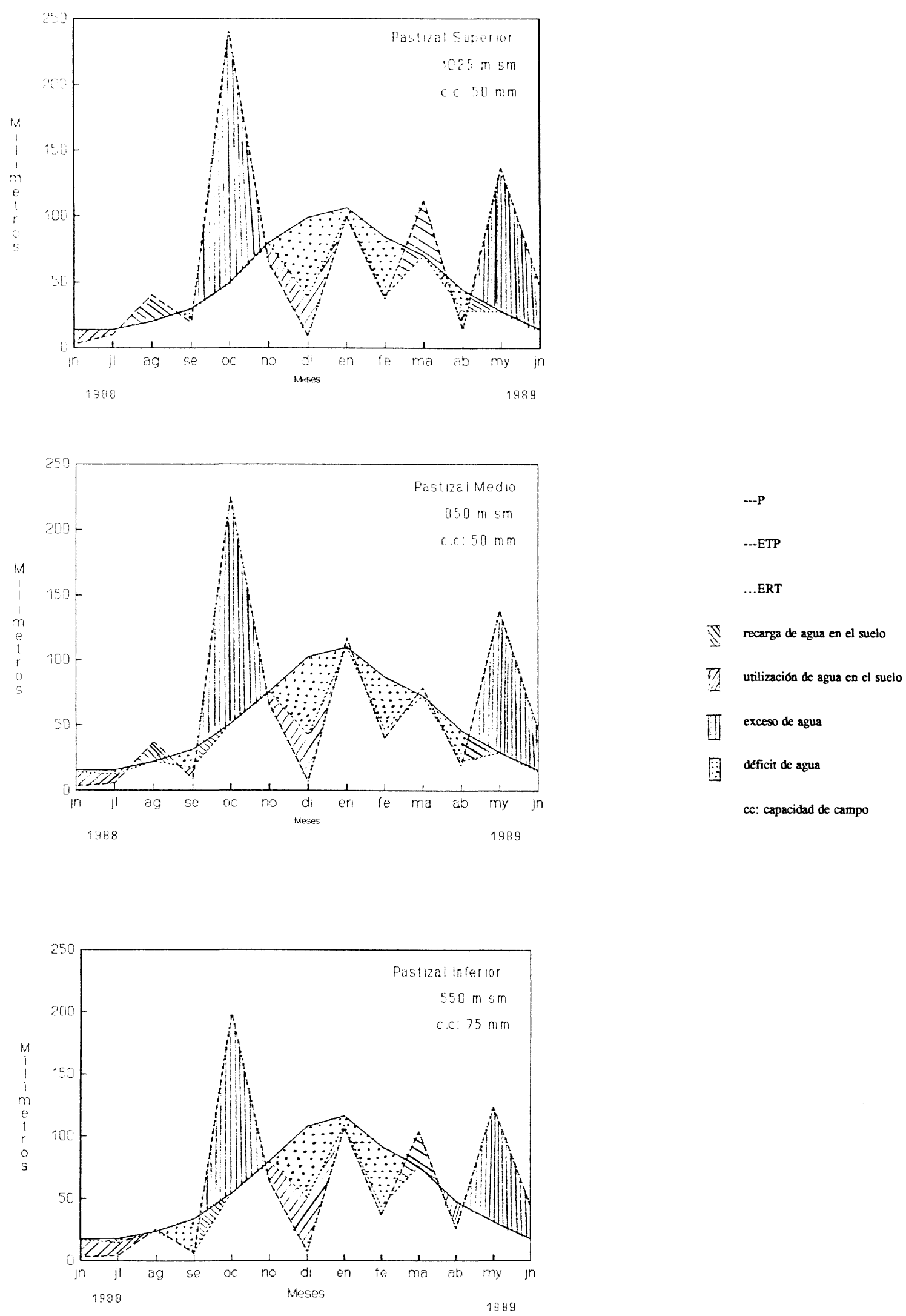
Grafico II.3: Balances hidricos segun el metodo de Thornthwalte (Burgos y Vidal 1951 ), de los pastizales
situados a diferente altitud, correspondientes al periodo funio de $1988-j u n 10$ de 1989 


\section{II.3- METODOLOGIA}

\section{1- LA PRODUCTIVIDAD PRIMARIA NETA Y SU ESTIMACION}

Los métodos de cosecha empleados para estimar la productividad primaria neta han sido criticados en los últimos tiempos, debido a que los mismos pueden conducir a errores de sobreestimación de la productividad (Singh et al. 1984, Sala et al. 1988, Biondini et al. 1991).

De acuerdo con Sala et al. (1988) y Biondini et al. (1991), el error por sobreestimación se incrementa con el número de fechas de muestreo y con los compartimientos distinguidos en la materia seca. En el presente trabajo se establecieron las fechas de cosecha, teniendo en cuenta los conocimientos previos de la fenología de los pastizales serranos (Frangi et al. 1980a-b, Kristensen 1992, Ricci 1992, Barrera y Frangi 1994, Frangi y Botino, 1995). Consideramos que un muestreo menos intensivo conduciría a un pobre entendimiento de la dinámica de los mismos. Por otra parte la distinción en compartimientos vivos y muertos es indispensable para poder estimar los procesos de productividad, mortalidad, caída a la hojarasca y desaparición, que ocurren en los pastizales. Al respecto, Long et al. (1989) han detectado importantes subestimaciones de la productividad aérea y subterránea en pastizales tropicales, cuando se han usado métodos que contemplan sólo los cambios en la materia seca total de la vegetación, sin tener en cuenta que simultáneamente con la formación de nuevos tejidos ocurre mortalidad y descomposición de otros ya formados. Por otra parte diversos autores (Coleman 1976, Persson 1990) han señalado la existencia de subestimación de la productividad de raíces debido a que no puede cuantificarse, con métodos de cosecha, la exudación de las mismas, la pérdida de pelos radicales, capas corticales y consumo de herbívoros. Biondini et al. (1991) señalan que los cálculos que corrigen los errores de sobreestimación, no garantizan una correcta estimación de la productividad. 


\section{2- PRODUCTIVIDAD PRIMARIA AEREA NETA}

La estimación de la materia seca (biomasa y necromasa) y cálculo de la productividad primaria aérea neta (PPAN) son llevadas a cabo mediante el empleo del método de cosecha (Milner y Hughes 1970), que se basa en el corte y posterior medición del material vegetal aéreo, a intervalos durante un período determinado.

Para minimizar las pérdidas de material vegetal por consumo de grandes herbívoros presentes en la zona, se emplearon clausuras. Estas se instalaron a fines de mayo de 1988, diez en cada uno de los pastizales a estudiar, distribuídas aleatoriamente. Se construyeron con alambre tejido romboidal, de abertura de malla de $7 \times 7 \mathrm{~cm}$, estacas de madera de $90 \mathrm{~cm}$ de altura y estacas de hierro pequeñas en forma de L, para sujeción. Cada clausura tiene sección vertical triangular, con las estacas de madera utilizadas como parantes y las pequeñas de hierro fijando el alambre tejido al suelo. La superficie cubierta por cada clausura es de $2,25 \mathrm{~m}^{2}$ (foto II.1).

En cada pastizal se realizaron diez cortes en cada fecha de muestreo, utilizando parcelas rectangulares de $0.25 \times 1 \mathrm{~m}$. Ambos, tamaño y número de parcelas, fueron adoptados teniendo en cuenta el trabajo realizado por Barrera y Frangi (1994), en la misma zona.

Las fechas de muestreo fueron establecidas de acuerdo a la experiencia previa que se tiene acerca de la fenología de los pastizales serranos, con un total de nueve fechas de corte.

El muestreo que se llevó a cabo es el siguiente: (1) Se realizaron cortes en cinco clausuras, de las diez instaladas en cada pastizal (dos parcelas de corte por clausura). (2) En la siguiente fecha de muestreo se cortaron nuevamente en las mismas clausuras, en lugares no cortados en muestreos anteriores. (3) Una vez realizadas las cuatro extracciones de vegetación por clausura éstas fueron trasladadas a otro lugar dentro del mismo pastizal. En los muestreos siguientes se repitió este procedimiento. Los sitios donde ya se realizaron cortes se marcaron convenientemente para evitar superposiciones. Con este sistema de muestreo se logró cubrir una mayor área de mediciones empleando menor cantidad de materiales (alambrado, estacas y otros). 


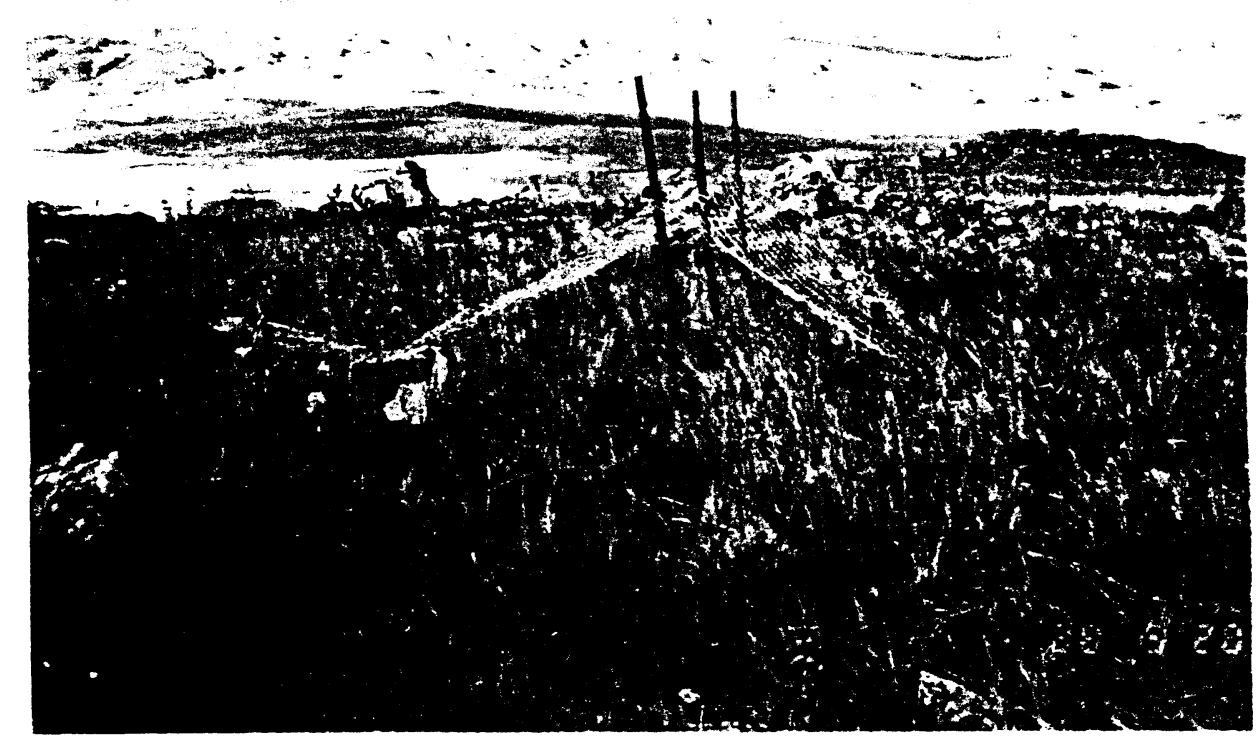

Foto II.1: Past1zal superior (1025 m sm). Clausura para la estimación de materia seca.

La vegetación colectada de cada parcela de corte fue colocada en bolsas plásticas y conservada en congelador a $-12^{\circ} \mathrm{C}$ hasta su separación manual en los compartimientos verde gramíneas (vg), verde dicotiledóneas (vd), seco en pié (s), frutos (f) que se refiere a la rama florífera completa, y hojarasca (h). Este material fue secado en estufa a $70^{\circ} \mathrm{C}$ durante $48 \mathrm{~h}$. y luego pesado en balanza de precisión.

Dados el número y tamaño de las unidades muestrales, y con el fin de disminuir el tiempo empleado en la separación de las mismas, se probó un sistema de separación de los compartimientos vg y s a partir de alícuotas o submuestras. Cada alícuota se obtuvo de una muestra previamente homogeneizada manualmente y representó aproximadamente un 30-40 $\%$ de la misma. Los compartimientos de verde dicotiledóneas, frutos y hojarasca se extrajeron en su totalidad de las unidades muestrales dadas su escasa biomasa y la gran variabilidad que presentan. 
Para comprobar la efectividad de este procedimiento se efectuó un muestreo preliminar en los tres sitios mencionados. De las diez muestras extraídas por pastizal, la mitad se separó en forma completa y las restantes a partir de alícuotas, como se detalla en el párrafo anterior. Luego se realizó el prdocedimiento inverso: los compartimientos $\mathbf{s}$ y vg obtenidos por separación completa se reunieron, homogeneizaron y se separaron alícuotas, mientras que se realizó la separación completa de las unidades muestrales de las cuales anteriormente se habían extraído submuestras. Las medias de la materia seca y de los porcentajes que representan los compartimientos de verde gramineas y seco en pié de la muestra total, hallados por separación completa versus los hallados por separación de alícuotas, no mostraron diferencias significativas. A fin de compararlas se utilizó el test de $\mathbf{t}$ de Student, nivel de confianza del $95 \%$. Previamente, a los porcentajes se les aplicó la transformación $\operatorname{arc} . \operatorname{sen} \sqrt{\%}$, para normalizar los datos (Snedecor y Cochran 1967, Sokal y Rohlf 1969). En las siguientes fechas se continuó con este método ya que se reduce el tiempo de separación en un $50 \%$, con resultados estadísticos satisfactorios.

La PPAN, mortalidad, caída a la hojarasca y desaparición se calculó utilizando el método de suma de incrementos de biomasa entre dos momentos consecutivos, teniendo en cuenta la dinámica del material muerto (Frangi et al. 1980a). Se consideran significativas aquellas diferencias de biomasa y necromasa, entre muestreos consecutivos, que se hallan comprendidas entre extremos de tendencias crecientes o decrecientes, los cuales resultan diferentes estadísticamente al $5 \%$ de nivel de significación. Las fórmulas empleadas son las siguientes:

PRODUCTIVIDAD PRIMARIA NETA AEREA (PPAN)

$\operatorname{PPAN}=\Delta \mathrm{B}^{+}+\left(\mathrm{M}^{-}-\Delta \mathrm{B}^{-}\right)=\Delta \mathrm{B}^{+}+\mathrm{m}$

MORTALIDAD AEREA (M)

$M=\Delta B^{-}+m$, siendo $m=\Delta S-\Delta B^{-}+\Delta H^{+} \quad($ siempre que $m>0)$ 
$\mathrm{C}=\Delta \mathrm{H}^{+}+\mathrm{c}$, siendo $\mathrm{c}=\Delta \mathrm{B}^{-}-\Delta \mathrm{S}-\Delta \mathrm{H}^{+} \quad($ siempre que $\mathrm{c}>0)$

DESAPARICION DE HOJARASCA (D)

$\mathrm{D}=\mathrm{d}-\Delta H$, siendo $\mathrm{d}=\Delta \mathrm{B}^{-}-\Delta S$ (siempre que $\mathrm{D}>0 \mathrm{y} \mathrm{d}>0$ )

donde:

$\triangle \mathrm{B}^{+}$: Incremento de biomasa viva

$\triangle \mathrm{B}^{-}$: Decrecimiento de biomasa viva

$\triangle \mathrm{s}$ : Variación del seco en pie

$\triangle \mathrm{H}^{+}:$Incremento de hojarasca

$\triangle_{\mathrm{H}}$ : Variación de hojarasca

\section{3- PRODUCTIVIDAD SUBTERRANEA MEDIANTE CILINDROS DE CRECIMIENTO}

Se determinó la producción de raices hasta $20 \mathrm{~cm}$ de profundidad por ser ésta la zona de mayor concentración de las mismas (Barrera y Frangi 1994), estimando la biomasa de raíces por períodos, dentro de cilindros de tierra libres de ellas. Para ello se instalaron en cada uno de los pastizales, al comienzo de cada intervalo, treinta cilindros de malla de plástico de 10 $\mathrm{cm}$ de altura y $6,5 \mathrm{~cm}$ de diámetro y abertura de malla de $1 \mathrm{~cm}^{2}$, con la ayuda de un barreno calador tipo balde de $10 \mathrm{~cm}$ de diámetro y $13 \mathrm{~cm}$ de altura. En cada pozo se ubicaron dos cilindros plásticos, superpuestos, de 0 a $10 \mathrm{~cm}$ y de 10 a $20 \mathrm{~cm}$ de profundidad. Los cilindros se rellenaron con tierra tamizada, libre de raíces, en una cantidad correspondiente a la indicada por la densidad aparente del suelo.

En cada muestreo efectuado, se retiraron 20 cilindros, correspondientes a diez unidades de muestreo, instalados en la fecha anterior, los cuales fueron reemplazados en igual número en otros sitios. Por otra parte, 10 cilindros instalados en mayo de 1988 y en julio de 1989 fueron retirados después de un año de su colocación. 
Las muestras fueron colocadas en bolsas de nylon, conservadas en congelador y posteriormente lavadas con agua corriente sobre tamiz de malla fina $\left(1 \mathrm{~mm}^{2}\right)$ (Böhm 1979) inmerso en un recipiente colector, recogiendo el material radical en flotación con un colador y revisando el material en el recipiente colector para minimizar las pérdidas de raíces. El paso de las mismas a través de la malla es ínfimo debido a que su longitud o ramificación hace que queden retenidas en la malla aún siendo de muy pequeño diámetro. El material extraido se secó en estufa a $70^{\circ} \mathrm{C}$ hasta peso constante, y luego se pesó en balanza analítica.

\section{4- MASA RADICAL Y PRODUCTIVIDAD PRIMARIA NETA SUBTERRANEA POR COSECHAS DE BIOMASA}

En cada fecha de muestreo se tomaron con un barreno calador, de $6,5 \mathrm{~cm}$ de diámetro y $10 \mathrm{~cm}$ de altura, 20 cilindros, diez de 0 a $10 \mathrm{~cm}$ de profundidad y otros diez de 10 a 20 $\mathrm{cm}$.

Las muestras de tierra fueron conservadas y procesadas de la misma manera que las muestras para estimar la productividad subterránea.

Posteriormente cada muestra se separó en cuatro compartimientos, raíces gruesas vivas (rgv), raíces gruesas muertas ( $\mathrm{rgm})$, raíces finas vivas (rfv) y raíces finas muertas $(\mathbf{r f m})$. Se considera el límite entre las categorías de raíces gruesas o finas al diámetro de $1 \mathrm{~mm}$, diferenciándose en vivas o muertas de acuerdo a su aspecto (Böhm 1979, McClaugherty et al. 1982). Las raíces vivas son elásticas, translúcidas, blancas a marrón; las muertas son quebradizas, opacas, de color gris a negro.

Se compararon los valores de masa de cada compartimiento entre fechas de muestreo, que constituyen extremos de tendencias crecientes o decrecientes, mediante el test $\mathbf{t}-$ Student ( $\mathbf{P}$ $<0.05$ ). Se calculó la productividad, mortalidad y desaparición subterráneas por diferencias de biomasa aplicando la fórmula de Frangi et al. (1980a) ajustando la fórmula para su aplicación a sistemas subterráneos: 
PRODUCTIVIDAD PRIMARIA NETA SUBTERRANEA (PPSN)

$P P S N=\Delta R V^{+}+\left(M-\triangle R V^{+}\right)=\Delta R V^{+}+m$

MORTALIDAD SUBTERRANEA (M)

$\mathrm{M}=\Delta R \mathrm{~V}^{\cdot}+\mathrm{m}$, siendo $\mathrm{m}=\Delta \mathrm{RM}-\Delta \mathrm{RV}^{-} \quad($ siempre que $\mathrm{m}>0)$

DESAPARICION DE RAICES (D)

$\mathrm{D}=\Delta \mathrm{RV} \cdot \Delta \mathrm{RM}($ siempre que $\mathrm{D}>0)$

donde:

$\triangle \mathrm{RV}^{+}$: Incremento de raices vivas

$\triangle R V:$ Decrecimiento de raices vivas

$\triangle \mathrm{RM}$ : Variación en las raices muertas

\section{5- ANALISIS DE NUTRIENTES, ESTIMACION DE LOS MINERALES TOTALES Y CALCULO DE FLUJOS DE NUTRIENTES}

Procesamiento de muestras y métodos anlíticos utilizados

Alícuotas de las muestras obtenidas (biomasa aérea: vd,vg, f; necromasa aérea: $\mathbf{s}$ y h; biomasa subterránea: rv; necromasa subterránea: rm) fueron acondicionadas en envases plásticos para su posterior análisis quimico. Las muestras fueron luego molidas y tamizadas a través de una malla inoxidable de $0,85 \mathrm{~mm}$ (malla 20 ) en un molino Wiley y digeridas en medio ácido. La concentracion de $\mathbf{N}$ fue medida por la técnica de semi-micro Kjeldahl; las concentraciones de $\mathbf{P}, \mathbf{K}$ y $\mathbf{C a}$ fueron determinadas mediante un espectrómetro de emisión de plasma Beckman Spectra Scan como se describe en Lugo et al (1990). La precisión se verificó analizando una muestra certificada estandar de hojas de citrus del National Bureau of Standards (EEUU) por cada conjunto de 30 muestras. Adicionalmente un duplicado de cada décima muestra fue analizado para verificar la consistencia de los resultados. Los 
replicados que difirieron en más del $5 \%$ fueron analizados nuevamente. El peso de cenizas se obtuvo por incineracion en horno-mufla a $450{ }^{\circ} \mathrm{C}$. La materia orgánica se obtuvo por diferencia entre el peso seco y las cenizas; para obtener el contenido de carbono de la biomasa se multiplicó el valor de materia organica por 0,465 .

\section{Almacenajes Minerales. Minerales en distintos compartimientos}

En este trabajo se emplean los siguientes términos con el significado operativo indicado en sus definiciones.

Mineralomasa: es la masa de nutrientes presentes en la masa vegetal viva. Se la estimó multiplicando la concentración de nutrientes por la biomasa del compartimiento correspondiente.

Necronutrientes: es la masa de nutrientes en la masa vegetal muerta. Se la estimó multiplicando la concentración de nutrientes por la necromasa del compartimiento correspondiente.

Almacenaje mineral se lo define como aquellos nutrientes presentes en la materia orgánica vegetal. Se estimó como la mineralomasa + nutrientes en la necromasa.

Nutrientes en los horizontes minerales del suelo: se estimó multiplicando la concentración de los nutrientes disponibles en los primeros $20 \mathrm{~cm}$ del suelo por la masa de esa capa superficial.

Minerales totales: se considera a la suma del almacenaje mineral + los nutrientes disponibles en horizontes minerales del suelo. 


\section{Cálculo de flujos}

Se han desarrollado fórmulas específicas de cálculo de requerimientos, retorno, retención, translocación, descomposición (materia orgánica) o mineralización (nutrientes) y absorción. Para ello se consideraron las fórmulas e ideas de Cole y Rapp (1981) y Gray (1983).

Requerimiento: es la cantidad de nutrientes necesaria para la productividad neta. Se calcula mediante la siguiente fórmula:

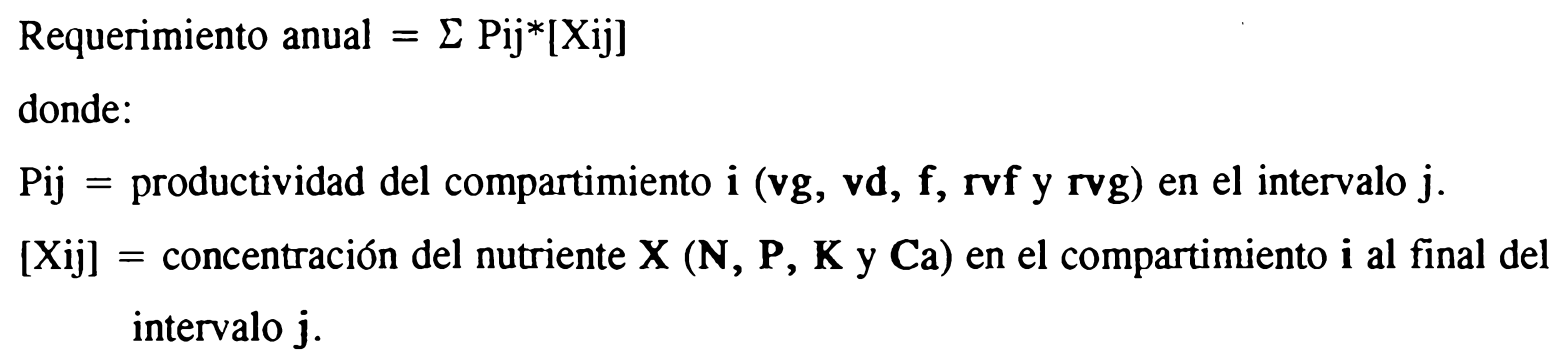

Retomo: nutrientes en la materia seca devuelta al suelo a través de la caída a la hojarasca y desaparición de raíces.

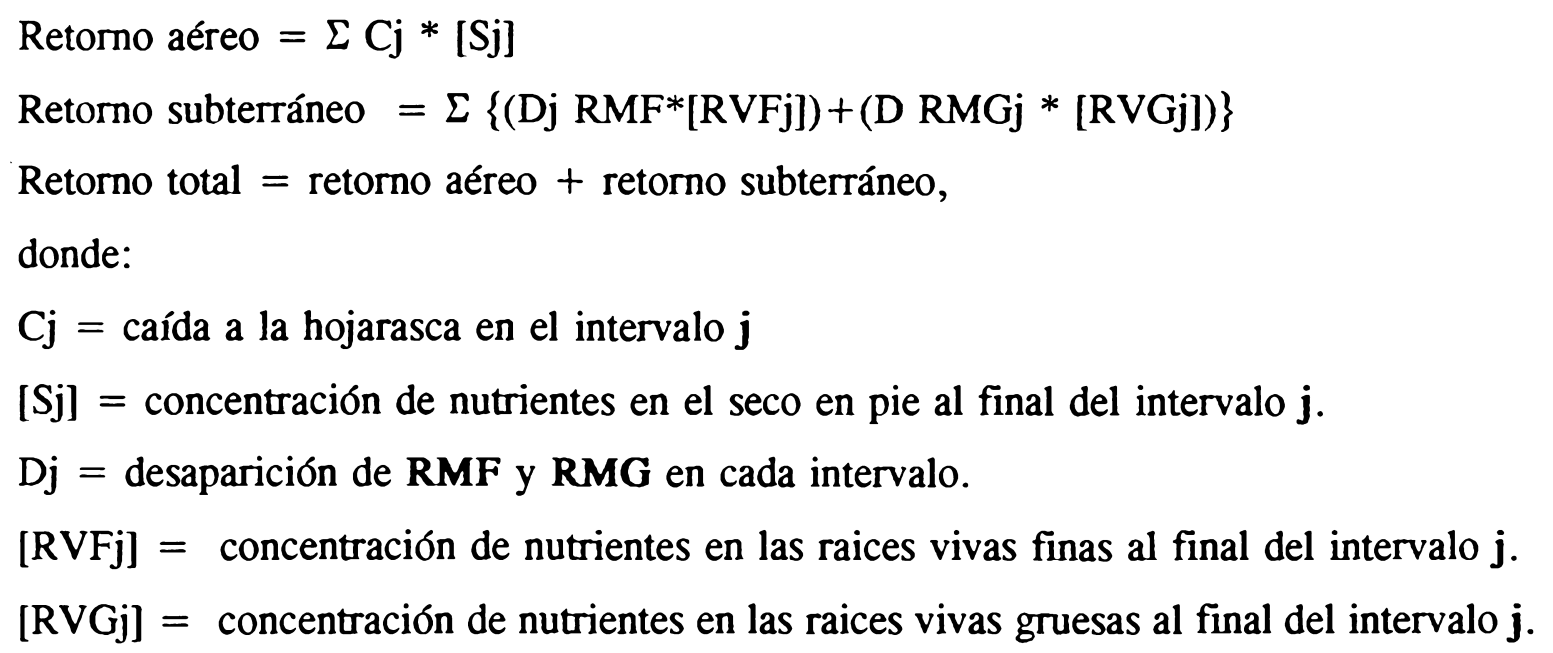

Cuando no se dispomá de la concentración de una fecha determinada, se usó la media entre las fechas más próximas anterior y posterior al momento mencionado. 
Lavado: dado que el balance de nutrientes en la cuenca sobre la que se ubican los pastizales estudiados, estimado en forma independiente por Dascanio y Bianchi (inédito) no es deficitario para los nutrientes analizados, se asume que las diferencias entre los flujos de entrada y salida de los compartimientos aéreos en pie son debidas al pluviolavado. Dichas cantidades de nutrientes se consideran que ingresan a la solución del suelo y pueden ser reabsorvidas por las raices, pero no son perdidas del pastizal considerado.

Retención: Cantidad de nutrientes que se incorpora a la biomasa como resultado del incremento anual de la misma

$$
\text { Retención }=\text { Requerimiento }- \text { Retorno }
$$

Retranslocación aérea: se refiere al proceso por el cual los nutrientes son recuperados desde las hojas senescentes y luego utilizados en la producción de nuevos tejidos.

$$
\text { Retranslocación }=\Sigma([\text { vivo aéreo j] } * \mathrm{Mj})-([\mathrm{Sj}] * \mathrm{Mj})
$$

Se asume que $\mathrm{Pvd} /(\mathrm{Pvd}+\mathrm{Pvg})=\mathrm{Mvd} /(\mathrm{Mvd}+\mathrm{Mvg})$. De este modo el primer término de la fórmula anterior se calculó de la siguiente manera:

$\left\{\left\{[v g]^{*}(1-[\mathrm{Pvd} /(\mathrm{Pvd}+\mathrm{Pvg})]\}+\{[v d] *[\mathrm{Pvd} /(\mathrm{Pvd}+\mathrm{Pvg})]\}\right\}^{*} \mathrm{Mj}\right.$

donde:

$\mathrm{Mj}=$ mortalidad aérea en el intervalo $\mathbf{j}$.

[vivo aéreoj] = concentración de nutrientes en el material aéreo vivo al final del intervalo j.

Absorción: Requerimiento - retranslocación

Mineralización: el cálculo de estos procesos en el material aéreo se realizó mediante la estimación de la desaparición de la hojarasca, a partir de diferencias en la necromasa de la hojarasca entre momentos consecutivos, según la fórmula de Frangi et al.(1980a) 
Mineralización aérea $=\Sigma[\mathrm{Hj}]^{*} \mathrm{Dj}$

donde:

$\mathrm{Dj}$ : desaparición de hojarasca en el intervalo $\mathbf{j}$.

[Hj]: concentración de nutrientes en la hojarasca al final del intervalo $\mathbf{j}$.

La descomposición y mineralización subterráneas se consideraron igual a la desaparición de materia seca y retorno de nutrientes subterráneos respectivamente.

\section{Análisis de suelos}

Se realizaron análisis de los suelos de los pastizales estudiados. La textura fue determinada a partir del método de Bouyoucos (Forsythe 1980). Las bases de intercambio se estimaron aplicando el método de valoración de "S" de Hissink (Arens y Etchevere 1966). La reacción del suelo se estimó mediante la determinación del pH en pasta empleando peachimetro. Para la determinación de la concentración del fósforo total se utilizó el método de Bray y Kurtz 1 (1945). El nitrógeno total fue determinado mediante el método Kjeldahl (Duchaufour 1970). La estimación del \% de carbono se realizó mediante el método de Walkley y Black (Fassbender 1980).

\section{Modelos}

Se realizaron modelos de los ciclos de materia seca, materia orgánica, nitrógeno, fósforo, potasio y calcio en los tres pastizales, empleando el lenguaje de energia de Howard T. Odum (1971).

\section{6- TRATAMIENTO ESTADISTICO DE LOS TRES PASTIZALES}

Las masas aéreas y subterráneas de los tres sitios fueron comparadas mediante análisis de la varianza de dos factores (fechas y sitios de muestreo). El mismo tipo de análisis fue aplicado con la finalidad de comparar, entre pastizales, los porcentajes que representan el vivo aéreo y las raices vivas, finas y gruesas, con respecto al vivo total. A los porcentajes se les aplicó la transformación arco seno $\sqrt{ } \%$. Previo a la realización del ANOVA se corroboró la 
homogeneidad de varianzas y la independencia de las fechas mediante test de autocorrelación. Para comparar las concentraciones de nutrientes entre los sitios muestreados se realizó un ANOVA de dos factores (sitios y fechas) sin replicaciones, utilizándose la interacción doble como estimación del error. Se empleó el test de F para la significancia de diferencias entre varianzas y test de rango Studentizado de Tukey $(\mathrm{P}<0,05)$ para la comparación de medias, cuando el anális de la varianza fue significativo (Sokal y Rohlf 1969).

En los análisis de regresión se aplicó el método de mínimos cuadrados. Con la finalidad de establecer si el empleo de los modelos estableciedos fue apropiada, se graficaron los residuos versus las Xi (Weisherg 1980). 
CAPITULO III: PASTIZAL SUPERIOR 


\section{III.1-RESULTADOS}

\section{1-MATERIA SECA TOTAL}

La media anual de materia seca total del período de estudio es $1552 \pm 67 \mathrm{~g} / \mathrm{m}^{2}$, de los cuales $75 \%$ corresponden al material subterráneo, $22 \%$ al aéreo y $3 \%$ a la hojarasca.

La materia seca total muestra una tendencia creciente desde el invierno de 1988 hasta fines del otoño de 1989, aunque los valores dentro de cada estación del año permanecieron constantes. En el invierno siguiente (julio de 1989), la masa total del pastizal desciende a valores similares a los de julio del año anterior.

\section{1 a-MATERIA SECA AEREA}

La materia seca en pie se reparte en un $36 \%$ correspondiente a los compartimientos vivos (repartida en $29 \%$ de gramíneas y graminiformes, $1 \%$ de estructuras reproductivas y $6 \%$ de dicotiledóneas) y $64 \%$ a seco en pie (Tabla III.1)

La biomasa de gramíneas y dicotiledóneas alcanzan valores máximos a mediados de primavera y comienzos del otoño (Tabla III.1, Gráfico III.1).

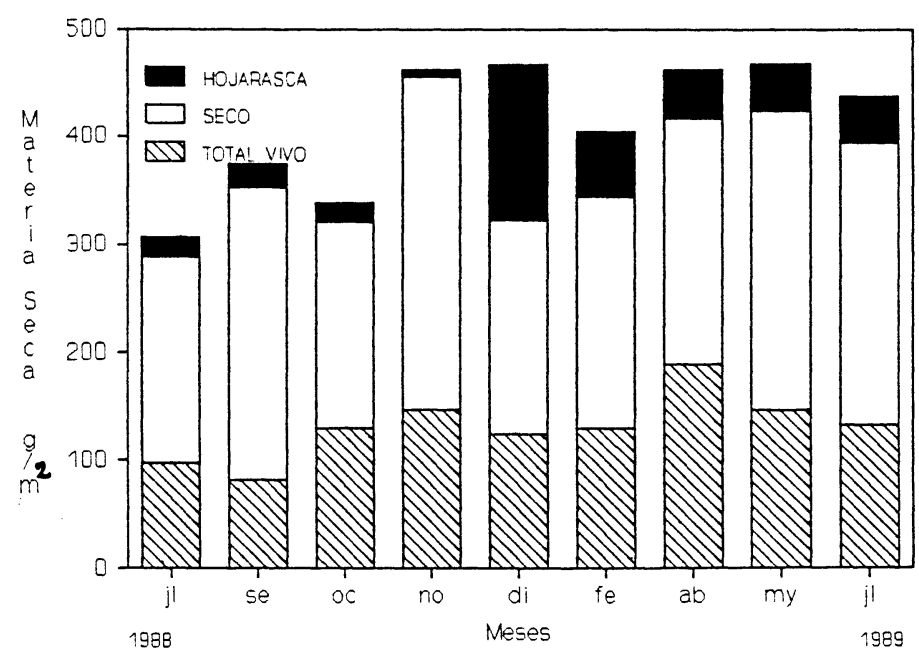

Graflco III.1: Past12al Superior ( $1025 \mathrm{~m} \mathrm{~mm})$. Materia seca ( $\left.\mathrm{g} / \mathrm{m}^{2}\right)$ de los compartimlentos aereos estimada durante el periodo jullo de 1988 -jullo de 1989. 
Tabla III.1: Pastizal Superior (1025 m $\mathrm{sm}$ ). Blomasa $y$

necromasa $\left(g / m^{2}\right)$ aerea. Medias \pm Error Standard, $n=10$.

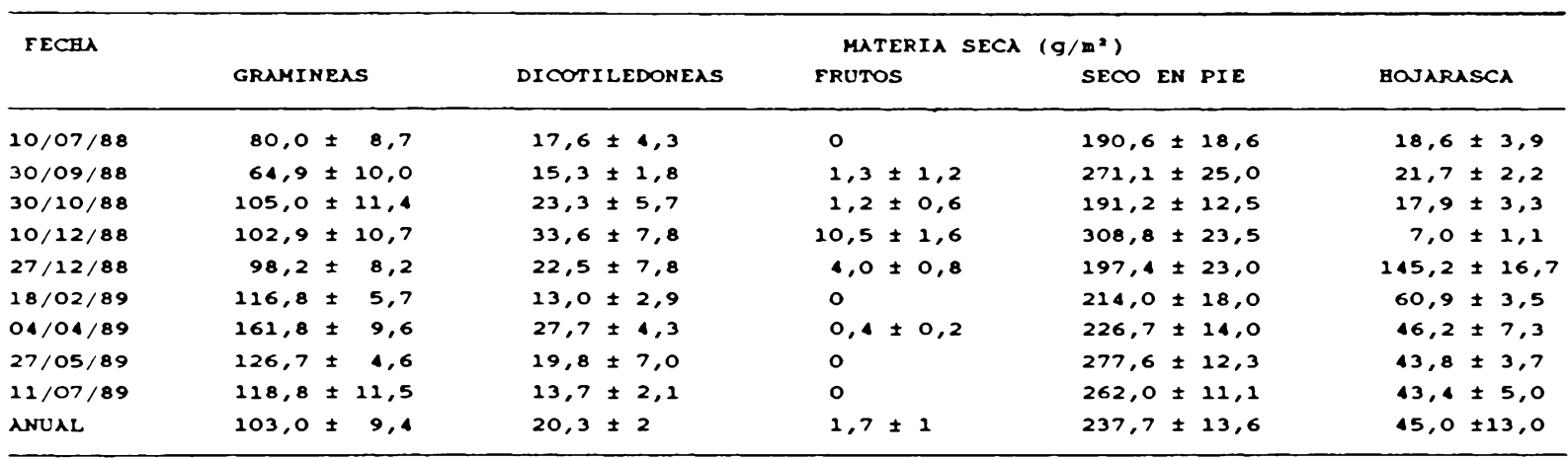

Se distinguen dos períodos de floración y fructificación: el principal, que se extiende desde principios hasta fines de primavera, con un máximo a mediados de dicha estación, y el otro a principios de otoño (Tabla III.1, Gráfico III.2).

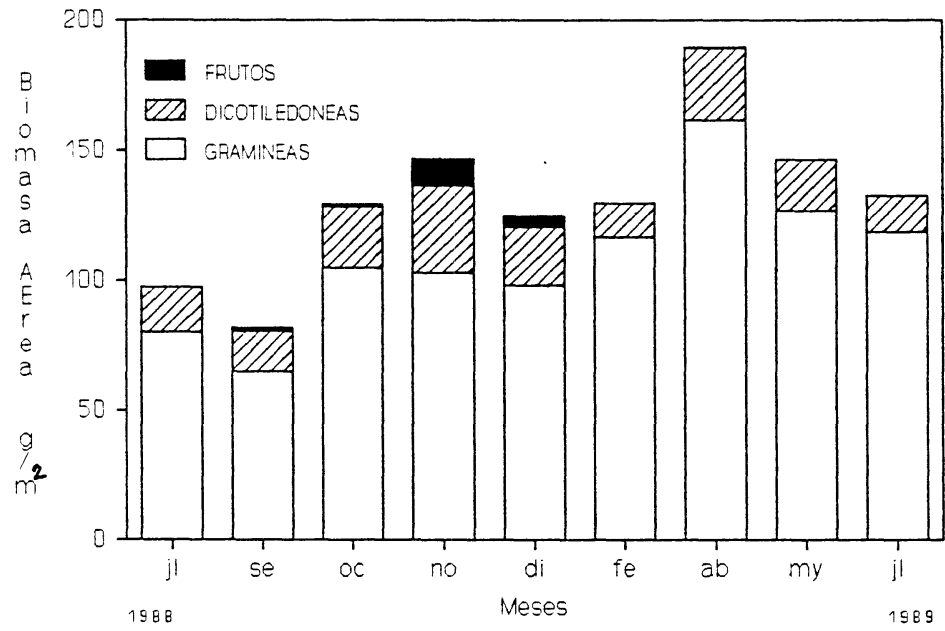

Grafico III.2: Pastizal Superior (1025 m sm). Blomasa ( $\left.\mathrm{g} / \mathrm{m}^{2}\right)$ de los compartimientos aereos estimada durante el periodo jullo de $1988-j u l 10$ de 1989.

De las especies de gramíneas y graminiformes que presentan flores o frutos en las diferentes fechas de muestreo, en la primavera temprana sólo se encuentran una Ciperácea y Vulpia dertonensis, que es una especie anual invernal. A mediados de primavera fructifican las especies cuyos géneros, de acuerdo con su régimen térmico son de afinidad microtérmica (Burkart 1975). A fines de dicha estación y principios del otoño, las especies que presentan estructuras reproductivas son principalmente de afinidad megatérmica (Tabla III. 2). 


\begin{tabular}{|c|c|c|c|c|c|}
\hline \multirow[t]{2}{*}{ REGIMEN TERMICO } & \multicolumn{4}{|c|}{ FECEU } & \multirow[b]{2}{*}{$4-4-89$} \\
\hline & $30-9-88$ & $30-10-88$ & $10-12-88$ & $27-12-88$ & \\
\hline MICROTERMICAS & $\begin{array}{l}\text { Carex sp. } \\
\text { vulpla dertonensis }\end{array}$ & v. dertonensis & $\begin{array}{l}\text { Carex sp. } \\
\text { Briza brizoldes } \\
\text { B. subarlstata } \\
\text { Bromus sp. } \\
\text { Plptochaetium hackell } \\
\text { P. montevidense } \\
\text { stipa fillculmis } \\
\text { S. neesiana }\end{array}$ & $\begin{array}{l}\text { Juncus sp. } \\
\text { P. hackel11 } \\
\text { P. montevidense } \\
\text { S. f1l1culmis } \\
11\end{array}$ & \\
\hline MEGATERMICAS & & & Alra caryophyllea & $\begin{array}{l}\text { Sorghastrum pellitur } \\
\text { Danthonia cirrata } \\
\text { Eragrostls lugens } \\
\text { Melica riglda }\end{array}$ & $\begin{array}{l}\text { A. caryophylea } \\
\text { E. lugens }\end{array}$ \\
\hline
\end{tabular}

El seco en pie presenta tres picos: uno invernal tardío primaveral, otro hacia fines de la primavera y el tercero hacia fines del otoño (Gráfico III.2).

\section{1 b-MATERIA SECA SUBTERRANEA}

La media anual de materia seca subterránea es $1130 \mathrm{~g} / \mathrm{m}^{2}$, de los cuales $80 \%$ corresponden a raíces vivas y $20 \%$ a raíces muertas. Las raíces vivas se reparten en $70 \%$ finas $+10 \%$ gruesas; y las raíces muertas en $14 \%$ finas $+6 \%$ gruesas (Gráfico III.3).

La materia seca del estrato superficial $(0-10 \mathrm{~cm})$, es $780 \mathrm{~g} / \mathrm{m}^{2}$. Corresponde en un $79 \%$ a raíces vivas $(68 \%$ finas $+11 \%$ gruesas) y $21 \%$ de raíces muertas $(15 \%$ finas $+6 \%$ gruesas) (Gráfico III.3).

En el estrato superficial se concentra el $68 \%$ de la biomasa subterránea total, el $68 \%$ de las raíces vivas, el $72 \%$ de las raíces gruesas y el $68 \%$ de las raíces finas.

En el estrato de $10-20 \mathrm{~cm}$ de profundidad el $82 \%$ de la materia seca corresponde a raíces vivas, repartidas en $74 \%$ de raíces finas $+8 \%$ de raíces gruesas. De las raíces muertas, el $11 \%$ son finas y $7 \%$ son gruesas (Gráfico III.3). 
Las raíces finas constituyen el compartimiento más dinámico de la biomasa subterránea, mientras que las raíces gruesas no mostraron diferencias significativas durante la mayor parte del año (Tabla III.3).

a)
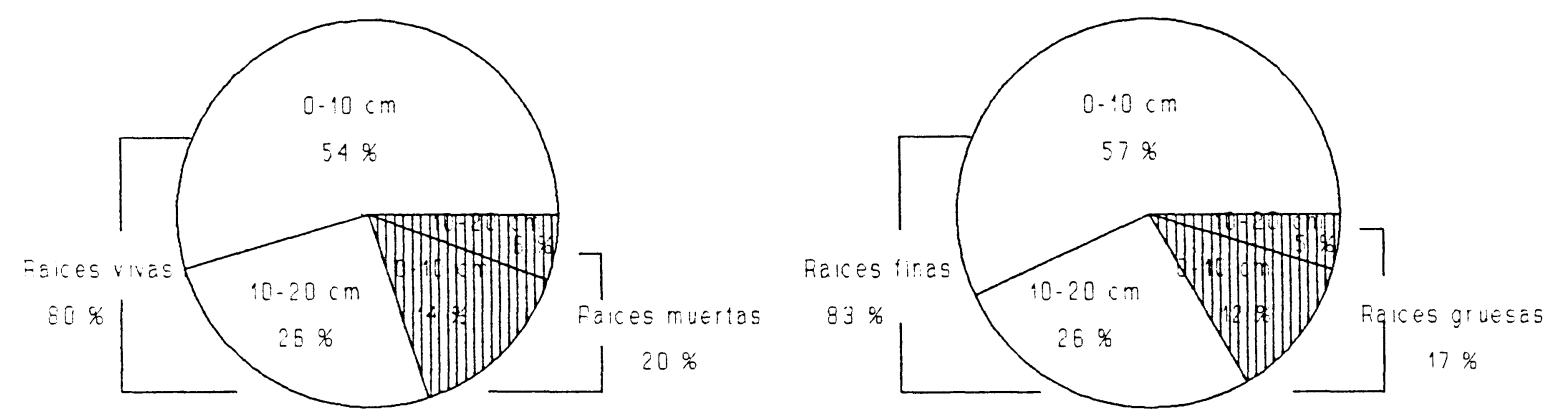
Grafico III.3: Pastizal superior ( $1025 \mathrm{~m} \mathrm{sm}$ ). a) porcentajes de ralces vivas y muertas y b) de raices
finas y gruesas en los estratos muestreados (0-10 y $10-20 \mathrm{~cm}$ de profundidad).

Tabla III.3: Past1zal Superior (1025 $\mathrm{m} \mathrm{sm})$. Blomasa y necromasa subterraneas \pm un error standard ( $\left.\mathrm{g} / \mathrm{m}^{2}\right)$, $n=10$, en los dos estratos muestreados $(0-10$ y $10-20 \mathrm{~cm}$ de profundidad).

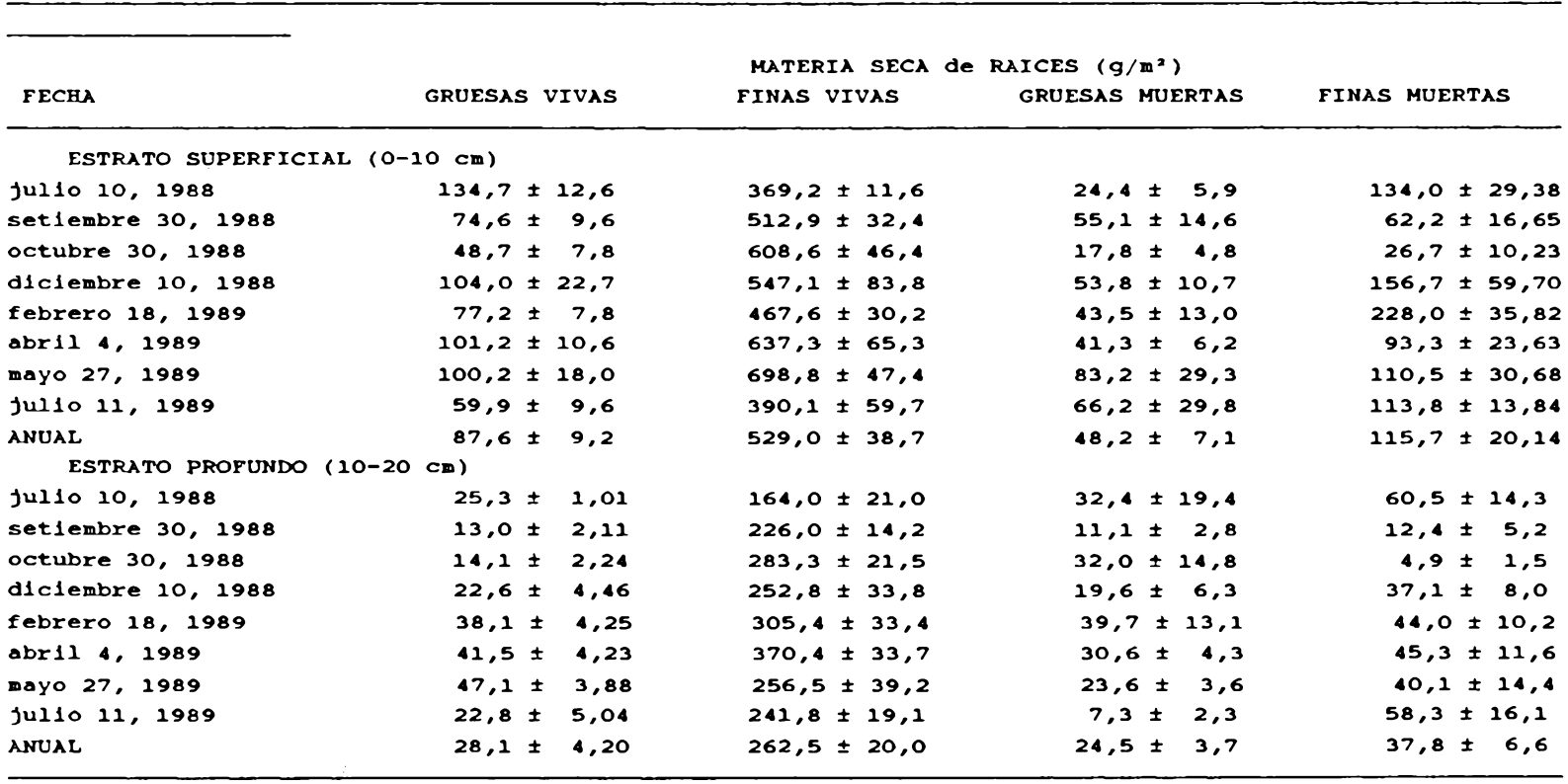

La materia seca subterránea es más elevada durante el período diciembre-mayo, con un máximo otoñal y un mínimo invernal. La biomasa subterránea, con altos valores en primavera, se estabiliza en el verano y alcanza un máximo en abril y mayo. En febrero se produce el pico de necromasa subterránea (Gráfico III.4). 


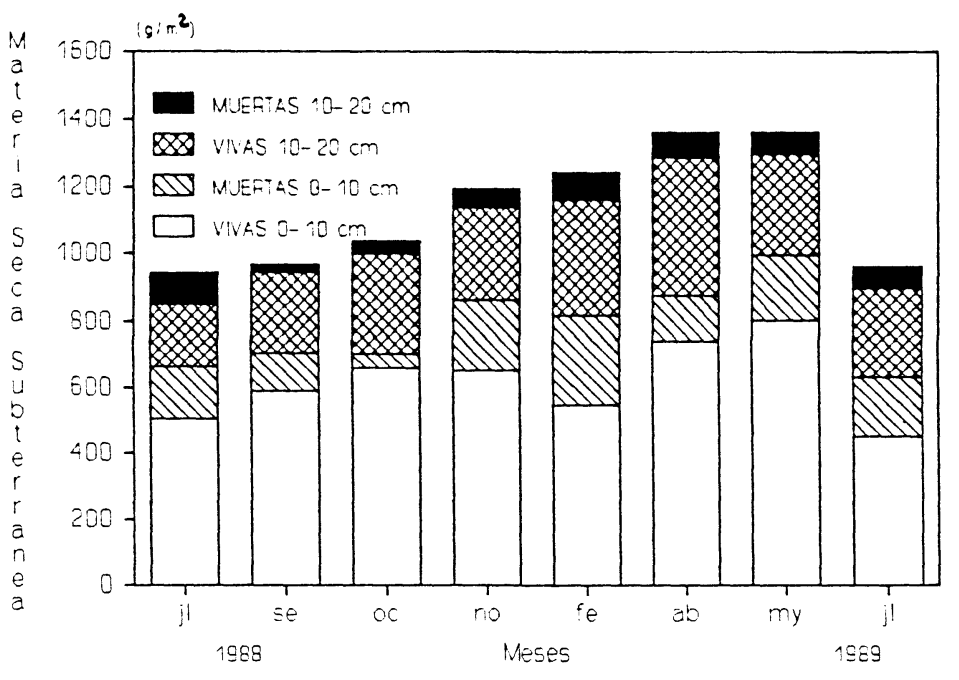

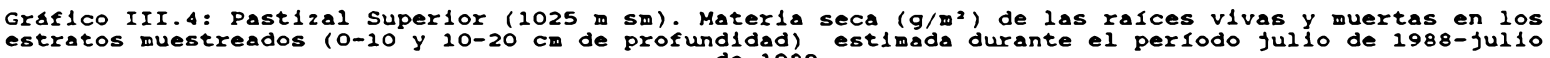
de 1989.

\section{2- HOJARASCA}

La hojarasca presenta valores bajos durante todo el año, excepto a fines de diciembre, cuando ocurre la mayor acumulación en este compartimiento. El valor más bajo se observa a comienzos del mismo mes. Se manifiesta un ciclo de crecimiento anual de este stock desde julio a diciembre y de decrecimiento hacia el invierno siguiente (Tabla III.1).

\section{3-PRODUCTIVIDAD PRIMARIA NETA}

La productividad neta del período de estudio es $1157 \mathrm{~g} / \mathrm{m}^{2}$.año de los cuales $67 \%$ corresponden a productividad subterránea y $33 \%$ a productividad aérea. El $64 \%$ de la productividad neta anual es inverno-primaveral y el $36 \%$ restante es estivo-otoñal (Tabla III.4).

De la productividad inverno-primaveral, las plantas destinan el $63 \%$ al crecimiento de raíces y el resto a estructuras aéreas. Durante el período estivo-otoñal $75 \%$ de la productividad es subterránea y el $25 \%$ restante es aérea (Tablas III.5 y III.6). 
Tabla III.4: Product1vidad primarla neta, mortalldad y desaparición totales (aereas + subterráneas) en el Pastlizal Superlor (1025 n sm) durante el perlodo jullo de 1988 -jullo de 1989.

\begin{tabular}{|c|c|c|c|c|c|c|c|}
\hline \multirow[t]{2}{*}{ Periodo } & \multirow{2}{*}{$\begin{array}{l}\text { Intervalo } \\
\text { (das) }\end{array}$} & \multicolumn{2}{|c|}{ PRODUCTIVIDAD TOTAL } & \multicolumn{2}{|c|}{ MORTALIDAD TOTAL } & \multicolumn{2}{|c|}{ DESAPARICION TOTAL } \\
\hline & & $\left(g / n^{2} \ln t\right)$ & $\left(g / a^{2} \cdot d 1 a\right)$ & $\left(g / m^{2} \ln t\right)$ & $\left(g / m^{2} \cdot d 1 a\right)$ & $\left(g / m^{2} \ln t\right)$ & $\left(g / a^{2} \cdot d 1 a\right)$ \\
\hline jullo-set lembre & 82 & 215,3 & 2,6 & 80,6 & 2,0 & 110,5 & 1,3 \\
\hline setlembre-octubre & 30 & 176,3 & 5,9 & 0,0 & 0,0 & 142,7 & 4,8 \\
\hline octubre-diclenbre & 41 & 322,9 & 7,9 & 303,3 & 7,4 & 10,9 & 0,3 \\
\hline diclembre-diclembre & 17 & 30,8 & 1,8 & 48,4 & 2,8 & 0,0 & 0,0 \\
\hline d1clenbre-febrero & 52 & 88,1 & 1,7 & 83,0 & 1,6 & 84,3 & 1,6 \\
\hline febrero-abr 11 & 45 & 316,0 & 7,0 & 12,7 & 0,3 & 159,5 & 3,5 \\
\hline abr11-mayo & 54 & 7,5 & 0,1 & 79,8 & 1,5 & 31,2 & 0,6 \\
\hline mayo-jul10 & 45 & 0,0 & 0,0 & 402,0 & 8,9 & 402,4 & 8,9 \\
\hline ANUAL & & 1156,9 & & 1009,8 & & 941, & \\
\hline
\end{tabular}

Las tasas diarias de productividad neta total del pastizal presentan valores pico durante la primavera y el otoño. Valores más bajos se registran a fines del invierno-principios de primavera y durante el verano. No se observa crecimiento neto de la vegetación a fines del otoño-principios del invierno (Tabla III.4, Gráfico III.5).

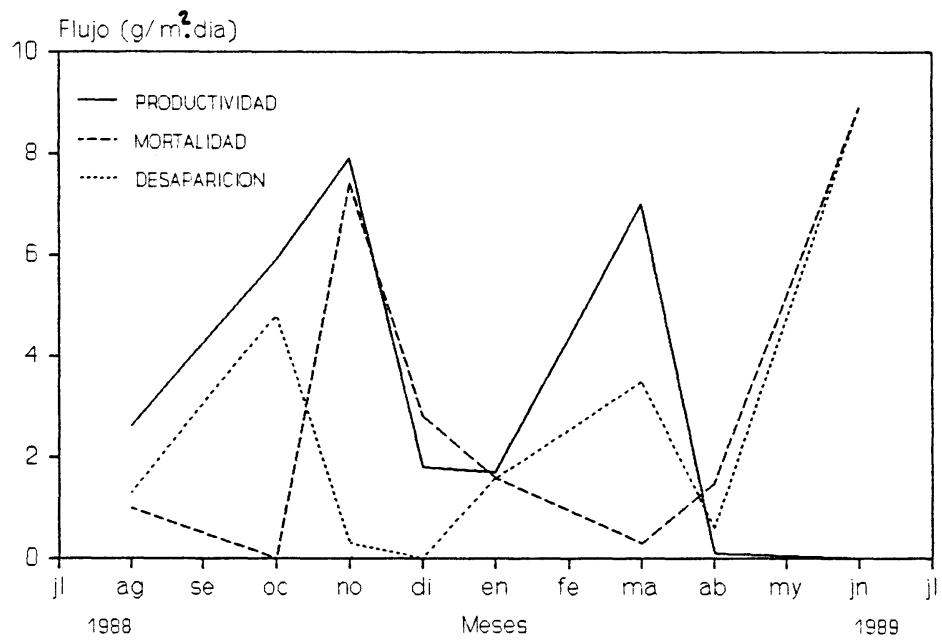

Graf1co III.5: Pastizal superlor (1025 $\mathrm{m} \mathrm{sm})$. Tasas diarlas ( $/ \mathrm{m}^{2}$.dia) de productividad prinaria neta, mortalldad $y$ desaparición totales durante el periodo jullo de 1988-jullo de 1989.

\section{3 a-PRODUCTIVIDAD PRIMARIA AEREA NETA}

La productividad primaria aérea neta (PPAN) anual es $378 \mathrm{~g} / \mathrm{m}^{2}$ año, de los cuales el $73 \%$ se producen durante el período inverno-primaveral y el $27 \%$ durante el período estivo-otoñal. 
Las tasas diarias de PPAN presentan un pico primaveral y otro otoñal. Durante el verano y mediados del otoño las tasas son bajas. A comienzos del invierno la PPAN es nula (Tabla III.5, Gráfico III.6).

\begin{tabular}{|c|c|c|c|c|c|c|c|c|c|}
\hline $\begin{array}{l}\text { Inte } \\
\text { (d) }\end{array}$ & $\begin{array}{l}\text { rvalo } \\
\text { as ) }\end{array}$ & $\begin{array}{c}\text { PPAN } \\
(g / m=\ln t)\left(g / m^{2}\right.\end{array}$ & $. . d 10)$ & $\begin{array}{l}\text { MORTALIDAD } \\
\left(g / m^{2} \ln t\right)(g / m\end{array}$ & $\begin{array}{l}\text { AEREX } \\
m^{2} \cdot d(a)\end{array}$ & $\left(g / m^{2} \ln \right.$ & $\begin{array}{l}D A \\
\left.g / m^{2} \cdot d 1 a\right)\end{array}$ & $\begin{array}{l}\text { DESAPARICION } \\
\left(g / m^{2} \ln t\right)(g / m\end{array}$ & $\begin{array}{l}\text { DN AEREA } \\
\left(m^{2} . d(a)\right.\end{array}$ \\
\hline jullo-set lembre & 82 & 81,9 & 1,0 & 80,6 & 1,0 & 0,0 & 0,0 & 0,0 & 0,0 \\
\hline setlembre-octubre & 30 & 48,1 & 1,6 & 0,0 & 0,0 & 79,9 & 2,7 & 83,7 & 2,8 \\
\hline octubre-diclembre & 41 & 137,2 & 3,3 & 117,6 & 2,9 & 0,0 & 0,0 & 10,9 & 0,3 \\
\hline diclembre-diclembre & 17 & 9,2 & 0,5 & 26,8 & 1,6 & 138,2 & 8,1 & 0,0 & 0,0 \\
\hline diclembre-febrero & 52 & 21,7 & 0,4 & 16,6 & 0,3 & 0,0 & 0,0 & 84,3 & 1,6 \\
\hline febrero-abr 11 & 45 & 72,8 & 1,6 & 12,7 & 0,3 & 0,0 & 0,0 & 14,8 & 0,3 \\
\hline abr11-mayo & 54 & 7,5 & 0,1 & 50,9 & 0,9 & 0,0 & 0,0 & 2,3 & 0,0 \\
\hline mayo-jul1o & 45 & 0,0 & 0,0 & 14,0 & 0,3 & 14,0 & 0,3 & 14,4 & 0,3 \\
\hline ANUAL & & 378,4 & & 319,2 & & 232,1 & & 210,4 & \\
\hline
\end{tabular}

El esfuerzo reproductivo del pastizal, estimado para las gramíneas y graminiformes como el cociente entre la producción de estructuras reproductivas/producción neta total (Gadgil y Solbrig 1972), expresado en porcentaje, es 0,9\%. El 96\% de la producción de estructuras reproductivas es primaveral, el resto ocurre durante el otoño.

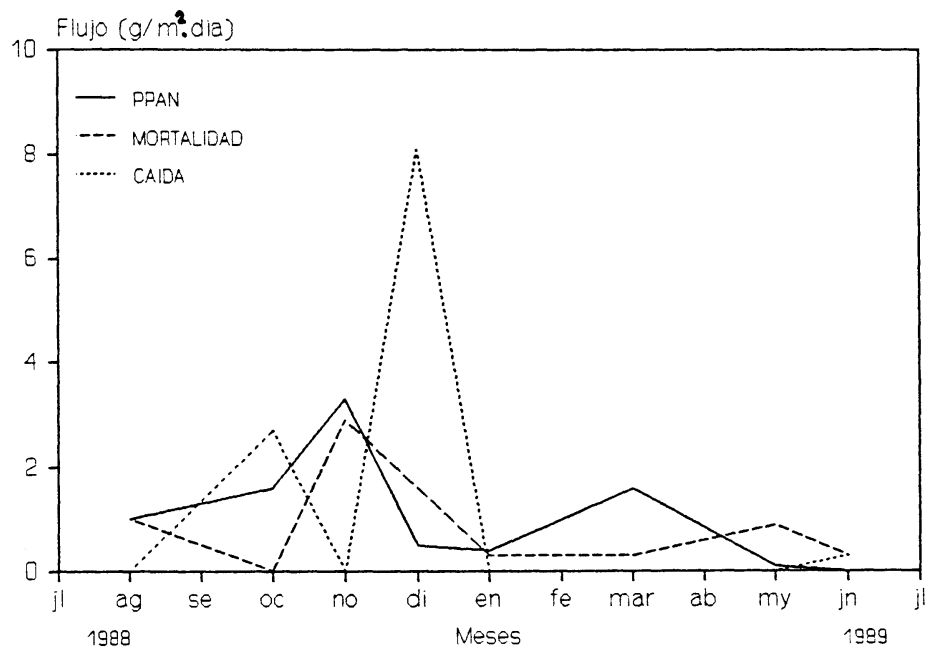

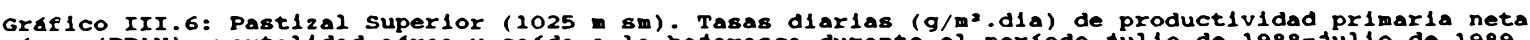
aerea (PPAN), mortalldad aerea y carda a la hojarasca durante el periodo jullo de $1988-j u l 10$ de 1989. 


\section{3 b-PRODUCTIVIDAD SUBTERRANEA NETA}

La productividad estimada a partir del enraizamiento en cilindros de suelo vacío en intervalos de aproximadamente 40 días, los cuales se reemplazan periodicamente, fue nula debido probablemente a que el tiempo que permanecieron enterrados dichos cilindros no fue suficiente como para permitir el crecimiento de raíces dentro de ellos.

La estimación de la productividad subterránea anual varía según el método empleado. A partir del método de ocupación de suelo en cilindros que permanecieron enterrados durante un año (Tabla III.6) la producción de raíces es un $30 \%$ menor que la obtenida mediante la sumatoria de las diferencias significativas de materia seca entre intervalos sucesivos. A partir de este último método se obtuvieron los siguientes resultados: de la producción subterránea anual, $778 \mathrm{~g} / \mathrm{m}^{2}$.año, el $58 \%$ se produce durante el período inverno-primaveral, $11 \%$ durante el verano y el $31 \%$ en el otoño. Las tasas diarias de productividad neta subterránea son altas desde mediados a fines de primavera y a comienzos del otoño (Tabla III.7, Gráfico III.7).

Tabla III.6: Producción pribarla neta subterranea anual en el Past1zal super10r (1025 m sm) durante el perlodo Juilo $1988-j u l 101989$ y jullo 1989 -jullo 1990 , estimada mediante cillndros de suelo vaclo. Medio

\begin{tabular}{|c|c|c|}
\hline & & PRODUCCION DE RAICES \\
\hline Periodo & No de muestras & $\left(g / m^{2} \cdot\right.$ afio $)$ \\
\hline $1988-1989$ & 5 & $490 \pm 47$ \\
\hline
\end{tabular}

Tabla III.7: Productividad primarla neta, mortalldad y desaparicion subterraneas en el pastizal superior ( $1025 \mathrm{~m} \mathrm{sm}$ ) durante el perlodo jullo de $1988-j u 110$ de 1989 .

\begin{tabular}{|c|c|c|c|c|c|c|c|}
\hline Perlodo & $\begin{array}{c}\text { Intervalo } \\
\text { (dias) }\end{array}$ & $\begin{array}{c}\text { PRODUCTIVIDA } \\
\left(g / m^{2} \ln t\right)\end{array}$ & $\begin{array}{l}\text { D SUBTERRANEA } \\
\left(g / m^{2} \cdot d 1 a\right)\end{array}$ & $\begin{array}{r}\text { MORTALIDAD } \\
\left(g / \omega^{2} \mid n t\right)\end{array}$ & $\begin{array}{l}\text { SUBTERRANEA } \\
\left(g / m^{2} . d 1 a\right)\end{array}$ & $\begin{array}{r}\text { DESAPARICION } \\
\left(g / m^{2} \ln t\right)\end{array}$ & $\begin{array}{r}\text { SUBTERRANEA } \\
\left(g / m^{2} \cdot d 1 a\right)\end{array}$ \\
\hline Jullo-setlembre & 82 & 133,4 & 1,6 & 0,0 & 0,0 & 110,5 & 1,3 \\
\hline setlembre-octubre & 30 & 228,2 & 4,3 & 0,0 & 0,0 & 59,0 & 2,0 \\
\hline octubre-diclembre & 41 & 185,7 & 4,5 & 185,7 & 4,5 & 0,0 & 0,0 \\
\hline diclembre-diclembre & $=\quad 17$ & 21,6 & 1,3 & 21,6 & 1,3 & 0,0 & 0,0 \\
\hline diclembre-febrero & 52 & 66,4 & 1,3 & 66,4 & 1,3 & 0,0 & 0,0 \\
\hline febrero-abr 11 & 45 & 243,2 & 5,4 & 0,0 & 0,0 & 144,7 & 3,2 \\
\hline abr11-mayo & 54 & 0,0 & 0,0 & 28,9 & 0,5 & 28,9 & 0,5 \\
\hline mayo-jul10 & 45 & 0,0 & 0,0 & 388,0 & 8,6 & 388,0 & 8,6 \\
\hline ANUAL & & 778,5 & & 690,6 & & 731,1 & \\
\hline
\end{tabular}




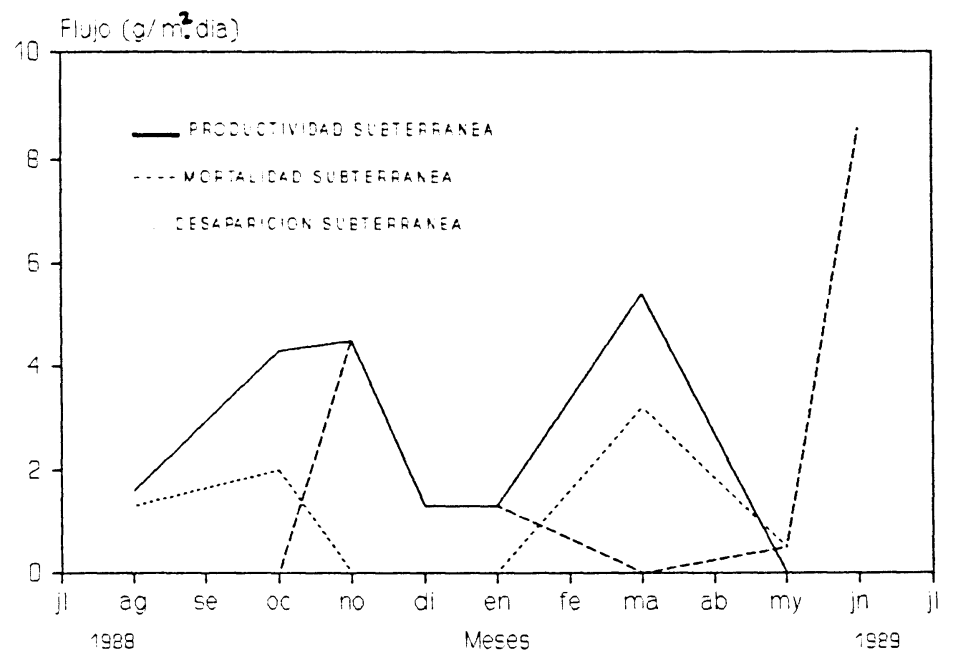

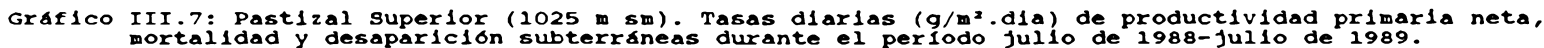

\section{4-MORTALIDAD}

La mortalidad total es $1010 \mathrm{~g} / \mathrm{m} 2$ año, de los cuales un $68 \%$ se debe a mortalidad de las raíces.

El 25\% de la mortalidad aérea anual ocurre a fines del invierno, $45 \%$ durante la primavera y $24 \%$ en el otoño (Tabla III.4).

La tasa diaria de mortalidad es elevada a mediados de primavera y a fines del otoño-principios del invierno, siendo mínimas a comienzos de la primavera y del otoño (Tabla III.4, Gráfico III.5).

La tasa de mortalidad aérea diaria es máxima a mediados de primavera, disminuye durante el verano y se mantiene con bajos valores el resto del año (Tabla III.5, Gráfico III.6).

La mortalidad de raíces se observa desde fines de primavera hasta fines del verano, es nula a comienzos del otoño, con tasas diarias muy elevadas a fines de este último período (Tabla III.7, Gráfico III.7). 


\section{5-CAIDA A LA HOJARASCA}

La caída a la hojarasca presenta un pequeño pico a principios de primavera, un máximo a fines de esta estación y valores mínimos a fines de otoño, siendo nula durante el resto del año (Tabla III.5, Gráfico III.6).

\section{6-DESAPARICION DE MATERIA SECA}

En el año de estudios la desaparición total de materia seca es $941 \mathrm{~g} / \mathrm{m}^{2}$.año. El $78 \%$ de los mismos se deben a la desaparición de raíces y el $22 \%$ a la desaparición de material aéreo.

La desaparición de material vegetal ocurre $28 \%$ durante la primavera, $9 \%$ durante el verano y $69 \%$ en el otoño.

La tasa diaria de desaparición de materia seca es elevada a principios de primavera, a fines del verano-principios del otoño, y presenta su valor máximo a fines del otoño-principios del invierno. A fines de primavera la desaparición es nula (Tabla III.4, Gráfico III.5).

La tasa de desaparición de material aéreo es máxima en la primavera. Presenta valores más bajos en el verano y minimos en el otoño (Tabla III.5).

La tasa diaria de desaparición de raíces, con valores bajos a principios de primavera, se hace nula durante el verano, y aumenta a principios de otoño, alcanzando valores muy elevados a fines de este último período (Tabla III.7, Gráfico III.7). 


\section{7 -NUTRIENTES}

\section{7 a-CONCENTRACION DE NUTRIENTES}

Las mayores concentraciones de N, P, K y Ca se observan en la biomasa aérea (Tabla III.8).

En las dicotiledóneas la concentración de nutrientes es $\mathbf{N}>\mathbf{C a} \approx \mathbf{K}>>\mathbf{P}$. La variación en la concentración de $\mathbf{C a}, \mathbf{K}$ y $\mathbf{P}$ muestra que es durante el verano cuando las dicotiledóneas presentan menor concentración de esos elementos. El $\mathbf{N}$ presenta una tendencia inversa, con un máximo estival. Los valores más elevados de Ca se corresponden con el invierno y la primavera temprana (Gráfico III.8).

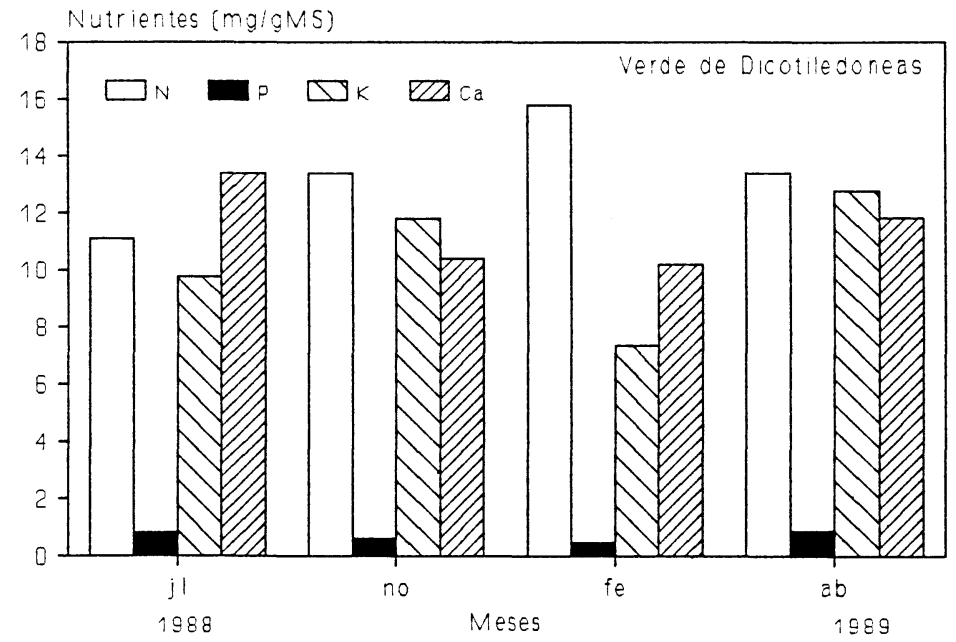

Grafico III.8: Past12al superlor (1025 m sm). Concentracion de nutrientes (mg/gms) en los tej1dos aereos
vivos de las dicotiledoneas, durante el periodo jullo de $1988-j u 110$ de 2989 . 


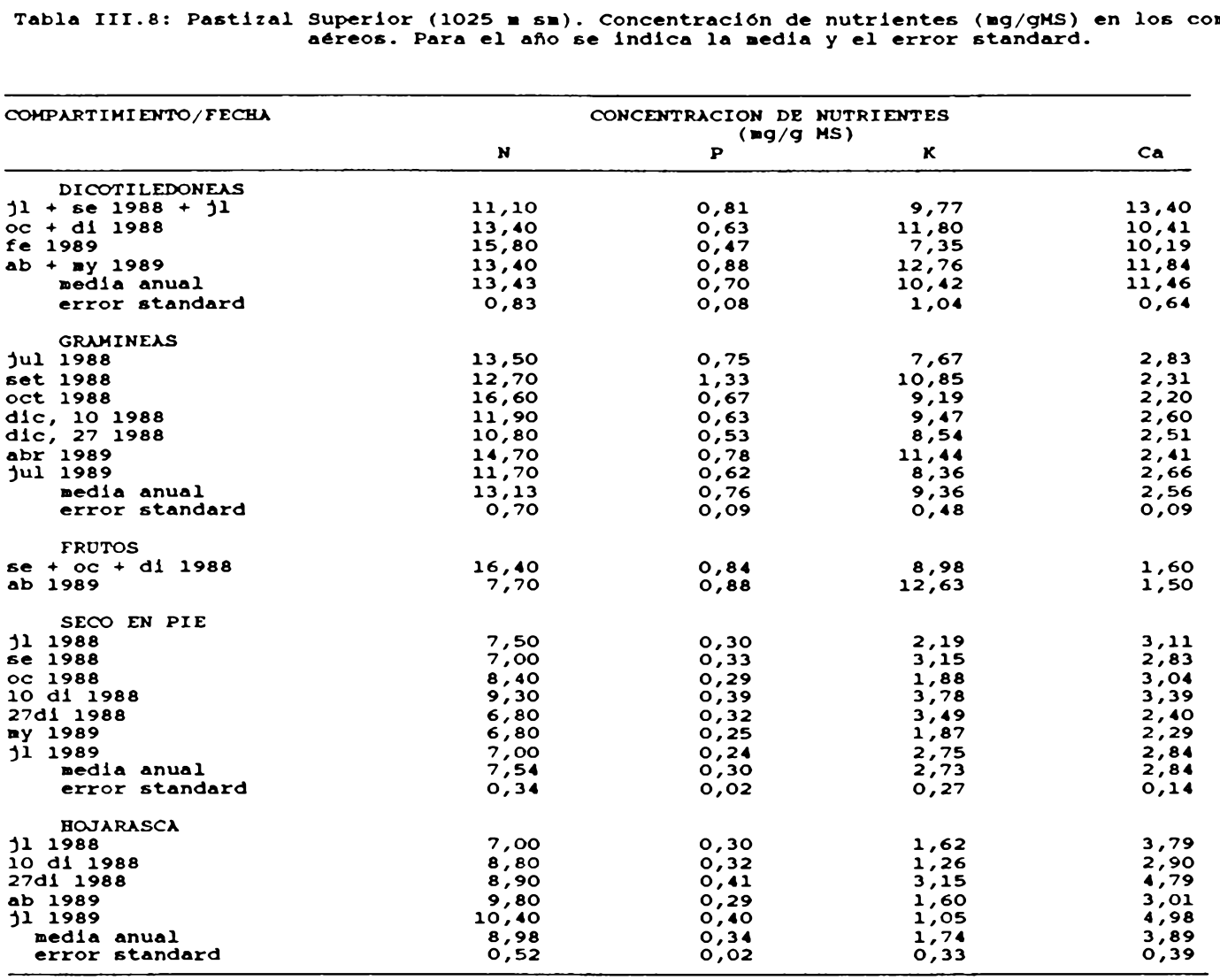

En las gramíneas la concentración de nutrientes presenta el siguiente orden: $\mathbf{N}>\mathbf{K}>>$ Ca $>$ P. La concentración de $\mathbf{N}$ alcanza un máximo a mediados de primavera. El P presenta su valor más elevado a principios de dicha estación y luego varía poco durante el resto del año. La concentración de $\mathbf{K}$ en este compartimiento es mayor a comienzos de la primavera y a comienzos del otoño. La concentración de Ca se mantiene prácticamente constante durante todo el año (Tabla III.8, Gráfico III.9). 


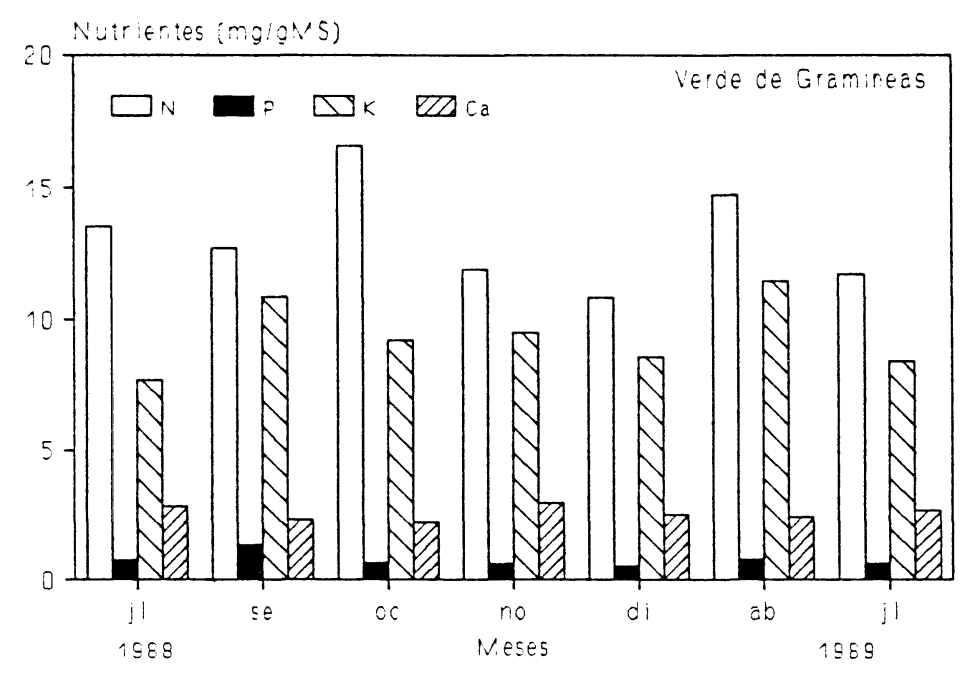
Graflco IIr.9: Pastizal superlor (1025 sm). Concentracion de nutrientes (mg/gms) en los tejldos aereos
vivos de las gramineas, durante el periodo jul10 de $1988-j u 110$ de 1989.

Comparando las gramíneas y dicotiledóneas (test $\mathrm{t}$ de Student, $\mathrm{P}<0,05$ ) las medias anuales de las concentraciones de los nutrientes analizados son similares, con excepción del Ca, que es 4,5 veces mayor en las dicotiledóneas.

En las estructuras reproductivas de las gramíneas las diferencias mayores se observan en las concentraciones de $\mathbf{K}$ y $\mathbf{N}$. La concentración de $\mathbf{N}$ en el período de floración invernoprimaveral, duplica a la correspondiente al período otoñal. En el caso del K, la concentración otoñal es 1,4 veces más elevada. El P y el Ca presentan valores similares en ambos períodos (Tabla III.8).

En el seco en pie la concentración de nutrientes se ordena de la siguiente forma: $\mathbf{N}>>$ $\mathbf{K} \approx \mathbf{C a}>\mathbf{P}$. Las concentraciones de los cuatro nutrientes considerados alcanzan un máximo a comienzos del mes de diciembre, coincidiendo con el pico en la mortalidad aérea. A fines de este mes, cuando la caída a la hojarasca es máxima, las concentraciones de dichos nutrientes presentan valores más bajos. Esta tendencia decreciente continua hacia el otoño (Tabla III.8, Gráfico III.10). 


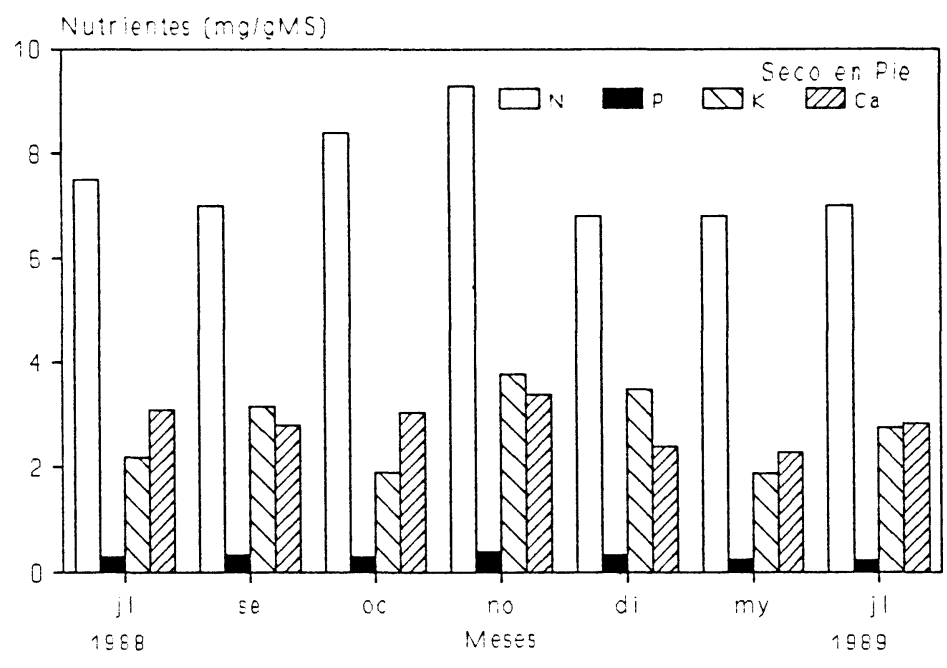

Graf1co III.10: Pastizal Superior (1025 m sm). Concentracion de nutrientes (mg/gMs) en el seco en pie, durante el perlodo jullo de 1988-jullo de 1989.

El seco en pie, comparado con los compartimientos aéreos vivos (test $\mathrm{t}$ de Student, $\mathrm{P}<$ $0,05)$, presenta concentraciones menores de los nutrientes analizados.

En la hojarasca la concentración de los nutrientes es $\mathbf{N}>>\mathbf{C a}>\mathbf{K}>\mathbf{P}$. El máximo en las concentraciones de los nutrientes $\mathbf{P}, \mathbf{K}$ y $\mathbf{C a}$ ocurre a fines de diciembre coincidiendo con el pico de materia seca de este compartimiento. Las concentraciones de los mismos disminuyen hacia el otoño. En el caso del $\mathbf{P}$ y $\mathbf{C a}$, los valores aumentan a principios del invierno, mientras que la concentración de $\mathbf{K}$ es mínima en dicho período. La concentración de $\mathbf{N}$ muestra una tendencia creciente desde julio de 1988 a julio de 1989 (Tabla III.7, Gráfico III.11). 


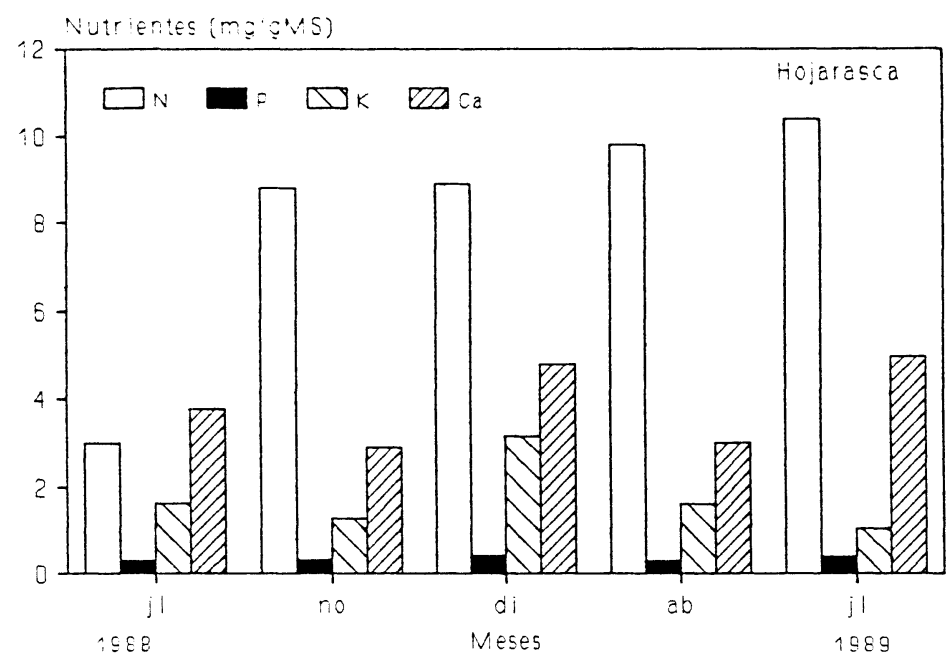

Graflco III.11: Pastizal Superior (1025 $\mathrm{m} \mathrm{sm})$. Concentración de nutrientes (mg/gMS) en la hojarasca, durante el perlodo jullo de $1988-j u l 10$ de 1989.

Las concentraciones de $\mathbf{N}$ y $\mathbf{C a}$ son mayores en la hojarasca que en el seco en pie, en cambio el $\mathbf{K}$ y el $\mathbf{P}$ presentan valores similares, el primero, y más bajos, el segundo (test $\mathbf{t}$ de Student, $\mathrm{P}<0,05)$.

En las raíces finas vivas la concentración de nutrientes en orden decreciente es: $\mathbf{N}, \mathbf{C a}$, $\mathbf{K}$ y $\mathbf{P}$. Las concentraciones de $\mathbf{C a}, \mathbf{P}$ y $\mathbf{N}$ disminuyen marcadamente a mediados del otoño, período en el cual la mortalidad en dicho compartimiento es máxima. El resto del año las concentraciones de Ca y $\mathbf{P}$ se mantienen cercanas al promedio anual. Los valores más elevados de $\mathbf{N}$ son inverno-primaverales. En el caso del $\mathbf{K}$, las mayores concentraciones son invernales, con un mínimo en el verano (Tabla III.9, Gráfico III.12). 


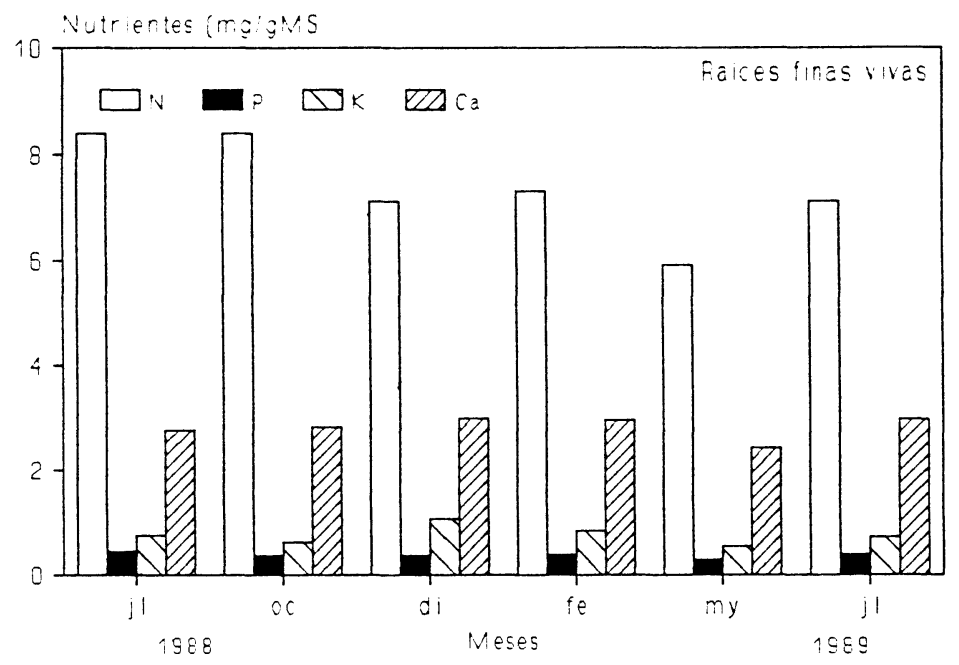

Grafico III.122 Pastizal Superior (1025 m sm). Concentración de nutrientes (mg/gMS) en las ralces finas vivas, duxante el periodo jullo de 1988 -jullo de 1989 .

Las concentraciones de los nutrientes analizados son mayores en las raíces finas vivas que en las raíces gruesas vivas $(P<0,05)$. En estas últimas, los valores del Ca presentan un mínimo a mediados de primavera y un máximo a fines de ese período. El $\mathbf{P}$ disminuye en el otoño, con respecto a los valores de primavera, alcanzando un máximo en el invierno. En este momento también la concentración de $\mathbf{K}$ es máxima. El $\mathbf{N}$ aumenta a mediados de primavera y luego se mantiene con valores similares (Gráfico III.13)

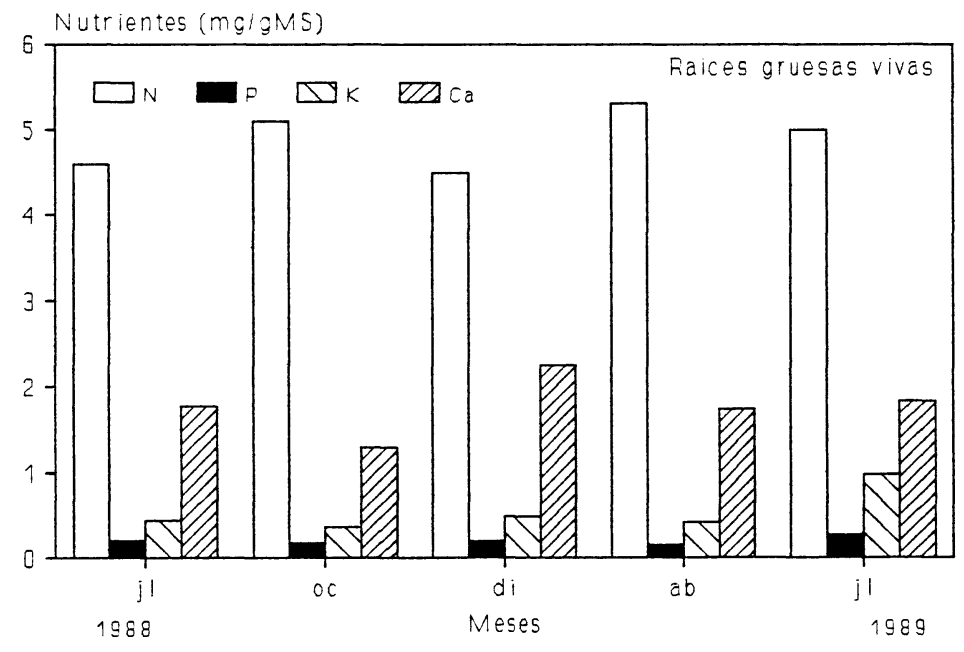

Graf1co III.13: Pastizal superior (1025 m sm). Concentración de nutrientes (mg/gms) en las raices gruesas vivas, durante el periodo jullo de $1988-j u l 10$ de 1989. 
Tabla III.9: Pastiral Superior (1025 m sm). Concentración de nutrientes (mg/gMs) en los compartimientos subterráneos. Para el ano se Indica la media y el error standard.

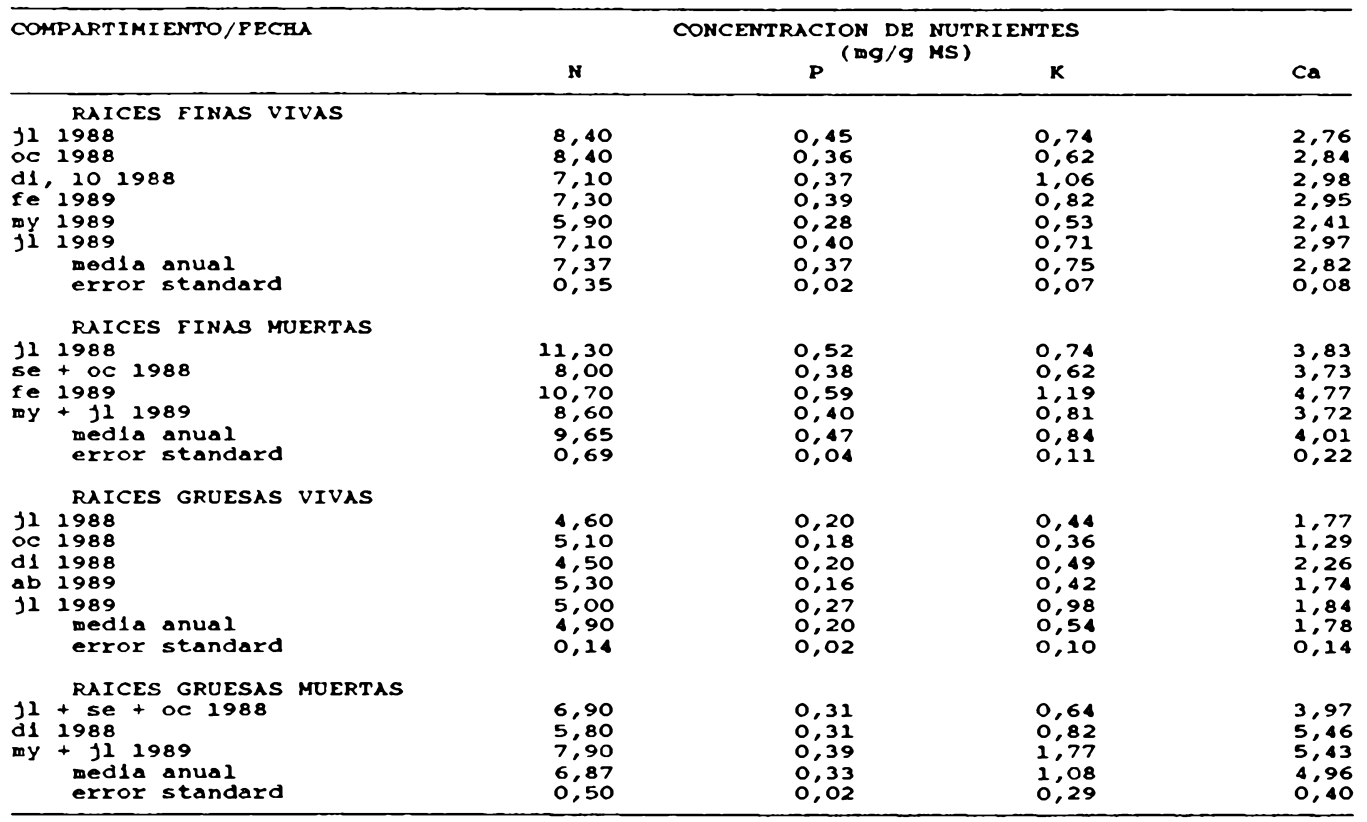

De los compartimientos subterráneos, las raíces finas muertas, tienen las mayores concentraciones de nutrientes (test $t$ de Student, $\mathrm{P}<0,05$ ). Los mismos muestran un máximo estival y luego disminuyen hacia el período otoño-invernal. Se observó una fuerte variación de la concentración de nutrientes, especialmente de $\mathbf{K}$ y $\mathbf{N}$ entre los meses de julio de 1988 y julio de 1989; en este último los valores de $\mathbf{K}$ y $\mathbf{N}$ duplicaron a los del año anterior (Tabla III.8, Gráfico III.14).

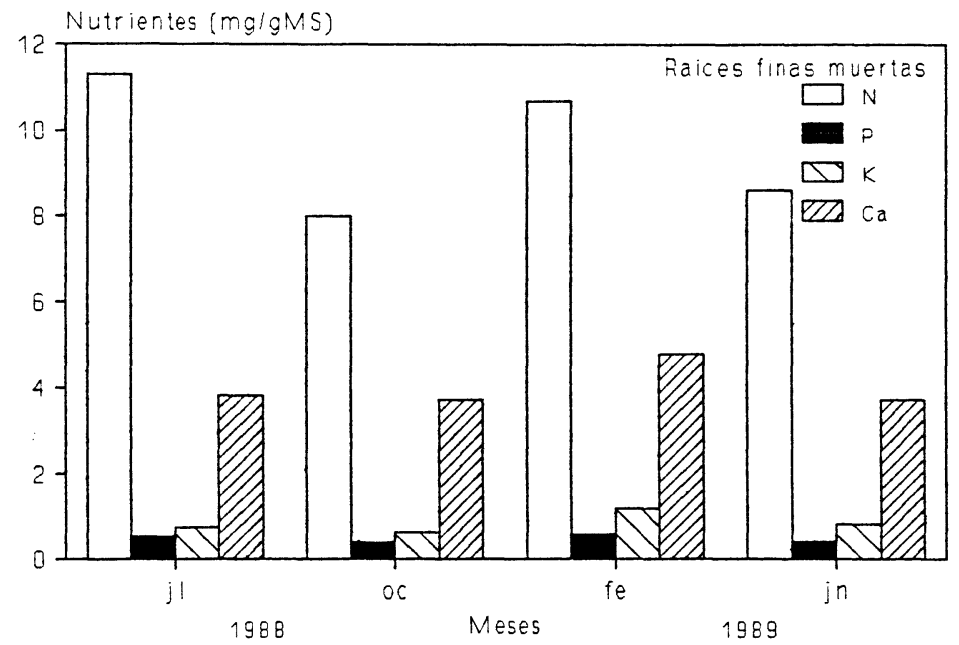

Grafico III.14: Pastizal Superior (2025 m sm). Concentración de nutrientes (mg/gms) en las ralces finas muertas, durante el periodo jullo de 1988 -jullo de 1989 . 
Las concentraciones de los nutrientes en las raíces gruesas muertas muestran una tendencia creciente desde julio de 1988 a julio de 1989. (Tabla III.8).

\section{7 b-ALMACENAJE MINERAL}

Los almacenajes de nutrientes en el material vegetal total (vivo + muerto) siguen el orden

$\mathbf{N}>>\mathbf{C a}>\mathbf{K}>\mathbf{P}$, siendo respectivamente 12,$4 ; 4,9 ; 3$ y $0,6 \mathrm{~g} / \mathrm{m}^{2}$. Del almacenaje mineral total, los compartimientos subterráneos representan el $67 \%$ del $\mathbf{N}$ y $69 \%$ del P (50\% en las raíces vivas y $18 \%$ en las raíces muertas), el $29 \%$ del $\mathbf{K}$ ( $21 \%$ en las raíces vivas y $8 \%$ en las muertas) y el $70 \%$ del Ca ( $48 \%$ en las raíces vivas y $22 \%$ en las muertas). En la biomasa aérea se almacenan el $14 \%$ del $\mathbf{N}, 16 \%$ del $\mathbf{P}, 44 \%$ del $\mathrm{K}$ y $10 \%$ del $\mathrm{Ca}$, mientras que en el seco en pie se encuentra el $15 \%$ del N, $12 \%$ del P, $23 \%$ del K y $14 \%$ del Ca; y en la hojarasca el $3 \%$ del $\mathbf{P}$, el $4 \%$ del $\mathbf{N}$ y del $\mathbf{K}$, y el $5 \%$ del $\mathbf{C a}$. En el material vivo (mineralomasa aérea + mineralomasa subterránea) se encuentra el $63 \%$ del $\mathbf{N}$, el $66 \%$ del P, el 65\% del $\mathbf{K}$ y el $59 \%$ del $\mathbf{C a}$ (Tablas III.9 y III.10).

Con respecto al almacenaje mineral aéreo, las dicotiledóneas contribuyen con el $8 \%$ del $\mathbf{P}, 6 \%$ del $\mathbf{N}, 11 \% \mathrm{~K}$ y $16 \%$ del $\mathbf{C a}$; las gramíneas más sus estructuras reproductivas almacenan el $40 \%$ del $\mathbf{P}$, el $34 \%$ del $\mathbf{N}$, el $49 \%$ del $\mathbf{K}$ y $19 \%$ del Ca. En el seco en pie se encuentran el $39 \%$ del $\mathbf{P}, 46 \%$ del $\mathbf{N}, 39 \%$ del $\mathbf{K}$ y $48 \%$ del $\mathbf{C a}$, mientras que en la hojarasca se encuentran el 10\% del P, 12\% del N, 6\% del K y 16\% del Ca (Tabla III.9). 
Tabla III.10: Past1zal Superlor (1025 n 5m). Almacenaje mineral (g/m) en los compartimientos aereos Para el año se lndica la media y el error standard.

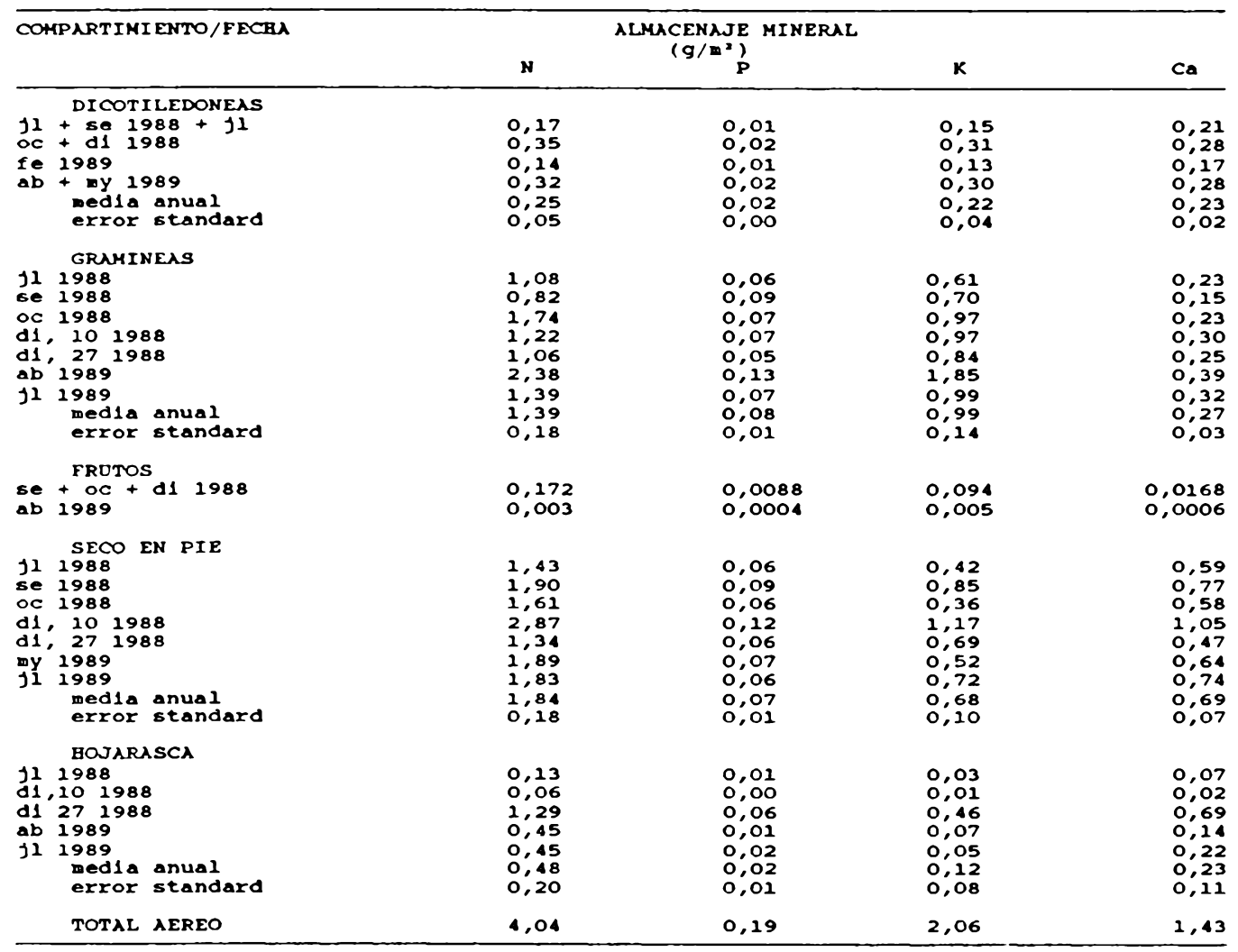
Tabla III.11: Pastizal superior (1025 $\mathrm{m} \mathrm{sm})$ Almacenaje mineral ( $\left.\mathrm{g} / \mathrm{m}^{2}\right)$ en los compartimientos
subterraneos. Para el año se indica la media y el error standard.

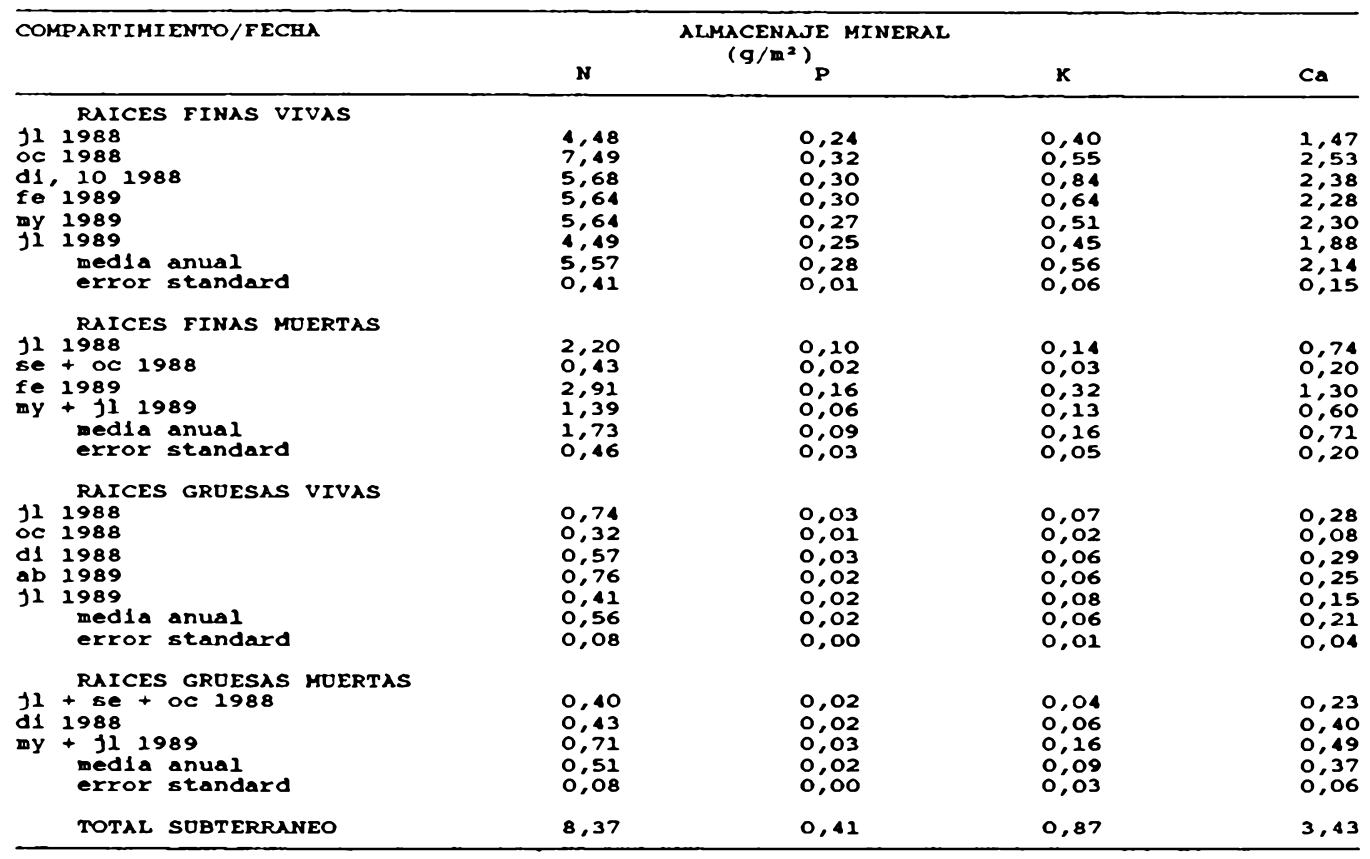




\section{7 c-SUELOS}

Los suelos de este pastizal, caracterizados de acuerdo con las clasificaciones de Arens y Etchevere (1966) se consideran, en cuanto a la profundidad, muy someros ya que dificilmente sobrepasan los $20 \mathrm{~cm}$; en cuanto a la textura, son franco arenosos, con presencia de gravas y gravillas y de acuerdo con el $\mathrm{pH}$ son suelos ácidos. El porcentaje de saturación con bases es bajo, mientras que el contenido de materia orgánica, según la clasificación propuesta por Hardy (Hardy 1961, en Fassbender 1982) es muy alto. El contenido de nitrógeno se encuentra dentro del rango más frecuente $(0,2$ y $0,7 \%$ de nitrógeno) citado para suelos (Fassbender 1982). La relación $\mathrm{C} / \mathrm{N}$ se encuentra dentro de los valores comunes (10 a 12) para el estrato A (Arens y Etchevere 1966) para suelos de pastizal. En cuanto al contenido de P, se consideran suelos deficientes. La saturación con bases es baja (inferior al 50\%). De acuerdo con estas caracteristicas este suelo se denomina Haplumbrets lítico. Estos suelos se caracterizan por presentar un epipedon úmbrico (horizonte superficial oscuro que tiene una saturación con bases inferior al 50\%; en cuanto al color, espesor, carbono orgánico y contenido de $\mathrm{P}$, reune las condiciones requerida por un epipedon mólico), y contacto lítico dentro de los primeros $50 \mathrm{~cm}$ profundidad del suelo (Soil Survey Staf 1990) (Tabla III.12).

\begin{tabular}{|c|c|c|c|}
\hline Profundidad $(\mathrm{cm})$ & $0-20$ & MO (₹) & 10,7 \\
\hline $\begin{array}{l}\text { pH (en pasta) } \\
\text { Composición granulometrica (z) }\end{array}$ & 4,1 & $\begin{array}{l}\text { C. I.C. (m.e./100) } \\
\text { Bases de Intercamblo (m.e./100) }\end{array}$ & 23,6 \\
\hline Arena & 54,4 & Cat+ & 5,8 \\
\hline arcilla & 9,6 & $M g++$ & 2,8 \\
\hline L1mo & 36,0 & Nat & 0,2 \\
\hline Fósforo (ppm) & 7,0 & $k+$ & 0,4 \\
\hline Carbono organico (z) & 6,2 & Saturacion con bases $(z)$ & 39 \\
\hline N1trogeno total disponible(z) & 0,49 & Densidad aparente $(\mathrm{g} / \mathrm{cm} 3)$ & 0,702 \\
\hline$C / N$ & 13 & & \\
\hline
\end{tabular}

\section{7 d- MINERALIZACION}

La mineralización de nutrientes estimada a partir de la cosecha de la hojarasca es 0,07 $\mathrm{g} / \mathrm{m}^{2}$.año de $\mathbf{P} ; 1,86 \mathrm{~g} / \mathrm{m}^{2}$.año de $\mathbf{N} ; 0,38 \mathrm{~g} / \mathrm{m}^{2}$.año de $\mathbf{K}$ y $0,77 \mathrm{~g} / \mathrm{m}^{2}$.año de Ca. Estos valores fueron calculados a partir de la desaparición de hojarasca, la cual incluye tanto a la descomposición como a la particulación del material e importación o exportación por 
transporte mediante agentes tales como el viento y el agua. La mineralización de nutrientes desde las raíces se considera igual al retorno por dicha via, y fue de acuerdo con las estimaciones para el año de estudios, $0,25 \mathrm{gP} / \mathrm{m}^{2}$.año; $5 \mathrm{gN} / \mathrm{m}^{2}$.año; $0,5 \mathrm{gK} / \mathrm{m}^{2}$.año; 1,9 $\mathrm{gCa} / \mathrm{m}^{2}$.año. De acuerdo con estas estimaciones las raíces aportaron al suelo mediante su descomposición y mineralización, durante el período de estudios, el $78 \%$ del P, $73 \%$ del $\mathrm{N}$, el $70 \%$ del Ca y el $56 \%$ del K proveniente de la vegetación.

\section{7 e-CICLO DE LA MATERIA SECA, MATERIA ORGANICA Y NUTRIENTES}

Ciclo de la materia seca y materia orgánica (Gráfico III.15)

El material vegetal vivo, (aéreo + subterráneo) representó el 67\% de la materia seca (9\%

$+58 \%$ respectivamente) y la necromasa el $33 \%$ ( $15 \%$ seco en pie $+15 \%$ raíces muertas $+3 \%$ hojarasca). Las mismas proporciones se mantienen cuando se refieren a la materia orgánica.

La mortalidad aérea anual constituyó el $84 \%$ de la productividad aérea. A su vez la caída a la hojarasca representó el $73 \%$ de dicha mortalidad. El $90 \%$ del material que se incorporó a la hojarasca desapareció en el término de un año. La mortalidad subterránea anual representó el $94 \%$ de la productividad subterránea y el $100 \%$ de las raíces que murieron, desaparecieron como tales durante el año. De este modo, durante el período de estudio, llegaron al suelo $963 \mathrm{~g} / \mathrm{m}^{2}$.año de materia seca (o $881 \mathrm{~g} / \mathrm{m}^{2}$.año de materia orgánica), incorporándose al mismo, de acuerdo con las estimaciones de desaparición, el $98 \%$ de esas cantidades. 
a)

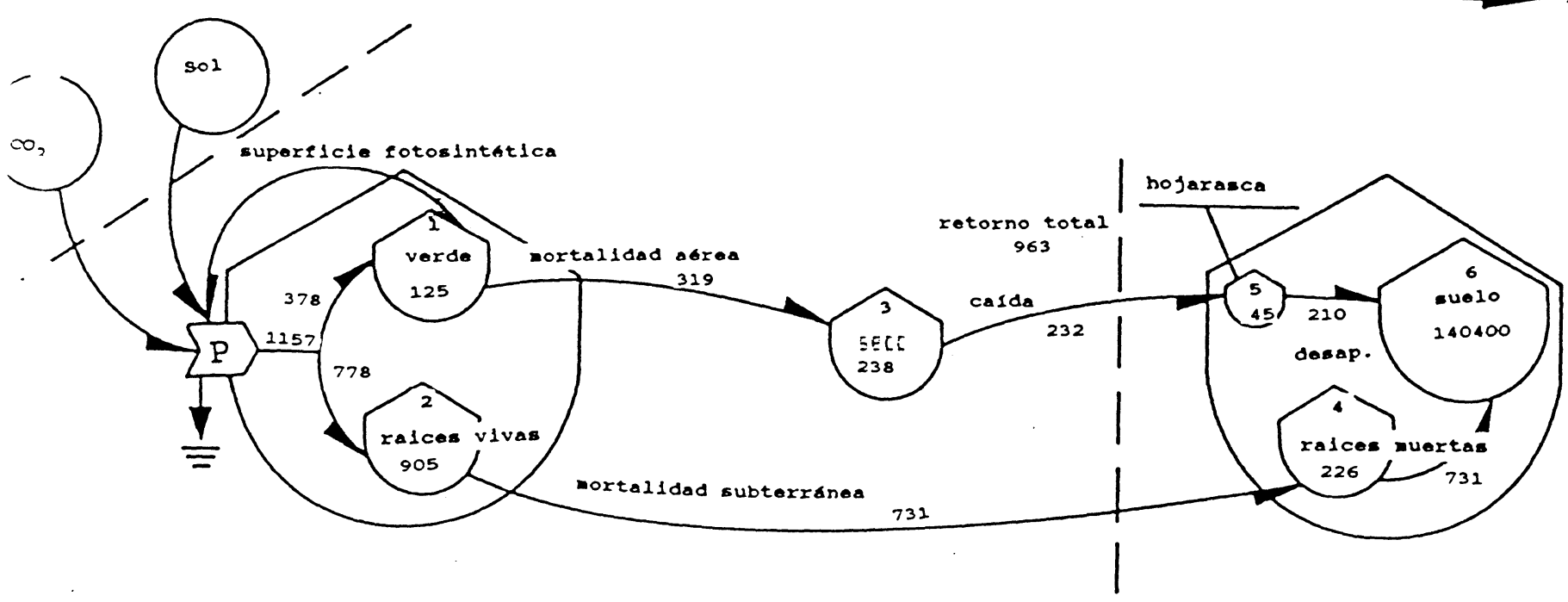

b)

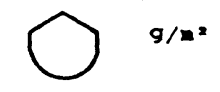

$9 / m^{2} \cdot$. ano

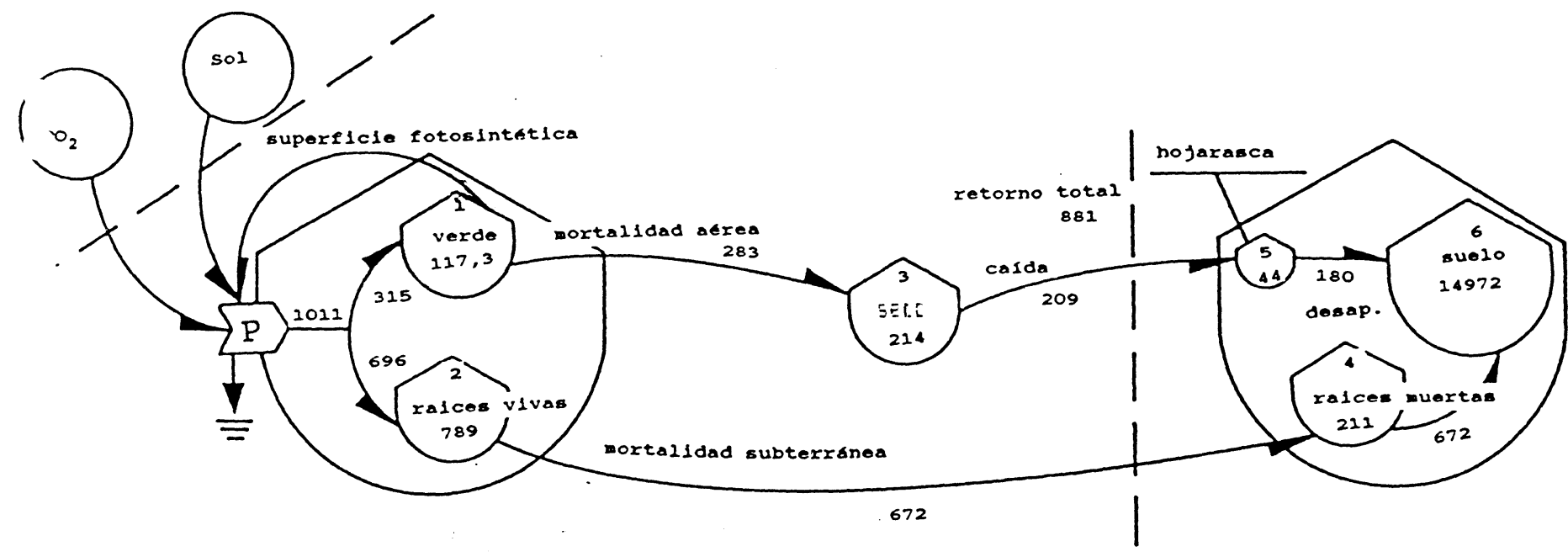

Graflco III.25: a) Modelo del Clclo de la materla seca y b) materla organica en el pastlizal superlor. 


\section{Ciclo del Fosfóro (Gráfico III.16)}

Los requerimientos de $\mathbf{P}$ que satisfacieron la productividad total de la vegetación fueron $0,58 \mathrm{gP} / \mathrm{m}^{2}$.año, $27 \%$ de los cuales provino de la retranslocación de nutrientes.

Del requerimiento anual de $P, 54 \%$ satisfizo la productividad aérea y el $46 \%$ restante, la productividad subterránea.

En el año de estudio, mediante la mortalidad aérea se incorporaron al seco en pie 0,105 $\mathrm{gP} / \mathrm{m}^{2}$.año, mientras que el retorno aéreo fue de $0,070 \mathrm{gP} / \mathrm{m}^{2}$.año. Durante este año se acumularon $0,004 \mathrm{gP} / \mathrm{m}^{2}$. año en dicho compartimiento y $0,03 \mathrm{gP} / \mathrm{m}^{2}$. año fueron lavados del material en pie, acelerando su incorporación al suelo.

El retorno total de $\mathbf{P}$ al suelo a través de los detritos vegetales fue $0,32 \mathrm{gP} / \mathrm{m}^{2}$.año (representando el $55 \%$ del fósforo requerido en la productividad), de los cuales el $78 \%$ fueron aportados por las raíces. El lavado de los tejidos aéreos en pie aportó al suelo 0,075 $\mathrm{gP} / \mathrm{m}^{2}$.año, el cual significa el $13 \%$ del P necesario en la productividad del pastizal. Durante el período de estudios la depositación atmosférica fue $0,006 \mathrm{gP} / \mathrm{m}^{2}$.año. Esta via representa el $1 \%$ del requerimiento anual.

La mineralización de $\mathbf{P}$ fue $0,32 \mathrm{gP} / \mathrm{m}^{2}$.año, de los cuales el $22 \%$ procedió de la mineralización de material aéreo y el $78 \%$ restante provino de las raíces.

Del $\mathbf{P}$ absorvido por las plantas durante el período de estudios, el 75\% retornó al suelo en el mismo lapso, a través de la caída a la hojarasca y la mortalidad de raíces; $17 \%$ ingresó mediado por la lluvia que lava los tejidos aéreos y $1 \%$ a través de la depositación atmosférica. El $7 \%$ restante se encuentra en el material vegetal que se incrementó teniendo en cuenta el inicio y el final del período de muestreo (seco en pie, hojarasca y raíces vivas). De este modo la demanda de fósforo del suelo por parte de las plantas (absorción) fue balanceada por los ingresos desde diferentes vias (pluviolavado, caida a la hojarasca, mortalidad de raíces y depositación atmosférica) sumado a la cantidad de nutriente que queda retenida en la vegetación durante el período de estudio. La misma se considera extraída de 
la solución del suelo. Si la concentración del $\mathrm{P}$ disponible ha de mantenerse constante, entonces esa magnitud debe ser provista por el complejo de intercambio y por meteorización.

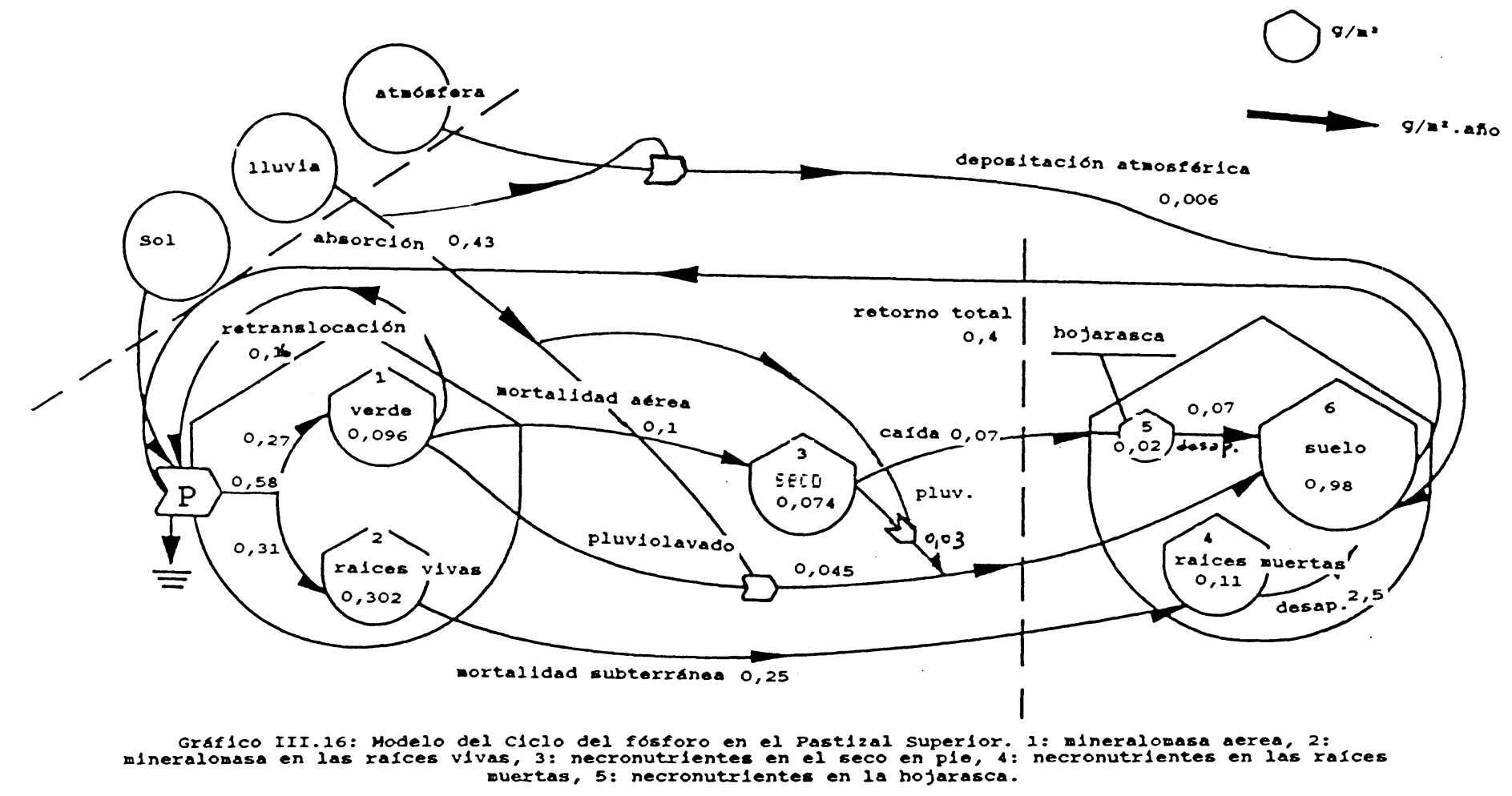

Ciclo del Nitrógeno (Gráfico III.17)

Los requerimientos totales de $\mathbf{N}$ de la vegetación fueron $10.7 \mathrm{gN} / \mathrm{m}^{2}$.año, la retranslocación aportó el $14 \%$ de los mismos.

Los requerimientos aéreos de $\mathbf{N}$ constituyeron el $47 \%$ del total; el $53 \%$ restante satisfizo las necesidades de las raíces.

Al seco en pie ingresó durante el período julio 1988-julio 1989, a través de la mortalidad aérea, $2,49 \mathrm{gN} / \mathrm{m}^{2}$.año. Se acumularon en dicho compartimiento $0,4 \mathrm{gN} / \mathrm{m}^{2}$.año $\mathrm{N}$ durante ese año, y el retorno a través de la caida a la hojarasca fue $1,97 \mathrm{gN} / \mathrm{m}^{2}$.año. El lavado de los tejidos en pie aportó $1,45 \mathrm{gN} / \mathrm{m}^{2}$.año.

El retorno de nitrógeno a través de la vegetación fue $6,7 \mathrm{gN} / \mathrm{m}^{2}$.año, de los cuales $74 \%$ provino del material subterráneo. Del $\mathbf{N}$ requerido para la productividad, en el año de estudio 
retornó el $63 \%$ por la via de los detritos, y $14 \%$ por medio del lavado de los tejidos aéreos.

Por mineralización se incorporaron al suelo $6,8 \mathrm{gN} / \mathrm{m}^{2}$.año. De los mismos $73 \%$ provinieron de la descomposición de las raíces.

Del $\mathrm{N}$ absorbido durante el período de muestreo $72 \%$ retornaron a través de los detritos vegetales, $16 \%$ se incorporó al suelo por lavado de los tejidos aéreos en pie, $8 \%$ quedo retenido en compartimientos vegetales que mostraron una tendencia creciente de un año con respecto al otro, y $3 \%$ por depositación atmosférica seca y húmeda. Queda un déficit que representa menos del $0,02 \%$ del $\mathbf{N}$ disponible en el suelo y que podría ser compensado por la fijación microbiana de $\mathbf{N}$, la cual no ha sido considerada.

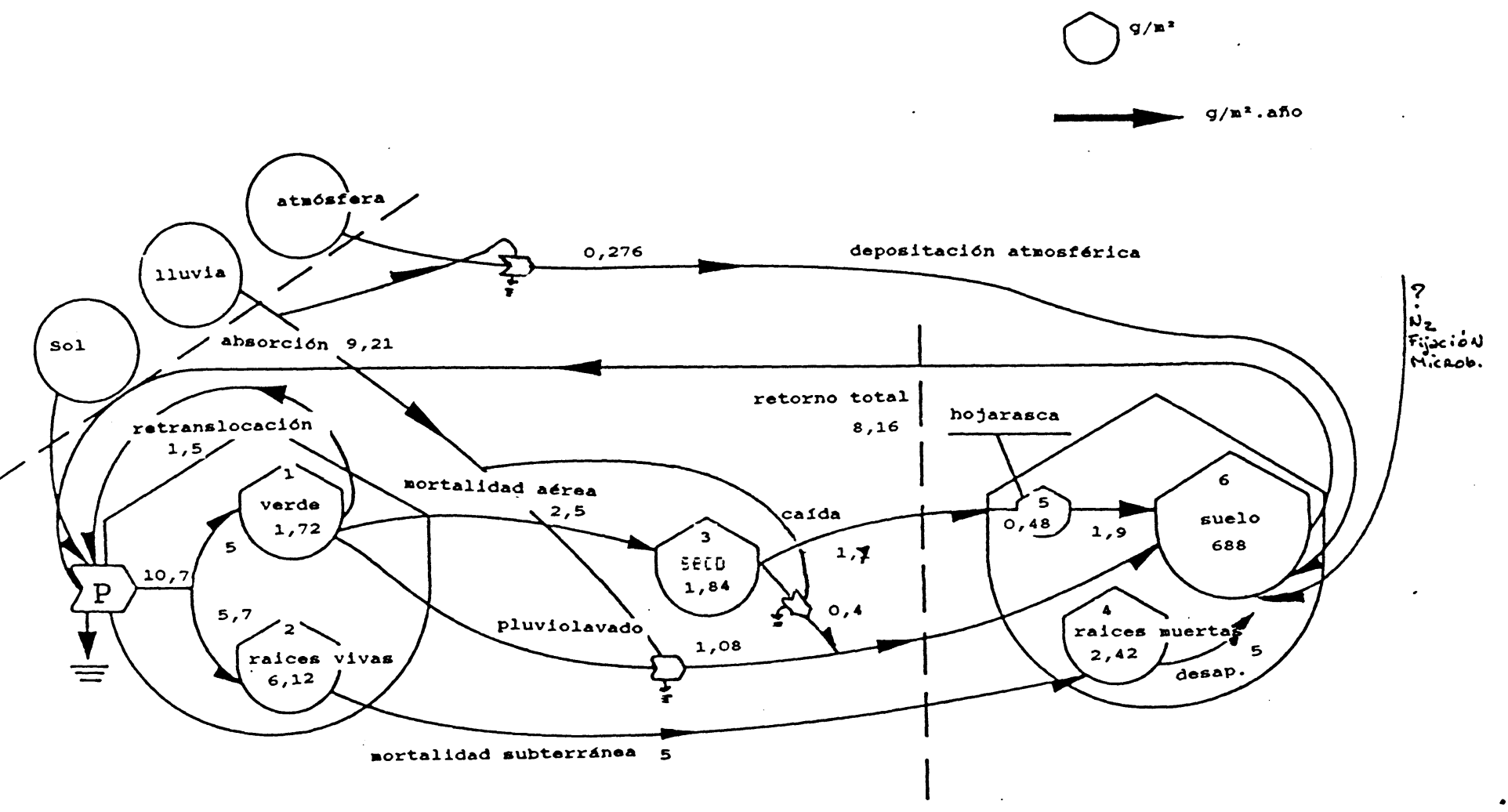

Graflco III.17: Modelo del clelo del nitrogeno en el Past1zal superior.

Referenclos como on el graflco III.16. 


\section{Ciclo del Potasio (Gráfico III. 18)}

Los requerimientos totales de $\mathbf{K}$ necesarios para la productividad primaria neta del sistema fueron $4,5 \mathrm{gK} / \mathrm{m}^{2}$.año, de los cuales el $48 \%$ fueron suministrados por retranslocación.

La productividad aérea requirió el $87 \%$ del $\mathbf{K}$ necesario para la productividad total.

La mortalidad y el retorno aéreos presentaron durante el año 1988-1989 una diferencia en favor de la primera en cuanto al $\mathbf{K}$ involucrado en dichos procesos $\left(1,05 \mathrm{gK} / \mathrm{m}^{2}\right.$. año y $0,67 \mathrm{gK} / \mathrm{m}^{2}$.año respectivamente), acumulándose $0,3 \mathrm{gK} / \mathrm{m}^{2}$.año en el seco en pie en dicho año.

El retorno de $\mathbf{K}$ al suelo, a través de la caida a la hojarasca y mortalidad de raíces, fue $1,16 \mathrm{gK} / \mathrm{m}^{2}$.año, de los cuales $57 \%$ provinieron del material aéreo y $43 \%$ del subterráneo.

La mineralización de $\mathrm{K}$ al suelo fue $0,86 \mathrm{gK} / \mathrm{m}^{2}$.año $(44 \%$ provenientes de la mineralización de la hojarasca y $56 \%$ de las raíces).

$\mathrm{El}$ retorno de $\mathrm{K}$ al suelo proveniente de la vegetación representa el 52\% de la absorción, $17 \%$ permanecieron retenidos en la vegetación y $30 \%$ se incorporaron al suelo a través del lavado desde los tejidos aéreos vivos. Sumándose a lo anterior el $\mathbf{K}$ proveniente de la depositación atmosférica, el cual representa el $26 \%$ de la cantidad absorvida durante el año de estimaciones, la diferencia entre ingresos y egresos de potasio en el suelo resulta positiva. 


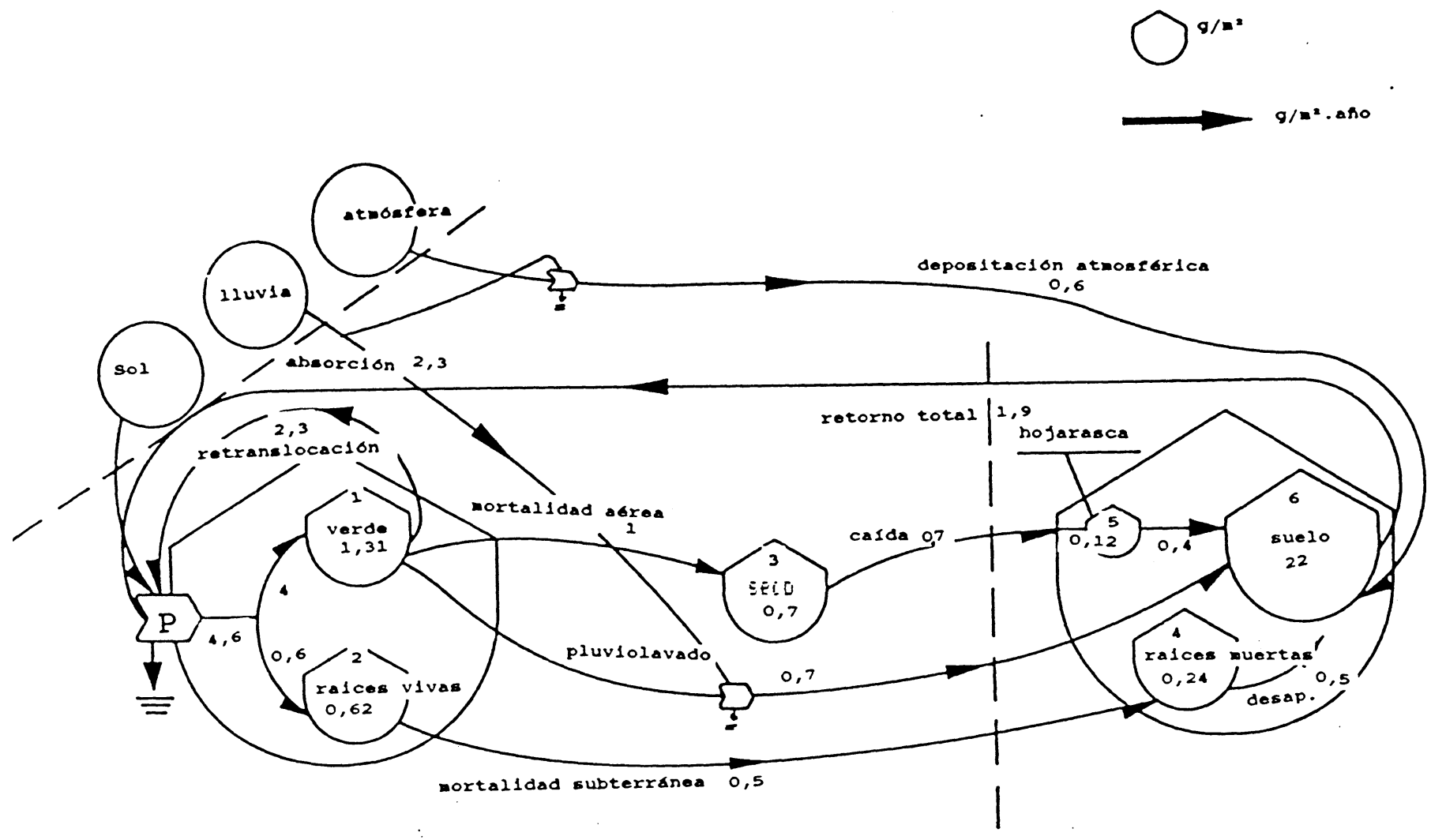

Graflco III.18: Modelo del clelo del potasio en el Pastizal superior. Referenclas como en el grafico

Ciclo del Calcio (Gráfico III.19)

Los requerimientos totales de Ca fueron $3,4 \mathrm{gCa} / \mathrm{m}^{2}$.año, los cuales se satisfacen enteramente por absorción, ya que no existe retranslocación de este nutriente debido a su escasa movilidad en la planta.

Mediante la mortalidad se incorporaron al seco en pie $0,92 \mathrm{gCa} / \mathrm{m}^{2}$.año, los cuales mostraron una tendencia acumulativa, ya que el retorno aéreo fue en el año de estudio 0,61 $\mathrm{gCa} / \mathrm{m}^{2}$.año.

El retorno total de Ca fue $2,5 \mathrm{gCa} / \mathrm{m}^{2}$.año, el cual provino mayoritariamente de las raíces (76\%).

Los aportes al suelo por mineralización fueron $2,7 \mathrm{gCa} / \mathrm{m}^{2}$.año $70 \%$ de los cuales provinieron de las raíces.

Comparando el retorno a través de la vegetación con la absorción durante el período de muestreos, el balance de $\mathbf{C a}$ en suelo dio un resultado negativo $\left(0,86 \mathrm{gCa} / \mathrm{m}^{2}\right.$.año), pero en 
la vegetación quedan retenidos $0,7 \mathrm{gCa} / \mathrm{m}^{2}$.año y el calcio proveniente de la depositación atmosférica es $1,4 \mathrm{gCa} / \mathrm{m}^{2}$.año, quedando un balance positivo para el suelo.

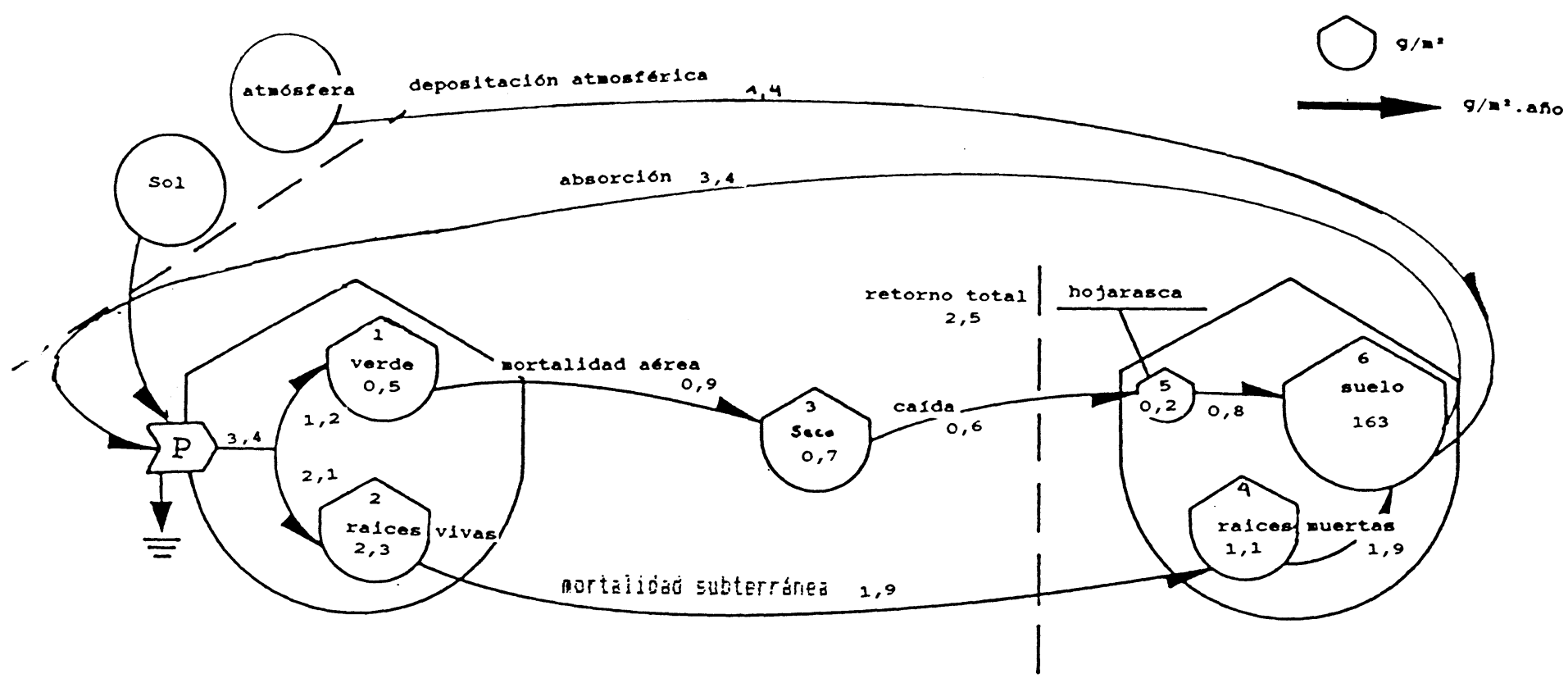

Graflco III.19: Modelo del clclo del calclo en el Pastizal superior. Referenclas cono en el grafico 


\section{III.2-DISCUSION}

Dinamica estacional de la materia seca y procesos funcionales

La cumbre serrana es un sitio frío y húmedo en invierno, con fuertes vientos que en verano provocan elevadas tasas evaporativas aún durante la noche (Kristensen 1992). A estos factores se suma la escasa profundidad del suelo, lo cual impone una limitación en cuanto al volumen de suelo como espacio físico y como recurso que puede ser explotado por la vegetación. La forma en la que una planta asigna su biomasa esta relacionada a presiones de selección históricas y al ambiente actual (Piper 1989). En el pastizal superior las plantas presentan una masa subterránea tres veces mayor a la aérea, lo cual se relaciona con la obtención de agua y nutrientes del suelo, y con la función de anclaje, dado que las ráfagas de viento suelen superar los $150 \mathrm{Km} /$ hora (Kristensen 1992).

La masa aérea y subterránea del pastizal superior (363 y $1131 \mathrm{~g} / \mathrm{m}^{2}$ respectivamente) hallada en este estudio coincide con las estimaciones realizadas por Barrera y Frangi (1994) en 1982, en pastizales de la misma zona. Para un pastizal de altitud y exposición similar señala un máximo de $352 \mathrm{~g} / \mathrm{m}^{2}$ en la materia seca aérea y $1350 \mathrm{~g} / \mathrm{m}^{2}$ en la subterránea. Con respecto a pastizales no pastoreados de EE UU, la masa de raíces de los mismos en los primeros $30 \mathrm{~cm}$ de profundidad presenta un rango entre $168 \mathrm{~g} / \mathrm{m}^{2}$ en sistemas de desierto y $1388 \mathrm{~g} / \mathrm{m}^{2}$ en pastizales de montaña (Sims et al. 1978). El pastizal estudiado se encuentra cercana al extremo superior de este amplio rango. Los mismos autores estimaron una masa aérea entre $85 \mathrm{~g} / \mathrm{m}^{2}$ en desiertos y $598 \mathrm{~g} / \mathrm{m}^{2}$ en pastizales de pastos altos. En este caso el pastizal superior presenta valores intermedios.

Las variaciones en la biomasa y necromasa y la dinámica seguida por las mismas se relacionan con las variaciones en las precipitaciones y en la temperatura a lo largo del año.

La biomasa aérea y subterránea presentan un marcado patrón estacional, con valores pico en la primavera y en el otoño, que son períodos favorables en cuanto a las condiciones térmicas e hídricas. En dichos períodos también aumenta el seco en pie, poniendo en evidencia que cuando la productividad neta aérea es elevada, también lo es la mortalidad. En 
cambio la hojarasca y la necromasa subterránea alcanza los valores mas bajos en esos momentos, debido a que las condiciones óptimas para el crecimiento de la biomasa también lo serían para los procesos de descomposición. Los últimos compartimientos mencionados presentan un pico en el verano coincidiendo con elevada temperaturas del aire y del suelo (Kristensen 1992) y una relacion precipitación-EVT negativa (cf. gráfico II.3). Frangi et al. (1980a) y Ricci (1992), en pastizales de la Sierra de la Ventana, señalan un patrón bimodal a lo largo del año en la marcha de la biomasa y necromasa aérea. Por otra parte una marcada estacionalidad en la dinámica de la masa subterránea es señalada en otros estudios de pastizales (Ares 1976, San Jose et al. 1982, Aerts et al. 1989, Montani et al. 1989, de Wysiecki y Pérez, 1994).

En este pastizal se verifica una acumulación de seco en pie y hojarasca al final del período de muestreo con respecto al inicio del mismo. El primero se incrementa en un $37 \%$ en julio 1989 con respecto a julio del año anterior. En la hojarasca este aumento es mucho mayor, representando el $126 \%$ del material inicial. Esta acumulación de necromasa se debería a que, después del incendio ocurrido a principios de 1987, el pastizal se encontraría en una fase de recuperación de su estructura, donde es frecuente que los compartimientos no productivos tiendan a alcanzar más tardiamente valores estables.

Las raíces finas vivas, señaladas como las más efectivas en la absorción de agua (Ares 1976) se concentran (67\%), en este pastizal, en los primeros diez centímetros de profundidad del suelo. Fernández et al. (1988) señalan que la densidad de raíces depende de la capacidad de crecimiento del sistema subterráneo en respuesta a cambios en el ecosistema suelo. En la cumbre serrana la escasa profundidad del suelo limitaría el almacenamiento de agua en el mismo, por lo cual adquiere mayor importancia la presencia de una biomasa de raíces capaces de aprovechar el agua cuando ésta se encuentra disponible. Cuando el agua es un factor limitante, la densidad radical desempeña un papel fundamental en la capacidad de aprovechamiento de dicho recurso (Fernández et al. 1988). El cociente raíces vivas/biomasa aérea viva, que expresa la proporción de tejido de absorción necesario para mantener una unidad de tejido fotosintético, varió entre 12 y 6 en el período de estudios. Los valores más elevados corresponden a la primera parte del año, que fue relativamente más seca que la segunda. 
En el pastizal superior existe producción durante todo el año, excepto a fines del otoñoprincipios del invierno. Es destacable que la misma, a lo largo del año, es asignada en su mayor proporción a las raíces. La gran masa de raíces de este pastizal se debe a una alta producción de las mismas.

En invierno se detecta productividad neta, tanto aérea como subterránea, siendo esta última 1,6 veces mayor que la primera. Ricci (1992) en pastizales serranos de la misma zona y Sala et al. (1981) en estudios de la productividad aérea de pastizales de la depresión del Salado señalan la existencia de producción neta aérea durante el invierno. A fines del invierno de 1988 la mortalidad aérea se asoció a la escasez de lluvias. Dicho déficit hídrico se manifiesta en la vegetación a través de la reducción de la biomasa aérea, mediante la mortalidad y la caída, el aumento de las raíces finas vivas y de su proporción con respecto a la biomasa aérea que sustentan. Un déficit de agua no demasiado severo puede reducir la tasa de expansión foliar, en lugar de la tasa fotosintética, de modo tal que más asimilados resultan disponibles para el crecimiento de las raíces (Schulze et al. 1987). En relación con el status hídrico de una planta Schulze (1982) señala que el crecimiento del tallo es promovido cuando el contenido de agua de toda la planta es relativamente alto, mientras que cuando es bajo, induce crecimiento de las raíces.

A mediados de la primavera aumentan las tasas diarias de productividad y de desaparición, coincidiendo con precipitaciones abundantes y el aumento de las temperaturas. Los fotoasimilados se asignan en mayor proporción al crecimiento subterráneo. Hacia fines de este período la producción y la mortalidad aérea son máximas. En diciembre se produce la mayor parte del esfuerzo reproductivo del pastizal, la muerte de gran parte de las plantas, principalmente de su parte aérea y la máxima caída a la hojarasca, coincidiendo con las escasas lluvias y la evapotranspiración potencial elevada. En las plantas la reproducción tiene un costo, que se expresa en una reducción de la tasa de crecimiento y/o un incremento en la mortalidad (Harper 1977). Se ha señalado en las plantas la existencia de un compromiso en la canalización de recursos (carbono y nutrientes) hacia diferentes órganos, de modo que lo que se destina a reproducción no puede emplearse al mismo tiempo en el crecimiento o mantenimiento de estructuras vegetativas (Schulze 1982, Schulze y Chapin 1987, Chapin 1980). 
En el verano la productividad aérea y subterránea disminuyen, respecto de las tasas primaverales, manteniéndose la tendencia de asignar una mayor proporción de los fotoasimilados hacia las raíces. En este período la desaparición de hojarasca aumenta. Este proceso, además de estar directamente ligado a la descomposición, se refiere también a material que es llevado por el viento, por pequeños animales o mezclado con el suelo (Frangi et al. 1980a, Sims y Singh 1978a).

El pico otoñal coincide con un aumento importante de las precipitaciones y consecuentemente de humedad del suelo. Las tasas diarias de productividad son elevadas, canalizándose la mayor parte de los fotoasimilados hacia las raíces. La mortalidad diaria para el mismo período es mínima y aumenta recién a fines del otoño- principios del invierno, cuando las temperaturas descienden y las heladas son más frecuentes.

La existencia de dos picos, uno primaveral y otro otoñal, en la productividad primaria neta del pastizal estudiado, se relaciona con la composición especifica del mismo. De acuerdo con la caracterización realizada por Burkart (1974), los pastizales de la provincia de Buenos Aires están constituidos floristicamente por una mezcla de especies de origen mega y microtérmico. En el pastizal superior se observa esta composición mixta de especies. Se ubicarían en dichos grupos Stipa filiculmis y Sorghastrum pellitum respectivamente, cada una de ellas, con más del 50\% de cobertura-abundancia (Frangi y Bottino 1995). Frangi et al. (1980a) y Ricci (1992) en pastizales de la Sierra de la Ventana, señalan la existencia de un pico primaveral y otro otoñal en la productividad neta aérea, que se relacionaría con el régimen térmico de las especies que lo componen. Sim y Singh (1978b) en pastizales de EEUU consideran que los pastizales que presentan especies de ciclo estival y de ciclo invernal presentan un patrón bimodal en la productividad neta anual, en tanto que los dominados por especies de una u otra afinidad térmica, presentan un solo pico durante la estación de crecimiento.

Las plantas vinculan entre si dos medios sumamente disímiles, el suelo y la atmósfera (Fernández et al. 1988). En relación con ello, la dinámica de la materia seca aérea se diferencia de la subterránea en varios aspectos. El tiempo de renovación, expresado como el cociente entre el tamaño de un compartimiento y el flujo de entrada al mismo, en el pastizal superior muestra un gran dinamismo, aunque existen diferencias en la velocidad de 
renovación entre compartimientos. El tiempo de renovación menor corresponde a la hojarasca, la cual se renueva casi 5 veces en un año. Si se compara el tiempo de recambio de los tejidos vivos aéreos, con respecto a los subterráneos, se observa que el sistema es más conservativo con respecto a estos últimos. Mientras que el vivo aéreo se recambia 3 veces en el año, la renovación de las raíces vivas es anual. Si se compara la renovación de los tejidos estacionalmente, se ve que el mayor dinamismo en los tejidos aéreos vivos es invernoprimaveral: 2,4 veces en dicho período (170 dias), versus 0,7 veces durante el período estivootoñal (196 dias). En las raíces las diferencias no son tan marcadas, 0,6 y 0,3 veces en cada período respectivamente. Hendrick y Pregitzer (1992) señalan que el tiempo de vida de una raíz puede estimarse groseramente como la mitad del tiempo que tarda en renovarse el compartimiento de las raíces vivas. En el caso que nos ocupa, el tiempo de vida medio de una raíz sería aproximadamente 7 meses. Análogamente una hoja viviría en promedio 2 meses. Sin embargo el aporte de materia seca al suelo desde los órganos subterráneos es 3 veces superior que el aporte desde la parte aérea. El suministro de materia orgánica al suelo desde la fracción fina de las raíces excede lo producido y suministrado al suelo desde la hojarasca (Persson 1979). Esta diferencia se debería principalmente a que, en el pastizal estudiado, el $67 \%$ de la productividad neta se asigna a las raíces. Otra diferencia se establece en la via principal seguida por el material aéreo y subterráneo. En el primero se distinguen compartimientos de acumulación (seco en pie y hojarasca), mientras que en los órganos subterráneos el pasaje de raíz viva a muerta y su posterior desaparición es muy rápida. En la dinámica del material aéreo, los picos en la mortalidad, caída y desaparición se encuentran desplazados en el tiempo. En las raíces, los picos de mortalidad y de desaparición son simultáneos. Mientras que la desaparición aérea constituye el $56 \%$ de la productividad neta aérea, en este pastizal el $94 \%$ de la productividad subterránea se incorpora al suelo ya sea por la via de los detritos o a través de la herbivoría de la fauna del suelo.

La abundante masa y productividad subterráneas de este pastizal tiene importantes implicancias en cuanto a la contribución a la materia orgánica y nutrientes del suelo y a la estabilidad de los mismos. La masa de raíces constituye un factor de estabilidad del suelo al menos por dos razones: el papel de la materia orgánica aportada al complejo coloidal del suelo en la retención de nutrientes y agua, y la contribución de la malla intrincada de raíces a la cohesión y retención de partícula y agregados del suelo. El valor que adquiere esta vía 
subsuperficial de aporte orgánico ya sido destacada por distintos autores (Chapman 1970, Klein 1977, Daubenmire 1974, Duchaufour 1965, Swift et al. 1979, Persson 1979).

Concentración, contenido y ciclo de nutrientes

Las concentraciones de los nutrientes reportadas en el presente trabajo resultan un promedio de distintos requerimientos y asignaciones de recursos de los grupos de especies que integran el pastizal.

En las gramíneas, se observaron aumentos en las concentraciones y contenidos de los nutrientes en la primavera temprana y en el otoño.

A fines de la primavera, aunque los contenidos principalmente de $\mathrm{P}$ y $\mathrm{K}$ aumentan, sus concentraciones disminuyen. En dicho período la productividad y mortalidad aéreas son máximas. Dado que en el pastizal dichos procesos funcionales presentan picos simultáneos, la dilución de los nutrientes permitiría, por una parte sostener el crecimiento de la vegetación a partir de los minerales acumulados al comienzo del periodo de mayor actividad, y por otra parte reduciría, junto con los mecanismos de retranslocación, la pérdida de nutrientes de las plantas cuando la mortalidad es más intensa. La dilución de los nutrientes $\mathrm{N}$ y $\mathrm{P}$ en los tejidos fotosintéticos a medida que avanza la estación de crecimiento y aumenta la biomasa aérea, ha sido señalada en diversos sistemas de pastizal (Christie 1979, Woodmansee y Duncan 1980, Aerts y Berendse 1989, Bobbink et al. 1989). En el pastizal superior, en la primavera los contenidos y concentraciones de nutrientes en las raíces finas vivas varían en forma similar a la señalada para los tejidos aéreos. Las concentraciones de los mismos se diluyen en el período de máxima productividad, aunque las variaciones tienen amplitudes menores que las observadas en la parte aérea. En las raíces gruesas vivas en cambio, el contenido de nutrientes disminuye a mediados de la primavera, dado por una importante reducción de su biomasa y por el decrecimiento de las concentraciones de los elementos considerados, con excepción del $\mathrm{N}$, que no varía. En suma, en la primavera el crecimiento de la vegetación es sostenido por la absorción de nutrientes, por la dilución de los mismos cuando la biomasa es máxima y probablemente por la tranferencia de nutrientes y reservas desde las raíces gruesas vivas, cuando la productividad primaveral se incrementa. 
A comienzos del otoño, las concentraciones y los contenidos de nutrientes en el verde de gramíneas se elevan, coincidiendo con el pico de productividad aéreo de ese periodo, aunque el mismo presenta, en peso seco, valores inferiores a los máximos de la primavera. En las raíces vivas se observa una disminución marcada de dichas concentraciones a la vez que sus contenidos aumentan. De acuerdo con esto es probable que la productividad, en el otoño, este sostenida en parte por procesos de dilución, evidentes en las raíces, y por la absorción de nutrientes del suelo, dado que la formación de nuevos tejidos aéreos no es acompañada de dilución de las concentraciones, como sí ocurre en la primavera.

En la primavera la productividad y mortalidad aéreas son comparativamente mayores que en el otoño, y la productividad y mortalidad subterráneas también son importantes. En el primer período mencionado, la dilución de los nutrientes $(\mathrm{P}, \mathrm{N}$ y $\mathrm{K})$, en los tejidos aéreos y radicales llevaría a una menor pérdida de los mismos a través de los procesos de mortalidad, con una mayor producción por unidad de nutriente, aumentando la eficiencia en el uso de los mismos. En el otoño en cambio, la mayor parte del crecimiento neto es subterráneo, mientras que la productividad y mortalidad aéreas son bajas. En ese periodo, las concentraciones de $\mathrm{P}$ y $\mathrm{N}$ se incrementan en la parte aérea, a la vez que se diluyen en las raíces, donde la mortalidad también es más intensa. A principios del invierno, cuando comienza a declinar la biomasa aérea, los contenidos de nutrientes en el verde decrecen, sin embargo, las concentraciones en las raíces se incrementan, atribuyéndose esta dinámica a la retranslocación de nutrientes desde las hojas que estan muriendo y su almacenamiento en las raíces. Los materiales retranslocados desde las hojas senescentes, facilitarían el crecimiento en un período siguiente, cuando retornan las condiciones más favorables.

La eficiencia en el uso de los nutrientes frecuentemente se estima como la inversa de la concentración de los mismos. Vitousek (1982) aplicó este índice a la caída de hojarasca de bosques. En el verde de gramíneas, la eficiencia calculada según este criterio mostraría, sólo en el caso del $\mathrm{N}$, una pequeña diferencia en favor de las especies presentes en la primvera con respecto a las otoñales. En las raíces tampoco se observan diferencias marcadas en la eficiencia en el uso del $\mathrm{N}, \mathrm{P}$ y $\mathrm{K}$ entre los dos períodos de mayor productividad. Por otra parte, Chapin (1980) señala que esta medida no es adecuada para la comparación de la contribución potencial de los nutrientes en la productividad futura, ya que existe un amplio 
rango de variación en las concentraciones de $\mathrm{N}$ y $\mathrm{P}$ entre especies, que no está asociada directamente a la mayor o menor productividad de las mismas. En el mismo trabajo se considera que una mejor estimación de la eficiencia en el uso de nutrientes es la obtenida a partir de la tasa de asimilación neta por gramo de nutriente. La misma (Tabla III.13), en contraposición con la inversa de la concentración, pone de manifiesto que la dilución constituiría un mecanismo eficiente en la producción de materia seca en el pastizal. Dicho índice, con respecto al $\mathrm{P}, \mathrm{N}$ y $\mathrm{K}$ en el verde es mayor en el período inverno-primaveral que en el estivo-otoñal. En las raíces, en cambio, no se observan diferencias estacionales marcadas en la eficiencia en el uso de los nutrientes mencionados. De acuerdo con estas estimaciones, la estrategia de producción de las especies primaverales es marcadamente diferente a la de las especies que prevalecen durante el verano y el otoño. En la primavera el costo de producir hojas, en términos de los nutrientes $\mathrm{P}$ y $\mathrm{N}$, es menor que el de producir raíces, lo cual se relaciona con la mayor velocidad de recambio de los tejidos aéreos (la biomasa aérea se renueva 2,4 veces en el período inverno-primaveral y las raíces sólo 0,7 veces), y con la existencia de mecanismos de dilución. En el otoño, en cambio, el costo de producción tanto de hojas como de raíces es similar, lo cual es coincidente con una menor diferencia en la velocidad de recambio entre ambos tipos de órganos (en el período estivootoñal la biomasa aérea se renueva 0,6 veces y las raíces 0,3 veces) y con la ausencia de dilución en los tejidos aéreos.

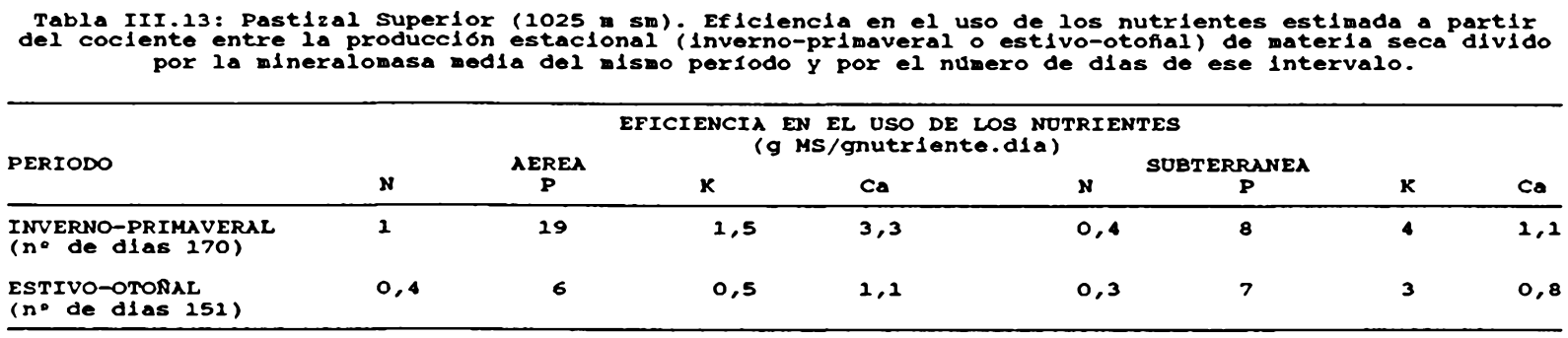

Las estructuras reproductivas de las gramineas que florecen y fructifican en el otoño tienen igual concentración de $\mathrm{P}$, mayor concentración de $\mathrm{K}$ y menor de $\mathrm{N}$ que las primaverales. Estas diferencias en las concentraciones no se expresan cuando se observa el contenido de los nutrientes que es siempre mayor en las estructuras reproductivas primaverales, debido a su biomasa. 
La concentración de $\mathrm{K}$ en las gramíneas y dicotiledóneas es aproximadamente 14 veces mayor que en las raíces, por lo cual los tejidos aéreos son los que participan en mayor medida del flujo de este elemento. Esta diferencia también explica la mayor eficiencia en la producción de raíces con respecto a la producción aérea, en términos de $\mathrm{K}$, en cualquier época del año. Durante la primavera y en el otoño no se observan grandes diferencias en las concentraciones del mismo en los tejidos vivos. En cambio es notable su disminución en los tejidos aéreos a principios del invierno a la vez que aumenta en los tejidos subterráneos vivos. En dicho período la productividad aérea decrece, mientras que existe mayor actividad subterránea. Es probable que parte del $\mathrm{K}$ que disminuye en las hojas de las gramíneas sea translocado hacia las raíces. El incremento invernal de $\mathrm{K}$ en las raíces se da tanto en las finas como en las gruesas. En estas últimas aumentan también los contenidos. Esto se relacionaría con la función de almacenaje que se le ha asignado a las raíces gruesas.

El Ca es un nutriente prácticamente inmóvil en la planta y su concentración varía poco en los tejidos vivos a lo largo del año. Evidencia de ello es también que su contenido sigue las variaciones de la materia seca. Es destacable la elevada concentración que este nutriente tiene en las dicotiledóneas, las cuales contienen casi la misma proporción de calcio que las gramineas (16\% y $19 \%$ respectivamente) con respecto al almacenaje de ese nutriente en la parte aérea, aunque la biomasa de aquellas representa solo el $20 \%$ de la materia seca aérea en pie del pastizal.

Las variaciones estacionales en las concentraciones y contenidos de los nutrientes analizados, en el seco en pie y hojarasca siguieron un patrón similar al del verde de gramíneas aunque con concentraciones notablemente menores en el caso de los nutrientes más moviles, K, P y N. Por dicha razón, la mayor masa del seco en pie con respecto a la biomasa aérea no se expresa en los contenidos, que son menores en el caso del $\mathrm{P}$ y $\mathrm{K}$ y aproximadamente iguales, en el caso del $\mathrm{N}$. Las diferencias en la concentración de los nutrientes entre el verde de gramíneas y el seco en pie se deberían principalmente a procesos de retranslocación de los nutrientes.

En el seco en pie las variaciones en los contenidos y concentraciones están estrechamente ligados a las variaciones en la materia seca. A fines del invierno y de la primavera, la 
mortalidad de estos períodos se refleja en un aumento de las concentraciones y contenidos de nutrientes en dicho compartimiento. En los períodos siguientes a los picos mencionados disminuyen ambas variables. La disminución del contenido mineral se debería principalmente a la caida a la hojarasca y la disminución en las concentraciones se relaciona con el lavado de los elementos. Este último acortaría el pasaje de los nutrientes al suelo desde el material aéreo, quedando disponibles para las plantas.

En la hojarasca se observa una variación similar tanto de las concentraciones como de los contenidos de $\mathrm{P}$ y K. Los mismos disminuyen a mediados de la primavera, probablemente como resultado de los procesos de descomposición y mineralización. Posteriormente la concentración y el contenido de los elementos considerados aumentan al final de la primavera, cuando la caida a la hojarasca es máxima. Las concentraciones de los nutrientes analizados, en ese momento alcanzan valores muy similares a los que presentaban en el seco en pie en el periodo inmediato anterior. En el caso del $\mathrm{Ca}$, en la hojarasca, su incremento a fines de la primavera supera en gran medida a las concentraciones que presentan el seco en pie y el verde de gramíneas en esa fecha. Esta diferncia se atribuye a la probable utilización de los compuestos más lábiles por parte de los organismos que participan en la descomposición, lo cual llevaría a una perdida de masa que no es acompañada por la liberación del nutriente, ya que el mismo integra compuestos más recalcitrantes de las paredes celulares de los tejidos aéreos. El mismo proceso permitiría explicar, en parte la tendencia creciente mostrada por la concentración de $\mathrm{N}$ en la hojarasca a lo largo del año. En este caso es probable también que ocurran procesos de enriquecimiento por parte de los microorganismos descomponedores, lo que llevaría a la inmovilización e incremento en la concentración del $\mathrm{N}$. En las raíces muertas el patrón seguido por las concentraciones y contenidos de los cuatro nutrientes es coincidente. Se observa un decrecimiento primaveral, asociado con el proceso de desaparición de materia seca que ocurre en este compartimiento. En dicho período la descomposición y mineralización serían más activas. Luego, las concentraciones y los contenidos de minerales aumentan durante el verano. Es probable que los procesos de enriquecimiento microbiano y descomposición de los compuestos más lábiles contribuyan al incremento estival en las concentraciones. La mineralización de los nutrientes de las raíces, que por otra parte contienen la mayor proporción de aquellos en la vegetación, durante los períodos de máximo crecimiento, pone en evidencia la sincronía de los procesos de producción y desaparición 
observados en la materia seca, lo cual llevaría a mejorar la disponibilidad de los nutrientes para las plantas en los momentos oportunos, minimizando el período extrabiótico de esos recursos.

En el pastizal superior, comparando el ciclado de la materia seca con el de los nutrientes, se observa que aunque el $67 \%$ de la productividad primaria neta es destinada al crecimiento de las raíces, los requerimientos de nutrientes involucrados en la producción subterránea son menores que los involucrados en la producción aérea en el caso del $\mathrm{K}$ y $\mathrm{P}$, aproximadamente iguales, en el caso del $\mathrm{N}$ y sólo mayores para el $\mathrm{Ca}$. En los almacenajes de $\mathrm{P}, \mathrm{N}$ y $\mathrm{Ca}$, en cambio, es más evidente la importancia que las raíces tienen en este pastizal, ya que las mismas capitalizan prácticamente el $70 \%$ de dichos nutrientes. El $\mathrm{K}$, dada su elevada concentración en los tejidos aéreos vivos, se encuentra mayoritariamente almacenado en los mismos.

En relación con lo anterior, para el $\mathrm{P}, \mathrm{N}$ y $\mathrm{Ca}$, la importancia de los compartimientos aéreos vivos en la circulación de los nutrientes en el pastizal está dada por su tasa de renovación (se recambian 3 veces en un año), más que por el contenido de los mismos. En el caso del $\mathrm{K}$, tanto la tasa de renovación, que es igual a $3 \mathrm{anno}^{-1}$, como su contenido en los tejidos aéreos vivos, lleva a que dicho nutriente retorne en mayor proporción al suelo por medio del lavado de los tejidos aéreos y por la mortalidad y posterior caida a la hojarasca. Las raíces vivas y los nutrientes que ellas contienen, en cambio, se recambian a menor velocidad (anualmente), pero como se dijo, en ellas se almacena la mayor proporción de los nutrientes, por lo cual la muerte y desaparición de las mismas constituye la mayor via de retorno de minerales al suelo. En la parte aérea, además, la existencia del seco en pie, constituiría un retardo en el ciclado de los nutrientes que quedan retenidos en él y que no estan directamente disponibles para la descomposición; aunque, por otra parte, durante la fase de senescencia (paso de verde a seco en pie de las gramíneas y graminiformes) una fracción de los nutrientes tiene la oportunidad de ser retranslocado a otros sitios de almacenaje y utilización. Como ya fue señalado durante el año de estudios se observó un aumento de la necromasa aérea, hecho que además de las posibles fluctuaciones interanuales debidas al clima, se asocia a un proceso de reparación estructural post-fuego (en febrero de 1987 ocurrió un incendio). Ese aumento de necromasa hizo que queden retenidos en el seco en pie el 30 
$\%$ del $\mathrm{K}$ que ingresa a dicho compartimiento a través de la mortalidad, el $16 \%$ del $\mathrm{N}$ y del Ca y sólo el $4 \%$ del P.

Como surge de los modelos de circulación de los nutrientes, la liberación de los mismos al suelo es siempre mayor en las raíces, sin embargo la velocidad a la que ocurre este proceso varía según la época del año y la procedencia, aérea o subterránea de los detritos (Tabla III.14).

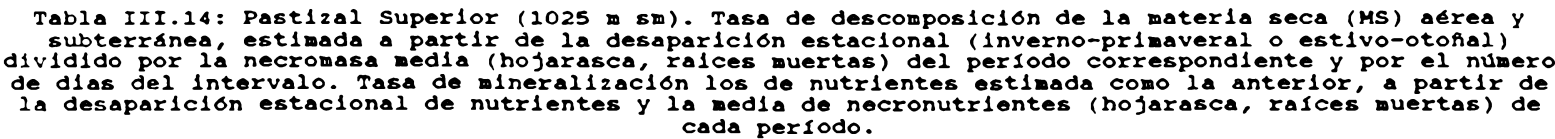

TASA DE DESCOMPOSICION de MS $y$ de MINERALIZACION DE LOS NUTRIENTES

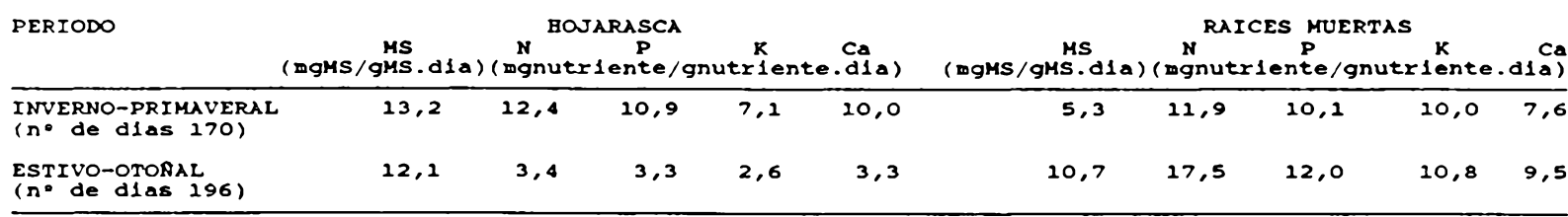

Las tasas de mineralización de las raíces son similares a las de la hojarasca en la primavera y marcadamente mayores en el otoño. En las raíces no se observan diferencias en dichas tasas entre ambas épocas del año, a excepción del $\mathrm{N}$, el cual es liberado a mayor velocidad en el otoño. En la hojarasca las tasas primaverales, que son superiores a las otoñales, responden estrechamente a la velocidad de descomposición de la materia seca de ese compartimiento. En el período estivo- otoñal, en cambio, luego del pico en la caida a fines de la primavera, se evidencia que la tasa de descomposición de la materia seca es mayor que la de liberación de los nutrientes. Esto podría atribuirse a una preferencia de sustratos por parte de los organismos descomponedores. En varios estudios se establece que en la descomposición aérea se distinguen dos fase, una inicial, correspondiente a la degradación de los compuestos más lábiles (carbohidratos hidrosolubles) y una segunda fase, más lenta que la anterior, correspondiente a la descomposición de los compuestos más recalcitrantes (lignina, cutina, celulosa) (Hunt 1977, Andren y Paustian 1987, Gallardo y Merino 1993, Rustad 1994). En las raíces, la mineralización de nutrientes opera a mayor velocidad que la descomposición durante la primavera, mientras que ambas tasas son similares en el otoño. 
Principalmente en las raíces finas, la descomposición comienza tan pronto como la raíz es formada (Stanton 1988), probablemente favorecida por las características físicas y químicas de las mismas y una relativa mayor estabilidad del suelo en lo referente a humedad y temperatura respecto de la zona superficial del mismo, lo que influye también en que no exista una marcada diferencia estacional en las tasas de mineralización.

La retranslocación desde los tejidos senescentes constituye la forma más rápida y segura de obtener nutrientes y se relaciona con la movilidad de los mismos. Este mecanismo es más efectivo en el $\mathrm{K}$, que es retranslocado en mayor proporción, le siguen en orden de importancia el $\mathrm{P}$ y el $\mathrm{N}$.

Por otra parte, si se consideran: 1) la existencia del seco en pie, que amortigua la rápida renovación de los nutrientes en la parte aérea, 2) la masa de nutrientes presentes en las raíces muertas, la cual es entre 2 y 4 veces mayor que en la hojarasca, y 3) las tasas de mineralización de las raíces muertas, similares a las de la hojarasca en el período invernoprimaveral, y aproximadamente 3 veces mayor en el período estivo-otoñal, la via subterránea de incorporación de los nutrientes al suelo no sólo es mayor por la cantidad de nutrientes que involucra, sino que es más directa que la aérea en la devolución de nutrientes al suelo disponibles para la absorción por parte de las plantas.

Otro mecanismo que permite la incorporación de los nutrientes al suelo es el lavado de los tejidos aéreos en pie. Esta via constituye un circuito más corto en la devolución de nutrientes fácilmente aprovechables por las plantas. Por otra parte el sistema radical, constituído principalmente por raíces finas concentradas en los primeros centímetros del suelo, sumado a la existencia de asociaciones micorrícicas, actuaría como una densa red que permitiría captar estos nutrientes sin que se pierdan del pastizal. Con respecto a la descomposición de los tejidos, si bien esta via es más lenta, presenta como probable ventaja el enriquecimiento microbiano de nutrientes y, como se ha dicho, la puesta a disposición de las plantas en el momento más necesario por sincronización de los procesos de descomposición y absorción para la fotosíntesis. 
CAPITULO IV: PASTIZAL MEDIO 


\section{IV.1-RESULTADOS}

\section{1-MATERIA SECA TOTAL}

La media anual de material seco es $1261 \pm 73 \mathrm{~g} / \mathrm{m}^{2}$ de los cuales $62 \%$ corresponden a las raíces, $33 \%$ al material aéreo y $5 \%$ a hojarasca.

La materia seca total en este pastizal presenta una tendencia creciente con un máximo a fines de la primavera. La masa vegetal total se duplica en un año, teniendo en cuenta la fecha de inicio y de finalización del muestreo.

\section{1 a-MATERIA SECA AEREA}

La materia seca aérea es $409 \pm 37 \mathrm{~g} / \mathrm{m}^{2}$. De ellos, $34 \%$ corresponden a los compartimientos vivos y el $66 \%$ restante al seco en pie. De aquellos compartimientos vivos, las gramíneas, dicotiledóneas y estructuras reproductivas representan respectivamente el $82 \%$, $17 \%$, y $1 \%$ (Tabla IV.1).

Tabla VI.1: Pastizal Medio ( $850 \mathrm{~m}$ sm). Blomasa y
Tomasa $\left(g / \mathrm{m}^{2}\right)$ aerea. Medias \pm Error Standard, $\mathrm{n}=10$

\begin{tabular}{|c|c|c|c|c|c|}
\hline FECHA & GRAMINEAS & DICOTILEDONEAS & $\begin{array}{l}\text { MATERIA SECA } \\
\text { FRUTOS }\end{array}$ & $\begin{array}{l}\left(g / m^{2}\right) \\
\quad S E C O \text { EN PIE }\end{array}$ & BOSARASCA \\
\hline $10 / 07 / 88$ & $76,0 \pm 11,2$ & $20,3 \pm 3,3$ & o & $145,2 \pm 15,3$ & $46,6 \pm 6,8$ \\
\hline $30 / 09 / 88$ & $63,3 \pm 8,0$ & $13,3 \pm 3,3$ & o & $236,0 \pm 16,6$ & $28,1 \pm 5,0$ \\
\hline $30 / 10 / 88$ & $93,5 \pm 18,0$ & $17,2 \pm 5,6$ & $0,1 \pm 0,01$ & $240,6 \pm 25,0$ & $24,9 \pm 5,4$ \\
\hline $10 / 12 / 88$ & $129,3 \pm 10,1$ & $22,1 \pm 3,6$ & $12,9 \pm 2,1$ & $291,2 \pm 21,1$ & $8,9 \pm 1,2$ \\
\hline $27 / 12 / 88$ & $108,8 \pm 10,7$ & $24,5 \pm 4,8$ & $1,8 \pm 0,5$ & $267,8 \pm 10,6$ & $139,6 \pm 13,7$ \\
\hline $18 / 02 / 89$ & $95,7 \pm 5,6$ & $17,2 \pm 5,4$ & 0 & $203,2 \pm 12,5$ & $79,8 \pm 6,3$ \\
\hline $04 / 04 / 89$ & $156,6 \pm 6,6$ & $22,6 \pm 5,8$ & $1,0 \pm 0,8$ & $243,9 \pm 21,2$ & $55,9 \pm 8,9$ \\
\hline $27 / 05 / 89$ & $247,3 \pm 6,6$ & $33,5 \pm 7,8$ & 0 & $380,1 \pm 22,2$ & $63,7 \pm$ \\
\hline $11 / 07 / 89$ & $141,4 \pm 7,6$ & $42,4 \pm 10,4$ & 0 & $409,2 \pm 13,4$ & $60,0 \pm 6,2$ \\
\hline ANUAL & $112,4 \pm 10,4$ & $23,7 \pm 2,8$ & $1,8 \pm 1,3$ & $268,6 \pm 26,0$ & $56,4 \pm 12,0$ \\
\hline
\end{tabular}

La biomasa de aérea (gramíneas y dicotiledóneas) presenta un pico a fines de primavera y otro a fines del verano-comienzos del otoño (Tabla IV.1, Gráfico IV.1). 


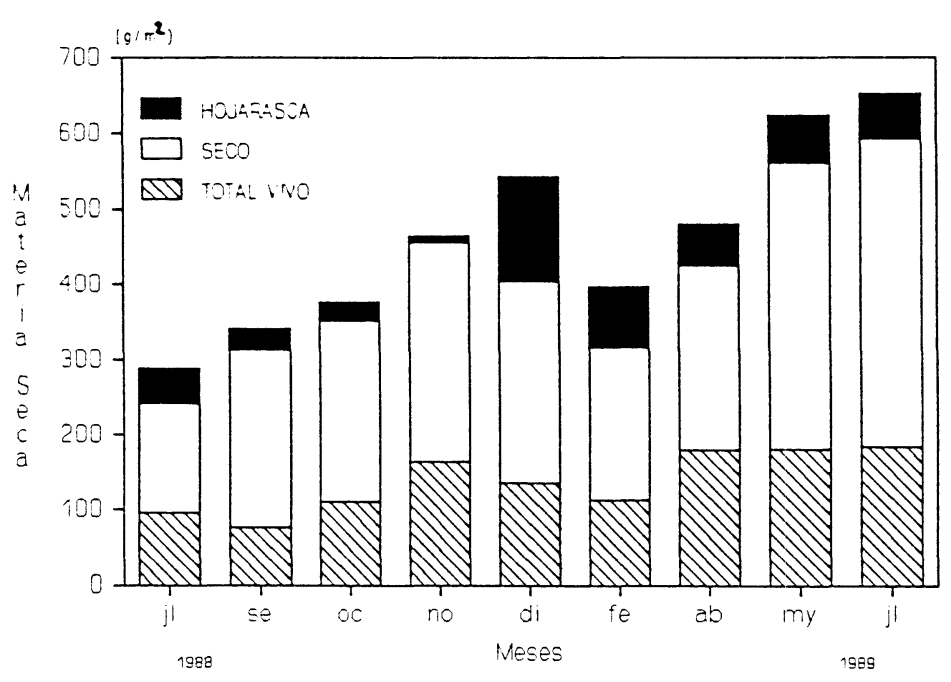

Grafico IV.1: Pastizal Medio ( $850 \mathrm{~m} \mathrm{sm})$. Materla seca ( $\left./ \mathrm{m}^{2}\right)$ de los compartimlentos aereos estimada durante el periodo jullo de $1988-j u l 10$ de 1989.

Las estructuras reproductivas se observan desde fines de octubre hasta fines de diciembre, con un pico a principios de diciembre. Su biomasa se hace nula durante el verano y están presentes, pero con valores más bajos a comienzos del otoño (Tabla IV.1, Gráfico IV.2).

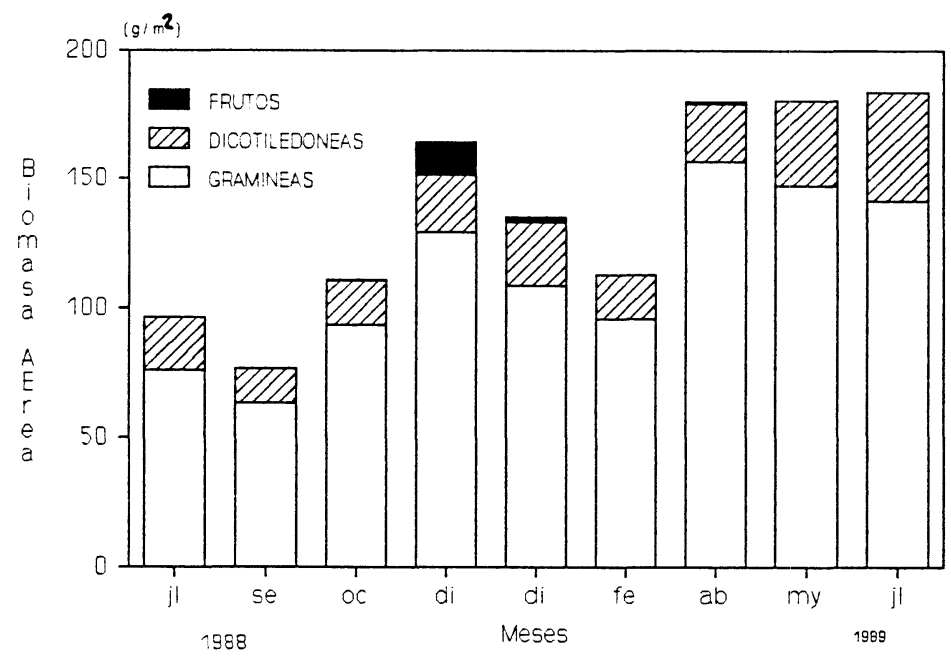
Grafico IV.2: Pastizal Medio (850 m $\mathrm{sm}$ ). Blomasa ( $\left(\mathrm{g} / \mathrm{m}^{2}\right)$ de los compartimlentos aereos estimada durante
el periodo jullo de $1988-j u l 10$ de 1989.

Las especies de gramíneas fructificadas presentes en primavera y otoño se señalan en la tabla IV.2, indicándose su régimen térmico (micro o mesotérmico) de acuerdo con Burkart (1975). De allí puede verificarse que en la primavera hay un número moderadamente mayor 
de especies microtérmicas con respecto a las mesotérmicas, más visibles en el verano.

Tabla IV.2: Past1zal Med10 ( 850 - sm). Especles de gramineas y gramlniformaes halladas en flor en las fechas de muestreo durante el periodo jullo de 1988 - jullo de 1989 . Se sefiala el reglien termico de 108

\begin{tabular}{|c|c|c|c|}
\hline \multirow{2}{*}{$\begin{array}{l}\text { REGIMEN TERMICO } \\
\text { MICROTERMICAS }\end{array}$} & $30-10-88$ & $\begin{array}{l}\text { FECBA } \\
20-12-88\end{array}$ & $27-12-88$ \\
\hline & $\begin{array}{l}\text { Vulpla dertonensis } \\
\text { Briza subaristata }\end{array}$ & $\begin{array}{l}\text { B. subarlstata } \\
\text { P1ptochaet1um hackel11 } \\
\text { P. montevidenso } \\
\text { St1pa f1l1culmis }\end{array}$ & $\begin{array}{l}\text { Carex sp. } \\
\text { P. montevidense } \\
\text { P. st1poldes }\end{array}$ \\
\hline MEGATERMICAS & Eragrost1s lugens & $\begin{array}{l}\text { Danthonia cirrata } \\
\text { Deyeuxia virldiflavescens } \\
\text { Melica riglda }\end{array}$ & $\begin{array}{l}\text { D. cirrata E. lugens } \\
\text { D. virldiflavescens } \\
\text { Sorghastrum pellitum }\end{array}$ \\
\hline
\end{tabular}

El seco en pie presenta dos picos, uno primaveral tardío y otro otoñal (Tabla IV.1, Gráfico IV.1).

\section{1 b-MATERIA SECA SUBTERRANEA}

La media anual es $782 \pm 44 \mathrm{~g} / \mathrm{m}^{2}$, de los cuales el $71 \%$ se concentra en los primeros 10 $\mathrm{cm}$ de profundidad distribuídos en $56 \%$ de raíces vivas $+15 \%$ de raíces muertas. El $29 \%$ correspondiente los $10 \mathrm{~cm}$ siguientes en profundidad, se reparte en $23 \%$ de raíces vivas + $6 \%$ de raíces muertas (Tabla IV.2, Gráfico IV.3).

a)

b)
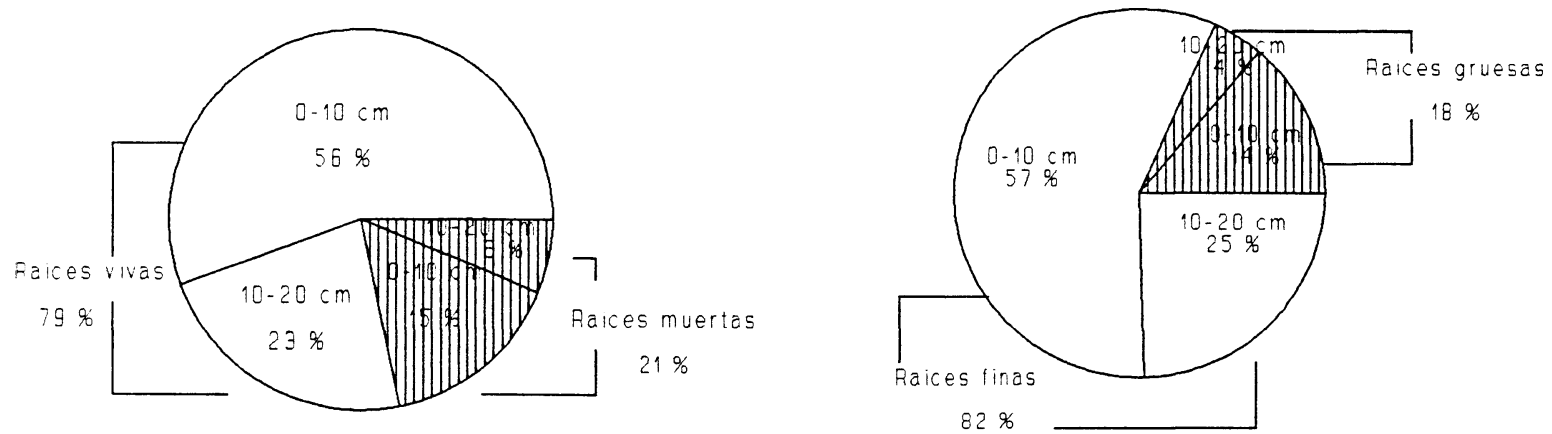

Graflco IV.3: Past1zal Medlo (850 m sm). a) Porcentajes de ralces vivas y muertas y b) de ralces flnas y gruesas en $10 \mathrm{~s}$ estratos muestreados (0-10 y 10-20 ca de profundidad).

Con respecto al tamaño, las raíces finas y gruesas representan el $81 \%$ y el $19 \%$ respectivamente de la masa subterránea total (Gráfico IV.3). Dicha masa presenta un pico 
a fines del invierno (Gráfico IV.4).

La biomasa de raíces vivas, presenta una tendencia creciente desde fines del invierno alcanzando un pico a mediados de primavera, disminuye hacia fines de esta estación y permanece invariable durante el verano. Desde comienzos hasta mediados del otoño las raíces vivas aumentan gradualmente. En los diez primeros centímetros de profundidad se observan las mayores variaciones en la biomasa subterránea. En los diez centímetros profundidad siguientes las raíces vivas aumentan a principios de septiembre y se mantienen con altos valores durante el resto del año (Gráfico IV.4).

La biomasa de raíces muertas, en los primeros diez centímetros de profundidad, presenta un máximo a fines de primavera y valores mínimos a comienzos de dicha estación y del otoño. Este compartimiento a mayor profundidad $(10-20 \mathrm{~cm})$

no varió durante el año de estudio (Tabla IV.3).

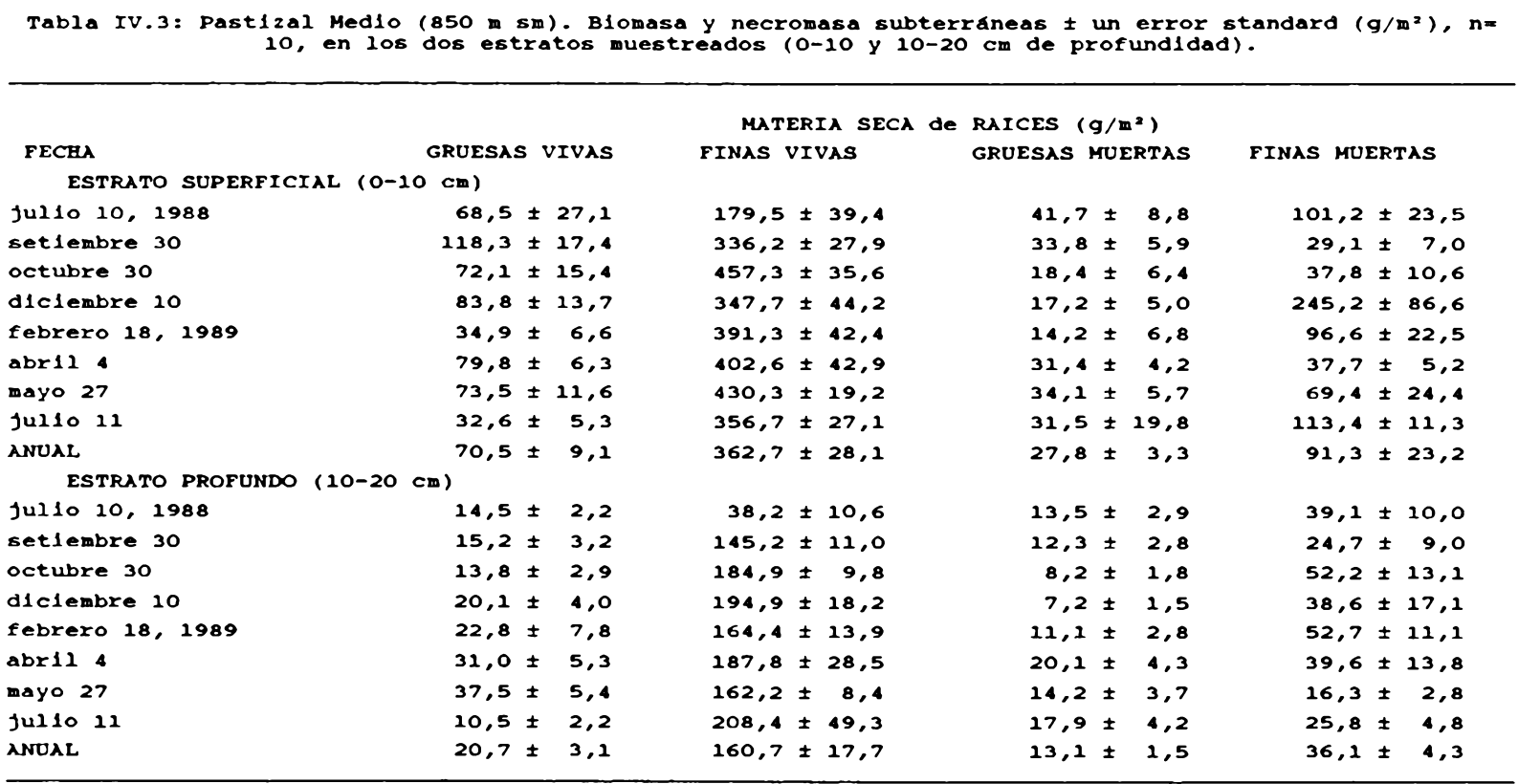




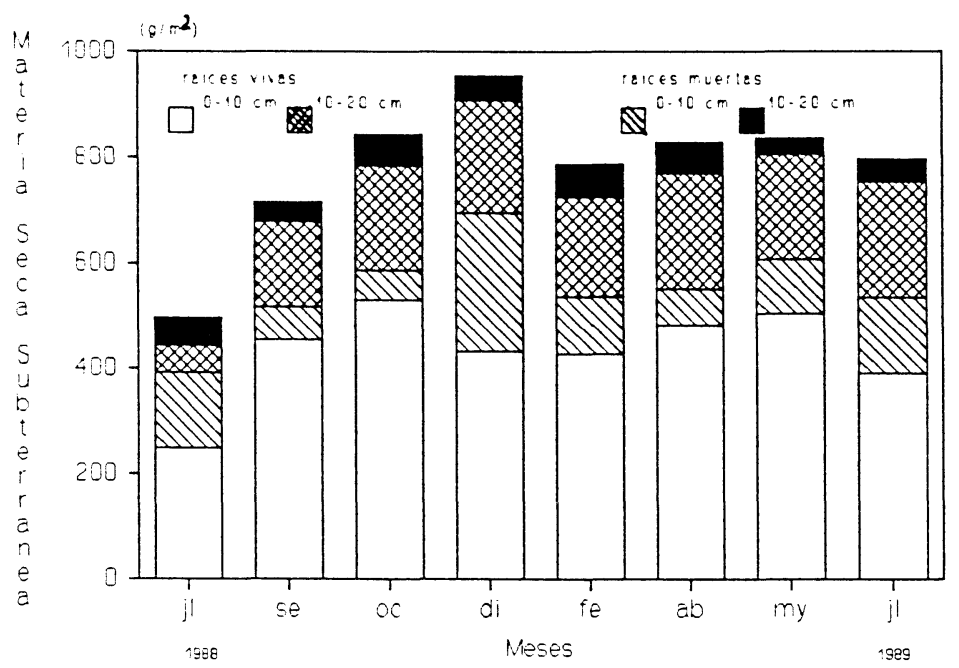

Graflco IV. 4: Past1zal Medio $(850 \mathrm{~m} \mathrm{sm})$. Materla seca $\left(\mathrm{g} / \mathrm{m}^{2}\right)$ de las raices vivas y muertas en los

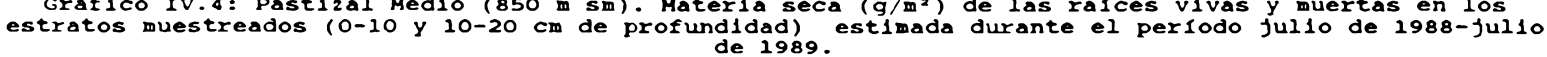

\section{2- HOJARASCA}

La hojarasca presenta bajos valores la mayor parte del año (media anual \pm error standard: $\left.56 \pm 12 \mathrm{~g} / \mathrm{m}^{2}\right)$. La mayor acumulación de la misma ocurre a fines de diciembre $(140 \pm 14$ $\left.\mathrm{g} / \mathrm{m}^{2}\right)$, con un mínimo a principios de ese mes $\left(9 \pm 1 \mathrm{~g} / \mathrm{m}^{2}\right)$ (Tabla IV.1, Gráfico IV.1).

\section{3-PRODUCTIVIDAD PRIMARIA NETA}

La productividad primaria neta (aérea + subterránea) del período de estudio es $1280 \mathrm{~g} / \mathrm{m}^{2}$ año, de los cuales $46 \%$ corresponden a productividad aérea y $54 \%$ a subterránea (Tabla IV.4).

\begin{tabular}{|c|c|c|c|c|c|c|c|}
\hline Perlodo & $\begin{array}{c}\text { Intervalo } \\
\text { (dias) }\end{array}$ & \multicolumn{2}{|c|}{ PRODUCTIVIDAD TOTAL } & $\begin{array}{l}\text { MORTALIDAD } \\
\left(g / m^{2} \mid n t\right)\end{array}$ & $\begin{array}{l}\text { TOTAL } \\
\left(a / m^{2} d 1 a\right)\end{array}$ & \multicolumn{2}{|c|}{ DESAPARICION TOTAL } \\
\hline jul1o-setlembre & 82 & 405,0 & 4,9 & 90,8 & 1,1 & 114,2 & 2,4 \\
\hline setlembre-octubre & 30 & 164,6 & 5,5 & 21,1 & 0,7 & 3,2 & 0,2 \\
\hline octubre-diclembre & 41 & 291,0 & 7,1 & 242,4 & 5,9 & 16,0 & 0,4 \\
\hline diclembre-d1clembre & 17 & 75,6 & 4,4 & 107,2 & 6,3 & 33,0 & 2,9 \\
\hline diclembre-febrero & 52 & 0,0 & 0,0 & 14,9 & 0,3 & 239,2 & 4,6 \\
\hline febrero-abr 11 & 45 & 108,0 & 2,4 & 40,7 & 0,9 & 69,8 & 1,6 \\
\hline abr11-mayo & 54 & 143,1 & 2,7 & 141,5 & 2,6 & 0,0 & 0,0 \\
\hline mayo-julio & 45 & 92,7 & 2,1 & 83,7 & 1,9 & 0,0 & 0,0 \\
\hline ANUAL & & 1280,0 & & 742,3 & & 475,4 & \\
\hline
\end{tabular}


De la asimilación neta anual el $73 \%$ corresponde al período inverno-primaveral y el $27 \%$ restante es otoñal (Tabla IV.4). En cada uno de estos períodos la distribución de fotoasimilados en parte aérea y subterránea varía: el crecimiento aéreo representa el $32 \%$ de la productividad inverno-primaveral y el $82 \%$ de la productividad otoñal (Tablas IV.5 y IV.6).

Las tasas diarias de productividad neta del pastizal más elevadas se observan a fines del invierno y de la primavera, siendo nulas durante el verano (Tabla IV.4, Gráfico IV.5).

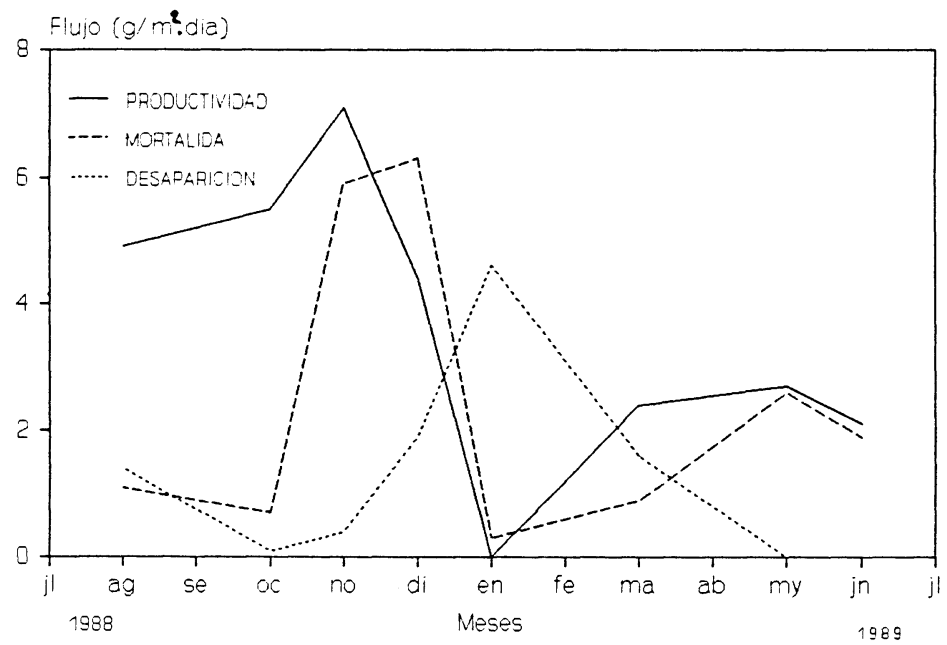
Graflco VI.5: Pastizal Medio ( $850 \mathrm{~m} \mathrm{sm}$ ). Tasas diarias (g/m² dia) de productividad primaria neta,
mortalidad y desaparicion totales durante el periodo julio de $1988-j u l 10$ de 1989.

\section{3 a-PRODUCTIVIDAD PRIMARIA AEREA NETA}

De la productividad aérea anual, $584 \mathrm{~g} / \mathrm{m}^{2}$.año, el $15 \%$ se producen en el invierno, 36 $\%$ en la primavera y $49 \%$ en el otoño. En el verano la productividad aérea es nula.

La tasa diaria de productividad aérea alcanza su valor máximo a fines de diciembre. En el otoño presenta un incremento moderado (Tabla IV.5, Gráfico IV.6). 


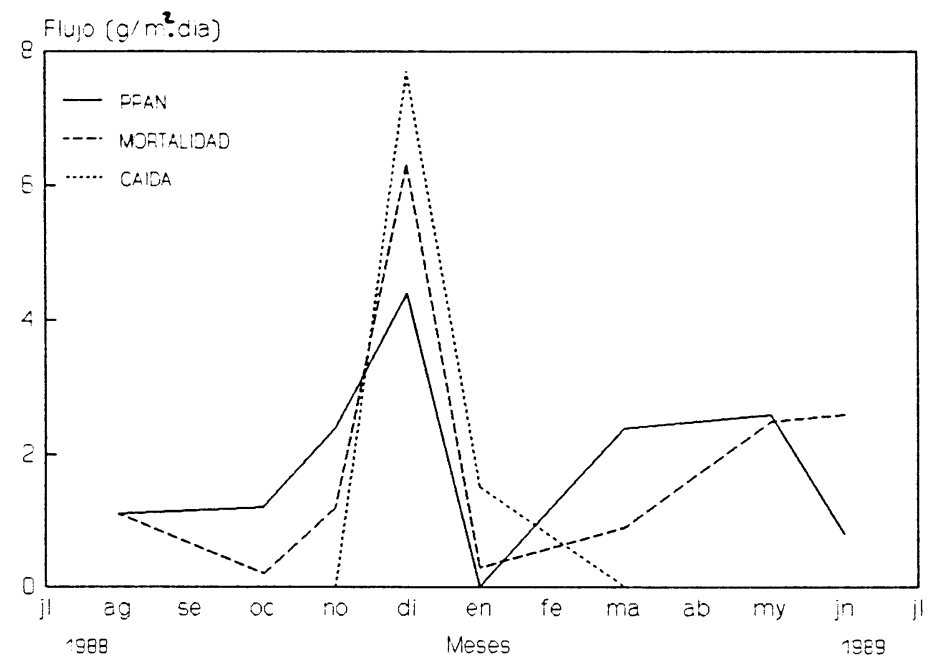

Gráfico IV.6: Pastizal Medio ( $850 \mathrm{~m} \mathrm{sm}$ ). Tasas diarlas (g/m dia) de productividad primarla neta aerea (PPAN), mortalidad aerea y calda a la hojarasca durante el periodo jullo de $1988-j u 110$ de 1989 .

Tabla IV.5: Productividad primaria neta, mortalidad, calda a la hojarasca y desaparlcion aereas en el pastizal Medio ( 850 m sm) durante el perlodo jullo de $1988-j u 110$ de 1989.

\begin{tabular}{|c|c|c|c|c|c|c|c|c|c|}
\hline \multirow{3}{*}{$\begin{array}{l}\text { Perlodo } \\
\text { jullo-setlembre }\end{array}$} & \multirow{2}{*}{$\begin{array}{l}\text { [ntervalo } \\
\text { (d1as) }\end{array}$} & \multirow{2}{*}{\multicolumn{2}{|c|}{$\begin{array}{c}\text { PPAN } \\
\left(q / m^{2} \ln t\right)\left(q / m^{2} d 1 a\right)\end{array}$}} & \multirow{2}{*}{\multicolumn{2}{|c|}{$\begin{array}{c}\text { MORTALIDAD AEREA } \\
\left(q / m^{2} \ln t\right)\left(q / m^{2} d i a\right)\end{array}$}} & \multirow{2}{*}{\multicolumn{2}{|c|}{$\begin{array}{c}\text { CAIDA } \\
\left(q / m^{2} \ln t\right)\left(q / m^{2} d 1 a\right)\end{array}$}} & \multirow{2}{*}{$\begin{array}{l}\text { DESAPARICION } \\
\left(q / m^{2} \ln t\right)(q /\end{array}$} & \multirow{2}{*}{$\begin{array}{r}\text { AEREA } \\
\left.m^{2} d 1 a\right)\end{array}$} \\
\hline & & & & & & & & & \\
\hline & 82 & 90,8 & 1,1 & 90,8 & 1,1 & 0,0 & 0,0 & 18,5 & 0,5 \\
\hline setiembre-octbre & 30 & 34,8 & 1,2 & 4,5 & 0,2 & 0,0 & 0,0 & 3,2 & 0,1 \\
\hline octubre-diclembre & 41 & 99,3 & 2,4 & 50,7 & 1,2 & 0,0 & 0,0 & 16,0 & 0,9 \\
\hline diclembre-diclembre & 17 & 75,6 & 4,4 & 107,2 & 6,3 & 130,7 & 7,7 & 0,0 & 0,0 \\
\hline diclembre-febrero & 52 & 0,0 & 0,0 & 14,9 & 0,3 & 79,4 & 1,5 & 139,2 & 1,3 \\
\hline febrero-abril & 45 & 108,0 & 2,4 & 40,7 & 0,9 & 0,0 & 0,0 & 23,9 & 0,3 \\
\hline abri1-mayo & 54 & 137,8 & 2,4 & 136,2 & 2,5 & 0,0 & 0,0 & 0,0 & 0,0 \\
\hline mayo-jul1o & 45 & 38,0 & 0,8 & 29,0 & 0,6 & 0,0 & 0,0 & 0,0 & 0,0 \\
\hline ANUAL & & 584,3 & & 474 & & 210,1 & & 200,8 & \\
\hline
\end{tabular}

\section{3 b-PRODUCTIVIDAD NETA SUBTERRANEA}

La productividad subterránea anual estimada por los métodos: (1) enraizamiento en cilindros con suelo libre de raíces, que permanecieron enterrados un año, y (2) por diferencias significativas de biomasa, es $255 \mathrm{~g} / \mathrm{m}^{2}$.año y $696 \mathrm{~g} / \mathrm{m}^{2}$.año respectivamente, para la totalidad del perfil muestreado $(0-20 \mathrm{~cm})$ (Tablas IV.6 y IV.7). 
Tabla IV.6: Producción primarla neta subterránea anual, entre 0-20 cm de profundidad, en el Pastizal Med10 durante jul10 1988 -jullo 1989 y jullo 1989-jullo 1990, estimada medlante cillndros de suelo vaclo. Media $t$ error standard.

\begin{tabular}{|c|c|c|}
\hline Perlodo & No de muestras & $\begin{array}{c}\text { PRODUCCION DE RAICES } \\
\left(g / m^{2} \text {. ARO }\right)\end{array}$ \\
\hline $1988-1989$ & 5 & $255 \pm 29$ \\
\hline
\end{tabular}

Tabla IV.7: productividad primarla neta, mortalldad y desaparición subterráneas en el pastizal Medio durante el perlodo fullo de 1988-jullo de 1989.

\begin{tabular}{|c|c|c|c|c|c|c|c|}
\hline \multirow{2}{*}{$\begin{array}{l}\text { Perlodo Int } \\
\text { jul1o-setlembre }\end{array}$} & $\begin{array}{l}\text { tervalo } \\
\text { (dias) }\end{array}$ & \multicolumn{2}{|c|}{$\begin{array}{l}\text { PRODUCTIVIDAD SUBTERRANEA } \\
\left(\mathrm{g} / \mathrm{m}^{2} \ln t\right)\left(\mathrm{g} / \mathrm{m}^{2} d 1 \mathrm{a}\right)\end{array}$} & \multicolumn{2}{|c|}{$\begin{array}{l}\text { MORTALIDAD SUBTERRANEA } \\
\left(g / m^{2} \mid n t\right)\left(g / m^{2} d 1 a\right)\end{array}$} & \multicolumn{2}{|c|}{$\begin{array}{l}\text { DESAPARICION SUBTERRANEA } \\
\left(a / m^{2} \mid n t\right)\left(g / m^{2} d 1 a\right)\end{array}$} \\
\hline & 82 & 314,2 & 3,8 & 0,0 & 0,0 & 95,7 & 1,2 \\
\hline setlembre-octubre & 30 & 129,8 & 4,3 & 16,6 & 0,6 & 0,0 & 0,0 \\
\hline octubre-diclembre & 41 & 191,7 & 4.7 & 191,7 & 4,7 & 0,0 & 0,0 \\
\hline diclembre-diclembre & e 17 & 0,0 & 0,0 & 0,0 & 0,0 & 33,0 & 1,9 \\
\hline diclembre-febrero & 52 & 0,0 & 0,0 & 0,0 & 0,0 & 100,0 & 1,9 \\
\hline febrero-abr 11 & 45 & 0,0 & 0,0 & 0,0 & 0,0 & 45,9 & 1.0 \\
\hline abr11-mayo & 54 & 5,3 & 0,1 & 5,3 & 0,1 & 0,0 & 0,0 \\
\hline mayo-jul1o & 45 & 54,7 & 1,2 & 54,7 & 1,2 & 0,0 & 0,0 \\
\hline ANUAL & & 695,7 & & 268,3 & & 274,6 & \\
\hline
\end{tabular}

Las tasas diarias estimadas por diferencias de biomasa, son elevadas desde fines del invierno y alcanzan un pico a mediados de la primavera, Durante el resto del año el crecimiento subterráneo es mínimo (otoño) o nulo (verano) (Tabla IV.7, Gráfico IV.7).

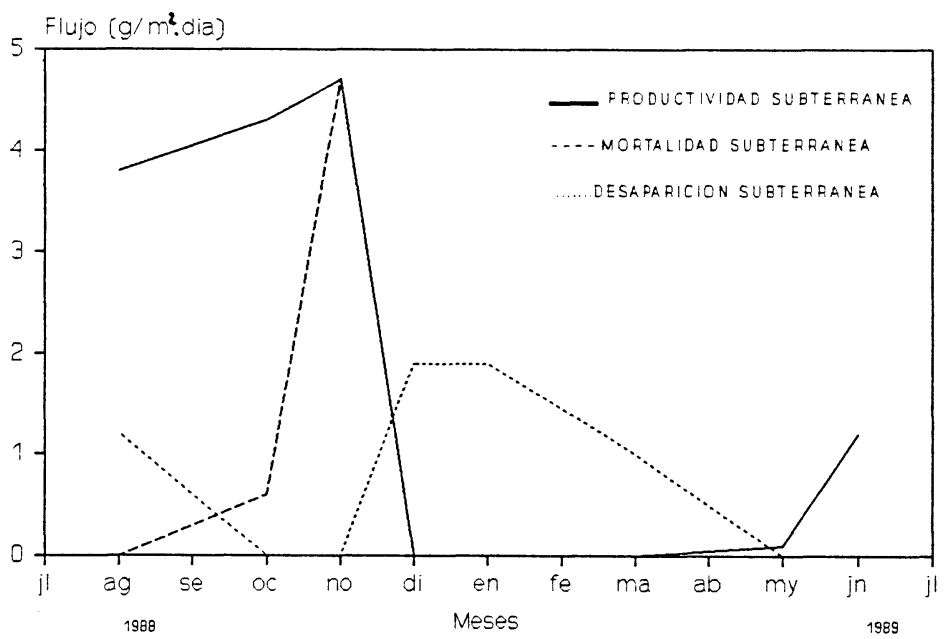

Graflco IV.7: Pastizal Medio (850 $\mathrm{m} \mathrm{sm})$. Tasas diarlas (g/m² dia) de product1vidad primar1a neta, mortalidad $y$ desaparición subterráneas durante el periodo jullo de $1988-j u 110$ de 1989. 


\section{4-MORTALIDAD}

La mortalidad anual es $742 \mathrm{~g} / \mathrm{m}^{2}$.año, el $64 \%$ de este valor corresponde a mortalidad aérea (Tabla IV.4).

El $12 \%$ de la mortalidad anual ocurre a fines del invierno, $46 \%$ hacia fines de la primavera y $30 \%$ a mediados del otoño (Tabla IV.4).

Las tasas diarias de mortalidad más elevadas se observan a fines de diciembre (Tabla IV.4, Gráfico IV.5).

\section{5-CAIDA A LA HOJARASCA}

Corresponden a este proceso $210 \mathrm{~g} / \mathrm{m}^{2}$. año. Las tasas diarias de caida a la hojarasca tienen un máximo a fines de la primavera, descienden durante el verano y el resto del año se hacen nulas (Tabla IV.5, Gráfico IV.6).

\section{6-DESAPARICION DE MATERIAL AEREO Y SUBTERRANEO}

Se pierden desde el material vegetal de este pastizal $475 \mathrm{~g} / \mathrm{m}^{2}$ año, de los cuales, el 42 $\%$ proviene de la parte aérea.

No se observa desaparición de material subterráneo durante la mayor parte del año, con tasas diarias bajas a fines del invierno y un pequeño pico a principios del verano (Tabla IV.7, Gráfico IV.7).

La desaparición de material aéreo, con una tasa diaria baja, se detecta desde fines del invierno, durante la primavera y a principios de otoño, con un pico poco marcado durante el verano. (Tabla IV.5, Gráfico IV.6). 


\section{7-NUTRIENTES}

\section{7 a-CONCENTRACION DE NUTRIENTES}

Las mayores concentraciones de N, P, K y Ca se encontraron en la biomasa aérea viva.

En las dicotiledóneas la concentración de nutrientes presentó el siguiente orden: $\mathbf{N}>$ Ca $>\mathbf{K}>>$ P. Las concentraciones de $\mathbf{P}, \mathbf{K}$ y $\mathbf{C a}$ fueron mayores en los períodos inverno-primaveral y otoñal; las concentraciones mínimas ocurrieron en el verano para los dos primeros, y a mediados de la primavera para el tercero. El $\mathbf{N}$ presentó un máximo en el otoño (Tabla IV.8, Gráfico IV.8).

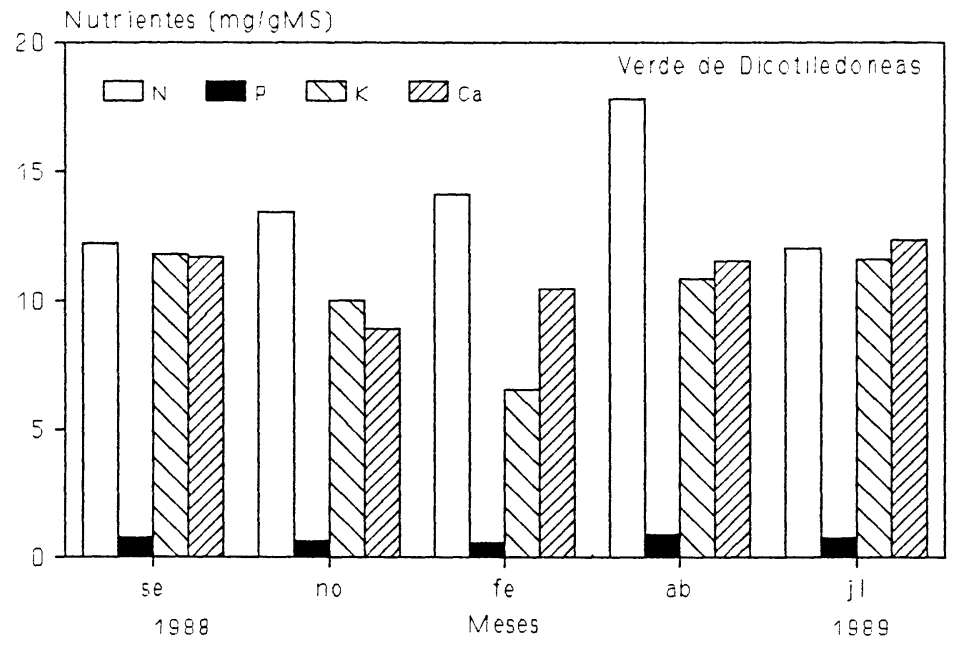
Grafico IV.8: Pastizal Medio (850 $\mathrm{m} \mathrm{sm}$ ). Concentracion de nutrientes (mg/gms) en los tej1dos aereos
vivos de las dicotiledóneas, durante el periodo julio de 1988 -julio de 1989.

En las gramíneas las concentraciones de nutrientes fueron: $\mathbf{N}=\mathbf{K}>>$ Ca $>$ P. Las concentraciones de $\mathbf{N}$ y $\mathbf{P}$ presentaron un máximo a principios de otoño. El $\mathbf{K}$, aumentó su concentración, en este compartimiento, en la primavera y a principios del otoño. El Ca mantuvo valores cercanos al promedio durante todo el año (Tabla IV.8, Gráfico IV.9). 
Tabla IV.8: Pastizal Medlo ( $850 \mathrm{~m} \mathrm{sm}$ ). Concentración de nutrlentes (mg/gMs) en los compart1mientos aéreos. Para el afio se indica la media y el error standard.

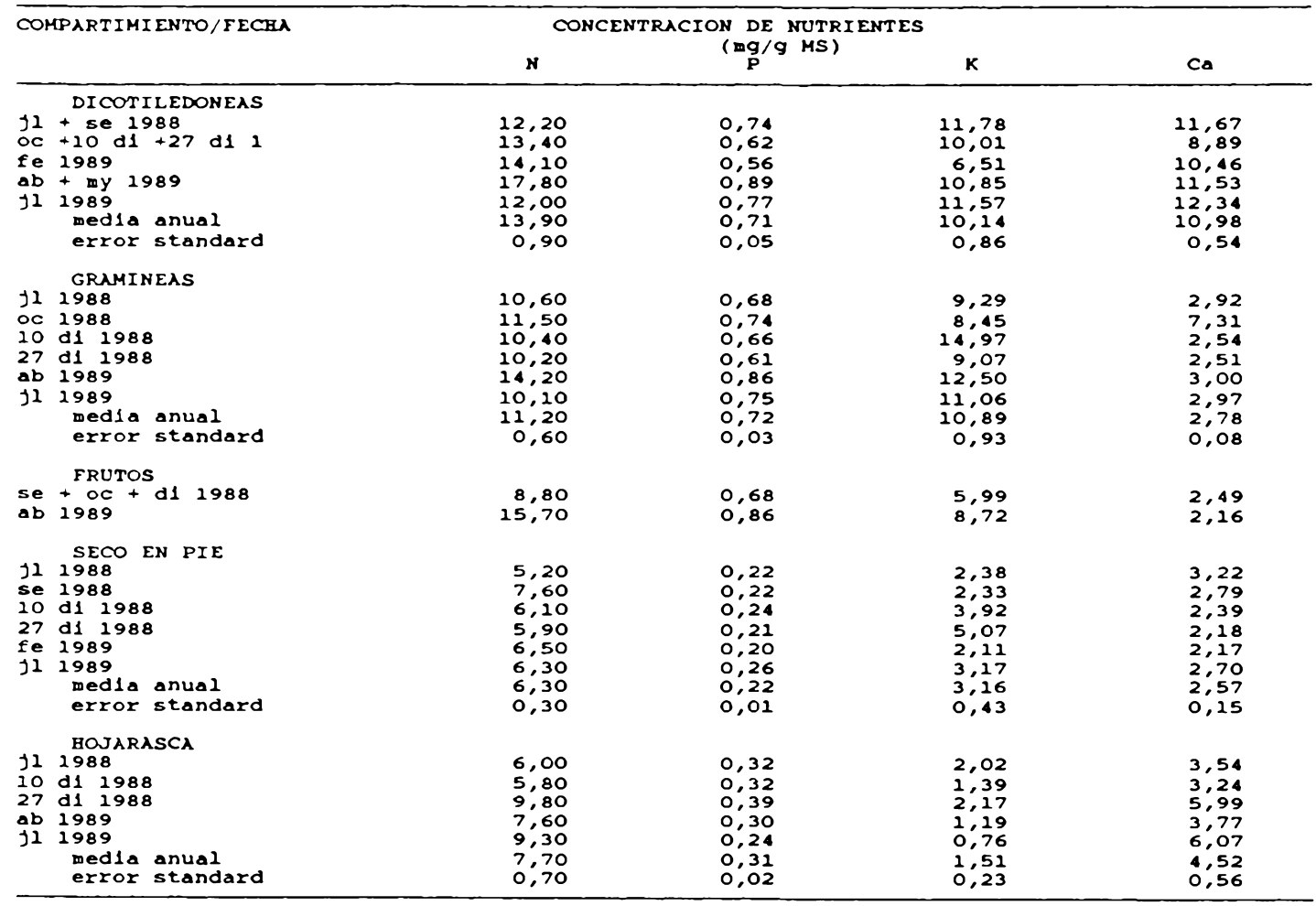

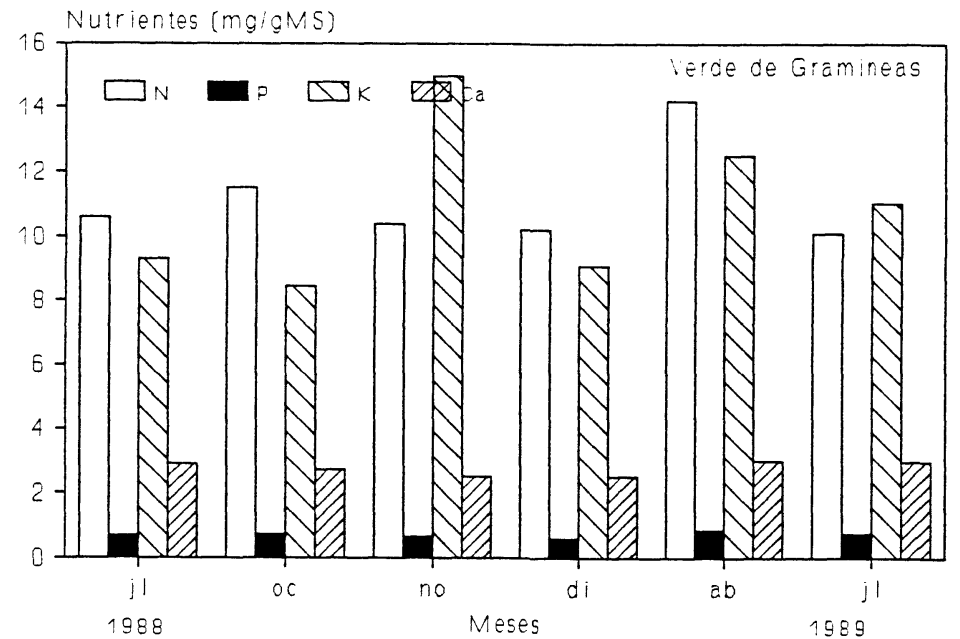

Graflco IV.9: Pastizal Medio ( $850 \mathrm{~m} \mathrm{sm}$ ). Concentración de nutrientes (mg/gMs) en los tej1dos aereos vivos de las gramineas, durante el periodo jullo de 1988 -julio de 1989.

Las concentraciones de $\mathbf{P}$ y $\mathbf{K}$ en las gramíneas y dicotiledóneas fueron similares, mientras que en esta últimas el $\mathbf{N}$ fue 1,2 veces mayor y el Ca fue 4 veces mayor que en las gramíneas (test $\mathrm{t}$ de Student, $\mathrm{P}<0,05$ ). 
Las estructuras reproductivas del período de floración primaveral presentaron concentraciones de $\mathbf{N}, \mathbf{P}$ y $\mathbf{K}$ inferiores a las correspondientes al período de floración otoñal. La concentración de Ca fue menor en este último (Tabla IV.8).

En el seco en pie la concentración de nutrientes fue: $\mathbf{N}>\mathbf{K}>\mathbf{C a}>>\mathbf{P}$. Las concentraciones más elevadas de $\mathbf{P}, \mathbf{K}$ y Ca son primaverales e invernal-tempranas y las más bajas son estivales en 1989. El $\mathbf{N}$ presentó valores máximos durante la primavera y menores en el invierno (Tabla IV.8, Gráfico IV.10).

Las concentraciones de $\mathbf{P}, \mathrm{K}$ y $\mathbf{N}$ en el seco en pie fueron menores que en las gramíneas y dicotiledóneas (2,5 veces menos de $\mathbf{P} ; 1,8$ veces menos de $\mathbf{N}$ y 4,3 veces menos de $K$ ) (test $t$ de Student, $P<0,05)$.

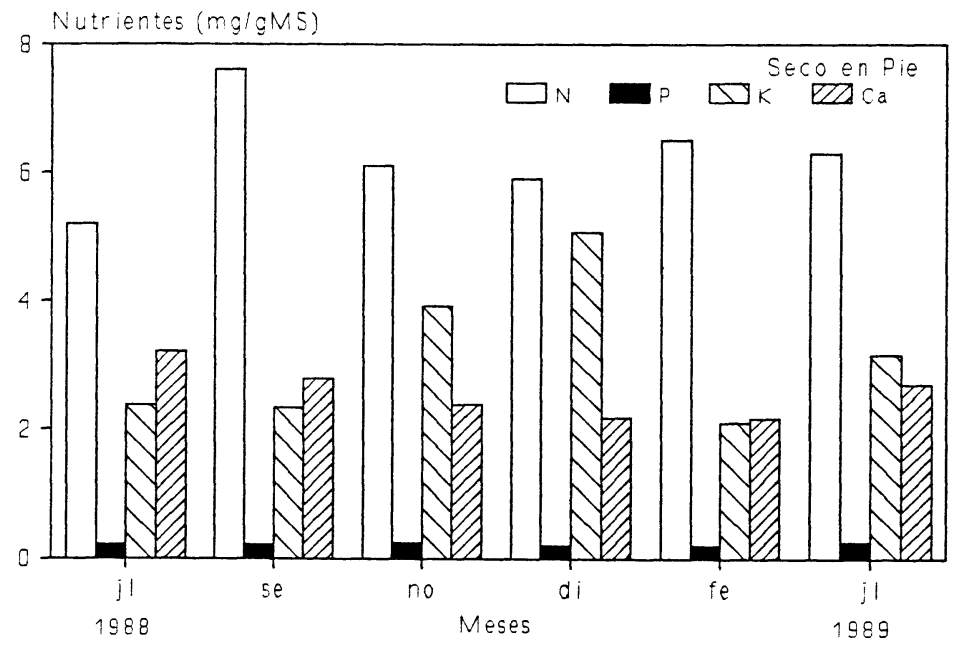
Graflco IV.10: Pastizal Medlo (850 m sm). Concentracion de nutrientes (mg/gms) en el seco en ple,
durante el periodo Julio de 1988 -jullo de 1989.

En la hojarasca la concentración de nutrientes se ordenó de mayor a menor en la siguiente secuencia: N, Ca, K y P. Este compartimiento presentó concentraciones mínimas de los cuatro nutrientes analizados a principios de diciembre. A fines de ese mes, coincidiendo con el pico de caída, dichos nutrientes alcanzaron concentraciones máximas. Los valores disminuyeron hacia el otoño (Tabla IV.8, Gráfico IV.11). 


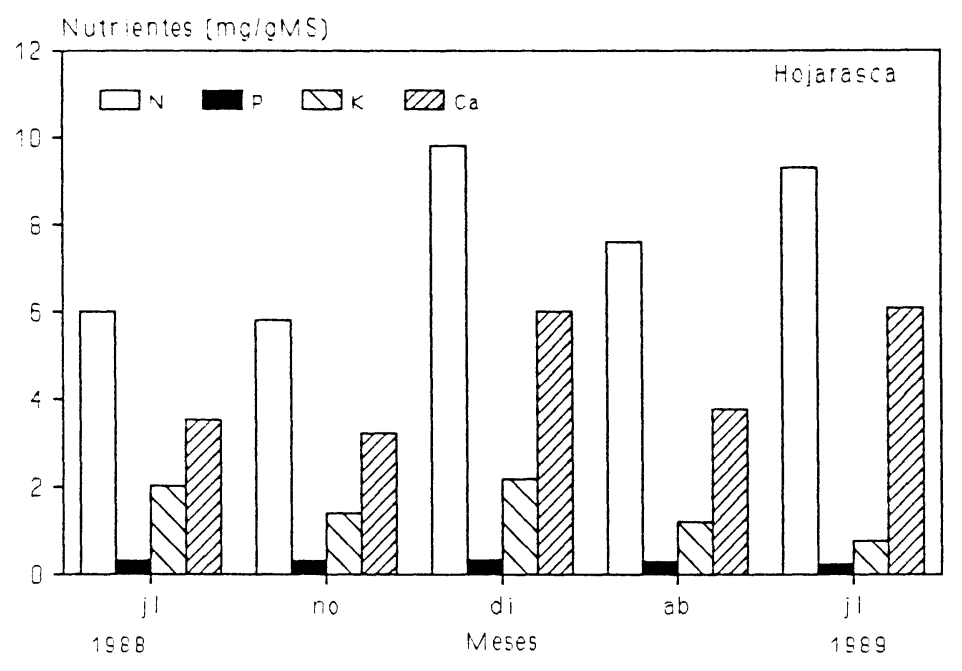
Grafico IV.11: Pastizal Medio (850 m 5 m). Concentración de nutrientes (mg/gMs) en la hojarasca, durante
el perIodo Jullo de $1988-j u l 10$ de 1989.

No se observaron diferencias significativas en las concentraciones de nutrientes entre el seco en pie y la hojarasca, con excepción del $\mathbf{K}$ y del $\mathbf{C a}$ cuyas concentraciones son 2 veces mayor en el primero y 1,7 veces mayor en el segundo compartimiento mencionado respectivamente (test $\mathrm{t}$ de Student, $\mathrm{P}<0,05$ ).

En las raíces finas vivas la concentración de nutrientes presentó el siguiente orden: $\mathbf{N}$ Ca $>>\mathbf{K}>\mathbf{P}$. En las mismas, dichas concentraciones disminuyeron a mediados de la primavera y aumentan nuevamente a fines de ese período, luego disminuyen hacia el invierno de 1989 (Tabla IV.9, Gráfico IV.12).

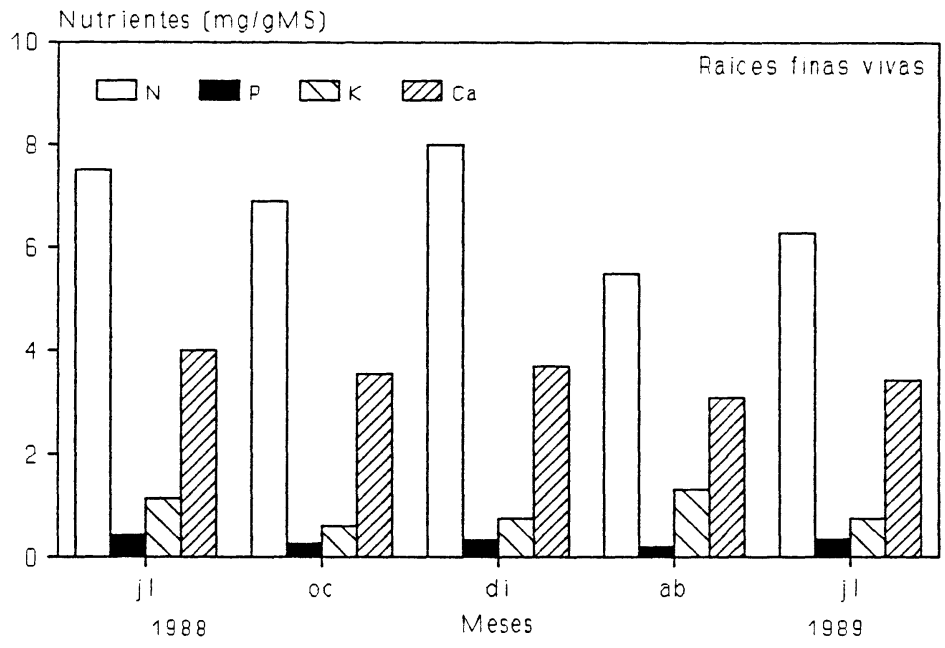
Graflco IV.12: Past12al Medio (850 $\mathrm{m} \mathrm{sm}$ ). Concentración de nutrientes (mg/gMS) en $1 \mathrm{as}$ raices finas 
Las raíces finas vivas presentaron concentraciones mayores que las raíces gruesas vivas, Las últimas mostraron el siguiente orden en la concentración de nutrientes: $\mathbf{N}>\mathbf{C a}>\mathbf{K}$ $>$ P. Las concentraciones más elevadas de estos nutrientes ocurrieron en el invierno y en el verano (Tabla IV.9, Gráfico IV.13).

\begin{tabular}{|c|c|c|c|c|c|}
\hline \multirow{2}{*}{\multicolumn{2}{|c|}{ COMPARTIMIENTO/FECEU }} & \multicolumn{3}{|c|}{ CONCENTRACION DE NUTRIENTES } & \multirow[b]{2}{*}{ Ca } \\
\hline & & N & $\mathbf{P}$ & $\mathbf{k}$ & \\
\hline $\begin{array}{l}j 1 \\
o c \\
d 1 \\
a b \\
j 1\end{array}$ & $\begin{array}{l}\text { RAICES FINAS VIVAS } \\
1988 \\
1988 \\
1988 \\
1989 \\
1989 \\
\text { med1a anual } \\
\text { error standard }\end{array}$ & $\begin{array}{l}7,50 \\
6,90 \\
8,00 \\
5,50 \\
6,30 \\
6,80 \\
0,40\end{array}$ & $\begin{array}{l}0,42 \\
0,27 \\
0,33 \\
0,20 \\
0,34 \\
0,31 \\
0,03\end{array}$ & $\begin{array}{l}1,15 \\
0,61 \\
0,75 \\
1,32 \\
0,76 \\
0,92 \\
0,12\end{array}$ & $\begin{array}{l}4,01 \\
3,56 \\
3,71 \\
3,10 \\
3,44 \\
3,56 \\
0,13\end{array}$ \\
\hline $\begin{array}{l}j 1 \\
d 1 \\
a b\end{array}$ & $\begin{array}{l}\text { RAICES FINAS MUERTAS } \\
+ \text { Se + OC } 1988 \\
1988 \text { - } \\
+ \text { my + J1 } 1989 \\
\text { media anual } \\
\text { exror standard }\end{array}$ & $\begin{array}{r}10,60 \\
11,30 \\
8,50 \\
10,13 \\
0,69\end{array}$ & $\begin{array}{l}0,54 \\
0,56 \\
0,36 \\
0,49 \\
0,05\end{array}$ & $\begin{array}{l}1,41 \\
1,37 \\
0,80 \\
1,20 \\
0,16\end{array}$ & $\begin{array}{l}7,02 \\
7,01 \\
6,68 \\
6,90 \\
0,09\end{array}$ \\
\hline $\begin{array}{l}j 1 \\
\text { se } \\
\text { oc } \\
\text { fe } \\
a b \\
j 1\end{array}$ & $\begin{array}{l}\text { RAICES GRUESAS VIVAS } \\
1988 \\
1988 \\
1988 \\
1988 \\
1989 \\
1989 \\
\text { med1a anual } \\
\text { error standard }\end{array}$ & $\begin{array}{l}4,60 \\
3,30 \\
5,00 \\
4,40 \\
4,70 \\
4,90 \\
4,48 \\
0,23\end{array}$ & $\begin{array}{l}0,22 \\
0,16 \\
0,15 \\
0,32 \\
0,24 \\
0,21 \\
0,22 \\
0,02\end{array}$ & $\begin{array}{l}0,75 \\
0,45 \\
0,37 \\
1,27 \\
0,76 \\
0,61 \\
0,70 \\
0,12\end{array}$ & $\begin{array}{l}1,97 \\
2,08 \\
1,66 \\
2,71 \\
2,47 \\
2,05 \\
2,16 \\
0,14\end{array}$ \\
\hline $\begin{array}{l}j 1 \\
o c \\
a b\end{array}$ & $\begin{array}{l}\text { RAICES GRUESAS MUERTAS } \\
1988 \\
1988 \\
+ \text { my } 1989 \\
\text { med1a anual } \\
\text { error standard }\end{array}$ & $\begin{array}{l}6,60 \\
9,00 \\
7,70 \\
7,77 \\
0,57\end{array}$ & $\begin{array}{l}0,32 \\
0,38 \\
0,38 \\
0,36 \\
0,02\end{array}$ & $\begin{array}{l}1,26 \\
0,64 \\
2,22 \\
1,37 \\
0,38\end{array}$ & $\begin{array}{r}3,85 \\
6,05 \\
14,38 \\
8,10 \\
2,62\end{array}$ \\
\hline
\end{tabular}

De los compartimientos subterráneos, las concentraciones más elevadas de $\mathbf{P}, \mathbf{K}$ y $\mathbf{C a}$ se encontraron en las raíces gruesas muertas. Con respecto a las raíces gruesas vivas presentó 1,7 veces más de $\mathbf{P}$ y $\mathbf{N} ; 2$ veces más de $\mathbf{K} ;$ y 3,7 veces más de Ca. En las raíces finas muertas la concentración de nutrientes se ordenó de la siguiente manera: $\mathbf{N}>\mathbf{C a}>>\mathbf{K}$ $>$ P. Dichas concentraciones presentaron una tendencia decreciente de un año a otro. En las raíces gruesas muertas la concentración de nutrientes fue: $\mathbf{C a} \approx \mathbf{N}>>\mathbf{K}>\mathbf{P}$. El $\mathbf{N}$, P y Ca presentaron una tendencia creciente de sus concentraciones en el año 1988 con respecto al año 1989. El K disminuye en la primavera alcanzando un máximo en el otoño (Tabla IV.9, Gráfico IV.14). 


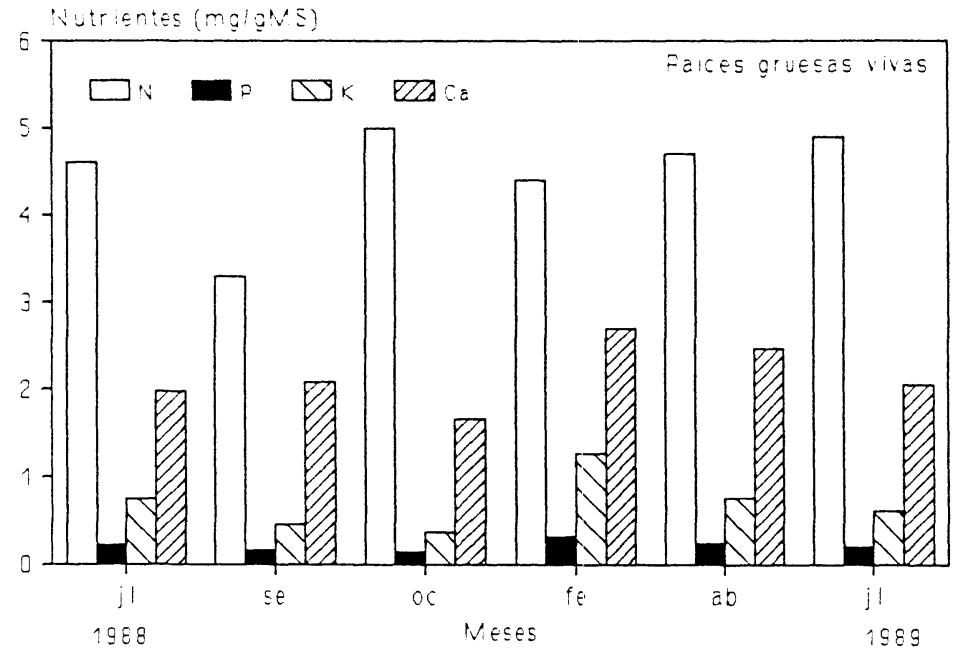

Graflco IV.13: Past1zal Medlo ( $850 \mathrm{~m} \mathrm{sm}$ ). Concentracion de nutrlentes (mg/gms) en las ralces gruesas vivas, durante el perlodo jullo de 1988 -jullo de 1989 .

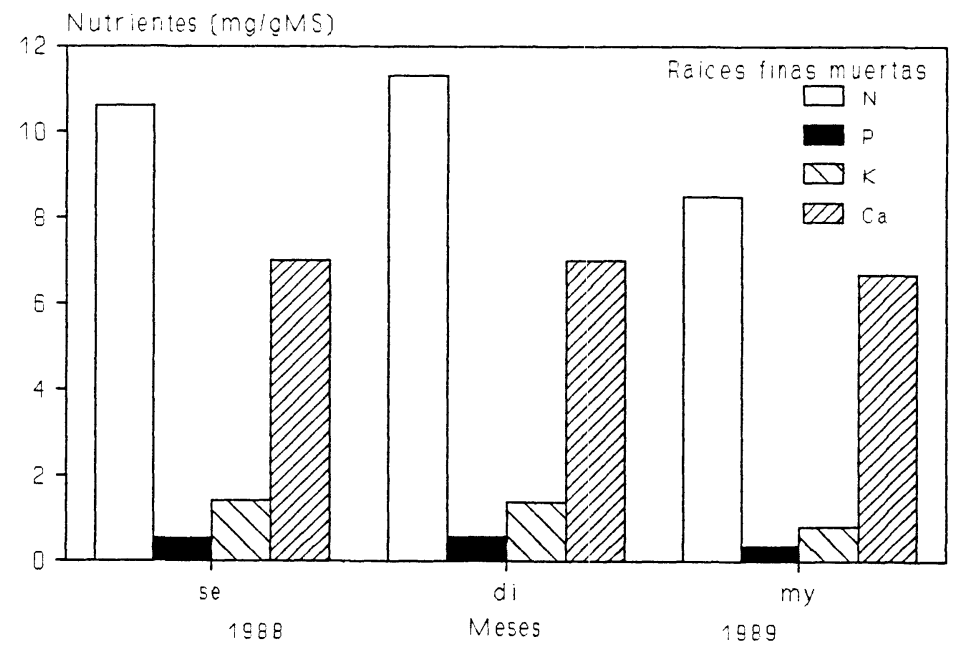

Grafico IV.14: Past1zal Medio ( $850 \mathrm{~m} s \mathrm{~s})$. Concentración de nutrientes (mg/gms) en las ralces finas muertas, durante el periodo jullo de 1988-jullo de 1989 . 


\section{7 b-ALMACENAJE MINERAL}

Las cantidades totales de nutrientes en la materia seca se ordenaron de mayor a menor de la siguiente manera: $\mathbf{N}, \mathbf{C a}, \mathbf{K}$ y $\mathbf{P}$, siendo respectivamente: 9,$9 ; 5,1 ; 3,4$ y $0,5 \mathrm{~g} / \mathrm{m}^{2}$.

El N se almacenó $40 \%$ en estructuras aéreas (repartido en $18 \%$ en la biomasa viva, $17 \%$ en el seco en pie y $5 \%$ en la hojarasca) y $60 \%$ en órganos subterráneos (39\% correspondientes a las raíces vivas y $21 \%$ a las muertas). El P se reparte $41 \%$ en los compartimientos aéreos ( $24 \%$ en el material vivo, $13 \%$ en el seco en pie y $4 \%$ en la hojarasca). El $59 \%$ restante se distribuye en $37 \%$ en las raíces vivas y $22 \%$ en las muertas. El $\mathbf{K}$ se almacenó mayoritariamente en el material aéreo (77\%, de los cuales $48 \%$ correspondieron al vivo, $26 \%$ al seco en pie y $3 \%$ a la hojarasca). El $23 \%$ restante se encontró $15 \%$ en las raíces vivas y $8 \%$ en las muertas. El Ca se almacenó principalmente en las raíces (38\% en las vivas y $30 \%$ en las muertas). En el material aéreo $12 \%$ se encuentró en el vivo, $13 \%$ en el seco en pie y $6 \%$ en la hojarasca. Del almacenaje mineral total, la mineralomasa (aérea + subterránea) constituyó el $56 \%$ del N, el $60 \%$ del P, el $63 \%$ del $\mathrm{K}$ y el $51 \%$ del Ca. Los porcentajes complementarios correspondieron a los necronutrientes (Tabla IV.10 y IV.11)

Con respecto al almacenaje mineral aéreo, las dicotiledóneas constituyeron el $9 \%$ del $\mathbf{N}$, el $10 \%$ del $\mathbf{P}$ y del $\mathbf{K}$ y el $18 \%$ del $\mathbf{C a}$; las gramíneas + sus estructuras reproductivas representaron el $34 \%$ del $\mathbf{N}$, el $45 \%$ del $\mathbf{P}$, el $53 \%$ del $\mathbf{K}$ y el $20 \%$ del $\mathbf{C a}$; en el seco en pie se almacenó el $42 \%$ del $\mathbf{N}$, el $32 \%$ del P, $31 \%$ del $\mathbf{K}$ y el $41 \%$ del $\mathbf{C a}$; y en la hojarasca se encuentra el $14 \%$ del $\mathbf{N}$, el $11 \%$ del P, el $4 \%$ del $\mathbf{K}$ y el $20 \%$ del Ca. (Tabla IV.10) 
Tabla IV.10: Pastizal Medio ( $850 \mathrm{~m} \mathrm{sm})$. Almacenaje mineral (g/m $\mathrm{m}^{2}$ en los compart1mientos aereos. Para el ano se indica la media y el error standard.

\begin{tabular}{|c|c|c|c|c|}
\hline COMPARTIMIENTO/FECHA & $\mathbf{N}$ & $\begin{array}{c}\text { ALMACENAJE } \\
\left(g / \mathbb{m}^{2}\right)\end{array}$ & $x$ & $\mathrm{ca}$ \\
\hline 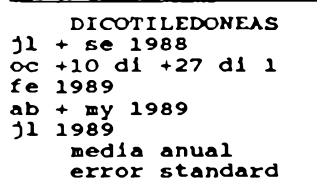 & $\begin{array}{l}0,31 \\
0,23 \\
0,24 \\
0,50 \\
0,51 \\
0,36 \\
0,05\end{array}$ & $\begin{array}{l}0,02 \\
0,01 \\
0,01 \\
0,02 \\
0,03 \\
0,02 \\
0,003\end{array}$ & $\begin{array}{l}0,30 \\
0,17 \\
0,12 \\
0,30 \\
0,49 \\
0,28 \\
0,06\end{array}$ & $\begin{array}{l}0,27 \\
0,16 \\
0,18 \\
0,32 \\
0,52 \\
0,30 \\
0,06\end{array}$ \\
\hline $\begin{array}{ll} & \text { GRAMINEAS } \\
\text { J1 } & 1988 \\
\text { OC } 1988 \\
10 & 19888 \\
27 & d 11988 \\
\text { ab } & 1989 \\
J 1 & 1989 \\
& \text { med1a anual } \\
& \text { error standard }\end{array}$ & $\begin{array}{l}0,81 \\
1,07 \\
1,34 \\
1,11 \\
2,22 \\
1,43 \\
1,33 \\
0,18\end{array}$ & $\begin{array}{l}0,05 \\
0,07 \\
0,08 \\
0,07 \\
0,13 \\
0,11 \\
0,08 \\
0,01\end{array}$ & $\begin{array}{l}0,71 \\
0,79 \\
1,94 \\
0,99 \\
1,96 \\
1,56 \\
1,32 \\
0,21\end{array}$ & $\begin{array}{l}0,22 \\
0,26 \\
0,33 \\
0,27 \\
0,47 \\
0,42 \\
0,33 \\
0,04\end{array}$ \\
\hline 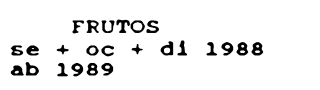 & $\begin{array}{l}0,11 \\
0,016\end{array}$ & $\begin{array}{l}0,01 \\
0,001\end{array}$ & $\begin{array}{l}0,08 \\
0,009\end{array}$ & $\begin{array}{l}0,03 \\
0,002\end{array}$ \\
\hline 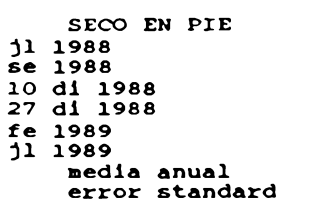 & $\begin{array}{l}0,76 \\
1,79 \\
1,76 \\
1,58 \\
1,58 \\
2,58 \\
1,68 \\
0,22\end{array}$ & $\begin{array}{l}0,03 \\
0,05 \\
0,07 \\
0,06 \\
0,05 \\
0,10 \\
0,06 \\
0,01\end{array}$ & $\begin{array}{l}0,35 \\
0,55 \\
1,14 \\
1,36 \\
0,51 \\
1,30 \\
0,87 \\
0,17\end{array}$ & $\begin{array}{l}0,47 \\
0,66 \\
0,70 \\
0,58 \\
0,53 \\
1,10 \\
0,67 \\
0,08\end{array}$ \\
\hline $\begin{array}{ll} & \text { HOJARASCA } \\
\text { j1 } 1988 \\
10 & \mathrm{~d} 1988 \\
27 & 11988 \\
\text { ab } 1989 & 1988 \\
11 & 1989 \\
\text { medla anual } \\
\text { error standard }\end{array}$ & $\begin{array}{l}0,28 \\
0,05 \\
1,37 \\
0,42 \\
0,56 \\
0,54 \\
0,20\end{array}$ & $\begin{array}{l}0,01 \\
0,00 \\
0,05 \\
0,02 \\
0,01 \\
0,02 \\
0,01\end{array}$ & $\begin{array}{l}0,09 \\
0,01 \\
0,30 \\
0,07 \\
0,05 \\
0,10 \\
0,05\end{array}$ & $\begin{array}{l}0,17 \\
0,03 \\
0,84 \\
0,21 \\
0,36 \\
0,32 \\
0,12\end{array}$ \\
\hline TOTAL AEREO & 3,97 & 0,19 & 2,62 & 1,64 \\
\hline
\end{tabular}

Tabla IV.11: Past12al Medio ( $850 \mathrm{~m} \mathrm{sm})$. Almacenaje mineral $\left(\mathrm{g} / \mathrm{m}^{2}\right.$ ) en los compartimientos subterraneos. para el aho se indica la media y el error standard.

\begin{tabular}{|c|c|c|c|c|c|}
\hline \multicolumn{3}{|c|}{ COMPARTIMIENTO/FECHA } & \multicolumn{3}{|c|}{$\begin{array}{c}\text { ALMACENAJE MINERAL } \\
\left(g / m^{2}\right)\end{array}$} \\
\hline & & $\mathbf{N}$ & $\mathbf{P}$ & $\mathbf{k}$ & $\mathrm{Ca}$ \\
\hline $\begin{array}{l}j l \\
o c \\
\text { fe } \\
a b \\
j 1\end{array}$ & $\begin{array}{l}\text { RAICES FINAS VIVAS } \\
1988 \\
1988 \\
1989 \\
1989 \\
1989 \\
\text { media anual } \\
\text { error standard }\end{array}$ & $\begin{array}{l}1,63 \\
4,43 \\
4,34 \\
3,25 \\
3,56 \\
3,44 \\
0,45\end{array}$ & $\begin{array}{l}0,09 \\
0,17 \\
0,18 \\
0,12 \\
0,19 \\
0,15 \\
0,02\end{array}$ & $\begin{array}{l}0,25 \\
0,39 \\
0,41 \\
0,78 \\
0,43 \\
0,45 \\
0,08\end{array}$ & $\begin{array}{l}0,87 \\
2,28 \\
2,01 \\
1,83 \\
1,94 \\
1,79 \\
0,21\end{array}$ \\
\hline $\begin{array}{l}j l \\
d 1 \\
a b\end{array}$ & $\begin{array}{l}\text { RAICES FINAS MUERTAS } \\
+ \text { Se + OC } 1988 \\
1988 \\
+ \text { my + Jl } 1989 \\
\text { media anual } \\
\text { error standard }\end{array}$ & $\begin{array}{l}1,22 \\
3,21 \\
0,92 \\
1,78 \\
0,59\end{array}$ & $\begin{array}{l}0,06 \\
0,16 \\
0,04 \\
0,09 \\
0,03\end{array}$ & $\begin{array}{l}0,16 \\
0,39 \\
0,09 \\
0,21 \\
0,07\end{array}$ & $\begin{array}{l}0,81 \\
1,99 \\
0,72 \\
1,17 \\
0,33\end{array}$ \\
\hline $\begin{array}{l}\text { jl } \\
\text { se } \\
\text { oc } \\
\text { fe } \\
\text { ab } \\
j l\end{array}$ & $\begin{array}{l}\text { RAICES GRUESAS VIVAS } \\
1988 \\
1988 \\
1988 \\
1988 \\
1989 \\
1989 \\
\text { media anual } \\
\text { error standard }\end{array}$ & $\begin{array}{l}0,38 \\
0,44 \\
0,43 \\
0,25 \\
0,52 \\
0,21 \\
0,37 \\
0,04\end{array}$ & $\begin{array}{l}0,02 \\
0,02 \\
0,01 \\
0,02 \\
0,03 \\
0,01 \\
0,02 \\
0,002\end{array}$ & $\begin{array}{l}0,06 \\
0,06 \\
0,03 \\
0,07 \\
0,08 \\
0,03 \\
0,06 \\
0,01\end{array}$ & $\begin{array}{l}0,16 \\
0,28 \\
0,14 \\
0,16 \\
0,27 \\
0,09 \\
0,18 \\
0,03\end{array}$ \\
\hline $\begin{array}{l}j 1 \\
o c \\
a b\end{array}$ & $\begin{array}{l}\text { RAICES GRUESAS MUERTAS } \\
1988 \\
1988 \\
+ \text { my } 1989 \\
\text { med1a anual } \\
\text { error standard }\end{array}$ & $\begin{array}{l}0,36 \\
0,24 \\
0,38 \\
0,33 \\
0,04\end{array}$ & $\begin{array}{l}0,02 \\
0,01 \\
0,02 \\
0,02 \\
0,002\end{array}$ & $\begin{array}{l}0,07 \\
0,02 \\
0,11 \\
0,07 \\
0,02\end{array}$ & $\begin{array}{l}0,21 \\
0,16 \\
0,72 \\
0,36 \\
0,14\end{array}$ \\
\hline & TOTAL SUBTERRANEO & 5,93 & 0,27 & 0,79 & 3,51 \\
\hline
\end{tabular}




\section{7 c-SUELOS}

Los suelos, presentan características similares a las del pastizal superior (1025 $\mathrm{m} \mathrm{sm}$ ). De acuerdo con Arens y Etchevere (1966) se consideran, en cuanto a la profundidad, muy someros; de textura, franca, con presencia de gravas y gravillas y de $\mathrm{pH}$ ácidos. El contenido de materia orgánica, según la clasificación propuesta por Hardy (Hardy 1961, en Fassbender 1982) es muy alto. El contenido de nitrógeno se encuentra dentro del rango más frecuente (0,2 y 0,7\% de nitrógeno) citado para suelos (Fassbender 1982) y la relación $\mathrm{C} / \mathrm{N}$ se encuentra dentro de los valores comunes (10 a 12) para el horizonte A (Arens y Etchevere 1966) de suelos de pastizal (Duchaufour 1965). En cuanto al contenido de P, se consideran suelos deficientes. La saturación con bases es baja (50\%). Este suelo se denomina Haplumbrets lítico (Soil Survey Staff 1990). Caracterizado por presentar un epipedon úmbrico y contacto lítico dentro de los primeros $50 \mathrm{~cm}$ profundidad del suelo (Tabla IV.12).

Tabla IV.12: Pastizal Medio (850 m $\mathrm{sm}$ ). Datos analiticos del suelo.

\begin{tabular}{|c|c|c|c|}
\hline Profundidad $(\mathrm{cm})$ & $0-20$ & MO (z) & 10,8 \\
\hline $\begin{array}{l}\text { pH (en pasta) } \\
\text { Composición granulometrica (z) }\end{array}$ & 4,3 & $\begin{array}{l}\text { C. I.C. (m.e./100) } \\
\text { Bases de intercambio (m.e./100) }\end{array}$ & 25,4 \\
\hline Arena & 46,4 & $\mathrm{Ca}^{++}$ & 8,5 \\
\hline Arcilla & 11,6 & $\mathrm{Mg}^{++}$ & 3,5 \\
\hline Limo & 42,0 & $\mathrm{Na}^{+}$ & 0,1 \\
\hline Fosforo (ppm) & 4,5 & $\mathrm{~K}^{+}$ & 0,5 \\
\hline Carbono organico (z) & 6,3 & Saturacion con bases $(z)$ & 50 \\
\hline Nitrogeno total disponible( $(\xi)$ & 0,44 & Densidad aparente $(\mathrm{g} / \mathrm{cm} 3)$ & 0,587 \\
\hline$C / N$ & 14 & & \\
\hline
\end{tabular}

\section{7 d-MINERALIZACION}

La liberación de nutrientes al suelo, estimada a partir de la desaparición de hojarasca y de las raíces muertas, fue similar desde ambos tipos de tejidos. La mineralización desde la hojarasca fue $0,07 \mathrm{~g} / \mathrm{m}^{2}$.año de $\mathbf{P} ; 0,32 \mathrm{~g} / \mathrm{m}^{2}$.año de $\mathbf{K} ; 0,89 \mathrm{~g} / \mathrm{m}^{2}$.año de Ca y 1,61 $\mathrm{g} / \mathrm{m}^{2}$.año de $\mathbf{N}$; mientras el aporte desde las raíces significó $0,07 \mathrm{~g} / \mathrm{m}^{2}$.año de $\mathbf{P} ; 0,25$ $\mathrm{g} / \mathrm{m}^{2}$.año de $\mathbf{K} ; 0,89 \mathrm{~g} / \mathrm{m}^{2}$.año de Ca y $1,61 \mathrm{~g} / \mathrm{m}^{2}$.año de $\mathbf{N}$. 


\section{7 e-CICLO DE LA MATERIA SECA, MATERIA ORGANICA Y NUTRIENTES}

Ciclo de la materia seca y materia orgánica (Gráfico IV.15)

La biomasa del pastizal es $753 \pm 53 \mathrm{~g} / \mathrm{m}^{2}$, y constituye el $60 \%$ de la materia seca (repartido en $11 \%$ aérea y $49 \%$ subterránea). La necromasa representa el $40 \%$ restante (21\% seco en pie $+15 \%$ raíces muertas $+5 \%$ hojarasca).

De la productividad primaria neta aérea anual, el $63 \%$ se transfirió, mediante la mortalidad, a los compartimientos muertos. A su vez la caída a la hojarasca representó el $56 \%$ de dicha mortalidad y el $96 \%$ del material que se incorporó a la hojarasca desapareció en el término de un año. La mortalidad subterránea anual representó el $39 \%$ de la productividad subterránea y el $100 \%$ de las raíces que murieron, desaparecieron como tales durante el año. De este modo, durante el período de estudio, llegaron al suelo $485 \mathrm{~g} / \mathrm{m}^{2}$.año de materia seca (o $431 \mathrm{~g} / \mathrm{m}^{2}$. año de materia orgánica), incorporándose al mismo, de acuerdo con las estimaciones de desaparición, el $98 \%$ de esas cantidades.

a

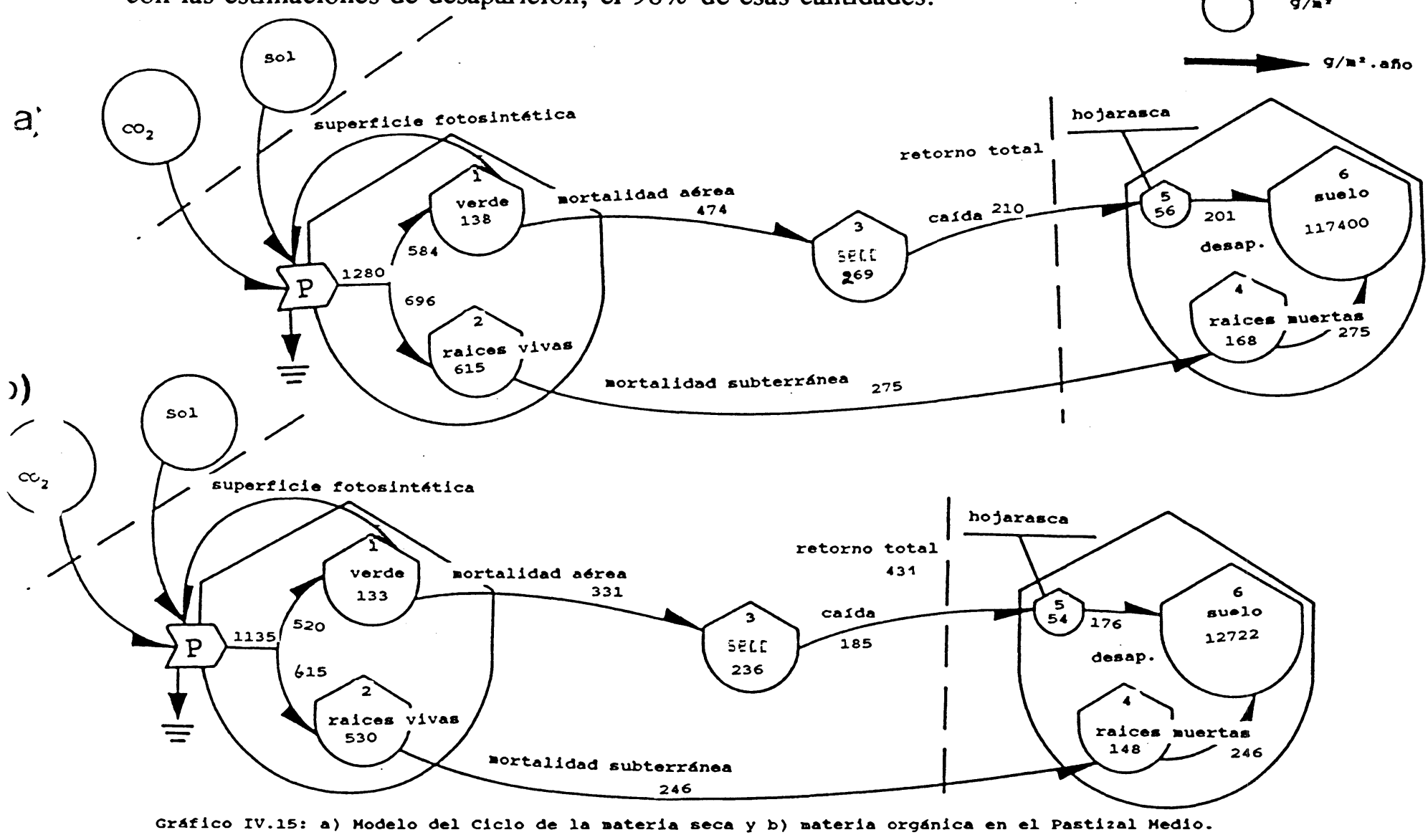




\section{Ciclo del Fosfóro.(Gráfico IV.16)}

Los requerimientos de $\mathbf{P}$ que satisfacieron la productividad total de la vegetación fueron $0,65 \mathrm{gP} / \mathrm{m}^{2} \mathrm{año}, 35 \%$ de los cuales provinieron de la retranslocación de nutrientes.

De los requerimientos totales, $68 \%$ se necesitaron para la productividad aérea y $32 \%$ para la subterránea.

Mediante la mortalidad aérea se incorporaron al seco en pie $0,11 \mathrm{gP} / \mathrm{m}^{2}$ año. El retorno a través de la caida a la hojarasca fue $0,043 \mathrm{gP} / \mathrm{m}^{2}$ año, quedando acumulados durante el período de estimaciones $0,07 \mathrm{gP} / \mathrm{m}^{2}$ año en el seco en pie.

El ingreso total de $\mathbf{P}$ al suelo fue $0,23 \mathrm{~g} / \mathrm{m}^{2}$.año. Desde la vegetación retornaron 0,11 $\mathrm{gP} / \mathrm{m}^{2}$.año, de los cuales el $62 \%$ provino de las raíces. A través del pluviolavado se incorporaron directamente al suelo $0,032 \mathrm{gP} / \mathrm{m}^{2}$.año.

La mineralización de los detritos vegetales aportó al suelo, durante el período 1988-1989, $0,14 \mathrm{gP} / \mathrm{m}^{2}$.año, los cuales provinieron por partes iguales de la mineralización de material aéreo y subterráneo.

El balance de $\mathbf{P}$ en el suelo considerando los aportes proveniente de la vegetación a través de los detritos y el pluviolado, menos la absorción, da un resultado negativo de 0,28 $\mathrm{gP} / \mathrm{m}^{2}$ año. El $85 \%$ de dicha diferencia se encuentra acumulada en la vegetación (5\% en el verde de dicotiledóneas, $19 \%$ en el verde de gramíneas, $25 \%$ en el seco en pie y $36 \%$ en las raíces finas vivas) debido al aumento, de un año con respecto al otro, de la materia seca y por lo tanto de la mineralomasa y los necronutrientes. Los $0,04 \mathrm{gP} / \mathrm{m}^{2}$ año faltantes serían suplidos por la depositación atmosférica, la cual fue para el año de estudios 0,06 gP/m².año. 


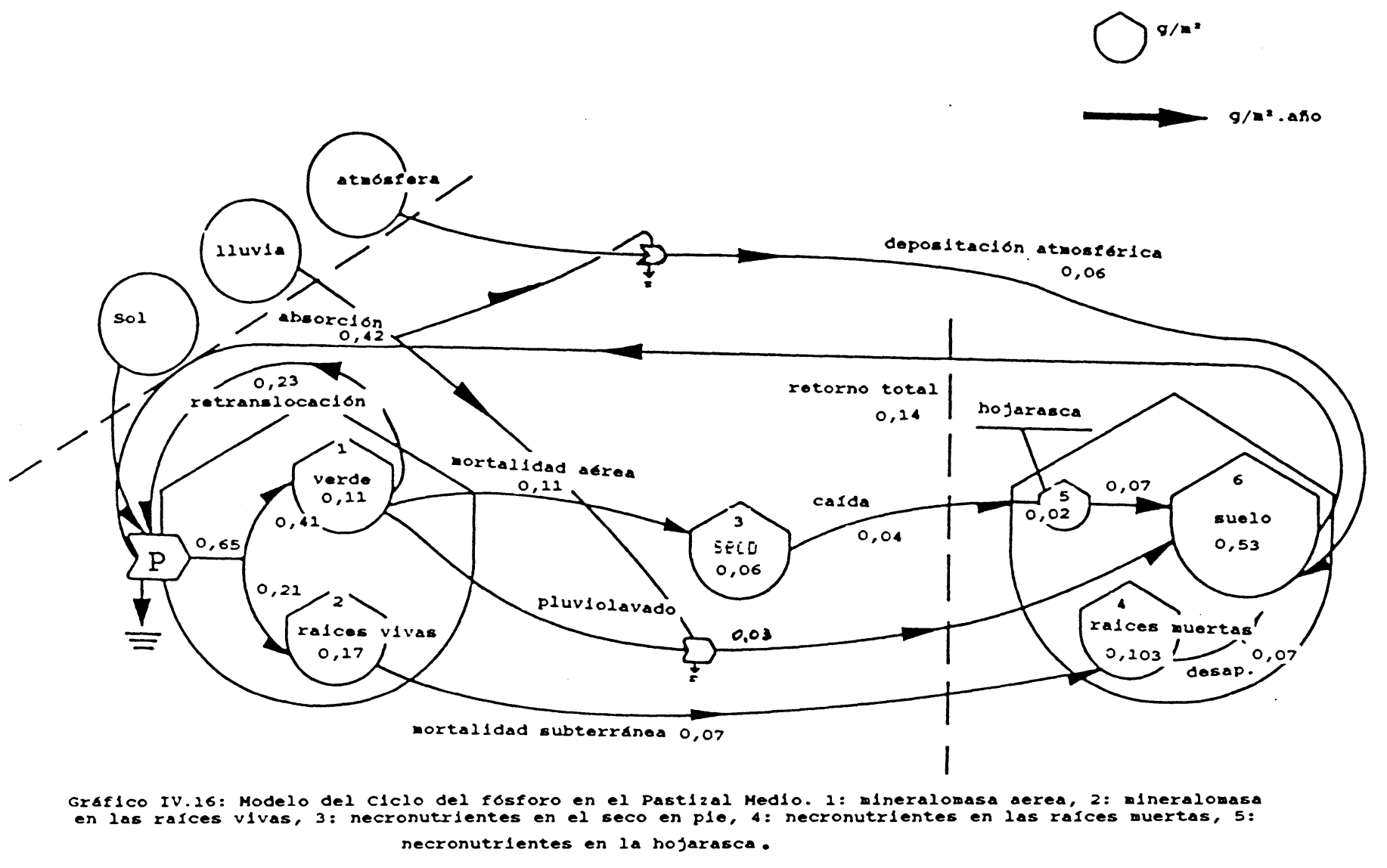

Ciclo del Nitrógeno (Gráfico IV.17)

Los requerimientos totales de $\mathbf{N}$ de la vegetación fueron $11,8 \mathrm{gN} / \mathrm{m}^{2}$.año, por medio de la retranslocación se proveyó el $20 \%$ de ellos.

La productividad aérea representó el $59 \%$ de los requerimientos totales de $\mathbf{N}$ y la productividad subterránea el $41 \%$ restante.

Se incorporaron al seco en pie entre julio de 1988 y julio de 1989, a través de la mortalidad aérea, $3,1 \mathrm{gN} / \mathrm{m}^{2}$.año. Se verificó una acumulación de $1,8 \mathrm{gN} / \mathrm{m}^{2}$.año en el seco en pie, dado que el retorno de $\mathrm{N}$ al suelo mediado por la caida a la hojarasca fue 1,3 $\mathrm{gN} / \mathrm{m}^{2}$.año.

El retorno de $\mathrm{N}$ al suelo a través de los detritos vegetales fue $2,9 \mathrm{gN} / \mathrm{m}^{2}$.año, de los cuales el $55 \%$ provino de las raíces. A través del lavado de los tejidos aéreos en pie se incorporaron al suelo $0,7 \mathrm{gN} / \mathrm{m}^{2}$.año y por depositación atmosférica ingresaron al pastizal $0,22 \mathrm{gN} / \mathrm{m}^{2}$.año durante el período de estudios. 
La incorporación de nitrógeno al suelo procedente de la mineralización fue 3,22 $\mathrm{gN} / \mathrm{m}^{2}$.año. De los mismos, partes iguales fueron aportadas por la descomposición y mineralización de los detritos aéreos y subterráneos.

El balance de $\mathbf{N}$ en el suelo, teniendo en cuenta los ingresos por diferentes vias (retorno y pluviolavado) menos la absorción, presentó un resultado negativo de $5,8 \mathrm{gN} / \mathrm{m}^{2}$ año. El $77 \%$ del mismo se encuentra en la vegetación, la cual se incrementó de un año con respecto al siguiente (3\% en las dicotiledóneas, $10 \%$ en las gramíneas, $31 \%$ en el seco en pie y $33 \%$ en las raíces finas vivas). Quedaría un balance negativo de $1,3 \mathrm{gN} / \mathrm{m}^{2}$.año, los cuales pueden ser provistos en parte por la depositación atmósferica $\left(0,22 \mathrm{gN} / \mathrm{m}^{2}\right.$.año) y por la fijación atmosférica de $\mathrm{N}$, a cerca de la cual se desconoce su magnitud en pastizales de la zona.

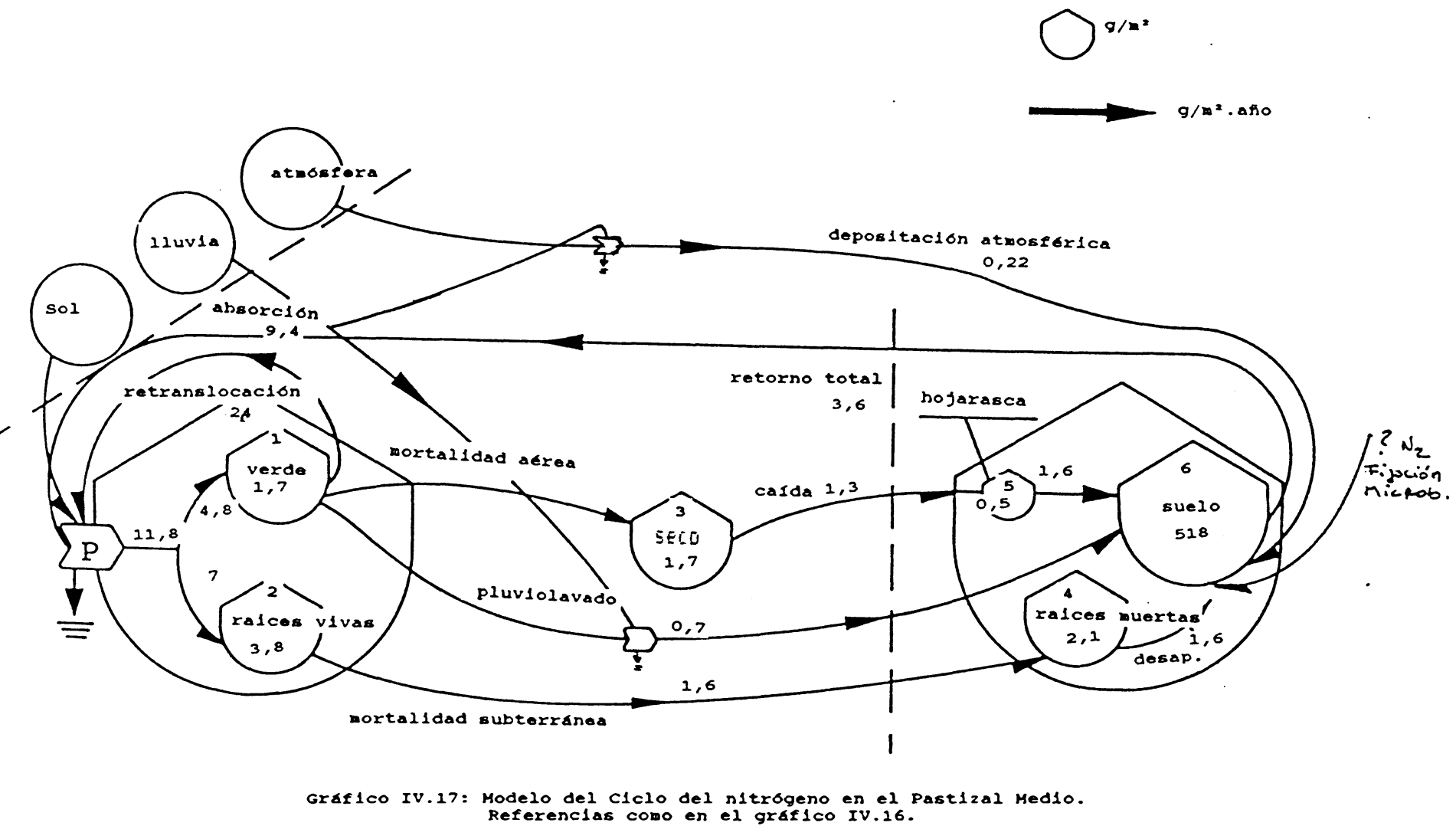




\section{Ciclo del Potasio (Gráfico IV.18)}

Los requerimientos totales de $\mathbf{K}$ del pastizal necesarios para la productividad primaria neta fueron $7,2 \mathrm{gK} / \mathrm{m}^{2}$.año, de los cuales el $51 \%$ fueron aportados por retranslocación.

Con respecto a los requerimientos totales, el $93 \%$ de los mismos fueron empleados en la productividad aérea.

En el año de estudios $0,9 \mathrm{gK} / \mathrm{m}^{2}$.año de se acumularon en el seco en pie. Por medio de la mortalidad aérea ingresaron al mismo $1,6 \mathrm{gK} / \mathrm{m}^{2}$.año, siendo la caída $0,8 \mathrm{gK} / \mathrm{m}^{2}$.año.

El retorno de $\mathbf{K}$ al suelo desde la vegetación fue $0,93 \mathrm{gK} / \mathrm{m}^{2}$.año, de los cuales $77 \%$ provinieron del material aéreo y $23 \%$ del subterráneo. A través del pluviolavado se incorporaron al suelo $0,3 \mathrm{gK} / \mathrm{m}^{2}$.año.

La mineralización de $\mathbf{K}$ es $0,57 \mathrm{gK} / \mathrm{m}^{2}$.año ( $56 \%$ provinieron de la descomposición de la hojarasca y $43 \%$ de las raíces).

El balance de $\mathbf{K}$ en el suelo (ingresos: pluviolavado y retorno, menos egresos: absorción), dio un resultado negativo de $2,12 \mathrm{gK} / \mathrm{m}^{2}$.año durante el período de estudios. Esta cantidad se acumuló temporariamente en el incremento de la mineralomasa y necronutrientes. Resultó, de este modo, balanceada la cantidad de $\mathrm{K}$ absorbida con respecto a la que ingresa al suelo más la que momentaneamente se encuentra retenida en la vegetación. Si se considera la depositación atmosférica de $\mathrm{K}\left(0,22 \mathrm{gK} / \mathrm{m}^{2}\right.$ año), la misma resultaría en un excedente. 


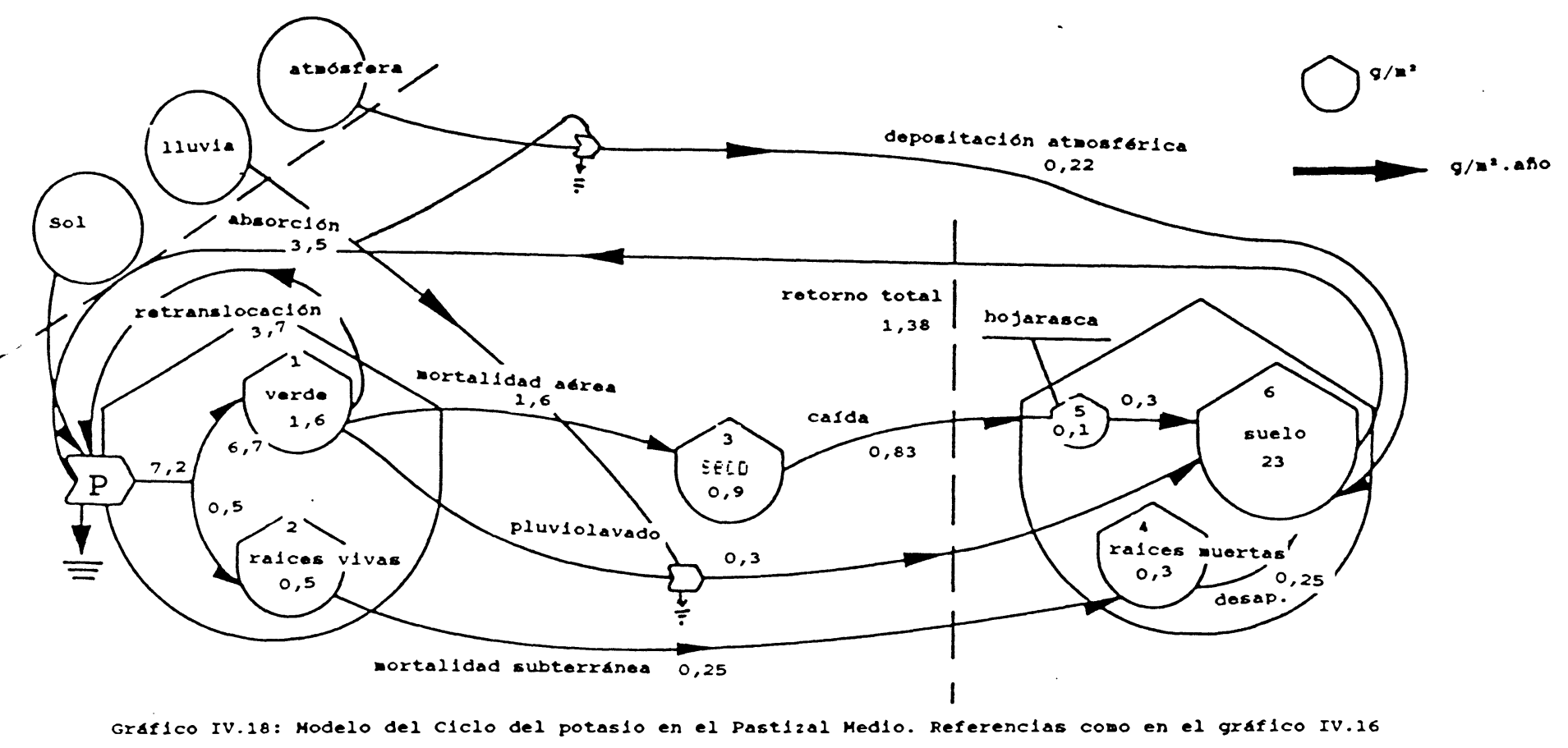

Ciclo del Calcio (Gráfico IV.19)

Los requerimientos totales de $\mathbf{C a}$ que posibilitaron la productividad del pastizal durante el período de estudios, fueron $4,4 \mathrm{gCa} / \mathrm{m}^{2}$.año, los cuales fueron satisfechos enteramente por absorción, ya que no existe retranslocación de este nutriente.

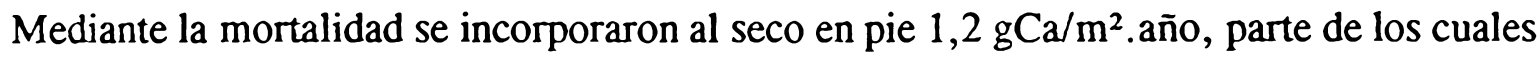
se acumuló en dicho compartimiento $\left(0,7 \mathrm{gCa} / \mathrm{m}^{2}\right.$.año), ya que el retorno de $\mathrm{Ca}$ al suelo a través de la caida, fue $0,5 \mathrm{gCa} / \mathrm{m}^{2}$.año.

El retorno total de $\mathrm{Ca}$ fue $1,28 \mathrm{gCa} / \mathrm{m}^{2}$.año, el cual provino en su mayor parte de las raíces $(62 \%)$.

Al suelo se incorporaron por mineralización $1,69 \mathrm{gCa} / \mathrm{m}^{2}$.año (48\% provino de las raíces). El balance de los aportes y egresos de Ca al suelo provenientes de la vegetación durante el período comprendido entre julio de 1988 y julio de 1989 , fue negativo $\left(3,1 \mathrm{gCa} / \mathrm{m}^{2}\right.$.año). De ellos, el $65 \%$ se encuentra involucrado en el aumento de la materia seca $(7 \%$ en las dicotiledóneas, $7 \%$ en la gramíneas, $19 \%$ en el seco en pie y $32 \%$ en las raíces finas vivas). La depositación atmósferica, $0,9 \mathrm{gCa} / \mathrm{m}^{2}$.año, aportaría el $29 \%$ de dicha diferencia, quedando un déficit de $0,1 \mathrm{gCa} / \mathrm{m}^{2}$.año. 


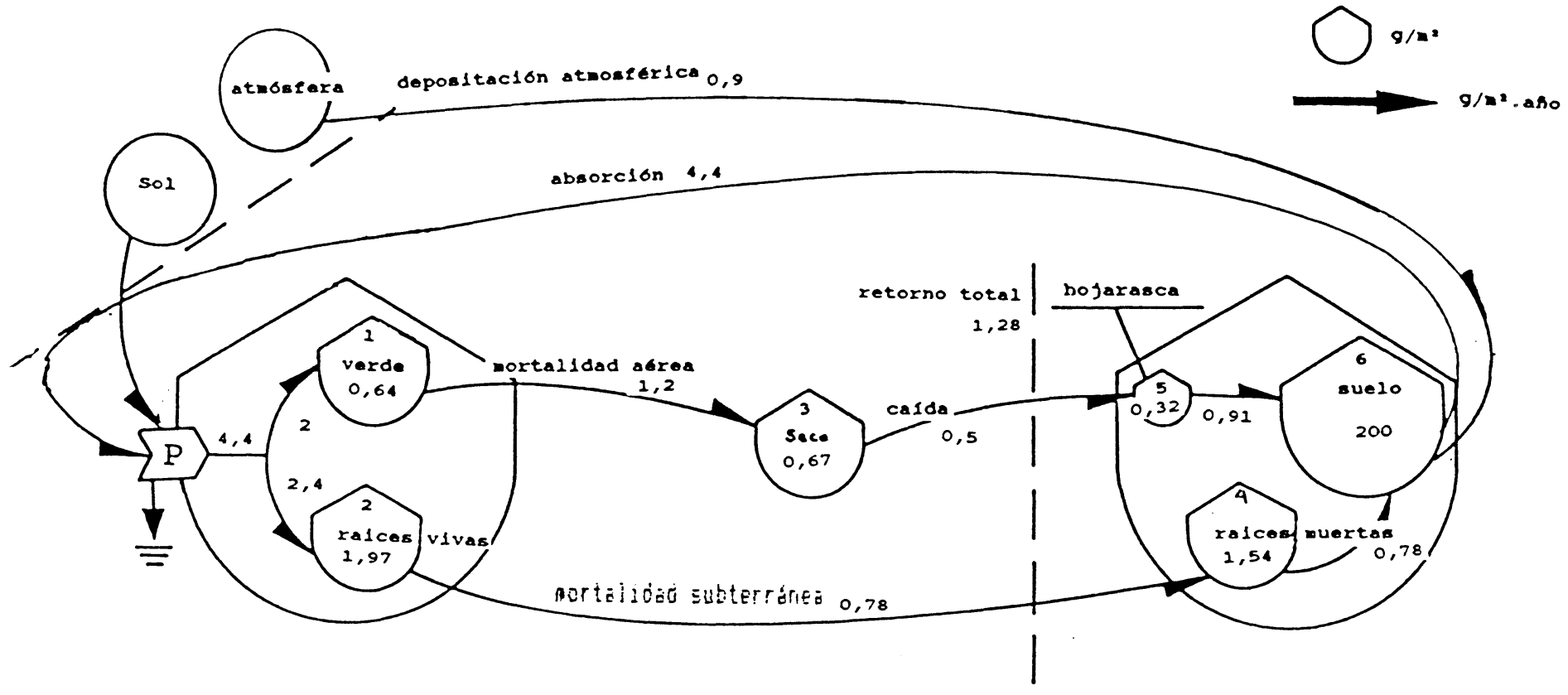

Graflco IV.19: Modelo del clclo del calclo en el Pastizal Medio. Referenclas como en el graflco IV.16. 


\section{IV.2-DISCUSION}

Dinámica estacional de la materia seca y procesos funcionales

En el pastizal medio, Sorghastrum pellitum y Stipa filiculmis son las gramíneas con mayor cobertura (Frangi y Bottino 1995). Otros pastizales con Sorghastrum, en la Sierra de la Ventana, cuya altitud, exposición y pendiente coinciden con las del pastizal medio presentan valores de materia seca aérea y subterránea cercanos a los obtenidos en este trabajo. El promedio de las estimaciones de materia seca realizadas por Ricci (1992) en pastizales pastoreados, durante dos años (1985 y 1986), es $319 \mathrm{~g} / \mathrm{m}^{2}$; Barrera y Frangi (1994) obtuvieron valores de materia seca aérea de $598,9 \pm 49,7 \mathrm{~g} / \mathrm{m}^{2}$ en julio de 1982 , y 667,1 $\pm 45,9 \mathrm{~g} / \mathrm{m}^{2}$ en diciembre de ese año; los mismos autores señalan $788,7 \pm 43 \mathrm{~g} / \mathrm{m}^{2}$, para la materia seca subterránea en julio y $1043 \pm 112 \mathrm{~g} / \mathrm{m}^{2}$ en diciembre; de Wysiecki y Pérez (com pers.) señalan una masa de raíces, promedio de un año de estimaciones, de $950 \pm 192$ $\mathrm{g} / \mathrm{m}^{2}$. Con respecto a pastizales de EEUU, el rango que presenta la masa de raíces en los primeros $30 \mathrm{~cm}$ de profundidad es 168 a $1388 \mathrm{~g} / \mathrm{m}^{2}$, y para la masa aérea es 85 a 589 $\mathrm{g} / \mathrm{m}^{2}$ (Sims et al. 1978). La masa subterránea del pastizal medio presenta valores intermedios, mientras que su masa aérea se encuentra cercana al valor más elevado de este rango.

Este pastizal es florísticamente similar al pastizal superior. Aunque se trata de la misma comunidad, en este sitio la relación aéreo : subterráneo es $1: 2$, mientras que en el pastizal superior esta relación es $1: 3$. Esta diferencia en la partición de la materia seca entre estructuras aéreas y subterráneas se relacionaría con las características mesoclimáticas de los sitios. Este pastizal presenta condiciones intermedias entre la cumbre y la zona basal. Las temperaturas extremas son mayores que las de la cumbre y los deficits de saturación son intermedios entre los pastizales de igual exposición ubicados respectivamente a mayor y menor altitud (Kristensen y Frangi 1995). Un proceso clave por el cual las plantas responden a cambios en su ambiente es la distribución de recursos en la producción de nuevas hojas, tallos, raíces y estructuras reproductivas (Schulze y Chapin 1987). Ambos pastizales están sometidos a condiciones climáticas con diferencias a nivel de sitio; la influencia del ambiente estaría reflejada en una menor proporción de biomasa aérea en el pastizal superior con respecto al de media ladera. 
El cociente biomasa subterránea/biomasa aérea varía a lo largo del año, y es indicador de la biomasa absorbente necesaria para el sostenimiento de la masa fotosintetizante bajo distintas condiciones de humedad y temperatura del ambiente. Este cociente en el pastizal medio presenta un rango entre 4 y 11 . Los valores más elevados corresponden al invierno y principios de primavera, con escasas lluvias. Los valores mas bajos de dicho cociente ocurren en el verano y al otoño siguientes, que fueron más lluviosos. Este mismo patrón fue señalado en el pastizal superior. En ambos sitios la disminución en la disponibilidad de agua afecta la asignación de fotoasimilados aumentando la superficie absorvente a través de la producción de raíces finas y la disminución de la biomasa aérea. Fernández et al. (1988) con respecto al cociente biomasa subterránea/biomasa aérea, señala que los valores altos reflejan un balance funcional de valor selectivo, permitiendo inferir que la alta asignación de carbono al sistema radical representa un atributo necesario para su perduración.

La presencia en el pastizal medio, de especies de origen micro y megatérmico, y la combinación de condiciones favorables en cuanto a precipitación y temperaturas en primavera y fines del verano-principios del otoño se relaciona con los picos de productividad neta en dichos momentos.

Hacia fines del invierno aumentan el seco en pie y las raíces vivas. En este pastizal, al igual que en el pastizal superior, hay productividad neta invernal. Sin embargo la tasa diaria de productividad de este período prácticamente duplica a la del pastizal ubicado a mayor altitud. Entre los muchos factores que pueden estar influyendo en esta diferencia, es probable que el pastizal medio se vea favorecido por condiciones de temperatura mayores y exposición al viento más atemperada que en la cumbre serrana. La tasa diaria de productividad invernal muestra que la asignación de fotoasimilados hacia estructuras subterráneas es tres veces superior a la aérea. Si bien hay crecimento aéreo invernal, la mortalidad aérea en este período también es importante. Esto se relacionaría con las características hídricas del invierno de 1988, relativamente seco, acentuándose esta condición de sequía durante el mes de setiembre, cuando la demanda evaporativa del aire aumenta. La disponibilidad de agua es uno de los principales factores que influencian la tasa de crecimiento y la translocación de carbono hacia diferentes órganos de las plantas (Detling 1979, Schulze 1982, Schulze y Chapin 1987, Walter 1977). La elevada producción de raíces y la pérdida de masa foliar a través de la 
mortalidad aérea llevan a que el cociente biomasa subterránea/ biomasa aérea alcance su máximo valor en dicho periodo.

A mediados de la primavera la tasa de productividad neta es elevada, coincidiendo con un período lluvioso. La mayor proporción de los productos de la asimilación neta de este período son destinadas al incremento de la biomasa subterránea y en mucho menor medida al aumento de biomasa aérea.

La importante biomasa de raíces, formada durante el invierno y parte de la primavera, permite sostener la elevada productividad diaria a fines de primavera, la cual es asignada en su totalidad al crecimiento aéreo. En este mismo período también la tasa diaria de mortalidad aérea y subterránea y de caída a la hojarasca es máxima. Hacia fines de la primavera ocurre el mayor esfuerzo reproductivo del pastizal, a la vez que las condiciones hídricas se tornan desfavorables debido a la elevada evapotranspiración y escasas precipitaciones. La combinación de estos factores probablemente contribuyan a explicar en gran medida la mortalidad y la caída a la hojarasca de este período. Además, la mortalidad de raíces a fines de primavera se detecta a través del aumento de las raíces finas muertas en los primeros diez centímetros de profundidad. A mayor profundidad la biomasa y necromasa mantiene valores similares a los de meses anteriores. Probablemente, condiciones de mayor humedad permiten la supervivencia de las raíces más profundas, mientras que las más superficiales se ven sometidas a la desecación provocada por la intensa evapotranspiración potencial que caracteriza a este período y la ausencia de lluvias durante todo el mes de diciembre.

En el verano ocurren los procesos de mortalidad y caída aéreos y de desaparición aérea y subterránea. En lo referente a la desaparición de hojarasca, este proceso está vinculado con la particulación, mezcla con el suelo y dispersión por el viento, además de la descomposición microbiana (Swift et al. 1979). En la parte subterránea, deben considerarse tanto la calidad orgánica de las raíces finas que facilitarían los procesos de descomposición, como la ocurrencia de lluvias importantes durante el mes de enero que podrían generar condiciones favorables para la misma. Dicho mes en 1989 fue abundante en lluvias, por lo cual se espera que aunque el balance entre las precipitaciones y la evapotranspiración de ese período fue negativo, existieron dias en que la humedad fue favorable para los procesos de 
descomposición, acelerados por las elevadas temperaturas de esa época del año.

Las lluvias a principios del otoño contribuyen a mejorar la disponibilidad de agua para la vegetación permitiendo el crecimiento, que es casi en su totalidad aéreo. Dado que muchas de las gramíneas presentes en esta época pertenecen al grupo de las mega o mesotérmicas, que fructifican a fines del verano o en el otoño (Burkart 1975), la finalización de su ciclo productivo se reflejaría en un incremento de la tasa diaria de mortalidad aérea a mediados del otoño, coincidiendo con el descenso en las temperaturas.

El tiempo de renovación es indicador del dinamismo de los procesos funcionales del pastizal. La mayor velocidad en la renovación de la materia seca corresponde a la hojarasca, la cual se renueva casi cinco veces en un año. La biomasa viva aérea se renueva en aproximadamente tres meses. El tiempo de renovación del seco en pie y de las raíces muertas es mayor, aproximadamente siete meses, mientras que la renovación de las raíces vivas es anual. Como ocurre en el pastizal superior, el sistema es más conservativo con respecto a las raíces que con la biomasa aérea.

Pese que el tamaño del compartimiento de la hojarasca es pequeño, la velocidad en la renovación de la misma lleva a que se incorpore al suelo una cantidad de materia seca similar a la que aportan las raíces. Esta característica diferencia al pastizal medio del pastizal superior. En este último las raíces tienen mayor importancia en la incorporacion de material vegetal al suelo. El pastizal medio, al menos durante el período estudiado, se encontraría en una etapa de acrecentamiento de la masa vegetal tanto aérea como subterránea. De este modo, el $81 \%$ de la producción aérea se incorpora al seco en pie a través de la mortalidad, pero sólo un $34 \%$ de dicha producción se incorpora al suelo. En las raíces, en cambio, no se acumula necromasa sino que la mortalidad y la desaparición son de igual magnitud. De la producción subterránea $40 \%$ muere y desaparece en el término de un año. Las raíces vivas aumentan el $100 \%$ y la biomasa viva aérea se incrementa el $91 \%$ teniendo en cuenta el inicio y la finalización del muestreo. El seco en pie crece el $85 \%$, en ese período. Esta incremento de la masa vegetal se relacionaría con el incendio ocurrido a principios de 1987 y con la variabilidad en las condiciones climáticas de un año, con respecto a otro. En cuanto a la variabilidad climática interanual, los sistemas de pastizal registran amplias variaciones en su 
biomasa en respuesta a las mismas. Abrams et al. (1986) señalan que la biomasa aérea es hasta tres veces menor en los años secos que en los mas lluviosos, en pastizales de pastos altos en Kansas (EEUU). En pastizales de EEUU, Sims y Sing (1978 a) estimaron una masa de raíces entre un $29 \%$ y un $49 \%$ mayor en 1970 que en 1972, en respuesta a mejores condiciones de humedad.

Concentración, contenido y ciclo de nutrientes

La característica más notable de este pastizal durante el año de muestreo fue el incremento de su biomasa y necromasa, lo cual influye en las variaciones de las concentraciones y en el ciclado de los nutrientes a lo largo de dicho año.

En el verde de gramíneas, las concentraciones de $\mathrm{P}$ y $\mathrm{N}$ tuvieron un patrón estacional similar. Las mismas se elevaron hacia mediados de la primavera, diluyéndose hacia fines de dicha época del año, cuando la productividad aérea fue máxima. Los contenidos, en cambio, mantuvieron una tendencia creciente durante toda la primavera. En relación con las concentraciones en las raíces vivas, se observó que estas se diluyen al comienzo de la primavera, cuando la productividad subterránea presenta valores máximos. La dilución de las concentraciones en las raíces, junto con la absorción de nutrientes permitiría el importante aumento en la biomasa de las mismas. Al aumentar la densidad de raíces, principalmente finas, también lo hace la superficie de absorción. En síntesis, el crecimiento máximo de las raíces antecede al de los tejidos fotosintéticos, y sería sostenido por absorción y en parte por la dilución en las concentraciones de los nutrientes N y P. El crecimiento aéreo sería sostenido por la absorción de la raíces y posteriormente, por la dilución de los nutrientes en los tejidos aéreos durante el período de máxima producción foliar. Este último fue también el de máxima mortalidad aérea. La dilución de los nutrientes en los tejidos tendría como resultado el aumento de la eficiencia en el uso de los nutrientes en la productividad. Además junto con los mecanismos de retranslocación disminuirían la pérdida extrabiótica de dichos nutrientes a través de la mortalidad.

En el otoño, las concentraciones y los contenidos de $\mathrm{P}$ y $\mathrm{N}$ en el verde de gramíneas aumentan, con respecto a los primaverales y estivales. En las raíces finas vivas dichas 
variables, en cambio, son menores en el otoño que en la primavera. En los tejidos fotosintéticos, la dilución de $\mathrm{P}$ y $\mathrm{N}$ observada en la primavera, no ocurre en el otoño. Aunque la productividad otoñal aérea, en términos de materia seca, es tan importante como la primaveral, la mortalidad aérea a principios del otoño es mucho menor. A su vez, las concentraciones otoñales de $\mathrm{N}$ y $\mathrm{P}$ en la parte aérea, comienzan a declinar hacia principios del invierno. Teniendo en cuenta las variables ambientales, Kristensen y Frangi (1995) han señalado que el pastizal medio recibe más insolación en el otoño e invierno, en relación con los otros pastizales de igual exposición, lo cual podría influir en la temperatura a nivel de sitio, retardando la mortalidad invernal, con respecto a los otros pastizales considerados. La disminución invernal en las concentraciones y contenidos aéreos de de $\mathrm{N}$ y $\mathrm{P}$ fue acompañada por una tendencia creciente de los mismos en las raíces finas vivas.

La concentración y contenido del $\mathrm{K}$ en las raíces vivas presentó un patrón similar al descripto para el $\mathrm{N}$ y $\mathrm{P}$ en la primera parte de la primavera. El K, nutriente sumamente móvil, tiene una activa participación en procesos fisiológicos que ocurren en la hojas, en particular en la síntesis de RubP-carboxilasa (Marschner 1983). Es probable que en las raíces el $\mathrm{K}$ disminuya durante la primavera tanto por dilución en la formación de nuevos tejidos como por ser destinado principalmente a los tejidos fotosintéticos. En el verano, en cambio, el $\mathrm{K}$ aumentó su concentración y contenido en las raíces gruesas vivas, disminuyendo luego en el otoño, a la vez que ambas variables aumentaron en las raíces finas vivas. En el verano, dada la mortalidad y desaparición de raíces finas, es probable que este nutriente se concentre principalmente en los tejidos de reserva, como son las raíces gruesas vivas. En el otoño se produce un importante aumento de la biomasa aérea y en menor proporción de las raíces, los cuales no fueron acompañados por dilución en las concentraciones, observada en la primavera, sino que en ambos tipos de tejido el nivel de $\mathrm{K}$ se incrementó.

Las estructuras reproductivas de las gramineas mostraron una marcada diferencia en las concentraciones, las cuales fueron mucho mayores en las floración otoñal que en la primaveral. Esta última, sin embargo, contiene 16 veces más $\mathrm{Ca}, 9$ veces más $\mathrm{P}$ y $\mathrm{K}$, y 7 veces más $\mathrm{N}$ que la primera, dada por su mayor biomasa.

A lo largo del año, las dicotiledóneas mostraron variaciones similares en las concentraciones de los cuatro nutrientes considerados. En la primavera existiría dilución de 
los nutrientes dada por la disminución en las concentraciones a la vez que aumenta la biomasa. En el otoño se incrementan las concentraciones de nutrientes, con respecto al verano, acompañado de un aumento importante en la biomasa de las hierbas de hoja ancha.

Los mayores contenidos de nutrientes en los tejidos aéreos durante el otoño, con respecto a los primaverales, podría deberse a varios factores. Bajo condiciones de sequía los nutrientes en el suelo se hacen menos disponibles, reduciendo el flujo de los mismos en el ecosistema (Schulze y Chapin 1987, Chapin 1991). Es probable que las condiciones hídricas desfavorables a fines de la primavera hayan limitado la absorción en esta época, por lo cual la dilución de los nutrientes en los tejidos al disminuir la absorción de los mismos fue más evidente. Por su parte, el otoño, con mejores condiciones hídricas resultaría un período con mayor disponibilidad de nutrientes. Otra posibilidad, no excluyente de la anterior es que, las especies predominantes durante el otoño, tengan requerimientos mayores que las especies primaverales. Esta diferencia se traduce en una menor eficiencia en el uso de los nutrientes en el otoño, con respecto a la primavera (tabla IV.13). Además, en el último período mencionado, el costo de producción de tejidos aéreos y subterráneos, en términos de los nutrientes P y N, resulta similar. En el otoño, en cambio, el costo de producir hojas es marcadamente menor que el de las raíces. Dichas diferencias estacionales se relacionaría con la existencia de mecanismos de dilución de los mismos durante el período inverno-primaveral y con mayores tasas de renovación de la biomasa del pastizal en dicho período, las cuales son 2,6 para el verde y 1,1 para las raíces. En contraposición, en el período estivo-otoñal, la existencia de dilución de nutrientes no es evidente y la velocidad en el recambio de los tejidos es mucho menor que la del período anterior, haciéndose mas marcada la diferencia entre la renovación aérea, 1,7 veces y la subterránea, 0,09 veces en el período mencionado.

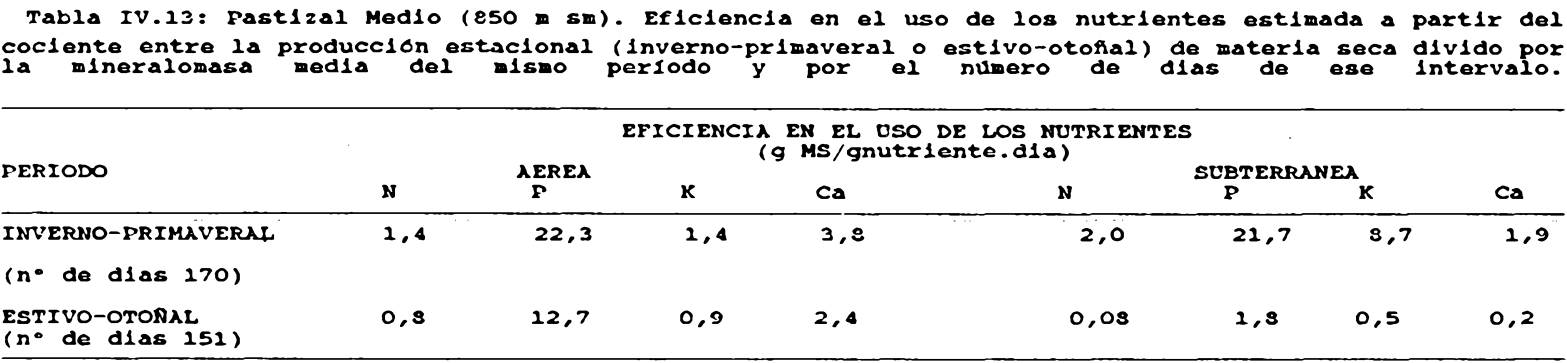


En el seco en pie las concentraciones de nutrientes variaron muy poco durante el año. Los contenidos de estos nutrientes aumentaron en los períodos de mayor mortalidad aérea (fines de la primavera y principios del invierno). El incremento de nutrientes (concentaciones y contenidos) en el seco en pie en coincidencia con los períodos de mortalidad aérea y su posterior declinación permite sostener que habría un pasaje directo de nutrientes desde dicho compartimiento al suelo, relacionado con el lavado y con la posible acción de organismos descomponedores. Con excepción del $\mathrm{Ca}$, las concentraciones y contenidos de nutrientes en el seco en pie son menores que en los órganos aéreos vivos, principalmente de $\mathrm{P}$ y $\mathrm{K}$, a pesar de que en el primer compartimiento mencionado la materia seca es 2 veces superior al segundo. Esto pone de manifiesto la existencia de mecanismos de retranslocación de nutrientes desde los tejidos senescentes. Dicho mecanismo constituye una forma eficiente de obtención de los mismos, ya que estarían más rápidamente disponibles para las plantas. El Ca presenta una baja movilidad en la planta y su concentración no declina en el seco en pie con respecto al verde, por lo cual su contenido esta en relación directa con la mayor masa de aquel compartimiento.

En este pastizal el pico de mortalidad y caída a la hojarasca ocurrieron en el mismo período, a fines de la primavera. Conjuntamente con el peso seco de la hojarasca, las concentraciones y contenidos de nutrientes disminuyeron marcadamente en el otoño temprano. Esto podría interpretarse como mineralización de dichos nutrientes. En el invierno, principalmente el Ca y el $\mathrm{N}$ aumentaron su concentración y no su contenido (ya que la caída a la hojarasca fue nula), posiblemente por enriquecimiento microbiano y por la pérdida de masa a través de la descomposición de los compuestos más lábiles, quedando los componentes más recalcitrantes de la materia seca. Estos mismos procesos permitirían explicar la existencia de mayores concentraciones en las raíces muertas, con respecto a la vivas, en todos los nutrientes analizados. A su vez, mientras que la concentración de Ca no se modificó en las raíces finas muertas a lo largo del año, los otros tres nutrientes disminuyeron marcadamente, lo cual indicaría que prevaleció la mineralización de los mismos.

En este pastizal los nutrientes involucrados en la productividad aérea fueron mayores que los necesarios para la productividad subterránea, con excepción del $\mathrm{Ca}$, que fue requerido en mayor proporción por estas últimas. En cambio el contenido de nutrientes en los tejidos 
vivos fue mayor en los subterráneos que en los aéreos. Esto se traduce en una mayor tasa de renovación (los nutrientes circularon con mayor velocidad), en estos últimos, con respecto a los primeros. El stock de $\mathrm{P}, \mathrm{N}$ y $\mathrm{K}$ contenido en la biomasa aérea se recambiaría 4 veces al año, y el Ca 3 veces. Las plantas serían más conservativas en cuanto a los nutrientes almacenados en las raíces vivas, ya que las tasas de renovación en las mismas son aproximadamente anuales.

En el pastizal medio, la materia seca que se produjo durante el año de estudio se localizó principalmente en las raíces finas vivas y en el seco en pie. Esto se debió a la importante productividad de este pastizal y a la intensidad de la mortalidad, que en términos de peso seco representó el $81 \%$ de la producción aérea y sólo el $39 \%$ de la productividad subterránea. Esta diferencia entre la dinámica de los tejidos subterráneos y aéreos implicaría para la vegetación un aumento en la superficie de absorción, en el primer caso, y un retardo en el retorno de materiales al suelo en el segundo. Sin embargo la proporción de los nutrientes involucrados en la mortalidad aérea con respecto a los requeridos en la productividad aérea fue mucho menor que la señalada para la materia seca. Esto podría explicarse en parte por la dilución en las concentraciones de los mismos en los tejidos, y por la existencia de mecanismos de retranslocación que permitirían la reutilización de los nutrientes a corto plazo. Este mecanismo permitió recuperar elevadas proporciones de los nutrientes requeridos por las plantas, desde los tejidos senescentes (el $52 \%$ del $\mathrm{K}$, el $35 \%$ del $\mathrm{P}$ y el $20 \%$ del $\mathrm{N}$ ).

La cantidad de nutrientes que se transfirió durante el año a través de la mortalidad fue mayor en la parte aérea que en la subterránea, sin embargo en el retorno total de nutrientes al suelo, ambos subsistemas aportaron cantidades similares. Esto se debería a la existencia de un retardo en el flujo aéreo de nutrientes dado por almacenamiento de los mismos en el seco en pie. En cambio, las raíces cuando mueren ya estan en contacto directo con los organismos descomponedores del suelo, por lo cual los nutrientes involucrados en las mismas resultan más rápidamente disponibles para los procesos de descomposición y mineralización.

La devolución de nutrientes al suelo desde la hojarasca igualó a la proveniente de las raíces. En cuanto a la velocidad en la liberación de los nutrientes (tabla IV.14), en la primavera las tasas de mineralización aéreas y subterráneas fueron similares. En el otoño las 
tasas de descomposición de materia seca y de liberación del Ca desde la hojarasca son aproximadamente 3 veces mayores que en las raíces. En el caso del $\mathrm{N}, \mathrm{P}$ y $\mathrm{K}$, las diferencias en favor de las tasas aéreas varían entre 1,4 y 1,6 veces respecto de las tasas de mineralización de las raíces. Por otra parte, existe una diferencia notable entre la hojarasca y las raíces, ya en que en estas últimas la liberación de los nutrientes $\mathrm{N}, \mathrm{P}$ y $\mathrm{K}$ es más rápida que la desaparición de la materia seca, mientras que en la hojarasca ambos procesos ocurren a velocidades similares. Esto podría relacionarse con la calidad de las raíces, principalmente las finas, en términos de los cocientes $\mathrm{C}: \mathrm{N}$ y $\mathrm{C}: \mathrm{P}$, los cuales son menores que los de la hojarasca (el rango en el cociente $\mathrm{C}: \mathrm{N}$ fue 36 a 46 en las raíces finas muertas, 40 a 73 en la hojarasca; el rango en el cociente C:P fue 720 a 1099 en las raíces finas muertas y 1011 a 1666 en la hojarasca). Si bien no existe un valor fijo del cociente C:N para la inmovilización o liberación de nitrógeno (Berg y Ekbohm 1983), el predominio de uno de estos procesos sobre el otro está en relación directa con la similitud entre el cociente C:nutriente de los organismos descomponedores y del sustrato (Swift et al. 1979). Al respecto estos autores proponen un modelo en el cual, a medida que progresa la descomposición, los compuestos del $\mathrm{C}$ de más fácil degradación son utilizados pero los nutrientes que se encuentran en menor proporción son retenidos y aún incorporados desde la solución del suelo, hasta que la relación C:nutriente alcanza valores cercanos a la propia de los microorganismos del suelo, a partir de ese momento predominaría la liberación de tales nutrientes.

Tabla IV.14: Past1zal Med10 (850 $\mathrm{m} s \mathrm{~m}$ ). Tasa de descomposicion de la materia seca (MS), est1mada a

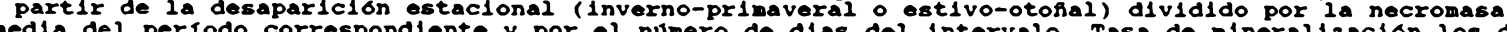
nutrientes estimada como la anterior, a partir de la desaparicion estacional de nutrlentes y la media de necronutrientes de cada periodo.

TASA DE DESCOMPOSICION Y TASAS DE MINERALIZACION DE LOS NUTRIENTES

PERIODO BOJARASCA RAICEB MUERTAS

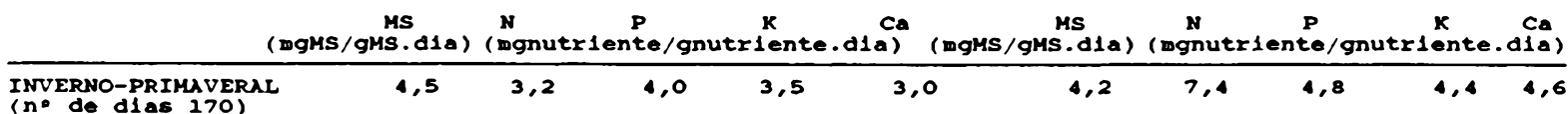


Otra forma de incorporación de nutrientes al suelo es el lavado, principalmente de los tejidos aéreos vivos. Esta via, más rápida que la de mortalidad y caida a la hojarasca, representa casi el $50 \%$ del $\mathrm{K}$ y del $\mathrm{P}$ y el $38 \%$ del $\mathrm{N}$ anualmente devuelto al suelo. El resto se incorporaría a partir de la mineralización de los nutrientes mencionados.

En el pastizal medio, la producción de nuevos tejidos, tanto aéreos como subterráneos, lleva a que exista una gran acumulación de nutrientes en la vegetación. Por lo cual el balance de los mismos entre la absorción y el retorno muestra marcadas diferencias negativas, sin embargo no se trata de una pérdida de nutrientes desde el sistema, sino de relocalización de los mismos. Este aumento de la masa vegetal ya fue señalado como parte del proceso de recuperación del pastizal después de haberse incendiado en 1987. Los tejidos aéreos vivos, las raíces finas vivas y el seco en pie, contienen la mayor parte de dicho incremento en la mineralomasa y necromasa respectivamente. 
CAPITULO V: PASTIZAL INFERIOR 


\section{V.1-RESULTADOS}

\section{V.1.1-MATERIA SECA TOTAL}

De la materia seca anual, $1225 \pm 43 \mathrm{~g} / \mathrm{m}^{2}$, el $44 \%$ corresponde al material aéreo, $52 \%$ a las raíces y $3 \%$ a la hojarasca.

La materia seca total muestra una tendencia creciente durante la primavera y en el otoño. A principios del invierno desciende a valores similares a los del año anterior.

\section{1 a-MATERIA SECA AEREA}

La media anual de materia seca aérea, excluyendo a la hojarasca, es $535 \mathrm{~g} / \mathrm{m}^{2}$, de los cuales el $73 \%$ corresponde al seco en pie y $27 \%$ a los compartimientos vivos. De éstos, el $25 \%$ corresponde a gramíneas y graminiformes, $2 \%$ a dicotiledóneas y menos del $1 \%$ a estructuras reproductivas. La biomasa de gramíneas verdes y de dicotiledóneas presentan un pico otoñal (Tabla V.1, Gráfico V.1).

En el seco en pie se observa un pico a fines del invierno y otro a fines del otoño (Tabla V.1, Gráfico V.1).

Tabla V.1: Pastizal Medio ( $850 \mathrm{~m} \mathrm{sm}$ ). Blomasa $y$

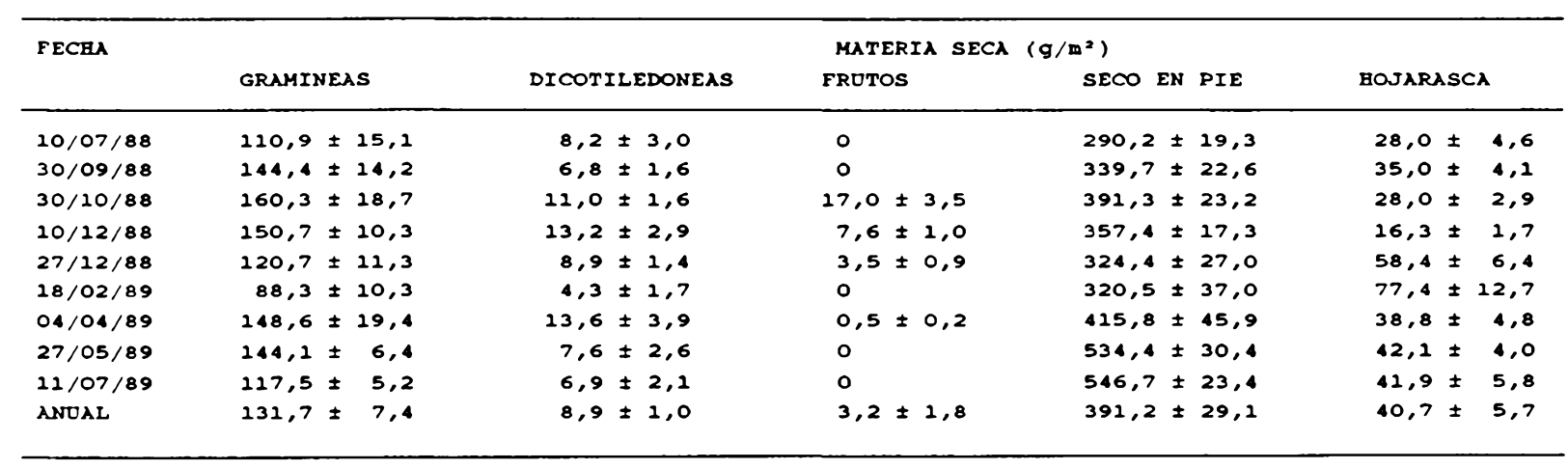




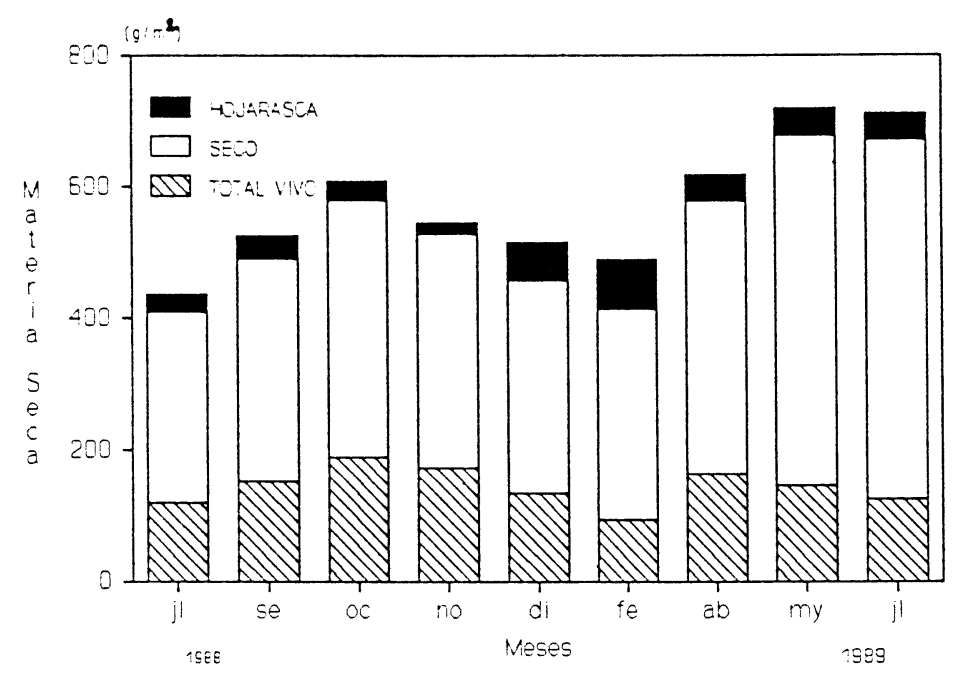
Graflco V.1: Pastizal Inferior (550 m $5 \mathrm{~m})$. Materla seca $\left(\mathrm{g} / \mathrm{m}^{2}\right)$ de los compartimlentos aereos estimada
durante el periodo julio de $1988-j u l 10$ de 1989 .

La floración de las gramíneas comienza a mediados de primavera, con un valor elevado de biomasa de estructuras reproductivas a fines de octubre, que corresponde en un $93 \%$ a la especie anual invernal Vulpia dertonensis. El pico de biomasa de dicho compartimiento correspondiente a las "flechillas" ocurre a principios de diciembre extendiéndose hasta fines de ese mes, pero con valores más bajos (Tabla V.1, Gráfico V.2). La mayoría de estas especies son de régimen microtérmico (Burkart 1975) (Tabla V.2).

Tabla V.2: Pastizal Inferlor (550 m sm) Especies de gramineas y graminiformaes balladas en flor en las
fechas de muestreo durante el periodo Juilo de 1988 Jullo de 1989 . Se sefala el regimen termico de 105 generos, segun Burkart (1975).

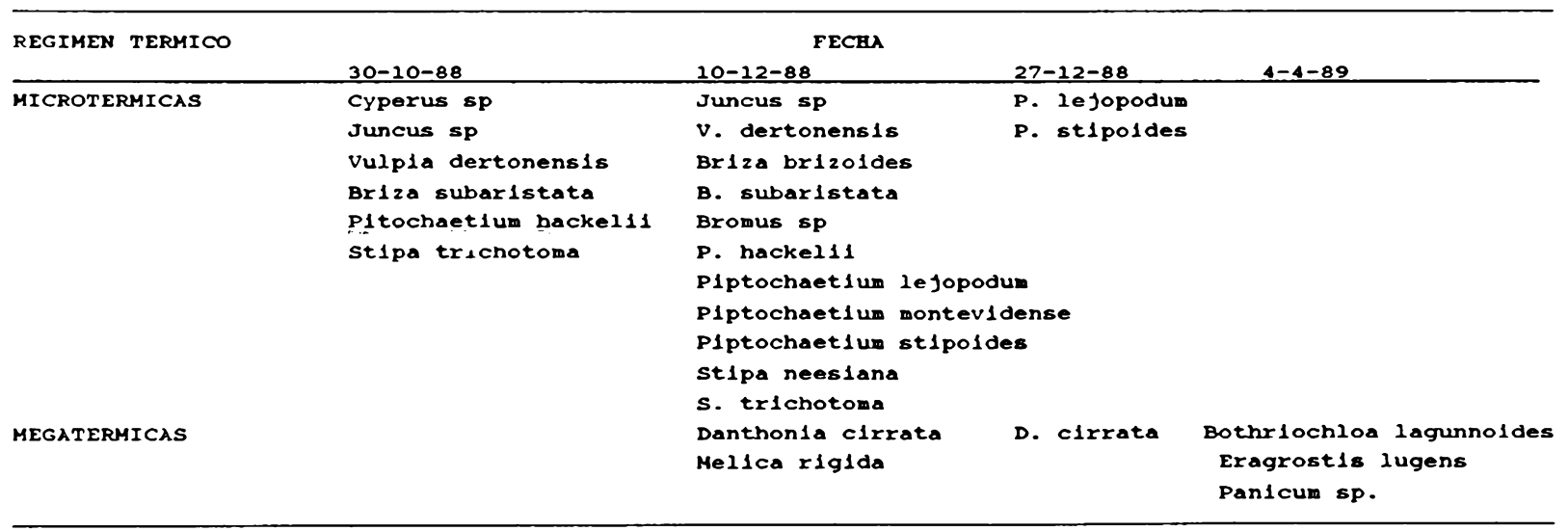


En otoño se observan estructuras reproductivas, de especies de régimen mesotérmico (Tabla V.2), pero su biomasa es mucho menor que en la floración primaveral (Gráfico V.2).

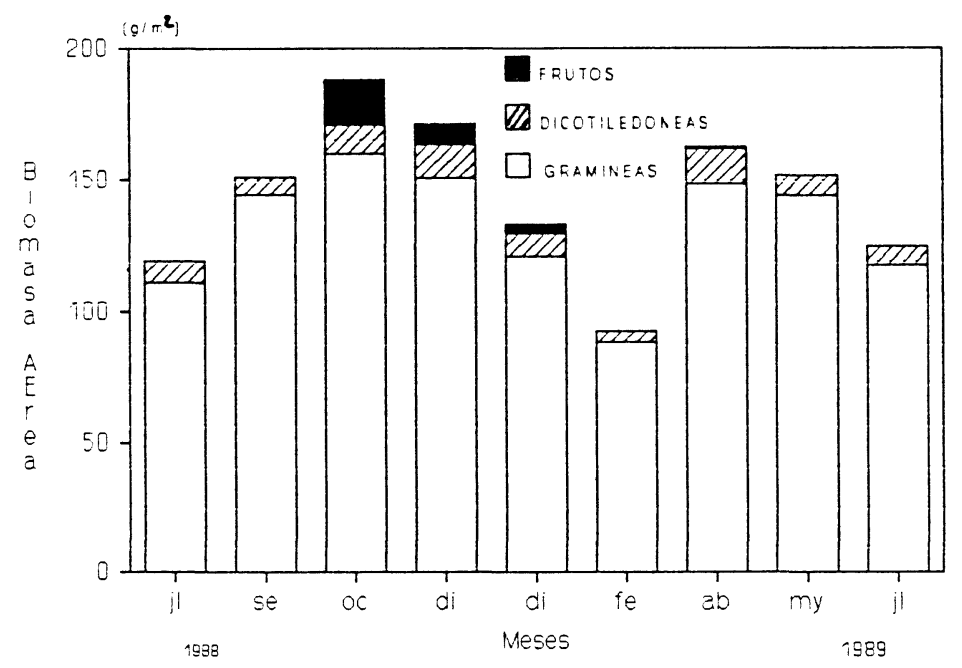

Graflco V.2: Pastizal Inferlor (550 m $\mathrm{sm})$. Blomasa $\left(\mathrm{g} / \mathrm{m}^{2}\right)$ de los compartimlentos aereos estimada durante el perlodo jullo de $1988-j u l 10$ de 1989.

\section{1 b-MATERIA SECA SUBTERRANEA}

La masa subterránea media anual es $642 \mathrm{~g} / \mathrm{m}^{2}$. El $64 \%$ se concentra en los primeros $10 \mathrm{~cm}$ de profundidad y $36 \%$ en los $10 \mathrm{~cm}$ siguientes (Tabla V.3).

En el estrato de $0-10 \mathrm{~cm}$ de profundidad, el $63 \%$ de la biomasa corresponde a las raíces vivas, repartida en $46 \%$ de raíces finas $+17 \%$ de raíces gruesas. Del $37 \%$ correspondiente a las raíces muertas, el $30 \%$ pertenecen a las raíces finas $+7 \%$ correspondientes a las raíces gruesas (Tabla V.3, Gráfico V.3). 


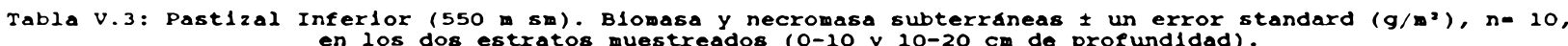

\begin{tabular}{|c|c|c|c|c|c|c|}
\hline FECRU & GRUESAS & S VIVAS & $\begin{array}{l}\text { MATERIA SECA de } \\
\text { FINAS VIVAS }\end{array}$ & $\begin{array}{l}\text { RAICES }\left(g / \mathrm{m}^{2}\right) \\
\text { GROESAS MOERTAS }\end{array}$ & FINAS & MOERTAS \\
\hline \multicolumn{7}{|c|}{ ESTRATO SUPERFICIAL $(0-10 \mathrm{~cm})$} \\
\hline Ju110 10, 1988 & $69,0 \pm$ & 9,0 & $133,8 \pm 18,3$ & $27,4 \pm 11,0$ & 121,6 & $\pm 12,9$ \\
\hline setlembre 30 & $95,3 \pm$ & 15,5 & $166,0 \pm 21,5$ & $31,9 \pm 8,0$ & 33,6 & $\pm 15,1$ \\
\hline octubre 30 & $43,6 \pm$ & 11,8 & $332,9 \pm 23,9$ & $17,4 \pm 6,0$ & 58,0 & $\pm 34,4$ \\
\hline dlclembre 10 & $45,4 \pm$ & 12,3 & $78,7 \pm 17,5$ & $42,8 \pm 11,0$ & 341,9 & $\pm 21,7$ \\
\hline febrero 18,1989 & $64,6 \pm$ & 22,8 & $225,0 \pm 40,7$ & $38,9 \pm 16,0$ & 193,6 & $\pm 32,3$ \\
\hline abrid 4 & $67,6 \pm$ & 12,5 & $296,8 \pm 59,9$ & $30,3 \pm 5,0$ & 84,4 & $\pm 17,2$ \\
\hline mayo 27 & $67,5 \pm$ & 16,3 & $187,4 \pm 32,0$ & $20,2 \pm 7,0$ & 50,8 & $\pm 12,8$ \\
\hline Jul10 11 & $73,3 \pm$ & 20,3 & $114,7 \pm 19,6$ & $15,4 \pm 4,0$ & 100,9 & $\pm 28,6$ \\
\hline ANUAL & $65,8 \pm$ & 5,4 & $191,9 \pm 29,3$ & $28,0 \pm 3,0$ & 123,1 & $\pm 33,6$ \\
\hline ESTRATO PROFUNDO $(10-20$ & $\mathrm{cm})$ & & & & & \\
\hline jul10 10,1988 & $36,0 \pm$ & 7,1 & $101,6 \pm 13,5$ & $22,4 \pm 6,0$ & 93,1 & 7,2 \\
\hline setlembre 30 & $29,4 \pm$ & 3,7 & $86,9 \pm 7,4$ & $8,8 \pm 3,0$ & 5,5 & $\pm \quad 4,8$ \\
\hline octubre 30 & $15,4 \pm$ & 2,2 & $127,7 \pm 10,3$ & $9,5 \pm 4,0$ & 4,4 & 1,0 \\
\hline diclembre 10 & $33,6 \pm$ & 6,7 & $95,8 \pm 14,7$ & $22,2 \pm 5,0$ & 48,4 & $\pm 7,0$ \\
\hline febrero 18,1989 & $17,4 \pm$ & 3,7 & $108,0 \pm 11,7$ & $17,4 \pm 9,0$ & 267,2 & $\pm 28,7$ \\
\hline$a b r 114$ & $34,8 \pm$ & 3,5 & $173,0 \pm 20,4$ & $19,6 \pm 2,0$ & 25,7 & $\pm \quad 3,7$ \\
\hline mayo 27 & $35,6 \pm$ & 5,4 & $183,7 \pm 14,5$ & $4,2 \pm 1,0$ & 19,2 & 9,3 \\
\hline Jul10 11 & $33,0 \pm$ & $\pm \quad 5,6$ & $103,4 \pm 18,4$ & $40,9 \pm 28,0$ & 37,7 & $\pm 6,4$ \\
\hline ANUAL & $29,4 \pm$ & $\pm 2,7$ & $122,5 \pm 12,1$ & $18,1 \pm 3,0$ & 62,6 & $\pm 28,9$ \\
\hline
\end{tabular}

En el estrato de $10-20 \mathrm{~cm}$ de profundidad, el $65 \%$ de la masa son raíces vivas, distribuído en $53 \%$ finas $+12 \%$ gruesas. Las raíces muertas se reparten en $27 \%$ finas $+8 \%$ gruesas (Tabla V.3, Gráfico V.3).

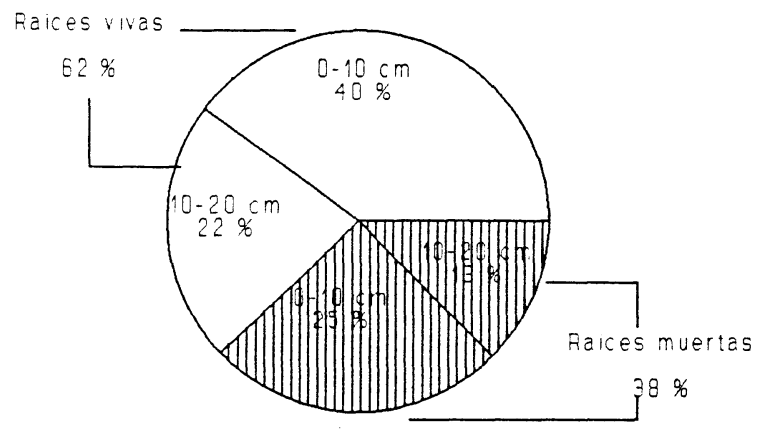

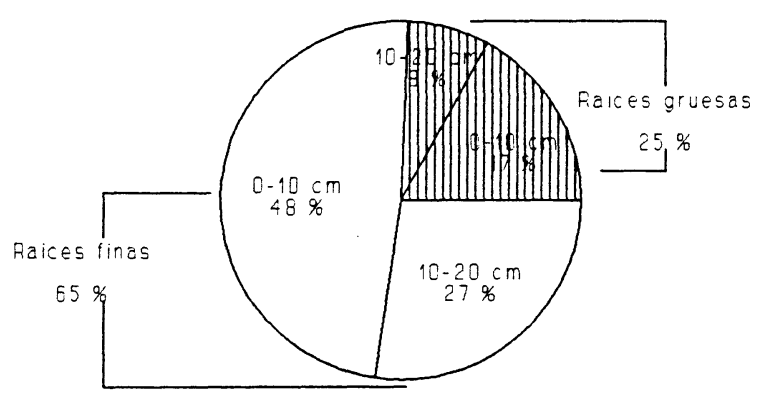
Grafico V.3: Pastizal Inferlor (550 m $\mathrm{sm}$ ). a) Porcentajes de raices vivas y muertas y b) de raices finas y
gruesas en los estratos muestreados (0-10 y $10-20 \mathrm{~cm}$ de profundldad). 
Las raíces vivas en los dos horizontes muestreados alcanzan valores máximos a mediados de primavera y principios de otoño (Gráfico V.4).

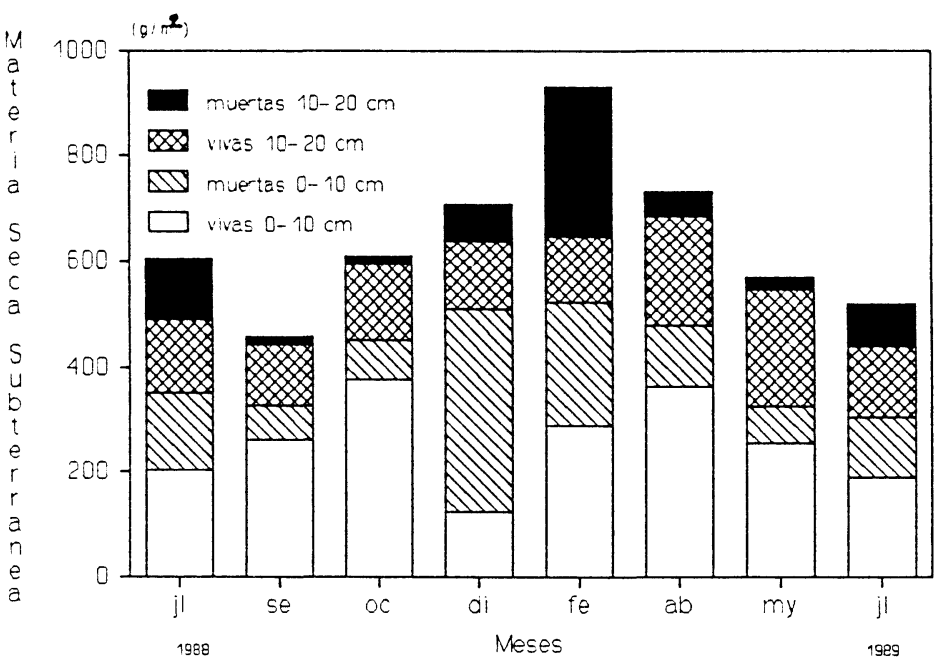

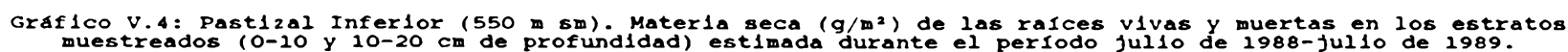

Las raíces muertas presentan un pico marcado a fines de primavera en los primeros $10 \mathrm{~cm}$ de profundidad y durante el verano en los $10 \mathrm{~cm}$ de profundidad siguientes (Gráfico V.4).

\section{2-HOJARASCA}

La mayor acumulación de hojarasca ocurre a fines de febrero. El resto del año presenta poca variación, con un mínimo a principios de diciembre (Tabla V.1, Gráfico V.1).

\section{3-PRODUCTIVIDAD PRIMARIA NETA}

De la productividad anual del pastizal, $1131 \mathrm{~g} / \mathrm{m}^{2}$.año, $41 \%$ corresponden a crecimiento aéreo y $59 \%$ al subterráneo. El $46 \%$ es primaveral y el $54 \%$ restante estivo- otoñal (Tabla V.4). 
Tabla V.4: Productlvidad primarla neta, mortalidad y desaparlción totales (aereas + subterráneas) en el Pastizal Inferlor (550 m sm) durante el perlodo jullo de 1988-jullo de 1989.

\begin{tabular}{|c|c|c|c|c|c|c|c|}
\hline \multirow{2}{*}{ Periodo } & Intervalo & PRODUCTIVIDAD & \multirow{2}{*}{$\begin{array}{l}\text { TOTAL } \\
\left.w^{2} d 1 a\right)\end{array}$} & \multicolumn{2}{|c|}{ MORTALIDAD TOTAL } & DESAPARICION & \multirow{2}{*}{$\begin{array}{r}\text { TOTAL } \\
\left.m^{2} d 10\right) \\
\end{array}$} \\
\hline & de d(as) & $\left(g / m^{2} \ln t\right)$ & & $\left(g / m^{2} \ln t\right)$ & $\left(g / m^{2} d 10\right)$ & $\left(g / m^{2} \ln t\right)$ & \\
\hline jullo-set lembre & 82 & 120,3 & 1,5 & 49,5 & 0,6 & 184,8 & 2,3 \\
\hline set1embre-octubre & 30 & 236,0 & 7,9 & 61,2 & 2,0 & 7,0 & 0,2 \\
\hline octubre-diclembre & 41 & 107,6 & 2,6 & 375,6 & 9,2 & 21,3 & 0,5 \\
\hline diclembre-diclembre & 17 & 58,1 & 3,4 & 57,1 & 3,4 & 0,0 & 0,0 \\
\hline diclembre-febrero & 52 & 168,6 & 3,2 & 87,3 & 1,7 & 21,6 & 0,4 \\
\hline febrero-abr 11 & 45 & 322,5 & 7,2 & 95,3 & 2,1 & 395,8 & 8,8 \\
\hline abr11-mayo & 54 & 118,1 & 2,2 & 216,5 & 4,0 & 163,4 & 3,0 \\
\hline mayo-jul1o & 45 & 0,0 & 0,0 & 176,5 & 3,9 & 64,2 & 1,4 \\
\hline ANOAL & & 1131,2 & & 1219,0 & & 858,1 & \\
\hline
\end{tabular}

De la productividad primaria neta total del pastizal, en la primavera el $66 \%$ es destinado a las raíces y el $44 \%$ restante a las estructuras aéreas; en el verano el $100 \%$ de la productividad es subterránea; en el otoño, el $46 \%$ corresponde a la productividad subterránea y el $64 \%$ a la productividad aérea (Tablas V.5 y V.6).

Las tasas diarias de productividad primaria neta presentan valores elevados a principios de la primavera y del otoño, manteniendo valores más bajos durante el resto del año (Tabla V.4, Gráfico V.5).

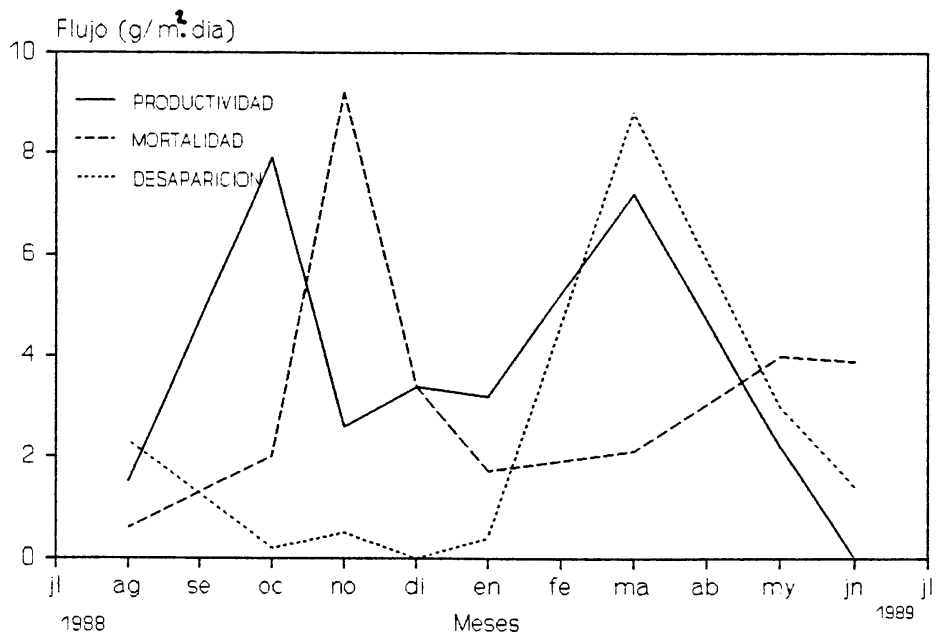

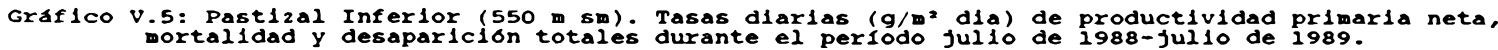




\section{3 a-PRODUCTIVIDAD PRIMARIA AEREA NETA}

La productividad aérea anual es $462 \mathrm{~g} / \mathrm{m}^{2}$.año. El $40 \%$ de la misma se produce durante el período inverno-primaveral y el $60 \%$ restante es estivo-otoñal. La tasa diaria de productividad aérea presenta dos picos poco marcados: uno a principios de primavera y otro a principios del otoño (Tabla V.5, Gráfico V.6).

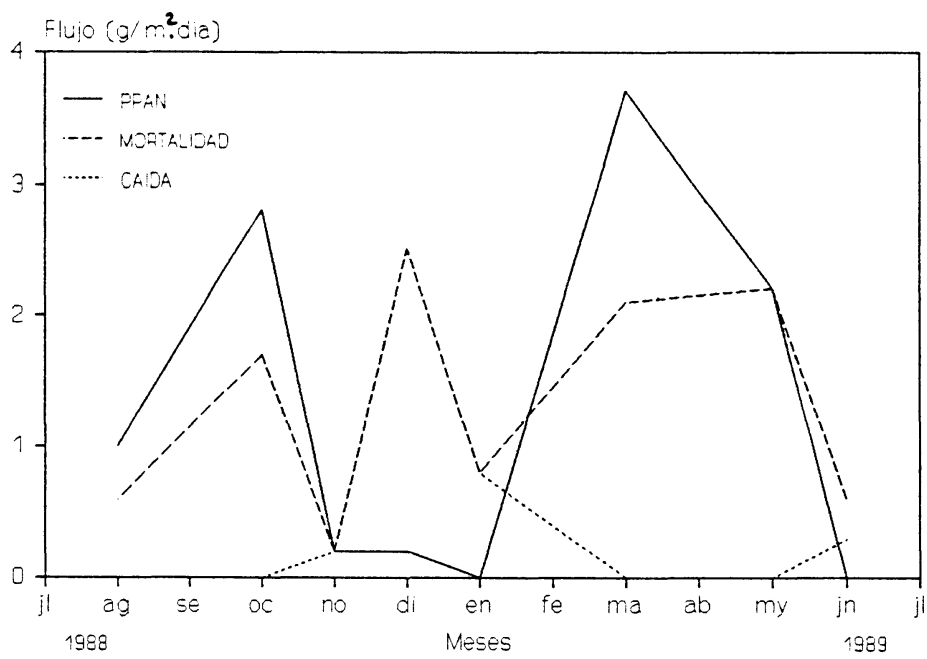

Grafico V.6: Pastizal Inferlor (550 m sm). Tasas diarlas (g/m dia) de productividad primarla neta aerea
(PPNA), mortalidad aerea y calda a la hojarasca durante el perlodo jullo de $1988-j u l 10$ de 1989.

Tabla V.5: Productlvidad primarla neta, mortalldad, calda a la hojarasca y desaparlción aereas en el Pastizal Inforlor (550 m sm) durante el perlodo jullo de 1988 -jullo de 1989.

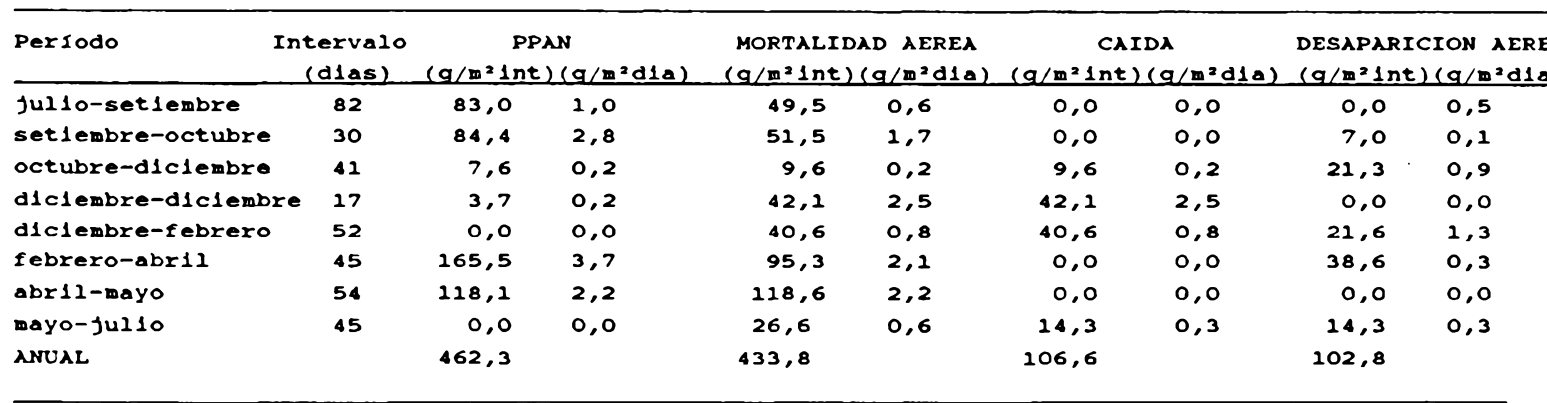




\section{3 b-PRODUCTIVIDAD SUBTERRANEA NETA}

La productividad anual estimada a partir de diferencias de biomasa subterránea es $669 \mathrm{~g} / \mathrm{m}^{2}$. año (Tabla $\mathrm{V} .6$ ) y por el método de cilindros de reemplazo anual es $195 \mathrm{~g} / \mathrm{m}^{2}$.año (Tabla V.7).

La tasa diaria de productividad subterránea presenta un pico a principios de primavera, manteniendo valores importantes a fines de esta estación y durante el verano (Tabla V.7, Gráfico V.7).

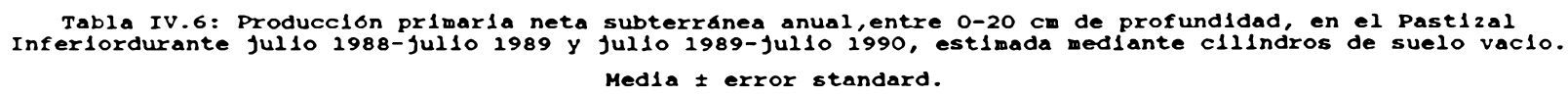

\begin{tabular}{lrr}
\hline Periodo & No de muestras & $\begin{array}{c}\text { PRODUCCION DE RaICes } \\
\left(\mathrm{g} / \mathrm{m}^{2} \cdot \text { ario) }\right.\end{array}$ \\
\hline $1988-1989$ & 5 & $195 \pm 24$ \\
$1989-190$ & 15 & $166 \pm 16$ \\
\hline
\end{tabular}

Tabla IV.7: Productividad primaria neta, mortalldad y desaparicion subterraneas en el Pastizal Medio durante el persodo jullo de 1988 -jullo de 1989 .

\begin{tabular}{|c|c|c|c|c|c|c|c|}
\hline Periodo & $\begin{array}{l}\text { ntervalo } \\
\text { (dias) }\end{array}$ & $\begin{array}{r}\text { PRODUCTIVIDAD } \\
\left(g / m^{2} \text { int }\right)\end{array}$ & $\begin{array}{l}\text { SUBTERRANEA } \\
\left(g / m^{2} d i a\right)\end{array}$ & $\begin{array}{r}\text { MORTALIDAD } \\
\left(\mathrm{g} / \mathrm{m}^{2} \text { Int }\right)\end{array}$ & $\begin{array}{l}\text { SUBTERRANEA } \\
\left(\mathrm{g} / \mathrm{m}^{2} d i \mathrm{a}\right)\end{array}$ & $\begin{array}{r}\text { DESAPARICION } \\
\left(\mathrm{g} / \mathrm{m}^{2} \text { int }\right)\end{array}$ & $\begin{array}{l}\text { SUBTERRANEA } \\
\left(\mathrm{g} / \mathrm{m}^{2} \mathrm{dia}\right)\end{array}$ \\
\hline jullo-setiembre & 82 & 37,3 & 0,5 & 0,0 & 0,0 & 184,8 & 2,3 \\
\hline setiembre-octubre & 30 & 151,6 & 5,1 & 9,7 & 0,3 & 0,0 & 0,0 \\
\hline octubre-diciembre & 41 & 100,0 & 2,4 & 366,0 & 8,9 & 0,0 & 0,0 \\
\hline diclembre-diciembre & e 17 & 54,4 & 3,2 & 25,0 & 0,9 & 0,0 & 0,0 \\
\hline diciembre-febrero & 52 & 168,6 & 3,2 & 46,7 & 0,9 & 0,0 & 0,0 \\
\hline febrero-abr 11 & 45 & 157,0 & 3,5 & 0,0 & 0,0 & 357,2 & 7,9 \\
\hline abril-mayo & 54 & 0,0 & 0,0 & 97,9 & 1,8 & 163,4 & 3,0 \\
\hline mayo-jul1o & 45 & 0,0 & 0,0 & 149,9 & 3,3 & 49,9 & 0,9 \\
\hline ANUAL & & 668,9 & & 685,2 & & 755,3 & \\
\hline
\end{tabular}


En otoño y principios de invierno el crecimiento de las raíces es nulo (Tabla V.7, Gráfico V.7).

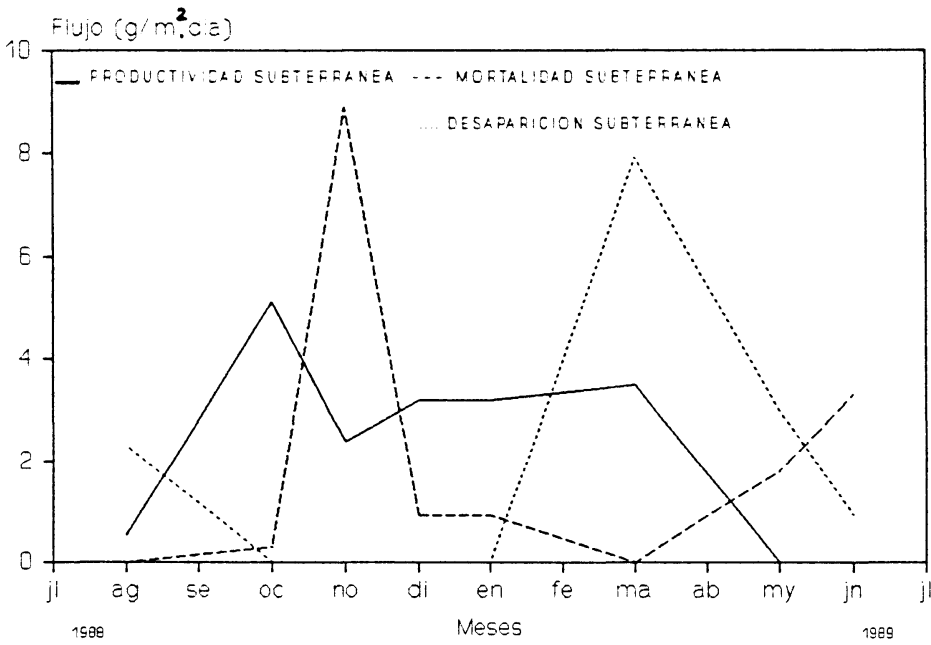

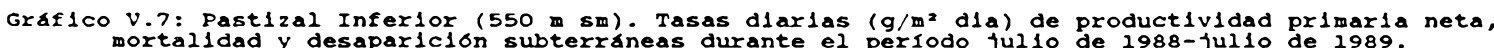

\section{4-MORTALIDAD}

La mortalidad anual es $1119 \mathrm{~g} / \mathrm{m}^{2}$.año, de los cuales 39\% corresponden a mortalidad aérea y $61 \%$ a subterránea (Tabla V.4).

La tasa diaria de mortalidad es muy elevada a mediados de la primavera, disminuye a fines de esta estación y durante el verano. Resulta nula a principios de otoño y se incrementa a mediados del mismo y comienzos del invierno (Tabla V.4, Gráfico V.5).

La tasa diaria de mortalidad aérea alcanza un máximo a fines de primavera y mediados del otoño (Tabla V.5, Gráfico V.6).

La mortalidad subterránea diaria es elevada a fines de primavera y a fines de otoño-principios de invierno (Tabla V.7, Gráfico V.7). 


\section{5-CAIDA A LA HOJARASCA}

Durante el año de muestreo, el material aéreo caído a la hojarasca es $107 \mathrm{~g} / \mathrm{m}^{2}$.año (Tabla V.5).

La tasa diaria de caída a la hojarasca presentan un pico a fines de la primavera, el resto del año los valores son cero o casi cero (Tabla V.5, Gráfico V.6).

\section{6-DESAPARICION DE MATERIAL AEREO Y SUBTERRANEO}

La desaparición anual de material vegetal (aéreo + subterráneo) durante el período de estudios es $858 \mathrm{~g} / \mathrm{m}^{2}$.año, de los cuales $88 \%$ corresponde a desaparición subterránea y los $12 \%$ restantes a desaparición aérea.

La desaparición diaria de material subterráneo es activa a fines del invierno, alcanza un pico a fines del verano-comienzos del otoño, disminuyendo a mediados del otoño-comienzos del invierno (Tabla V.7, Gráfico V.7).

La tasa diaria de desaparición aérea fue baja durante todo el año, los valores más elevados, cercanos a $1 \mathrm{~g} / \mathrm{m}^{2}$.día, ocurren durante la primavera y el verano (Tabla V.5). 


\section{7 - NUTRIENTES}

\section{7 a-CONCENTRACION DE NUTRIENTES}

Las concentraciones más elevadas de $\mathbf{P}, \mathbf{N}, \mathbf{K}$ y $\mathbf{C a}$ se encuentran en la biomasa aérea viva.

En las dicotiledóneas la concentración de nutrientes se ordena de la siguiente manera: $\mathbf{K}$ $>\mathbf{N}>\mathbf{C a}>>\mathbf{P}$. Las concentraciones de $\mathbf{N}$ y de $\mathbf{P}$ disminuyen en el verano, con respecto a las concentraciones inverno-primaverales, y aumentan en el otoño. La concentración de $\mathbf{K}$ muestra una tendencia creciente desde la primavera hacia el otoño. Los valores de Ca, en cambio, disminuyen en ese mismo sentido (Tabla V.8, Gráficos V.8).

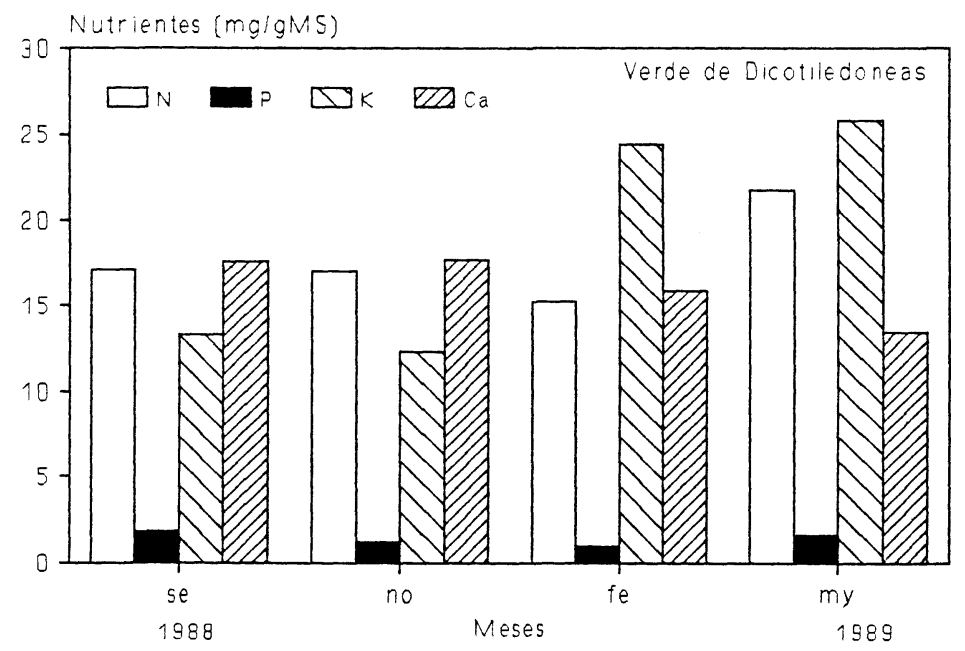

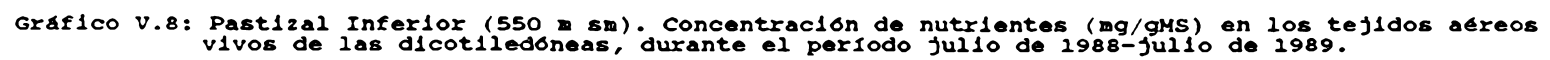

En las gramíneas la concentración de nutrientes presenta el siguiente orden: $K>\mathbf{N}>>$ Ca $>$ P. Dichas concentraciones muestran una tendencia decreciente hacia el verano y alcanzan un máximo en el otoño (Tabla V.8, Gráficos V.9). 


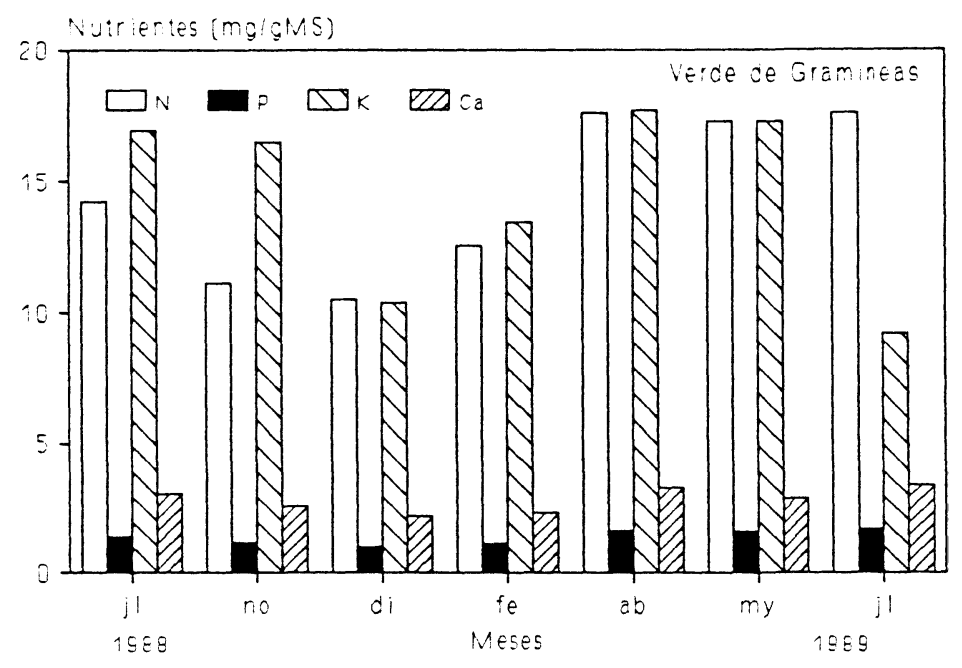

Grafico V.9: Pastizal Inferlor (550msm). Concentración de nutrientes (mg/gms) en los tejldos aereos vivos de las gramineas, durante el periodo jullo de 1988-jullo de 1989.

La concentración de Ca es 5,7 veces mayor en las dicotiledóneas que en las gramíneas. Con respecto a las concentraciones de los otros tres nutrientes considerados no difieren significativamente (test $\mathrm{t}$ de Student, $\mathrm{P}<0,05$ ).

En las estructuras reproductivas el pico de floración que ocurrió a principios de primavera correspondió a la especie anual Vulpia dertonensis. Estas presentan mayores concentraciones de $\mathbf{N}, \mathbf{P}$ y $\mathbf{C a}$ que las de las "flechillas". Con excepción del Ca, que es más elevado en $V$. dertonensis, las concentraciones de nutrientes son mayores en las flores y frutos otoñales, con respecto a los primaverales (Tabla V.8).

En el seco en pie las concentraciones de los nutrientes siguen el orden: $\mathbf{N}>\mathbf{K} \approx$ Ca $>$ P. Las mismas disminuyen desde el invierno de 1988 al verano siguiente, aumentando nuevamente en el invierno de 1989 (Tabla V.8, Gráfico V.10).

Las concentraciones de nutrientes en el seco en pie son menores que en los compartimientos aéreos vivos (3 veces menos de $\mathbf{P}, 5$ veces menos de $\mathbf{K}$ y 2 veces menos de N) (test t de Student $\mathrm{P}<0.05$ ) 
Tabla V.8: Past1zal Inferlor (550 m $\mathrm{sm}$ ). Concentracion de nutrientes (mg/gMs) en los compart1mlentos aéreos. Para el afio se Indica la medla y el error standard.

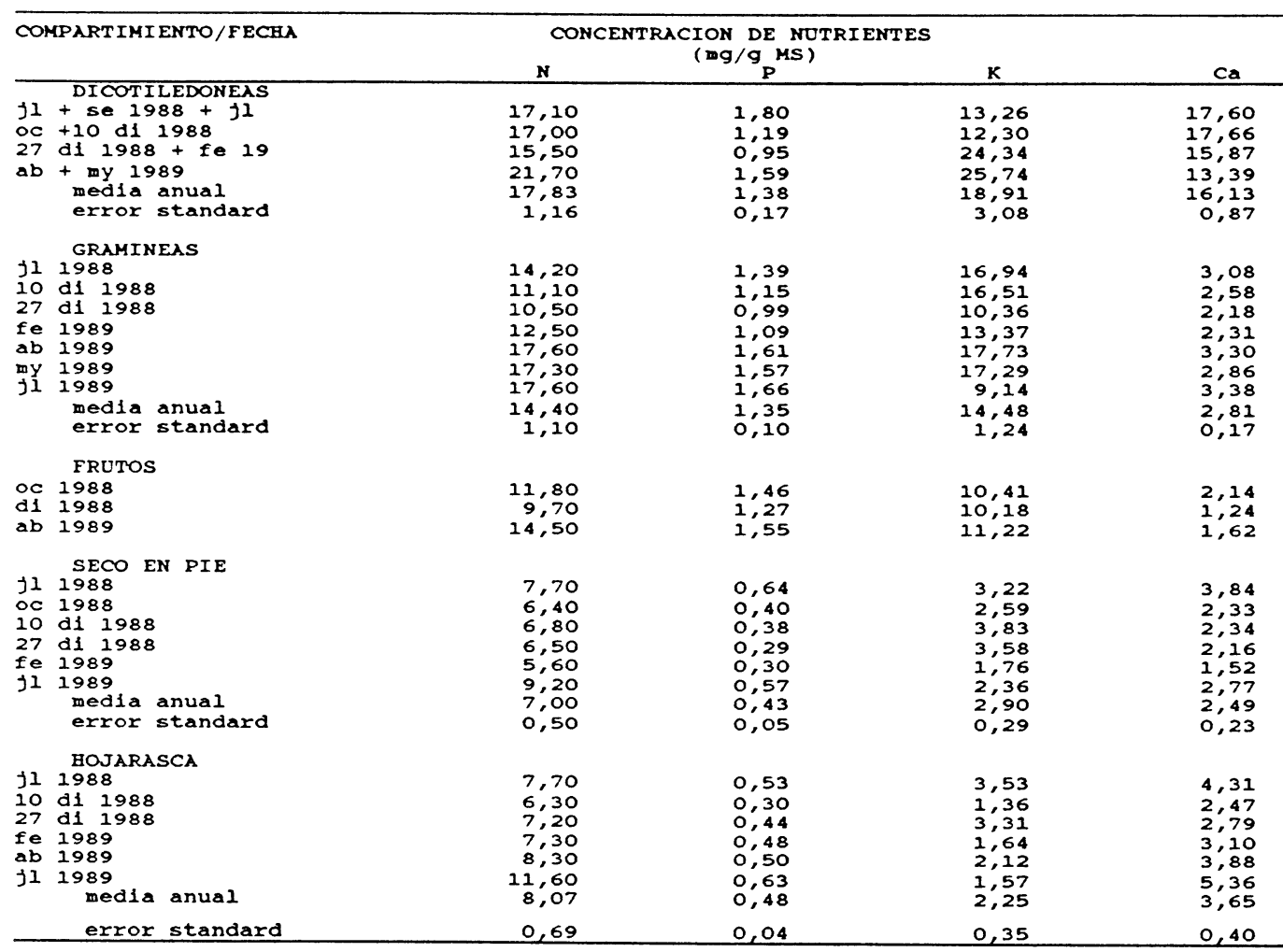

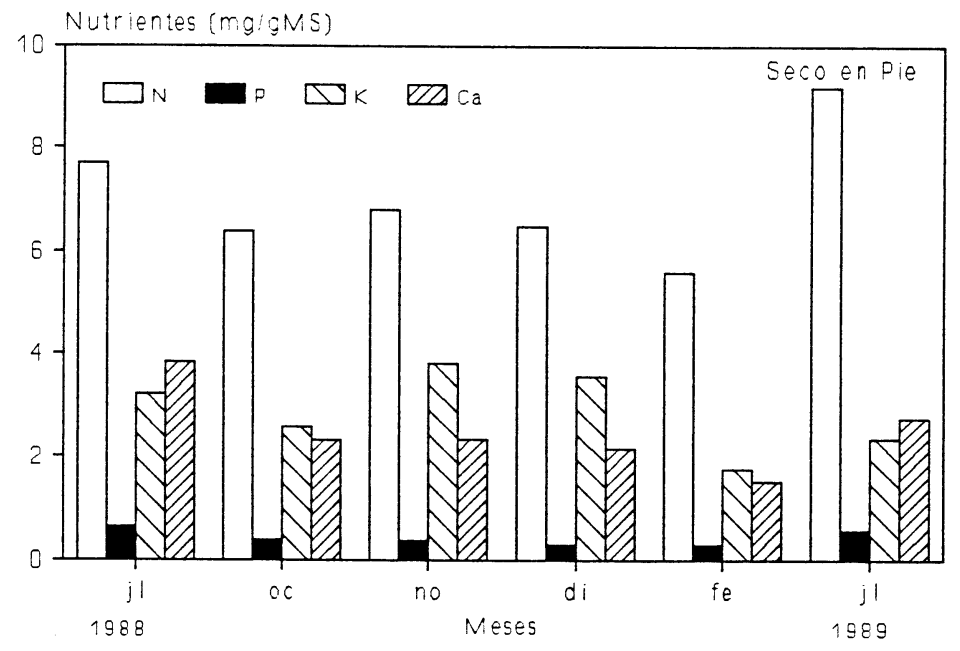

Graflco V.10: Pastizal Inferlor (550 m sm). Concentración de nutrientes (mg/gms) en el seco en ple, durante el perfodo fullo de 1988-jullo de 1989.

En la hojarasca la concentración de nutrientes es: $\mathbf{N}>>$ Ca $>\mathbf{K}>$ P. Este compartimiento presenta concentraciones mínimas de nutrientes a principios de diciembre. A 
fines de ese mes las mismas aumentan, alcanzando un máximo en el caso del $\mathbf{K}$. En los otros tres nutrientes se observa una tendencia creciente, con un máximo en el invierno (Tabla V.8, Gráfico V.11).

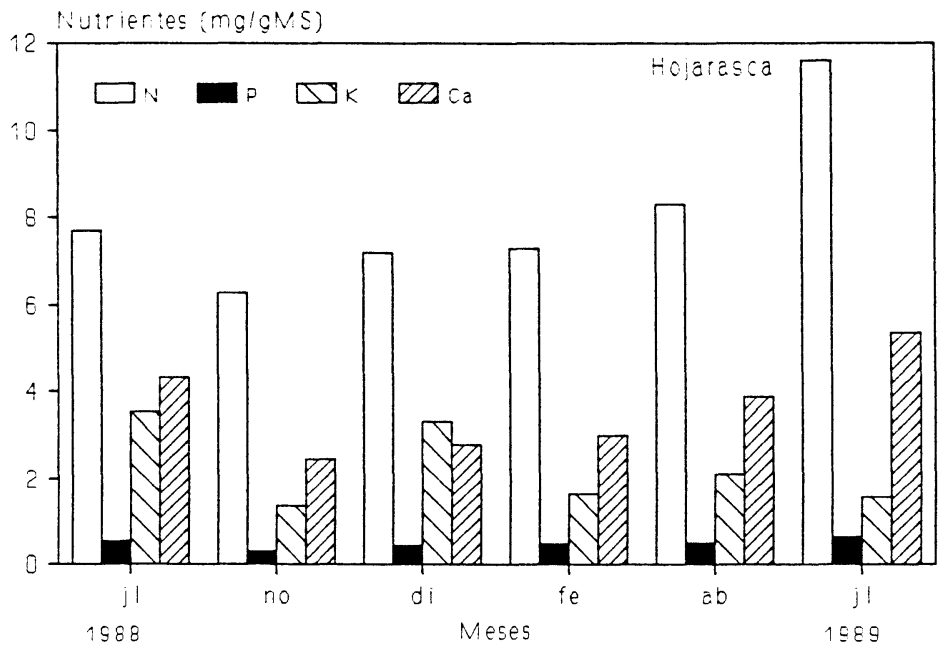

Grafico V.11: Pastizal Inferlor (550 m $\mathrm{sm}$ ). Concentración de nutrientes (mg/gms) en la hojarasca, durante el perlodo jullo de 1988 -jullo de 1989.

En las raíces finas vivas la concentración de nutrientes presenta el siguiente orden: $\mathbf{N}>$ Ca $>>K$ K $>$. Las concentraciones de estos nutrientes disminuyen en la primavera y aumentan a pricipios de otoño, con excepción del $\mathbf{N}$ que mantiene los valores primaverales (Tabla V.9, Gráfico V.12). Las raíces gruesas vivas, presentan concentraciones de $\mathbf{P}$ y $\mathbf{K}$ similares a las de las raíces finas vivas, $\mathbf{y}$ menores de Ca y $\mathbf{N}$ en el orden de 1,5 veces menos de dichos nutrientes (Tabla V.9, Gráfico V.13).

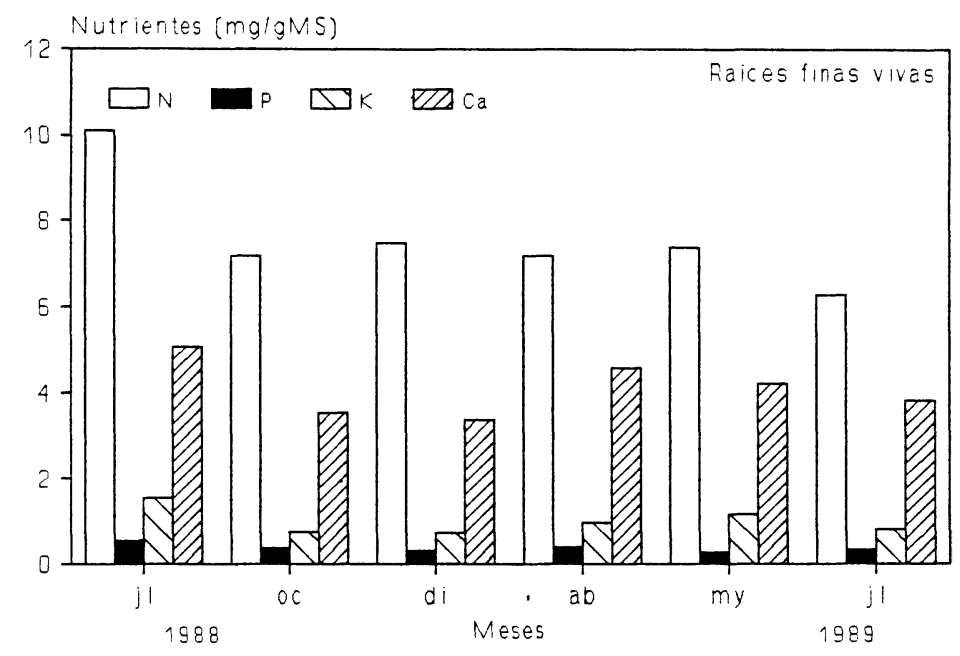

Graflco V.12: Pastizal Inferlor (550 m $\mathrm{sm}$ ). Concentración de nutrientes (mg/gMs) en las ralces f1nas vivas, durante el periodo jullo de 1988 -jullo de 1989 . 


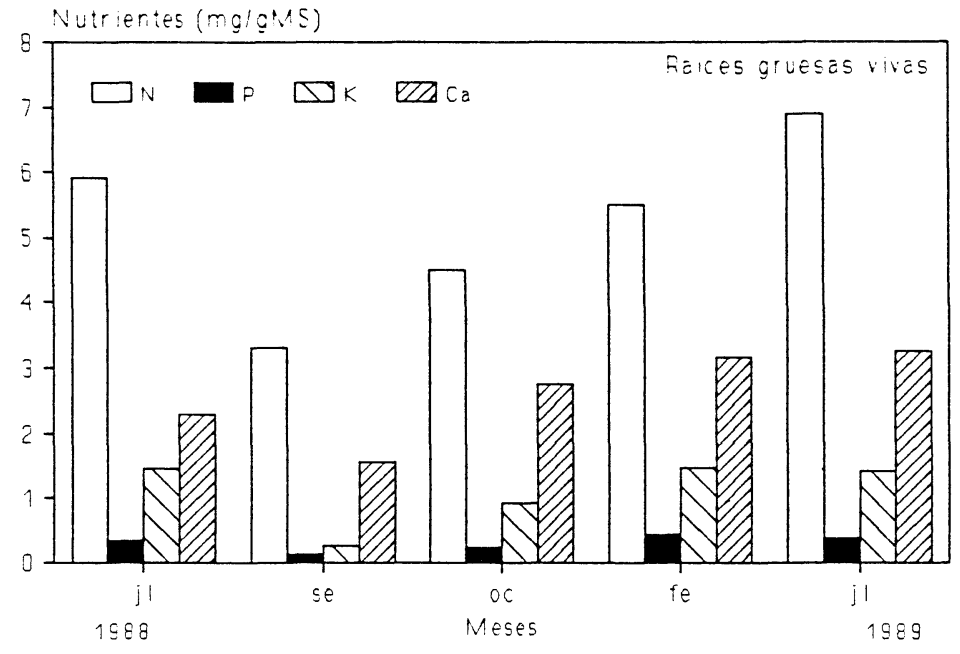

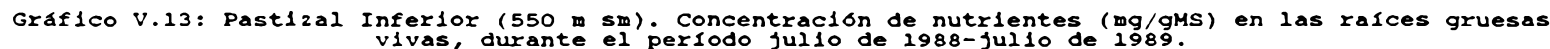

De los compartimientos subterráneos, las raíces finas muertas presentan las concentraciones más elevadas de nutrientes, las cuales se ordenan de la siguiente manera: $\mathbf{N}$

Ca $>\mathbf{K}>\mathbf{P}$, Dichas concentraciones disminuyen a mediados de la primavera. Las mismas, en el caso del $\mathbf{N}$ alcanzan valores máximos en el verano, mientras que en el $\mathbf{P}$ y en el $\mathbf{C a}$, las concentraciones más elevadas ocurren a fines de la primavera. El $\mathbf{K}$, mantiene valores cercanos a los primaverales durante todo el año. Las raíces muertas, finas y gruesas presentan concentraciones similares de nutrientes (Tabla V.9, Gráficos V.14). 
Tabla V.9: Pastlial Inferlor (550 $\mathrm{mm}$ ). Concentracion de nutrientes (mg/gms) en los compartimlentos subterraneos. Para el ano se indica la medla y el error standard.

\begin{tabular}{|c|c|c|c|c|c|}
\hline \multirow{2}{*}{\multicolumn{2}{|c|}{ COMPARTIMIENTO/FECHA }} & \multicolumn{3}{|c|}{$\begin{array}{c}\text { CONCENTRACION DE NUTRIENTES } \\
(\mathrm{mg} / \mathrm{g} M S)\end{array}$} & \multirow[b]{2}{*}{ ca } \\
\hline & & $\mathbf{N}$ & $P$ & $\mathrm{x}$ & \\
\hline $\begin{array}{l}\text { J1 } \\
\text { oc } \\
\text { di } \\
\text { ab } \\
\text { my } \\
\text { J1 } \\
\text { I }\end{array}$ & $\begin{array}{l}\text { RAICES FINAS VIVAS } \\
1988 \\
1988 \\
1988 \\
1989 \\
1989 \\
1989 \\
\text { medla anual } \\
\text { error standard }\end{array}$ & $\begin{array}{r}10,10 \\
7,20 \\
7,50 \\
7,20 \\
7,40 \\
6,30 \\
7,62 \\
0,50\end{array}$ & $\begin{array}{l}0,54 \\
0,37 \\
0,31 \\
0,38 \\
0,27 \\
0,32 \\
0,37 \\
0,04\end{array}$ & $\begin{array}{l}1,54 \\
0,74 \\
0,72 \\
0,96 \\
1,16 \\
0,80 \\
0,99 \\
0,12\end{array}$ & $\begin{array}{l}5,06 \\
3,54 \\
3,39 \\
4,56 \\
4,21 \\
3,83 \\
4,10 \\
0,24\end{array}$ \\
\hline $\begin{array}{l}\text { yl } \\
\text { se } \\
\text { di } \\
\text { fe } \\
\text { my }\end{array}$ & $\begin{array}{l}\text { RAICES FINAS MOERTAS } \\
1988 \\
+ \text { OC } 1988 \\
1988 \\
1989 \\
+ \text { J1 } 1989 \\
\text { med1a anual } \\
\text { error standard }\end{array}$ & $\begin{array}{r}10,90 \\
8,00 \\
10,10 \\
12,20 \\
10,90 \\
10,42 \\
0,62\end{array}$ & $\begin{array}{l}0,52 \\
0,47 \\
0,56 \\
0,58 \\
0,52 \\
0,53 \\
0,02\end{array}$ & $\begin{array}{l}1,65 \\
0,95 \\
1,02 \\
1,12 \\
1,06 \\
1,16 \\
0,11\end{array}$ & $\begin{array}{l}5,87 \\
6,54 \\
6,57 \\
6,18 \\
6,23 \\
6,28 \\
0,12\end{array}$ \\
\hline $\begin{array}{l}\text { jl } \\
\text { se } \\
\text { oc } \\
\text { fe } \\
\text { j1 }\end{array}$ & $\begin{array}{l}\text { RAICES GRUESAS VIVAS } \\
1988 \\
1988 \\
1988 \\
1988 \\
1989 \\
\text { medla anual } \\
\text { error standard }\end{array}$ & $\begin{array}{l}5,90 \\
3,30 \\
4,50 \\
5,50 \\
6,90 \\
5,22 \\
0,55\end{array}$ & $\begin{array}{l}0,34 \\
0,12 \\
0,24 \\
0,43 \\
0,38 \\
0,30 \\
0,05\end{array}$ & $\begin{array}{l}1,45 \\
0,26 \\
0,92 \\
1,47 \\
1,41 \\
1,10 \\
0,21\end{array}$ & $\begin{array}{l}2,31 \\
1,56 \\
2,76 \\
3,16 \\
3,25 \\
2,61 \\
0,28\end{array}$ \\
\hline 912 & $\begin{array}{l}\text { RAICES GRUESAS MUERTAS } \\
1988 \text { a JI } 1989\end{array}$ & 9,90 & 0,32 & 1,17 & 7,39 \\
\hline
\end{tabular}

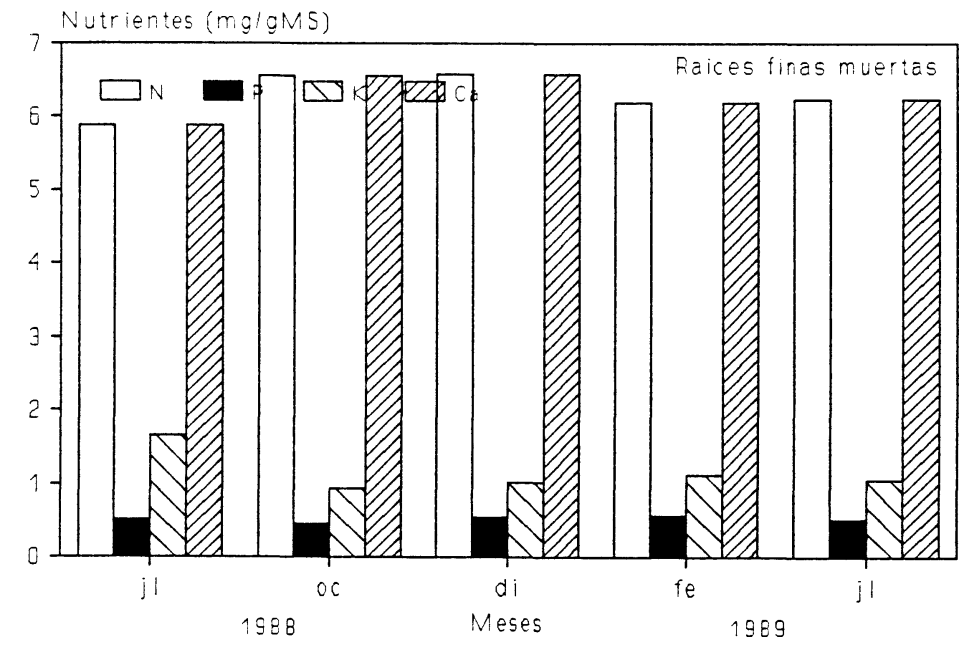

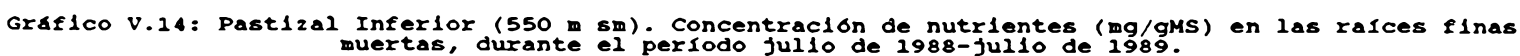

\section{7 b-ALMACENAJE MINERAL}

Los almacenajes de nutrientes en la materia seca presentan el siguiente orden : $\mathbf{N}>\mathbf{C a}$

$>\mathbf{K}>>\mathbf{P}$ y son respectivamente $11,5,4$ y $0,67 \mathrm{~g} / \mathrm{m}^{2}$. En los compartimientos aéreos 
se encuentran el $46 \%$ del $\mathbf{N}(19 \%$ en la biomasa viva, $24 \%$ en el seco en pie y $3 \%$ en la hojarasca), el $56 \%$ del P (29\% en la biomasa viva y $28 \%$ en el seco en pie), el $83 \%$ del $\mathbf{K}$ ( $57 \%$ en los compartimientos vivos, $24 \%$ en el seco en pie y $3 \%$ en la hojarasca) y el $32 \%$ del Ca ( $10 \%$ en el vivo, $18 \%$ en el seco en pie y $3 \%$ en la hojarasca). En las raíces, $31 \%$ del Ca se encuentran en las raíces vivas y $37 \%$ en las muertas. El P, K y $\mathbf{N}$ se distribuyen respectivamente, $22 \%, 10 \%$ y $26 \%$ en las raíces vivas y $22 \%, 8 \%$ y $28 \%$ en las muertas. Del almacenaje mineral total, las mineralomasas aérea + subterránea constituyen el $45 \%$ del $\mathbf{N}$, el $51 \%$ del P, el $63 \%$ del $\mathbf{K}$ y el $41 \%$ del Ca. Los porcentajes complementarios corresponden a los necronutrientes (Tablas V.10 y V.11).

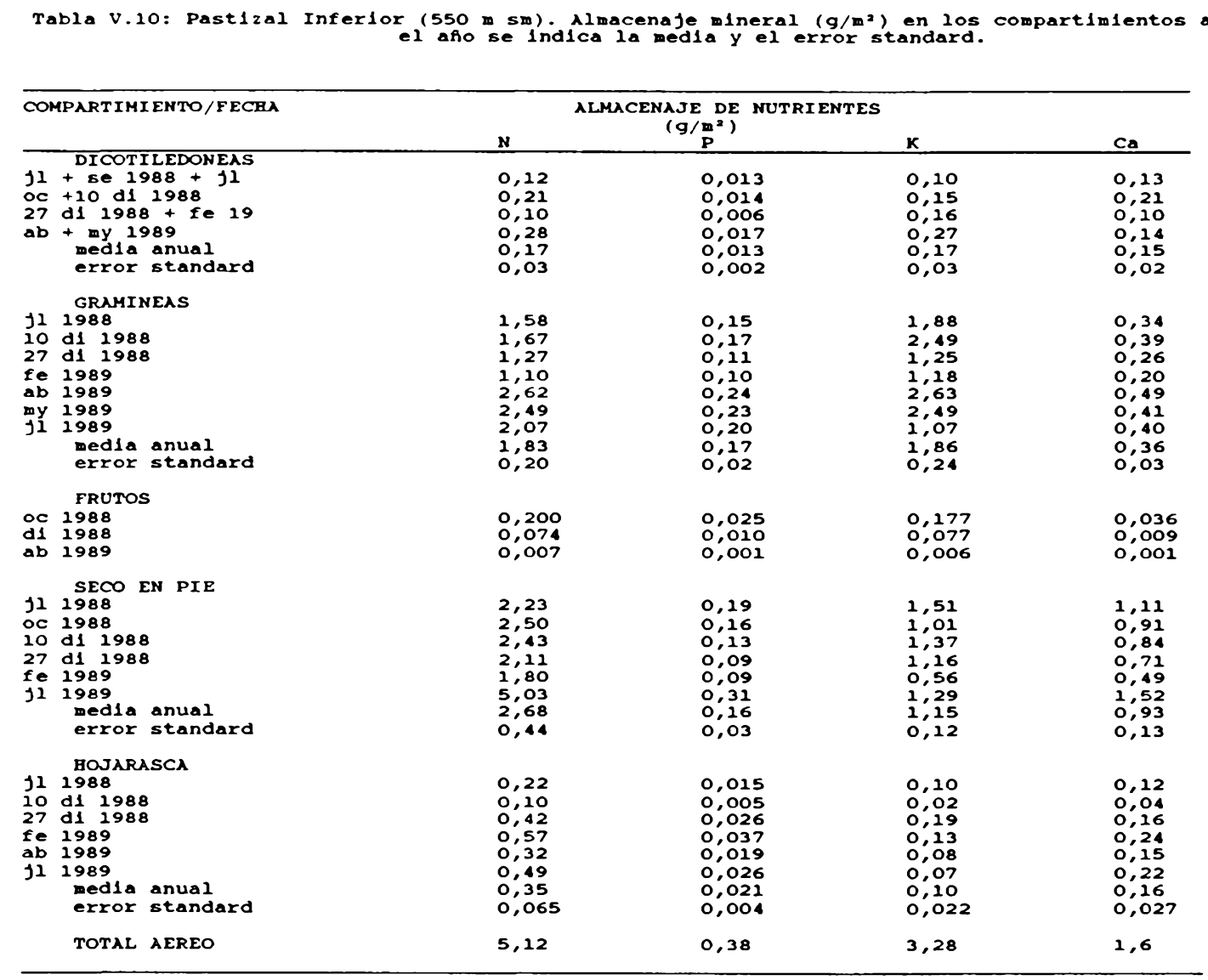

Del almacenaje mineral aéreo las dicotiledóneas representan el 3\% del P y del N, 5\% del K y $9 \%$ del Ca; las gramíneas más sus estructuras reproductivas constituyen el $48 \%$ del $\mathbf{P}$, $38 \%$ del $\mathbf{N}, 60 \%$ del $\mathbf{K}$ y $23 \%$ del $\mathbf{C a}$; el seco en pie representa el $43 \%$ del $\mathbf{P}$, el $52 \%$ del $\mathbf{N}$, el $32 \%$ del $\mathbf{K}$ y el $58 \%$ del $\mathbf{C a}$; la hojarasca comprende el $6 \%$ del $\mathbf{P}$, el $7 \%$ del $\mathbf{N}$, el $3 \%$ del $\mathbf{K}$ y el $10 \%$ del Ca. 


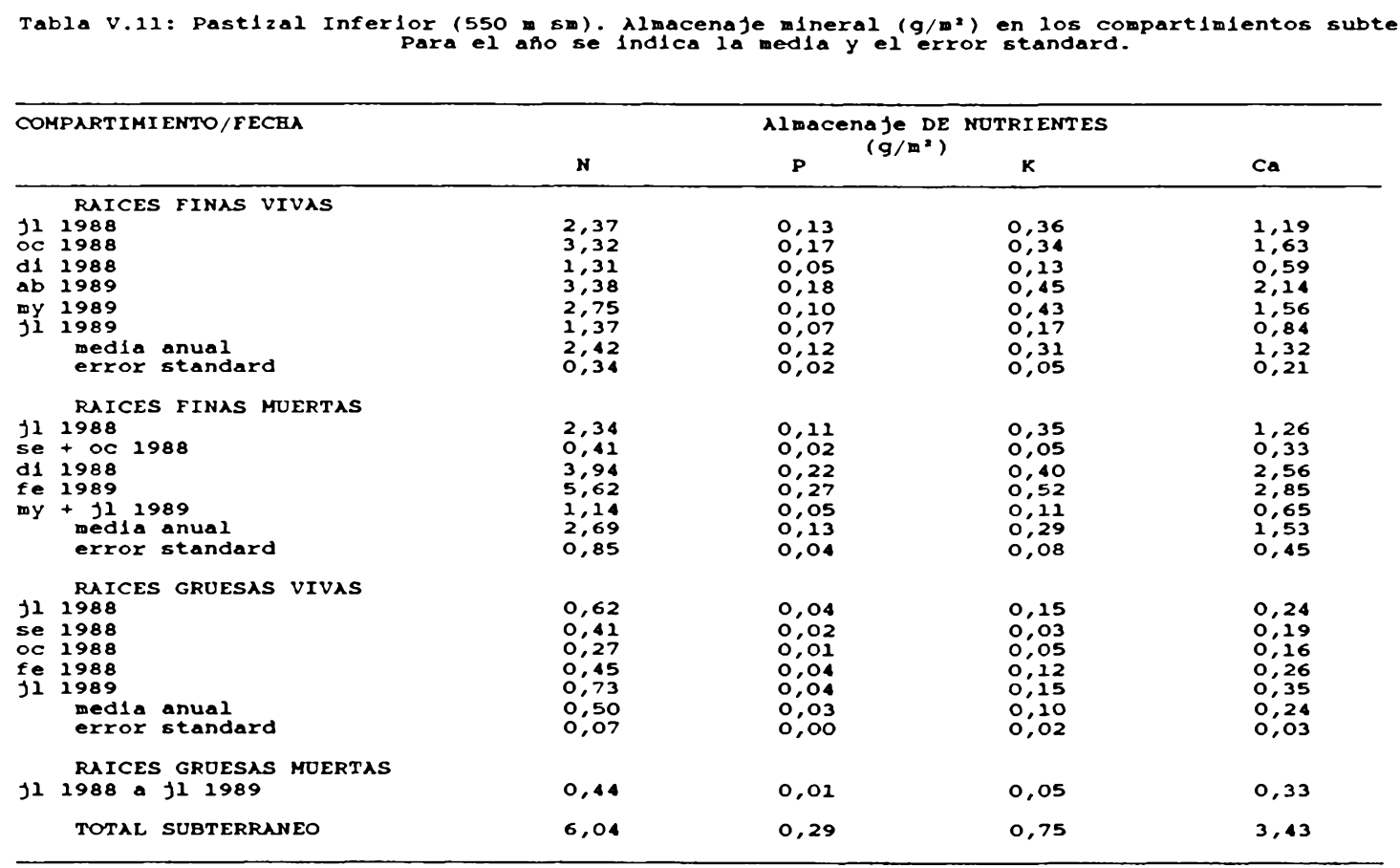

\section{7 c-SUELOS}

A los suelos de este pastizal se los define, de acuerdo con clasificaciones de Arens y Etchevere (1966), como suelos de textura franca, con gravillas, someros, con un pH que es medianamente ácido. El porcentaje de saturación con bases y la capacidad de intercambio catiónico son altos. Presenta elevado contenido de materia orgánica y el nitrógeno se encuentra dentro de los valores medios citados para suelos de pastizal (Fassbender 1982). El cociente $\mathrm{C} / \mathrm{N}$ es alto para horizontes superficiales de suelos de pastizal (Arens y Etchevere 1966, Duchaufour 1965). Esta caracterización de los suelos del pastizal basal es coincidente con la descripción de los mismos, realizada con anterioridad por Frangi et al. (1980a). Este suelo se denomina Hapludol lítico (Soil Survey Staff 1990), caracterizado por presentar un horizonte superficial mólico y contacto lítico en los primeros $50 \mathrm{~cm}$ de profundidad (Tabla V.12). 


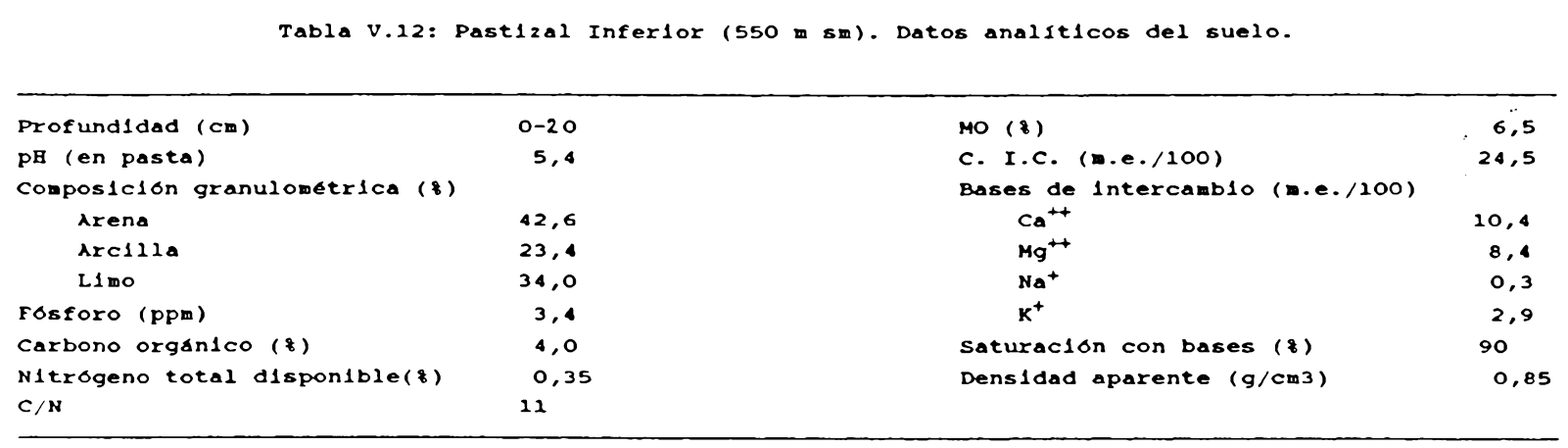

\section{7 d- MINERALIZACION}

La mineralización desde la hojarasca en orden decreciente es: $0,83 \mathrm{gN} / \mathrm{m}^{2}$.año, 0,37 $\mathrm{gCa} / \mathrm{m}^{2}$.año, $0,19 \mathrm{gK} / \mathrm{m}^{2}$. año y $0,05 \mathrm{gP} / \mathrm{m}^{2}$ año. La liberación anual de nutrientes al suelo desde las raíces es mayor en un orden de magnitud con respecto a la hojarasca, pero se mantiene la misma secuencia de mayor a menor entre nutrientes: $5 \mathrm{gN} / \mathrm{m}^{2}$.año, 3 $\mathrm{gCa} / \mathrm{m}^{2}$.año, $0,76 \mathrm{gK} / \mathrm{m}^{2}$.año y $0,3 \mathrm{gP} / \mathrm{m}^{2}$.año.

\section{7 e- CICLO DE LA MATERIA SECA, MATERIA ORGANICA Y NUTRIENTES}

Ciclo de la materia seca y de la materia orgánica (Gráfico V.15)

La biomasa total (aérea + subterránea) representa el $45 \%$ de la materia seca del pastizal ( $12 \%$ biomasa aérea $+33 \%$ biomasa subterránea). El $55 \%$ correspondiente a la necromasa se reparte en $32 \%$ en el seco en pie $+19 \%$ en las raíces muertas $+3 \%$ en la hojarasca. De la productividad aérea anual, el $94 \%$ se incorporó al seco en pie mediante la mortalidad aérea, pero sólo el $25 \%$ de la misma fue transferida al suelo, a través de la caída a la hojarasca. En las raíces, la mortalidad anual superó a la productividad en un $15 \%$, lo que se refleja en la disminución en la biomasa subterránea. El $96 \%$ del material vegetal aéreo y el $100 \%$ de las raíces que retornaron al suelo durante el período de muestreo, desaparecieron como tales durante el mismo. 


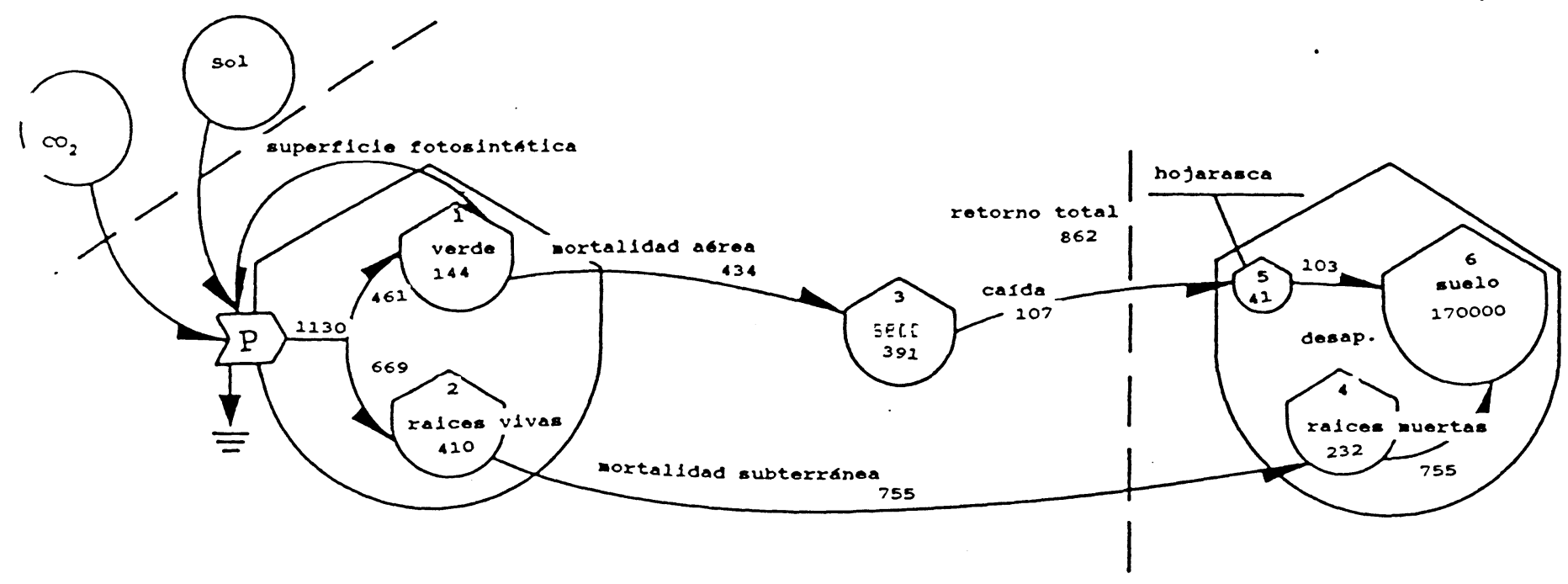

b

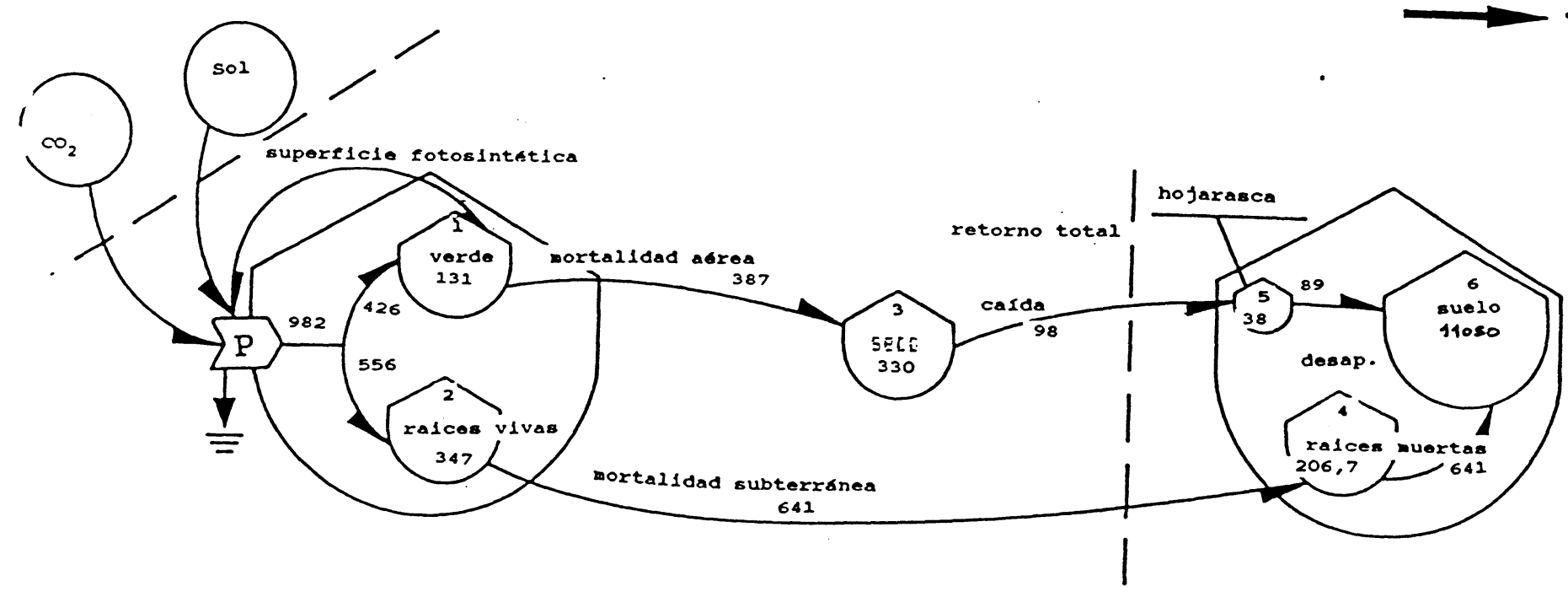

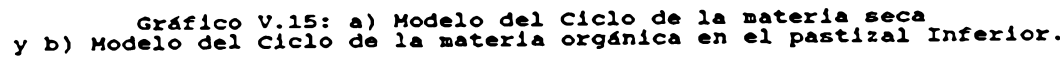


Los requerimientos de $\mathbf{P}$ de la vegetación que satisfacieron la productividad total fueron $0,92 \mathrm{gP} / \mathrm{m}^{2}$.año. El $47 \%$ de los mismos procedieron de la retranslocación de nutrientes.

De los requerimientos totales, el $74 \%$ intervino en la productividad aérea y el $26 \%$ en la productividad de las raíces.

A partir de la mortalidad aérea se incorporaron al seco en pie el equivalente al $24 \%$ del $\mathrm{P}$ requerido anualmente en la productividad aérea. El retorno aéreo a través de la caida a la hojarasca representó el 53\% del $\mathrm{P}$ involucrado en la mortalidad aérea, quedando retenidos en el seco en pie $0,12 \mathrm{gP} / \mathrm{m}^{2}$.año durante el año 1988-1989.

El retorno total de $\mathbf{P}$ desde la vegetación fue $0,45 \mathrm{gP} / \mathrm{m}^{2}$.año, de los cuales el $80 \%$ llegan al suelo a través de la via de los detritos ( $60 \%$ proveniente de las raíces) y el $20 \%$ restante fue lavado desde los tejidos aéreos vivos pasando directamente al suelo. Al mismo se incorporaron por mineralización $0,32 \mathrm{gP} / \mathrm{m}^{2}$.año, de los cuales el $82 \%$ fue aportado por la liberación de nutrientes del material subterráneo.

El balance de $\mathbf{P}$ en el suelo (retorno menos absorción), arrojó un saldo negativo de 0,04 $\mathrm{gP} / \mathrm{m}^{2}$.año, los cuales quedarían comprendidos dentro del $\mathrm{P}$ que se acumuló en el seco en pie. Además por depositación atmosférica ingresaron al pastizal $0,024 \mathrm{gP} / \mathrm{m}^{2}$.año, por lo cual el presupuesto de $\mathrm{P}$ quedaría balanceado dentro del mismo año, a pesar de la cantidad de este nutriente que es almacenado en el seco en pie. 


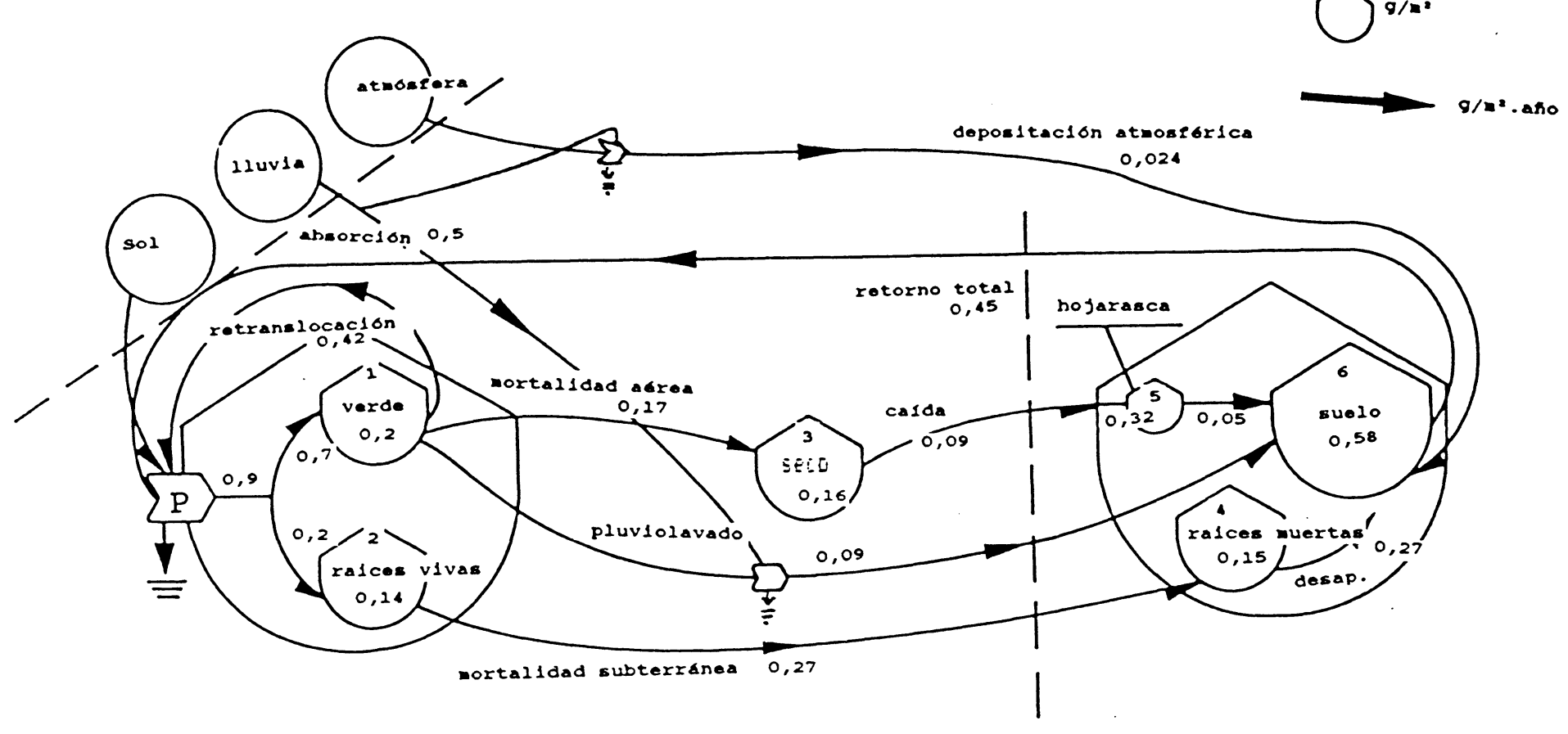

Graflco V.16: Modelo del clclo del fosforo en el pastizal Inferlor. 1: mineralomasa aerea, 2:

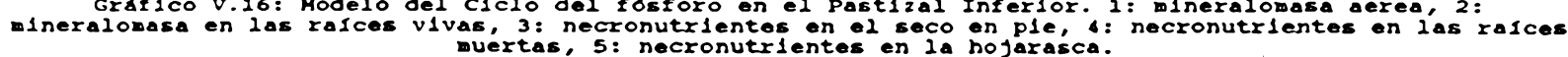

\section{Ciclo del Nitrógeno (Gráfico V.17)}

Los requerimientos totales de $\mathbf{N}$ de la vegetación fueron $12,05 \mathrm{gN} / \mathrm{m}^{2}$.año, la retranslocación satisfizo el $31 \%$ de los mismos.

Con respecto a los requerimientos totales de $\mathbf{N}$, se utilizó para la productividad aérea el $60 \%$ del mismo y el $40 \%$ para la productividad de las raíces.

Se observó una acumulación de $2,8 \mathrm{gN} / \mathrm{m}^{2}$.año en el seco en pie durante el año de estudio. Se incorporaron al mismo a través de la mortalidad aérea $2,9 \mathrm{gN} / \mathrm{m}^{2}$. año mientras que el retorno por esta via fue $1,5 \mathrm{gN} / \mathrm{m}^{2}$.año.

El retorno total fue $7,7 \mathrm{gN} / \mathrm{m}^{2}$.año, de los cuales el $85 \%$ fue aportado por los detritos vegetales $(14 \%$ aéreo $+71 \%$ subterráneo) y el $15 \%$ restante por pluviolavado de la biomasa aérea.

La incorporación de nitrógeno al suelo proveniente de la mineralización fue 6,33 $\mathrm{gN} / \mathrm{m}^{2}$.año, de los cuales $15 \%$ resultaron de la mineralización aérea y $85 \%$ de la mineralización subterránea. 
El balance de $\mathbf{N}$ en el suelo, egresos menos ingresos provenientes de la vegetación, da un resultado negativo de $0,67 \mathrm{gN} / \mathrm{m}^{2}$.año. Esta diferencia se encontraría contenida en la acumulación señalada en el seco en pie y se atenua si se considera la depositación atmosférica de $0,12 \mathrm{gN} / \mathrm{m}^{2}$.año, durante el período de estudios.

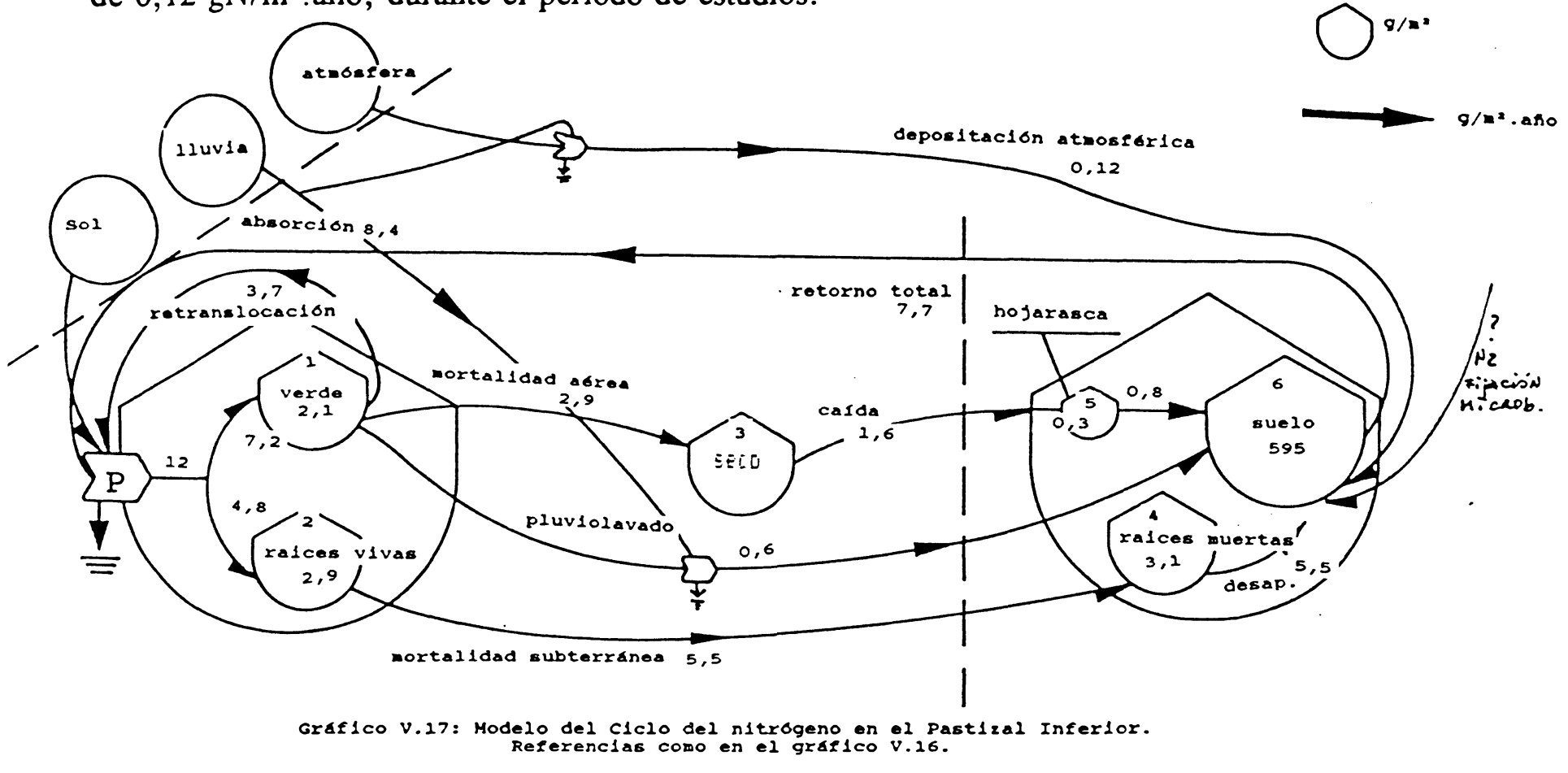

Ciclo del Potasio (Gráfico V.18)

Los requerimientos totales de $\mathbf{K}$ del pastizal necesarios para la productividad primaria neta fueron $8,42 \mathrm{gK} / \mathrm{m}^{2}$.año, de los cuales el $73 \%$ fueron satisfechos por retranslocación.

Del requerimiento total, se necesitó en la productividad aérea el $93 \%$ del $\mathbf{K}$, mientras que en la productividad subterránea se empleó el $7 \%$ restante.

El K mostró una tendencia acumulativa en el seco en pie en el año 1988-1989 (0,26 $\mathrm{gK} / \mathrm{m}^{2}$.año). Por medio de la mortalidad aérea ingresaron al mismo $1,02 \mathrm{gK} / \mathrm{m}^{2}$. año, mientras que retornaron al suelo $0,51 \mathrm{gK} / \mathrm{m}^{2}$. año a través de la caída a la hojarasca y $0,25 \mathrm{gK} / \mathrm{m}^{2}$.año por el pluviolavado de este compartimiento.

El retorno total de $\mathrm{K}$ es $2,2 \mathrm{gK} / \mathrm{m}^{2}$.año, de los cuales $58 \%$ provinieron de los detritos 
vegetales ( $24 \%$ del material aéreo y $34 \%$ del subterráneo) el $42 \%$ restante llega al suelo a través del pluviolavado de los tejidos aéreos en pie.

La mineralización de $\mathrm{K}$ fue $0,94 \mathrm{gK} / \mathrm{m}^{2}$.año, de ellos $19 \%$ procedieron de la mineralización de la hojarasca y $81 \%$ de las raíces.

El balance de $\mathbf{K}$ en el suelo, proveniente de la vegetación, da un resultado negativo de $0,06 \mathrm{gK} / \mathrm{m}^{2}$.año, los cuales serían compensados por la depositación atmosférica de $\mathrm{K}$ la cual fue $0,2 \mathrm{gK} / \mathrm{m}^{2}$.año durante el período de estudios.
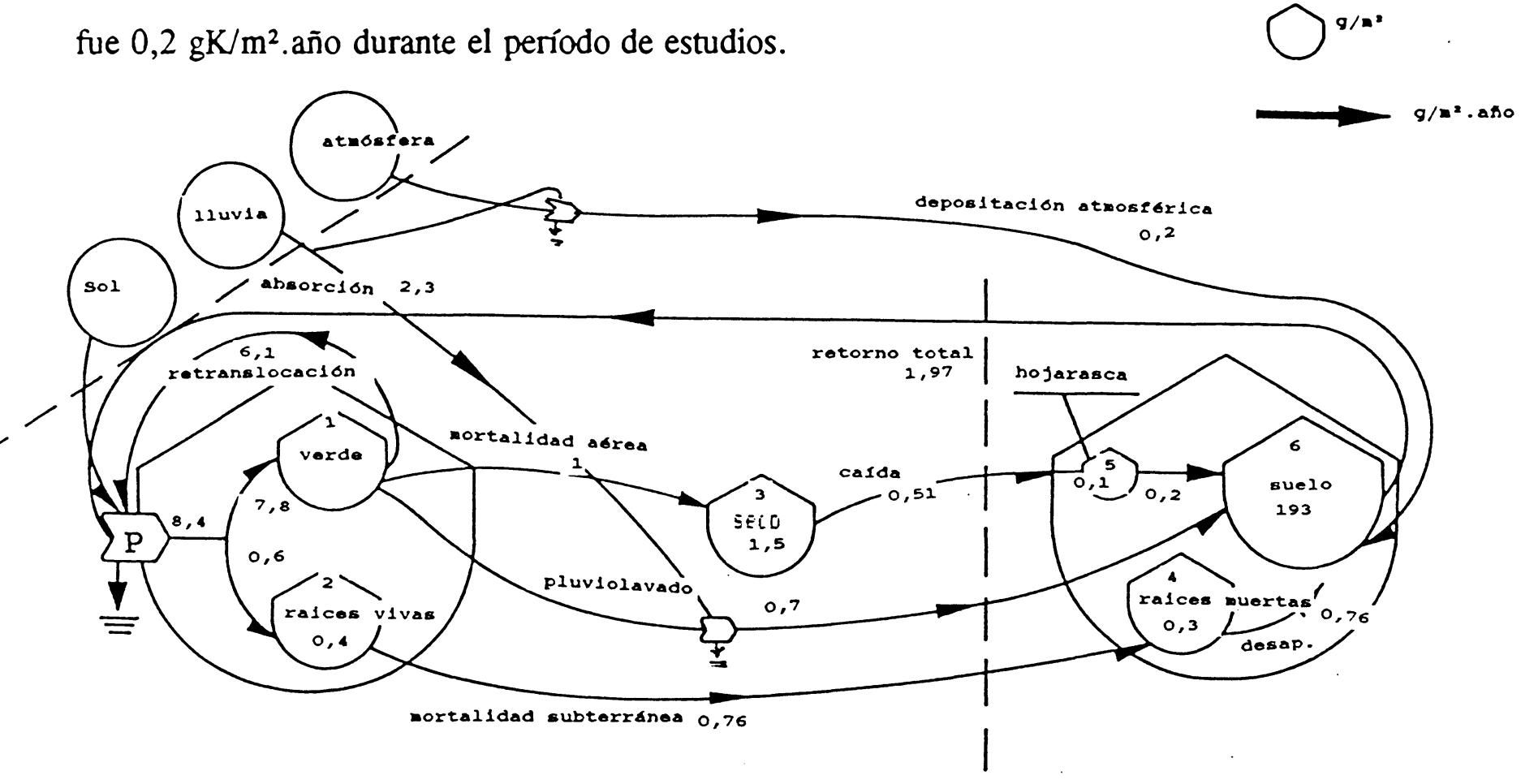

Graflco V.18: Modelo del clelo del potaslo en el pastizal Inferlor. Referenclas como en el graflco v.l6

\section{Ciclo del Calcio (Gráfico V.19)}

Los requerimientos totales de $\mathrm{Ca}$ en la productividad del pastizal fueron $4,14 \mathrm{gCa} / \mathrm{m}^{2}$.año, los cuales fueron satisfechos por completo por absorción.

De los requerimientos totales de $\mathrm{Ca}$, se necesitó el $38 \%$ en la productividad aérea y el $62 \%$ en la subterránea.

Por medio de la mortalidad aérea se incorporó al seco en pie $0,92 \mathrm{gCa} / \mathrm{m}^{2}$.año, de los cuales $0,40 \mathrm{gCa} / \mathrm{m}^{2}$. año se acumularon en dicho compartimiento. El retorno aéreo durante 
el año de estudio fue $0,47 \mathrm{gCa} / \mathrm{m}^{2}$. año.

El retorno total de Ca fue $3,66 \mathrm{gCa} / \mathrm{m}^{2}$.año, el cual provino en un $87 \%$ de las raíces.

La incorporanción al suelo de Ca por mineralización fue $3,56 \mathrm{gCa} / \mathrm{m}^{2}$.año $(90 \%$ procedieron de las raíces). El balance de los ingresos-egresos de Ca en el suelo provenientes de la vegetación da un déficit de $0,48 \mathrm{gCa} / \mathrm{m}^{2}$.año, que se corresponden con la cantidad acumulada en el seco en pie. La depositación de Ca desde la atmosféra es $0,7 \mathrm{gCa} / \mathrm{m}^{2}$.año, con lo cual se supera dicha diferencia.

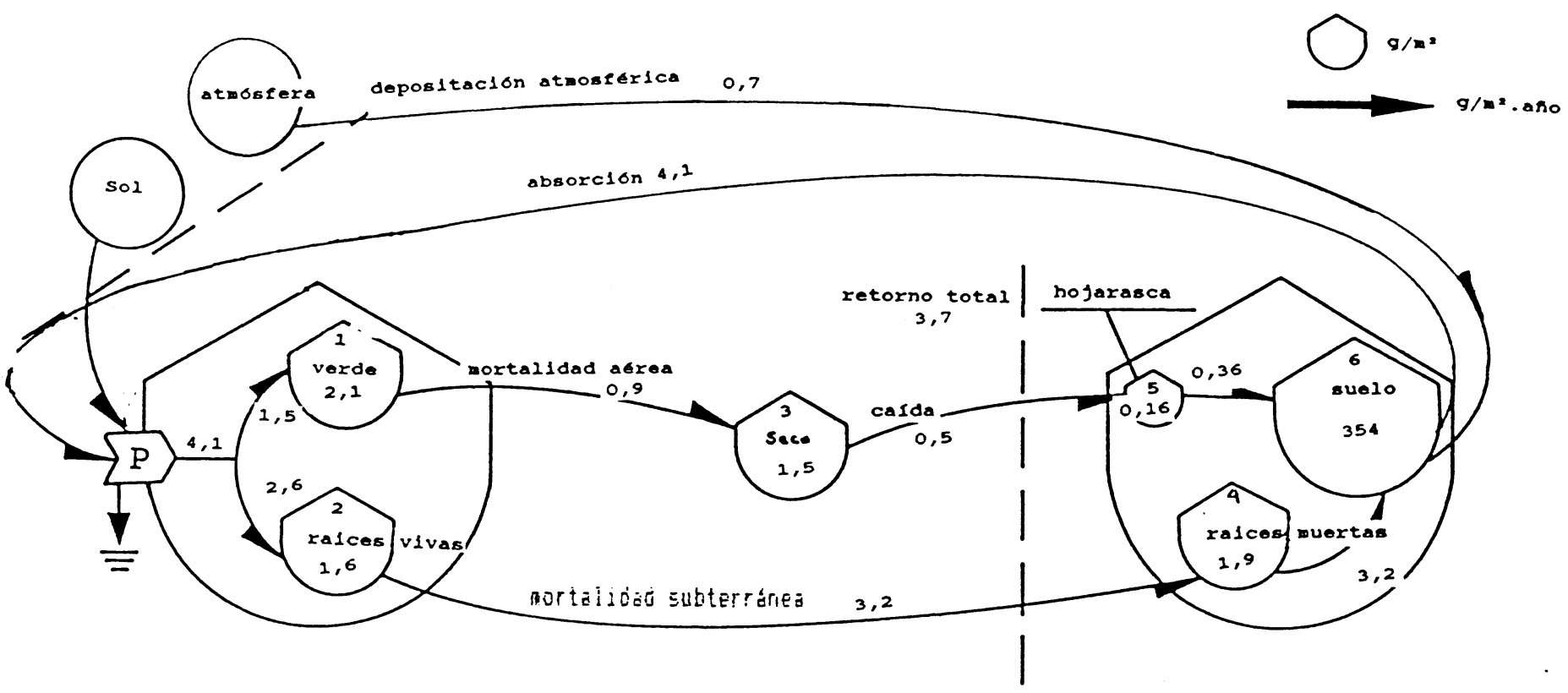

Graflco V.19: Modelo del clclo del calclo en el pastlzal Inferlor. Referenclas como en el grafico v.l6. 


\section{V.2-DISCUSION}

Dinámica estacional de la materia seca y procesos funcionales

El estudio de este pastizal pedemontano presenta como principal antecedente el trabajo realizado por Frangi et al. (1980 a), en el mismo sitio. Estos autores estimaron valores de biomasa aérea entre $191 \pm 12$ y $348 \pm 13 \mathrm{~g} / \mathrm{m}^{2}$ y de necromasa entre $640 \pm 26$ y $1003 \pm$ $44 \mathrm{~g} / \mathrm{m},{ }^{2}$ los cuales duplican a los obtenidos en el presente estudio. Con respecto a la productividad neta aérea anual, las estimaciones de Frangi y colaboradores $\left(553 \mathrm{~g} / \mathrm{m}^{2}\right.$.año durante 1975 y $689 \mathrm{~g} / \mathrm{m}^{2}$.año en 1976) son mayores a la de 1988-1989 (463 g/m².año). Barrera y Fangi (1994) realizaron estimaciones de la materia seca aérea y subterránea en este mismo sitio, en 1982. Señalan una masa aérea de $829 \pm 55 \mathrm{~g} / \mathrm{m}^{2}+$ en julio y de $820 \pm 76$ $\mathrm{g} / \mathrm{m}^{2}$ en diciembre; la hojarasca en esos mismos momentos es $139 \pm 13 \mathrm{~g} / \mathrm{m}^{2}$ y $234 \pm 9$ $\mathrm{g} / \mathrm{m}^{2}$ respectivamente. Estos valores son muy superiores a las obtenidas en el actual trabajo. Las diferencias disminuyen cuando se compara la materia seca subterránea. La misma fue $\mathbf{4 4 2}$ \pm 51 en julio y $562 \pm 48 \mathrm{~g} / \mathrm{m}^{2}$ en diciembre, para los primeros $30 \mathrm{~cm}$ de profundidad (Barrera y Frangi 1994), las cuales son similares a las registradas durante el período 19881989.

Las diferencias en la materia seca y en la productividad del pastizal inferior entre los estudios citados y el actual trabajo, se deberían en gran parte a la combinación de la variabilidad climática interanual y el efecto del fuego que actuó en este sitio a principios de 1987. El fuego tiene como resultado más evidente la reducción de la necromasa aérea. La componente viva se recupera más rápidamente, pero la necromasa presenta un retardo mayor para alcanzar los valores de pre-fuego. La masa del seco en pie y de la hojarasca en las estimaciones de Frangi et al. (1980 a) y de Barrera y Frangi (1994) duplican a las de los mismos compartimientos en el estudio actual. Otra posible influencia de dicho factor es la importante presencia de la especie anual Vulpia dertonensis, cuyo pico en la biomasa de estructuras reproductivas es casi el doble del correspondiente a las "flechillas" de este pastizal y cuya presencia no es destacada en el estudio realizado en el período 1975-1977. Es probable que el fuego haya permitido el incremento de esta especie anual, al aumentar la superficie del suelo desnudo que puede ocupar, dada la disminución en la materia seca aérea post-fuego de las especies perennes. Frangi et al. (1980 b), señalan al fuego como un factor 
pulsátil frecuente en la zona. En dicho trabajo, referido al efecto del mismo sobre la dinámica de la biomasa en un pastizal serrano, comprueban que la vegetación recupera su estructura y composición florística en forma rápida, en ausencia de otros disturbios, alcanzando en pocos años niveles semejantes a los anteriores al incendio. Por otra parte si se comparan los valores del vivo aéreo, del seco en pie y de la hojarasca al comienzo y al final del muestreo, se evidencia que en el pastizal inferior el vivo no aumentó, en cambio existe acumulación en los compartimientos muertos. El seco en pie aumentó un $90 \%$ y la hojarasca un $50 \%$, entre esos momentos. Este predominio de los procesos de producción y mortalidad, sobre la desaparición, que llevan a la acumulación de necromasa aérea sería parte de la recuperación de la estructura del pastizal a dos años del fuego. Además en las variaciones de la materia seca del pastizal, las lluvias juegan un rol fundamental. Abrams et al. (1986) señalan diferencias de hasta tres veces entre el máximo y mínimo valor alcanzado por la biomasa aérea viva durante diez años de estimaciones, coincidiendo el valor más bajo con un año de sequía. La biomasa aérea disminuyó un $47 \%$ durante una severa sequía ocurrida en 1988 , en Minesota (EE UU) (Tilman y El Haddi 1992). La temporada 1976-1977 fue hidricamente mas favorable que la temporada 75-76 (Frangi et al. 1980a). Con respecto a las mismas la temporada 1988-1989 es la más seca, teniendo en cuenta la relación entre la evapotranspiración potencial y las lluvias caídas en ese período.

A partir de las comparaciones entre los estudios realizados durante 1975-1977 (Frangi et al. 1980a) y 1988-1989 (actual estudio), se observa que coinciden los períodos de mayor crecimiento y los de mayor mortalidad y caída entre los años señalados, variando la tasa a la que ocurren dichos procesos para intervalos semejantes (Tabla V.13). En 1988-1989 se producen picos en la biomasa aérea viva y en la productividad aérea a mediados de la primavera y a principios del otoño, cuando las condiciones hídricas y térmicas son mas favorables, coincidiendo con los períodos señalados por Frangi et al. (1980a) como aquellos de mayor crecimiento aéreo. Sin embargo, los valores pico en la tasa diaria de productividad neta aérea estimada por estos autores son casi dos veces mayores que los del actual estudio. Como se dijo anteriormente, la biomasa aérea viva estimada en 1988-1989 es menor, con respecto al período 1975-1977, por lo cual se esperaría productividades aéreas menores, ya que existe un feed-back positivo entre la producción foliar y la ganancia de carbono (Schulze y Chapin 1987). Esta última, a su vez es función de la tasa de asimilación de carbono y de 
la cantidad de tejido foliar (Schulze 1982).

Con respecto a la mortalidad, los picos ocurren a fines de la primavera y del verano, y la época de mayor caída se detecta en el período diciembre - febrero, coincidiendo con lo señalados por Frangi et al. (1980a). En cambio, los valores de las tasas diarias de dichos procesos difieren notoriamente, siendo dos veces mayores en 1975-1977 que en 1988- 1989. Las tasas de desaparición aérea son notablemente menores en esta última temporada, con respecto a las estimadas en 1975-1977. Como se señaló la acumulación de materia seca en el seco en pie es el proceso mas destacado en la dinámica del material aéreo en el presente estudio.

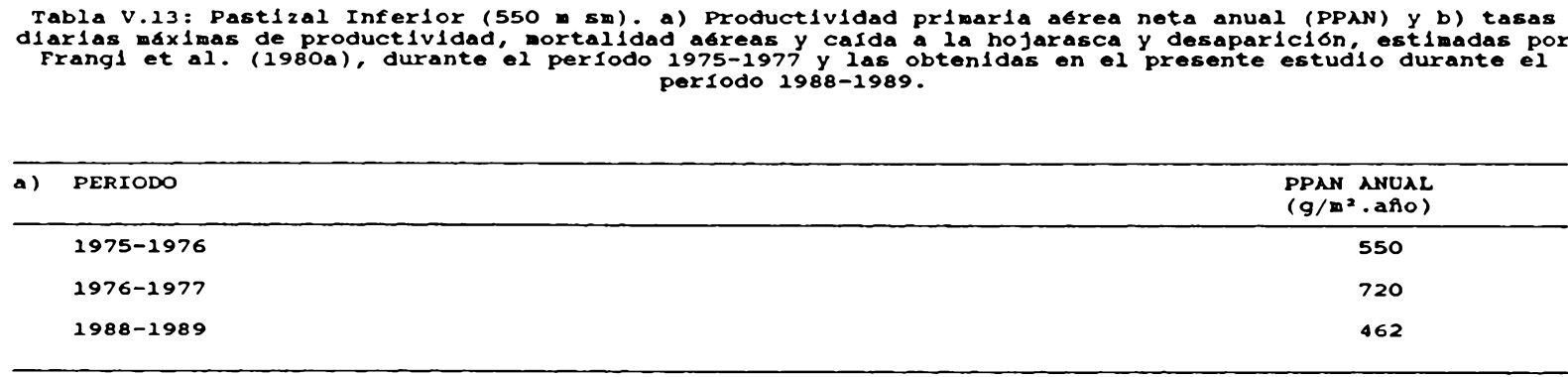

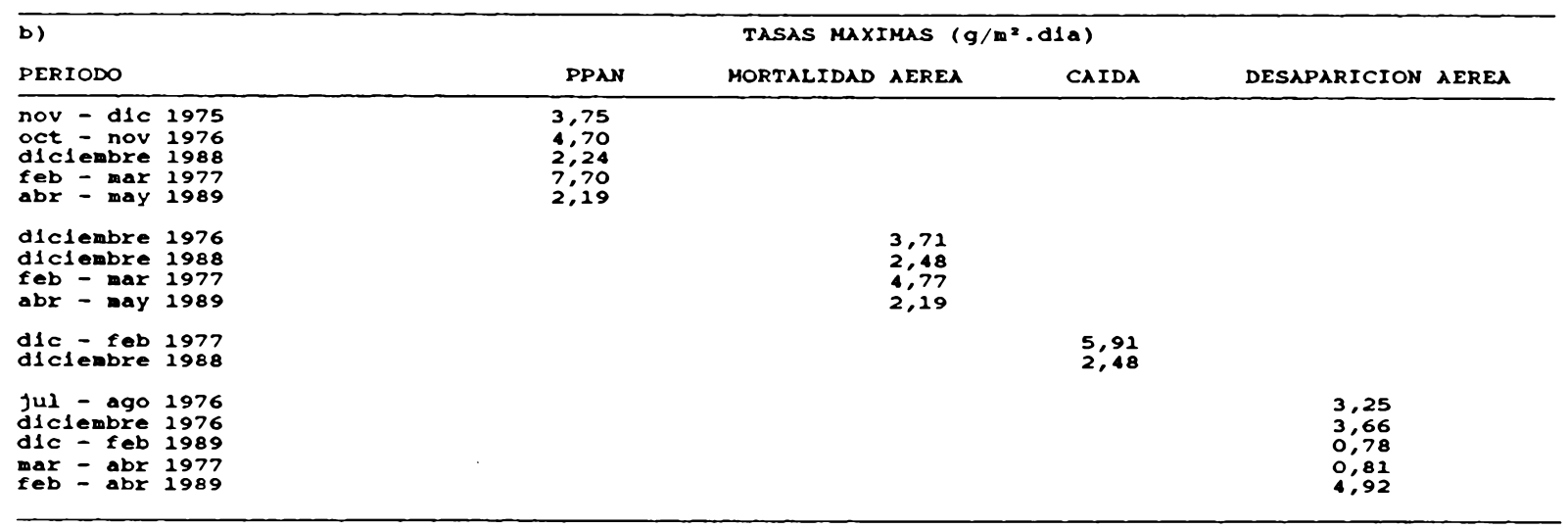

A partir de los estudios mesoclimáticos realizados por Kristensen y Frangi (1995), el pastizal inferior, comparado con los pastizales de igual exposición ubicados a mayor altitud, sería el sitio mas cálido, con menores velocidades del viento y con las mayores demandas evaporativas del aire. El suelo en este pastizal es más profundo y menos pedregoso, lo cual 
podría significar que la capacidad de almacenaje de agua en el mismo se ve aumentada, con respecto a los pastizales medio y superior. El cociente entre la materia seca aérea y subterránea es $1: 1$. Si se considera sólo el vivo, el cociente aumenta varíando entre cinco y tres según la época del año. Comparando este sitio con los pastizales de mayor altitud, existe una menor proporción de raíces con respecto al material aéreo. Múltiples factores entre los que se incluye mayores temperaturas, suelos más profundos y menor velocidad del viento, relacionados a su vez con la ubicación topográfica del pastizal influirian en la asignación de la biomasa entre estructuras aéreas y subterráneas.

Durante el invierno ocurre productividad neta, la cual es principalmente destinada a las estructuras aéreas. Sin embargo, el proceso más destacado es la desaparición de raíces muertas, en su mayoría finas. En los sistemas de pastizales la incorporación de materia orgánica al suelo se realiza principalmente a través de la degradación y humificación de las raíces (Chapman 1970, Daubenmire 1974, Duchaufour 1965, Klein 1977, Swift et al. 1979).

A mediados de primavera las altas tasas de productividad neta se destinan hacia las raíces, aunque la mortalidad de las mismas también es elevada. Dicha mortalidad se verifica en el estrato superficial, coincidiendo con un período de evapotranspiración elevada y lluvias escasas. Los aumentos en las tasas de mortalidad aérea concuerdan con la finalización del ciclo reproductivo de especies inverno - primaverales o microtérmicas y un período hidricamente desfavorable a fines de primavera, asociado con una fuerte reducción de la biomasa de raíces vivas finas, cuya función principal es la de absorción.

La productividad neta, que continúa durante el verano, se canaliza hacia el crecimiento de estructuras subterráneas. La asignación de los fotoasimilados al crecimiento de las raíces permitiría sobrellevar un período caracterizado por un balance negativo entre las lluvias y la evapotranspiración. No hay aumentos del vivo aéreo, prevaleciendo la mortalidad aérea y el pasaje del seco a la hojarasca. El verano se caracteriza por presentar el mayor cociente raiz/tallo vivos, asociando esa estación con un período en el cual la evapotranspiración potencial excede a las precipitaciones. Cuando la disponibilidad de agua para las plantas disminuye, se ve favorecido el crecimiento de las raíces (Schulze 1982), para mantener el 
acceso al agua, las plantas extienden nuevas raíces en zonas no exploradas del suelo y reexplotan el mismo suelo con el sistema de raíces establecido (Caldwell 1976 en Schulze et al. 1987). Esta importante biomasa de raíces facilitaría el crecimiento cuando ocurre una mayor disponibilidad de agua en el suelo.

A partir de condiciones de humedad más favorable, en el otoño, se destina casi la totalidad de la productividad neta a la biomasa aérea. Las lluvias otoñales permitirían además del crecimiento aéreo, una reactivación de aquellos procesos de degradación y humificación que determinan la disminución de los compartimientos subterráneos muertos. A fines del otoño, la mortalidad se observa en los compartimientos aéreos, pero en mayor proporción es subterránea, coincidiendo con la finalización del ciclo productivo de las plantas estivootoñales o mesotérmicas y con la aparición de las primeras heladas. Las importantes lluvias a mediados de mayo de 1988 estarían permitiendo que el material muerto se degrade rápidamente, observándose tasas de desaparición elevadas principalmente en las raíces, y en menor magnitud en la hojarasca.

Las raíces son las que contribuyen en mayor medida al aporte de materia orgánica al suelo, ya que casi el $90 \%$ de la materia seca que se incorpora al mismo, en este pastizal, proviene del material subterráneo. La mayor importancia de las raíces con respecto a la hojarasca se relaciona con la dinámica de la materia seca en el pastizal y la asignación de de fotoasimilados en mayor medida hacia las raíces que hacia las hojas. En primer lugar, durante este estudio, el $60 \%$ de la productividad neta anual se destina a las raíces. Pero la mayor diferencia surge en la via seguida por la materia seca a lo largo del año. En la parte aérea la mortalidad iguala a la producción, pero sólo el $22 \%$ de esta última se incorpora al suelo a través de la caída a la hojarasca y desaparición de la misma. El porcentaje restante se acumula como seco en pie. En cambio, en las raíces durante la temporada 1988-1989 la desaparición subterránea supera a la productividad. Esto indica que las raíces rápidamente mueren, y desaparecen como tales, sin acumularse de un año para otro.

De los compartimientos distinguidos en la materia seca del pastizal, el vivo aéreo, las raíces muertas y la hojarasca son los que presentan menor tiempo de renovación. Los mismos se renuevan aproximadamente tres veces en un año. Las raíces vivas, tardan aproximadamente 
siete meses en renovarse y el seco en pie un año. Con respecto a los compartimientos vivos, existe un mayor dinamismo en la biomasa aérea que en la subterránea, las plantas serían más conservativas con respecto a las raíces que con las hojas. El tiempo de vida medio de las raíces del pastizal, estimado como la mitad del tiempo de renovación (Hendrick y Pregitzer 1992), es de tres meses y medio aproximadamente. Analogamente, una hoja promedio viviría dos meses.

\section{Concentración, contenido y ciclo de nutrientes}

En la primavera, en el verde de las gramíneas y en las raíces vivas las concentraciones de $\mathrm{P}$ y $\mathrm{N}$ disminuyen, a la vez que el contenido de los mismos aumenta, coincidiendo con el pico de biomasa; esto se interpreta como una dilución de los nutrientes cuando la productividad es máxima. Dicho pico de biomasa (en octubre de 1988) representa un incremento de dos veces la masa invernal de raíces finas vivas y 1,4 veces la del verde de gramíneas, mientras que el incremento en la mineralomasa es de 1,3 y 1,1 respectivamente, por lo cual la dilución de la concentración de los nutrientes mencionados es mucho más marcada en las raíces que en la hojas de las gramíneas. En las raíces gruesas vivas, su biomasa a principios de la primavera (setiembre de 1988) se mantiene con valores similares a los invernales, pero en las mismas su contenido disminuye, debido a la disminución de la concentración de nutrientes. De acuerdo con lo expresado, el crecimiento de los tejidos en el pico de productividad primaveral sería sostenido por (1) absorción, ya que los contenidos de P y N aumentan; (2) por dilución, ya que sus concentraciones disminuyen; y (3) probablemente por el pasaje de nutrientes desde las raíces gruesas, que han sido señaladas como responsables de la función de almacenamiento, ya que en las mismas disminuye la concentración de nutrientes y el contenido de los mismos en el período anterior al de máximo crecimiento de los tejidos de absorción y fotosintéticos. Este cambio en los nutrientes de las raíces gruesas va acompañado de mortalidad. Los tres mecanismos señalados permitirían sostener altas tasas de crecimiento neto con menores cantidades de nutrientes, a la vez que se reduce la pérdida de los mismos desde las plantas, a través de la mortalidad, lo cual equivale a una mayor eficiencia en el uso de los nutrientes cuando la vegetación es más activa. 
El K presenta un patrón similar al señalado para el $\mathrm{N}$ y el $\mathrm{P}$, pero dado que dicho elemento, es requerido en mayor proporción por los tejidos aéreos la dilución en los mismos es menos marcada que la señalada para los otros dos nutrientes, mientras que se incrementa en las raíces. Esto se evidencia a través del aumento en el contenido de $\mathrm{K}$, que es proporcional al de materia seca, de la leve disminución en su concentración en los tejidos foliares, y de la constancia en el contenido de $\mathrm{K}$ en las raíces finas vivas, a pesar del importante aumento de biomasa ya señalado. Se podría interpretar que durante el período de mayor producción la absorción de $\mathrm{K}$ aumenta. Esto se relacionaría con lo señalado por Marschner (1983), en cuanto a que el K es el más importante soluto inorgánico en las plantas, ya que actúa como activador de enzimas y en particular, en el proceso fotosintéticos, participa en la síntesis de RubP-carboxilasa.

A fines de la primavera las concentraciones y los contenidos de $\mathrm{N}, \mathrm{P}$ y $\mathrm{K}$ en el verde de gramíneas y en las raíces finas vivas son mínimas, a la vez que se incrementan en las raíces gruesas vivas. En este período la mortalidad de los dos compartimientos mencionados primero es máxima, mientras que la biomasa de las raíces gruesas no varía con respecto al período anterior. Como se dijo, la dilución permitiría a las plantas disminuir las pérdidas de nutrientes debidas a mortalidad. El otro mecanismo que se pone de manifiesto es el de acumulación de nutrientes en las raíces gruesas vivas, los cuales podrían proceder de la retranslocación de los mismos desde los tejidos senescentes. Esto se evidencia a través de las marcadas diferencias existentes en las concentraciones entre el verde y el seco en pie, (en el verde de gramíneas las concentraciones de $\mathrm{K}, \mathrm{P}$ y $\mathrm{N}$ son 5,3 y 2 veces mayores, respectivamente, que en el seco). Otra forma de apreciar el proceso de retranslocación es que entre dichos tejidos no se manifiestan marcadas diferencias en los contenidos de esos elementos, a pesar de que la materia seca del seco en pie duplica a la del verde de gramíneas. Si bien las dicotiledóneas también forman parte del seco en pie, las mismas representan un escaso porcentaje de la materia seca aérea en este pastizal, por lo que las gramíneas son las que tienen mayor incidencia en la dinámica de la vegetación.

El verano en que se realizó este estudio fue más favorable en cuanto a las lluvias que la última parte de la primavera. En estas condiciones, las concentraciones de los nutrientes en el verde de gramíneas muestran una tendencia creciente, aunque la misma no se traslada a los 
contenidos debido a que la biomasa decrece. En cambio, la productividad estival es destinada a las raíces, y en esta época aumentan tanto las concentraciones como los contenidos de nutrientes en los tejidos subterráneos vivos. En síntesis, en el verano la actividad de la vegetación se localiza en las raíces, y habría absorción de nutrientes, mejorando el estado nutricional de los tejidos tanto aéreos como subterráneos.

La productividad aérea otoñal es mayor que la primaveral, sin embargo, este crecimiento no es acompañado de dilución. Al contrario, aumentan las concentraciones y los contenidos de nutrientes en los tejidos aéreos y subterráneos. Hacia fines del otoño y principios del invierno, la mortalidad aumenta, principalmente en las raíces, a la vez que disminuyen la concentración y los contenidos de nutrientes en las raíces finas vivas y los contenidos, pero no las concentraciones en el verde. En las raíces gruesas vivas las concentraciones no varían pero si aumentan los contenidos de nutrientes por el aumento en la biomasa de las mismas. Este comportamiento pone en evidencia que en los períodos de máxima mortalidad las concentraciones decrecen en los compartimientos más afectados por dicho proceso, y es probable que parte de los nutrientes recuperados sean almacenados en las raíces gruesas vivas.

En el verde de dicotiledóneas las concentraciones y los contenidos variaron en forma similar a la señalada para las grámineas. El aumento primaveral de la biomasa en este compartimiento estaría sostenido por la dilución de las concentraciones de nutrientes y por absorción, ya que la mineralomasa aumenta. En el verano la reducción de la biomasa es marcada y las concentracione de $\mathrm{Ca}, \mathrm{P}$ y $\mathrm{N}$ disminuyen, mientras que la concentración de $\mathrm{K}$ se duplica con respecto a los valores primaverales. Los contenidos y concentraciones de nutrientes aumentan en el otoño, junto con la biomasa de las hierbas de hoja ancha.

En cuanto a la eficiencia en el uso de los nutrientes, en la producción aérea ésta es mayor en el período estivo-otoñal que en el inverno-primaveral, mientras que en la producción de raíces, dicha eficiencia es similar en ambos períodos (tabla V.14). 


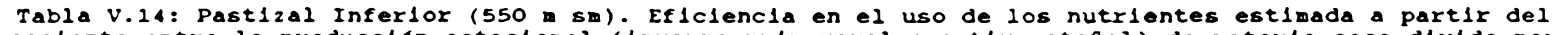
coclente entre la producción estaclonal (1nverno-primaveral o est1vo-otofial) de materla seca divido por la mineralomasa medla del mismo perjodo y por el numaro de dlas de ese lntervalo.

EFICIENCIA EN EL USO DE LOS NUTRIENTES

\begin{tabular}{|c|c|c|c|c|c|c|c|c|}
\hline \multirow[t]{2}{*}{ PERIODO } & \multirow{2}{*}{\multicolumn{2}{|c|}{${ }_{P}^{A E R E \lambda}$}} & & \multicolumn{2}{|l|}{$15 / 9$} & \multicolumn{2}{|c|}{ SUBTERRAN } & \multirow[b]{2}{*}{ Ca } \\
\hline & & & $\mathrm{x}$ & ca & $\mathbf{N}$ & $\mathbf{P}$ & $\mathbf{K}$ & \\
\hline $\begin{array}{l}\text { INVERNO-PRIMUVERAL } \\
\text { (no de dIAS } 170)\end{array}$ & 0,6 & 5,7 & 0,4 & 2,1 & 0,6 & 12,0 & 4,7 & 1,3 \\
\hline $\begin{array}{l}\text { ESTIVO-OTONAL } \\
\text { (n) de dIAs 151) }\end{array}$ & 0,9 & 10,0 & 0,9 & 5,1 & 0,7 & 24,7 & 4,8 & 1,3 \\
\hline
\end{tabular}

La mayor eficiencia estivo-otoñal en el uso de los nutrientes equivale a decir que el costo de producir hojas en términos de nutrientes es menor durante ese período, con respecto al inverno-primaveral. Esto se relacionaría con la tasa de renovación de la biomasa aérea, menor durante la primavera que en el otoño. Sin embargo la dilución de los nutrientes observada en el primer período, no ocurre en el segundo. Las mayores concentraciones y contenidos de nutrientes en los tejidos vivos en el otoño podrían estar relacionados con las condiciones hídricas más favorables en dicho período, lo cual habría permitido mayor absorción de nutrientes, con respecto a la primavera. En dicha época, la productividad habría sido sostenida en parte por la reservas de nutrientes, dado que el stress hídrico limitaría la absorción de los mismos. Esta suposición se basa en que además de una dilución marcada en los nuevos tejidos formados, existió una reducción en los contenidos de las raíces gruesas vivas (decreció la biomasa y las concentraciones de nutrientes), lo que podría interpretarse como utilización de reservas almacenadas en las mismas durante el pico de productividad primaveral. En el pico estivo-otoñal, en cambio, ninguno de estos procesos son evidentes, por lo cual el aumento de la biomasa (y de la mineralomasa) estaría sustentado principalmente por la absorción de nutrientes.

En el material muerto, las concentraciones siguieron estrechamente las variaciones observadas en el vivo. La necromasa subterránea se diferencia de la necromasa aérea, en que sus concentraciones son mucho mayores que las observadas en la raíces vivas, mientras que en los compartimientos aéreos se da la relación inversa. La disminución de las concentraciones en el seco en pie con respecto a los tejidos fotosintéticos se debería a la retranslocación de nutrientes desde los órganos aéreos senescentes y en parte al lavado de minerales desde el muerto en pie. El aumento de las concentraciones y del contenido de nutrientes en el seco en pie al comienzo del inviero se debería a las mayores concentraciones 
de nutrientes en los tejidos vivos en el período anterior, y no a una menor retranslocación, con respecto a dicho proceso durante la primavera. La hojarasca presenta concentraciones poco menores que las del seco en pie en la primera parte del año, mientras que a partir del verano en adelante dichas concentraciones aumentan, superando a las observadas en el seco en pie. En el caso del $\mathrm{P}$ y el $\mathrm{N}$ este comportamiento se podría deber a la acción de la microflora y microfauna descomponedora, que enriquecería los tejidos, hasta hacerlos más facilmente degradables. En el caso del $\mathrm{Ca}$, su concentración aumenta probablemente porque dicho elemento integra compuestos de dificil descomposición, a la vez que otros más lábiles son degradados más rápidamente por los microorganismos. En las raíces finas muertas, las altas concentraciones de nutrientes con respecto a las raíces vivas se debería también a procesos de inmovilización y enriquecimiento microbiano y a la descomposición diferencial de compuestos más lábiles en una fase inicial de la misma. En las raíces finas muertas se observa claramente que los contenidos y concentraciones son relativamente más bajos en la primavera y en el otoño, como consecuencia de que en esos períodos prevalecería la descomposición y la mineralización de los nutrientes. En la hojarasca los contenidos de los mismos descienden en primavera y otoño, con respecto a los valores invernales y estivales, respectivamente, pero el descenso en el otoño se debe a la pérdida de masa, a la vez que las concentraciones aumentan. El mantillo, en la primavera, estaría integrado por materiales remanentes de períodos anteriores, en una etapa más avanzada de la descomposición y mineralización, lo cual se evidencia a partir de la disminución de los contenidos y concentracion de los minerales. A fines de la primavera, cuando la caída es máxima, el material incorporado se encontraría en una fase de degradación de los compuestos más fácilmente digeribles por los microorganismos, y probablemente de enriquecimiento por parte de los mismos, por lo cual declina la materia seca total pero las concentraciones aumentan.

En este pastizal, los requerimientos de nutrientes en la productividad aérea son mayores que los subterráneos (con excepción del calcio). Dado que la relación biomasa subterránea:biomasa aérea es aproximadamente 3:1 y que los tejidos aéreos presentan mayores concentraciones de los nutrientes, los almacenajes de los mismos en la biomasa se encuentran en proporción similar (N) o mayor (K y P) en dichos tejidos con respecto a las raíces. En el caso del Ca, su concentración en las raíces finas vivas es dos veces mayor que en el verde de gramíneas, lo cual se refleja en los contenidos de ambos compartimientos vivos. 
Los requerimientos de nutrientes empleados en la formación de nuevas estructuras son satisfechos en gran medida por la retranslocación, la cual aporta el $31 \%$ del N, casi el 50 $\%$ del P y el $73 \%$ del $\mathrm{K}$. Esta última proporción puede estar sobreestimada teniendo en cuenta que el $\mathrm{K}$ puede ser lavado desde los tejidos con mucha facilidad. Esta última via constituye para las plantas una forma rápida de obtener minerales lixiviados desde las mismas. Estos probablemente queden retenidos en los materiales coloidales del suelo, de donde son retomados por raíces.

A partir de la relación entre los requerimientos de nutrientes en la productividad del pastizal y los almacenajes de los mismos en los tejidos vivos se establece la renovación anual del contenido de nutrientes en éstos. En los tejidos fotosintéticos se reemplazan tres veces en un año, mientras que las raíces presentan tasas de renovación menores, las cuales varían entre 1,4 para el $\mathrm{K}$ y 1,7 año $^{-1}$ para los otros nutrientes considerados.

En la materia seca aérea, en el pastizal inferior, se destaca el incremento del seco en pie de un año con respecto a otro. Este aumento se traslada a los nutrientes, los cuales quedan retenidos en dicho compartimiento. Esto se evidencia en parte por la diferencia positiva entre el ingreso de nutrientes al mismo a través de la mortalidad aérea y la salida por medio de la caída a la hojarasca. El retorno de nutrientes al suelo, a través de la mortalidad de las raíces fue mayor que los nutrientes incorporados a las mismas mediante la productividad. Esta diferencia se debe a que la materia seca de las raíces disminuye en un $14 \%$ en julio de 1989 , con respecto a julio de 1988. Este decrecimiento en la masa subterránea es interpretado como parte de las variaciones anuales de la materia seca, asociadas a las características climáticas prevalecientes.

Las tasas estacionales de descomposición y de liberación de nutrientes al suelo (tabla V.15) son mayores en las raíces que en la hojarasca, probablemente favorecidas por las características más constantes del suelo en cuanto a temperatura y humedad, y por estar las raíces en contacto más directo con los organismos descomponedores. Durante el período inverno-primaveral las tasas de descomposición y mineralización, tanto aéreas como subterráneas, son menores que en el período estivo-otoñal, probablemente relacionadas con 
las mayores precipitaciones y temperaturas durante la última época mencionada. Por otra parte, las tasas de descomposición son similares a las tasas de mineralización, tanto en la hojarasca como en las raíces muertas.

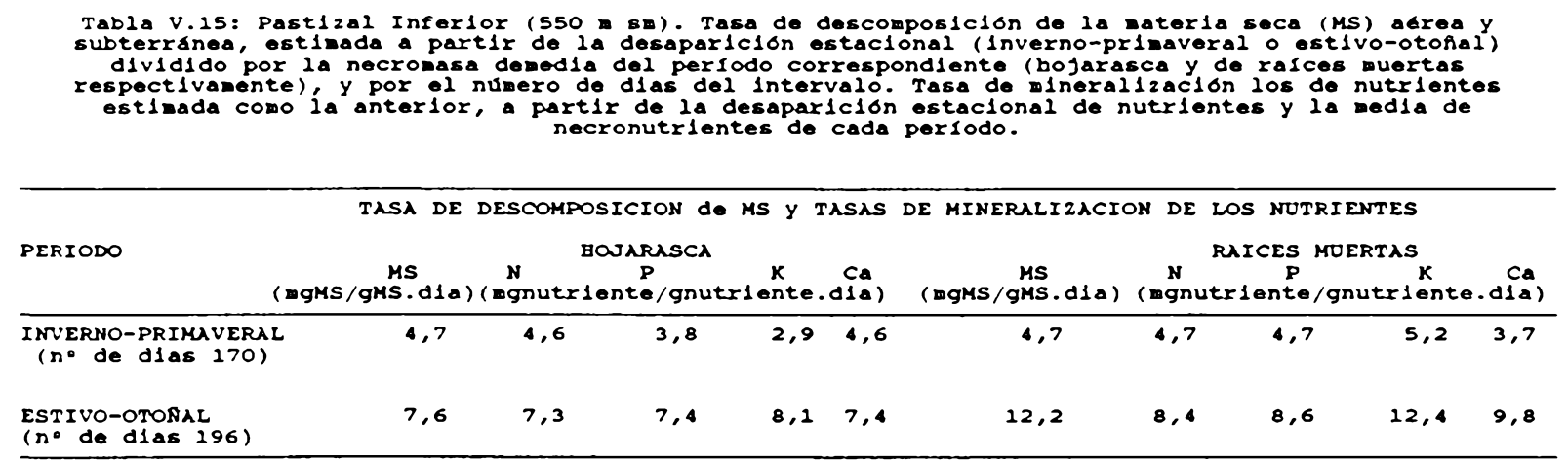

La diferencia señalada en las vias de retorno de los nutrientes al suelo resulta en una mayor incorporación de materia orgánica y minerales a través de las raíces en relación con los tejidos aéreos. Dado que la incorporación de minerales en la vegetación durante el año fue destinada en una proporción igual o mayor a la parte aérea, con respecto a las raíces, la retención de los mismos en los tejidos aéreos en pie y las diferencias en las velocidades de descomposición en favor de las raíces, llevan a que las mismas contituyan la principal fuente a partir de la cual se liberan recursos para nuevos ciclos productivos. 
CAPITULOVI:COMPARACION DELOSTRES PASTIZALES 


\section{VI.1-ALMACENAJES DE MATERIA SECA}

\section{Materia seca de los pastizales situados a diferente altitud}

La materia seca (aérea + subterránea) promedio anual es mayor en el pastizal superior (1025 m sm) que en los otros dos pastizales situados más abajo (850 m sm y $550 \mathrm{~m} \mathrm{sm}$ ) (test $t$ de Student, $\mathrm{P}<0,05)$ (Tabla VI.1.1).

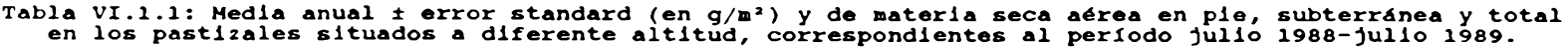

\begin{tabular}{|c|c|c|c|c|c|c|}
\hline PASTIZAL & ALTITUD (m Sm) & AEREA & & $\begin{aligned} & \text { SECA }\left(g / m^{2}\right) \\
& \text { SUBTERRANEA }\end{aligned}$ & & TOTAL \\
\hline Supertor & 1025 & $369 \pm 19$ & $(n=9)$ & $1231 \pm 67 \quad(n=8)$ & 1507 & $\pm 63(n=8)$ \\
\hline Med1o & 850 & $406 \pm 37$ & $(n=9)$ & $783 \pm 44 \quad(n=8)$ & 1208 & $\pm 70 \quad(n=8)$ \\
\hline Infertor & 550 & $535 \pm 11$ & $(n=9)$ & $642 \pm 49 \quad(n=8)$ & 1184 & $\pm 42(n=8)$ \\
\hline
\end{tabular}

La comparación de las medias anuales de materia seca aérea y subterránea permite establecer que la primera disminuye linealmente hacia la cumbre, en tanto que la segunda aumenta en forma exponencial en ese sentido (Gráfico VI.1.1).

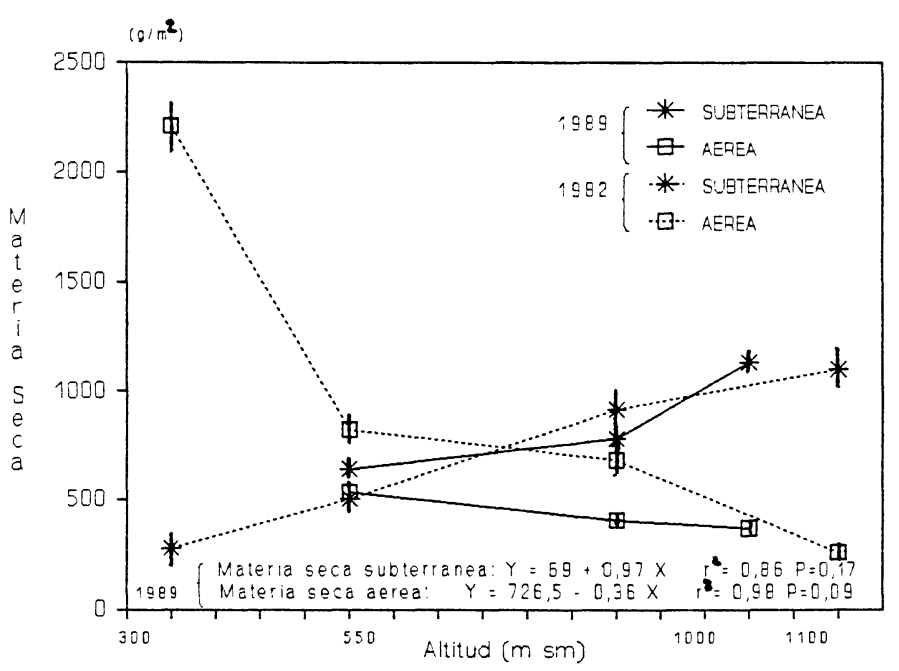

Grafico VI.1.1: Medias anuales de materla seca aereas y subterraneas de los past12ales en relacion con
su ublcación altitudinal, correspondientes a los anos 1982 (Barrera y Frangi 1994 ) y 1989 (esta tesis). su ublcacion altitudinal, correspondientes a los años 1982 (Barrera y Frang1 1994 )
Las lineas verticales corresponden a los errores standard.

Barrera y Frangi (1994), en el mismo cerro y sobre la misma ladera en que fue ralizado el presente trabajo, establecieron que la variación altitudinal de materia seca aérea es 
exponencial, y lineal para la materia seca subterránea. Los mencionados autores tomaron una mayor variedad de tipos fisonómicos (incluye pastizal tipo "tussock" de Stipa caudata y prados de altura), consecuentemente los datos actuales son parte "interior" de las tendencias observadas en un rango más amplio (Gráfico VI.1.1).

La materia seca aérea y la subterránea de los tres pastizales, varían de acuerdo a su localización a diferente altitud y a las fechas de muestreo. Si bien la interacción entre ambos factores es significativa, la misma representa una pequeña proporción con respecto a la variación explicada por los factores principales $(14 \%$ y $1 \%$ para la materia seca aérea y subterránea, respectivamente) (Tabla VI.1.2). A partir de la comparación de las medias (test de Tukey, $\mathrm{P}<0,05)$ entre pastizales se establece que la materia seca aérea aumenta desde la cumbre hacia la base, mientras que la materia seca subterránea disminuye en ese mismo sentido.

\begin{tabular}{|c|c|c|c|c|c|}
\hline \multicolumn{6}{|l|}{ a) Materla seca aerea } \\
\hline Fuente de variacion & Suma de cuadrados & 9.1 & Medla cuadrada & test de $\underline{F}$ & Nivel de sig. \\
\hline $\begin{array}{l}\text { Pastizal } \\
\text { Fecha } \\
\text { Pastizal x fecha } \\
\text { Error }\end{array}$ & $\begin{array}{l}1367526,5 \\
1726295,4 \\
452223,2 \\
2463704,7\end{array}$ & $\begin{array}{r}2 \\
8 \\
16 \\
243\end{array}$ & $\begin{array}{r}683763,2 \\
215786,9 \\
28263,9 \\
10138,7\end{array}$ & $\begin{array}{r}67,4 \\
21,3 \\
2,8\end{array}$ & $\begin{array}{l}0,0000 \\
0,0000 \\
0,0004\end{array}$ \\
\hline \multicolumn{6}{|c|}{ b) Materla seca subterránea } \\
\hline Fuente de variacion & Suma de cuadrados & 9.1 & Media cuadrada & test de $\underline{F}$ & Nivel de sig. \\
\hline $\begin{array}{l}\text { Fecha } \\
\text { Past1zal } \\
\text { Fecha } x \text { pastizal } \\
\text { Error }\end{array}$ & $\begin{array}{c}3129294 \\
10150511 \\
1796048,3 \\
9760515\end{array}$ & $\begin{array}{r}7 \\
2 \\
14 \\
216\end{array}$ & $\begin{array}{r}447042 \\
5075255 \\
128289,2 \\
45187,6\end{array}$ & $\begin{array}{r}9,9 \\
112,3 \\
2,8\end{array}$ & $\begin{array}{l}0,0000 \\
0,0000 \\
0,0006\end{array}$ \\
\hline
\end{tabular}

Comparando las medias mensuales se mantiene la misma tendencia en la mayoría de las fechas de muestreo, para la materia seca subterránea (Gráfico VI.1.2b). En la materia seca aérea, en cambio, los tres pastizales no difieren estadísticamente en el verano, que es un período en el cual la misma desciende. El resto del año la materia seca aérea es mayor en el pastizal inferior con respecto a los sitios ubicados a mayor altitud (Gráfico VI.1.2a). 
a)

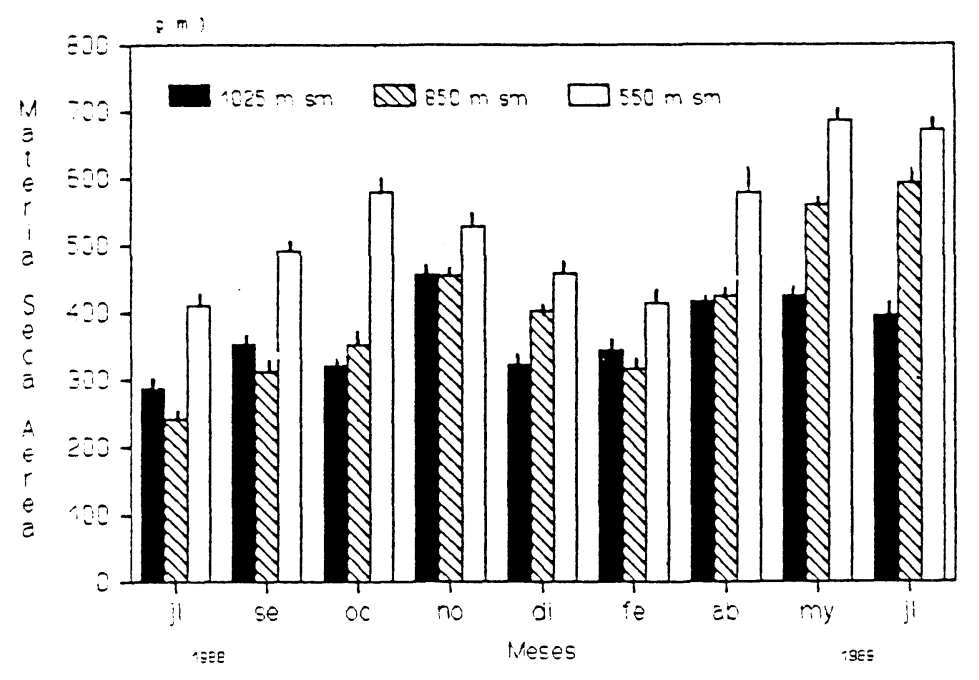

b)

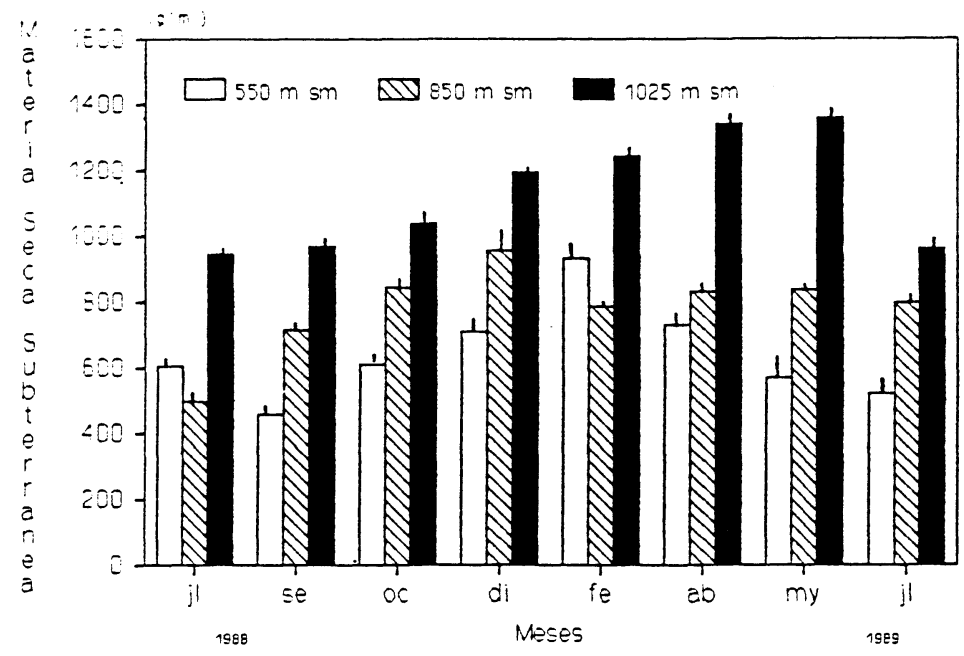

Graflco VI.1.2: Medias mensuales de materla seca a) aurea y b) subterranea, en los pastizales de diferente ublcacion altitudinal. Las ineas verticales corresponden a los errores standard.

A partir de las comparaciones de las medias anuales y mensuales de la materia seca, se establece que en los pastizales más elevados (1025 msm y $850 \mathrm{~m} \mathrm{sm}$ ) la materia seca aérea es menor que en el inferior ( $550 \mathrm{~m} \mathrm{sm}$ ), a la vez que la materia seca subterránea del pastizal 
cercano a la cumbre (1025 msm) es mayor que la de los otros dos. De este modo, el pastizal ubicado a $850 \mathrm{msm}$ resultaría una situación intermedia entre los pastizales extremos del gradiente altitudinal, los cuales están sujetos a condiciones ambientales más contrastantes entre si. De acuerdo con Kristensen y Frangi (1995) de los pastizales serranos expuesto al noreste, el cercano a la cumbre es el sitio más frío, y más húmedo, con los menores déficit de saturación, isotermo tanto diaria como anualmente, con suelos frios y con las mayores velocidades del viento que hacen que durante el verano se registren las mayores tasas evaporativas del aire; condiciones contrastantes con la cumbre se registran en el pastizal inferior, que es un sitio cálido, seco, con los mayores déficit de saturación del aire, anisotermo, con las mayores temperatura del suelo y donde las velocidades alcanzadas por el viento no superan la mitad de las de la cumbre. El pastizal ubicado a media ladera presenta características intermedias entre los extremos mencionados.

Como resultado de las tendencias observadas en la variación de la materia seca aérea y subterránea con la altitud, se observa que las proporciones que éstas representan con respecto a la materia seca total tambien varían. El porcentaje de materia seca aérea se incrementa desde la cumbre hacia la base, en tanto que disminuye el porcentaje de materia seca subterránea en ese mismo sentido. (Gráfico VI.1.3).

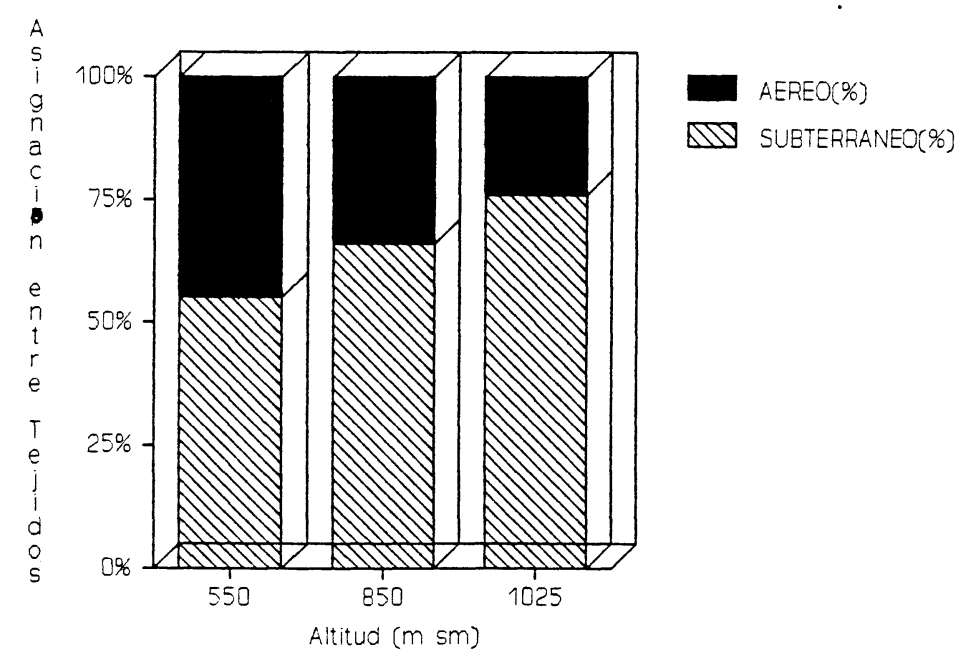


Con respecto a la materia seca aérea en pie, los pastizales aquí estudiados presentan valores cercanos al extremo superior del rango obtenido a partir de las estimaciones realizadas por Sims et al. (1978) para pastizales templados de EE. UU y se ecuentra dentro del rango señalado para pastizales templados de nuestro país (Tabla VI.1.3).

\begin{tabular}{|c|c|c|c|}
\hline Mater1a & $\begin{array}{l}\text { seca aerea en ple } \\
\left(g / \mathrm{m}^{2}\right)\end{array}$ & Tipo de vegetacion & Fuente \\
\hline & $\begin{array}{l}135 \\
598\end{array}$ & $\begin{array}{l}\text { pastizal de pastos cortos } \\
\text { (Pawnne, EE.UD.) } \\
\text { pastizal de pastos altos } \\
\text { (Osage, EE.UU.) }\end{array}$ & sims et al. (1978) \\
\hline & 650 & $\begin{array}{l}\text { pastizales de la Depresión del Salado } \\
\text { (Bs.As., Arg.) }\end{array}$ & sala et al. (1981) \\
\hline & 743 & $\begin{array}{l}\text { past1zal de Stipa longlglumls y } \\
\text { S. trichotoma (La Pampa, Arg.) }\end{array}$ & de wyslecky (1993) \\
\hline & $\begin{array}{l}524 \\
187\end{array}$ & $\begin{array}{l}\text { pastizales serranos de altura(1350 m sm) } \\
\text { (Cordoba, Arg.) } \\
\text { pajonal de Festuca hleronym } \\
\text { pajonal de Stlpa }\end{array}$ & Menghl et al. (1978) \\
\hline & $\begin{array}{r}2212 \\
824 \\
684 \\
267\end{array}$ & 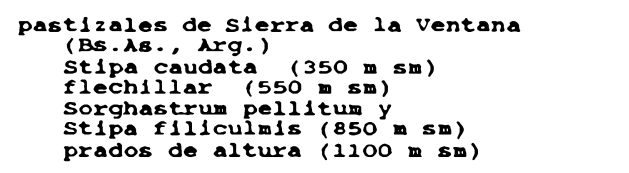 & Barrera Frangl (1994) \\
\hline & $\begin{array}{l}535 \\
406 \\
369\end{array}$ & $\begin{array}{l}\text { pastizal inferior }(550 \mathrm{~m} \mathrm{sm}) \\
\text { pastizal medio (850 } \mathrm{m} \mathrm{sm}) \\
\text { pastizal superior }(1025 \mathrm{~m} \mathrm{sm})\end{array}$ & Presente estudio \\
\hline
\end{tabular}

Con respecto a la materia seca subterránea, los pastizales estudiados en el presente trabajo se encuentra dentro del rango señalado para pastizales templados (Tabla VI.1.4). Sims et al. (1978) encontraron una relación inversa entre la biomasa de raíces y la media anual de temperatura. Long et al. (1989) en pastizales tropicales y San José et al. (1982) en sabanas Venezolanas, estimaron una masa radical mucho menor a la señalada para pastizales templados (Tabla VI.1.4). En los pastizales del presente estudios, el sitio relativamente más frío (pastizal superior) es también el de mayor masa subterránea comparado con el más cálido (pastizal inferior). Con respecto a los pastizales de altura en Sierra de la Ventana, Barrera y Frangi (1994) consideran que el gran desarrollo de la masa subterránea constituiría una respuesta adecuada para satisfacer los requerimientos hídricos, sobre un sustrato fino, somero, con base impermeable y en condiciones de fuertes vientos. El desarrollo del sistema radical en extensión lateral y profunda regula las posibilidades de usar un volumen determinado de suelo (Fernandez et al. 1988). 
Tabla VI.2.4: Materla seca subterranea de pastizales. Medla anual (g/m²).

\begin{tabular}{|c|c|c|c|c|}
\hline Mater1a & $\begin{array}{l}\text { seca subterránea } \\
\left(g / m^{2}\right)\end{array}$ & $\begin{array}{l}\text { Profundidad } \\
(\mathrm{Cm})\end{array}$ & T1po de vegetacion & Fuente \\
\hline & $\begin{array}{r}1388 \\
530 \\
905\end{array}$ & $\begin{array}{l}0-30 \\
0-30 \\
0-30\end{array}$ & $\begin{array}{l}\text { past1zal de ontaria } \\
\text { (Bridger, EE.OU) } \\
\text { past1zal de pastos cortos } \\
\text { (Pawnne, EE.UO.) } \\
\text { past1zal dé pastos altos } \\
\text { (Osage, EE.0O.) }\end{array}$ & sios et al. (1978) \\
\hline & 1400 & $0-25$ & $\begin{array}{c}\text { pastizal de pastos altos } \\
\text { (M1ssourl, EE.UU.) }\end{array}$ & Dahlman y Kucera (2965) \\
\hline & 1663 & $0-30$ & $\begin{array}{l}\text { pastlzales de la Depresion del salado } \\
\text { (Bs.As., Arg.) }\end{array}$ & Sorlano et al. (1990) \\
\hline & 834 & & pastura de Exagrost1s curvula & Montanl et al. (1989) \\
\hline & $\begin{array}{r}279 \\
503 \\
916 \\
1101\end{array}$ & $0-20$ & 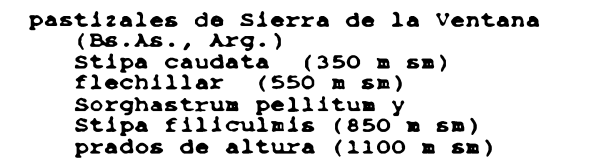 & Barrera Frang1 (1994) \\
\hline & $\begin{array}{l}508 \\
950\end{array}$ & & $\begin{array}{l}\text { flechillar ( } 450 \text { m sm) } \\
\text { sorghastrum pellitum y } \\
\text { Stlpa fillculmis ( } 850 \text { sm) }\end{array}$ & $\begin{array}{c}\text { de wysleckl y Perez } \\
(\text { Inedito })\end{array}$ \\
\hline & $\begin{array}{r}642 \\
783 \\
1132\end{array}$ & & 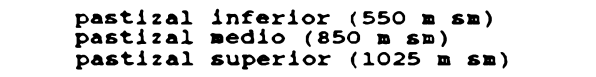 & Presente estudio \\
\hline & $\begin{array}{l}389 \\
109 \\
340\end{array}$ & $0-15$ & $\begin{array}{l}\text { pastizales troplcales } \\
\text { pastizal sallno } \\
\text { (Chaplngo, Mejlco) } \\
\text { sabana seca } \\
\text { (Nairobl, Kenya) } \\
\text { pastizal himeda } \\
\text { (Batyal, Thallandla) }\end{array}$ & Long et al. (1989) \\
\hline & 139 & $0-30$ & $\begin{array}{l}\text { sabana de Trachypogon } \\
\text { (Calabozo, venezuela) }\end{array}$ & San Jose et al. (1982) \\
\hline
\end{tabular}

\section{Cociente Raíces/Aéreo}

La relación raíces vivas/biomasa aérea viva es una estimación de la distribución de energía hacia organos aéreos y subterráneos (Sims et al. 1978), y a su vez, la distribución de la biomasa en las plantas está relacionada con las presiones de selección históricas y con las condiciones ambientales actuales (Piper 1989). Dicho cociente es mayor a medida que se asciende, aunque varía a lo largo del año. Presenta un rango entre 6 y 12 en el pastizal superior (1025 m sm), entre 3 y 9 en el pastizal medio $(850 \mathrm{~m} \mathrm{sm})$ y entre 1 y 3 en el pastizal inferior (550 m sm) (Gráfico VI.1.4). Por lo tanto, en esa dirección, aumenta la proporción de tejidos de sustentación (raíces) por unidad de tejido fotosintetizante. Esto se relaciona con condiciones ambientales más restrictivas a mayor altitud (menores temperaturas del aire y del suelo, fuertes vientos) que hacia el pie de monte.

Por otra parte, no puede establecerse de manera generalizada, una relación directa entre aridez y elevados cocientes raíces/aéreo; Sims et al. (1978) hallaron similares cocientes (raíces/aéreo $=2$ ) en pastizales norteamericanos extremos en un gradiente de precipitación 
(Jornada, el más seco y Osage, el más húmedo) y en el presente trabajo las diferencias altitudinales en los cocientes raíces/aéreo no pueden atribuírse a las lluvias, ya que entre la cumbre y el pie de monte se registraron unos pocos milímetros en favor de la primera, aunque no debe dejarse de lado que la profundidad del suelo en los pastizales situados sobre el cerro es menor que en el pastizal inferior. Noy-Meir (1973) señala que los cocientes raíces/aéreo de anuales de desierto tienen valores semejantes a los de anuales de ambientes no desérticos y que el rango de variación para pastos perennes de desierto es amplio (1 a 20). La relación raíces:aéreo está más relacionada con la forma de vida (Noy-Meir 1973, Liang et al. 1989) o con los regimenes de temperatura que con la aridez (Noy-Meir 1973, Sims et al. 1978).

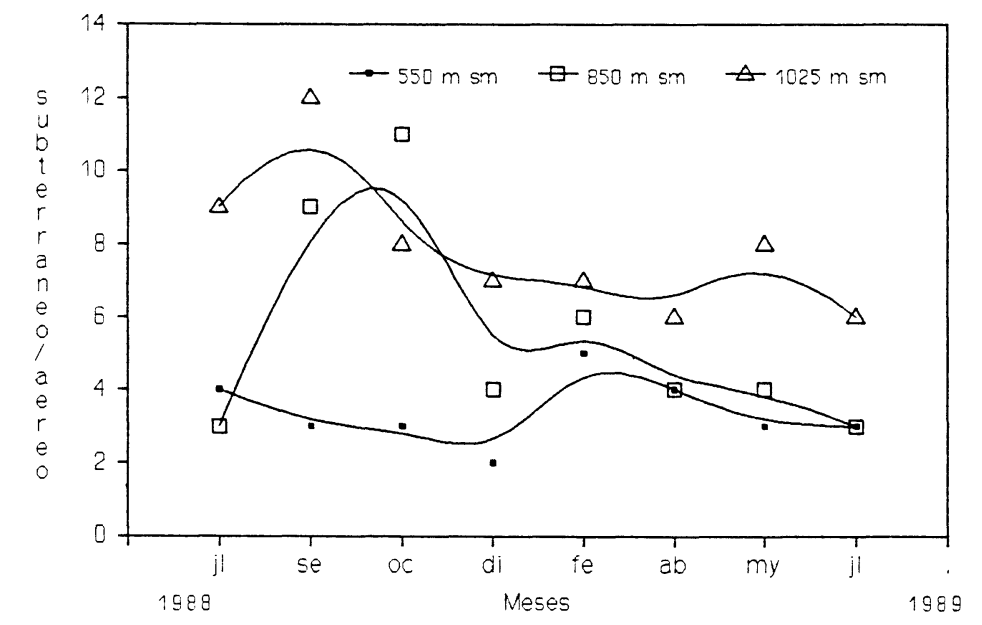

Grafico VI.1.4: Cociente biomasa subterranea/biomasa atrea en cada fecha de muestreo, en los pastizales sinuados a diferemte altinud.

El cociente raíces/aéreo, estimado a partir de las medias anuales de materia seca subterránea y aérea, en el presente trabajo disminuye junto con la altitud, siendo 3 en el pastizal superior, 2 en el pastizal medio y 1 en el pastizal inferior. En otros pastizales de la Sierra de la Ventana, el mismo cociente varía entre 0,2 , en el sitio de menor altitud, a 4 en pastizales de altura (Barrera y Frangi 1994), y la misma tendencia altitudinal es observada en dicho cociente en pastizales serranos pastoreados, siendo 2 a $450 \mathrm{~m} \mathrm{sm}$ y 3 a $850 \mathrm{~m} \mathrm{sm}$ (de Wysiecki y Pérez, no publicado). En pastizales alpinos, Grabherr (1989) estimo un 
cociente igual a 18. En pastizales de EE UU los mayores valores para el mismo cociente varía entre 13, en pastizales de pastos cortos y 6 en pastizales de montaña y en praderas mixtas; y los menores valores (cociente raíces/aéreo $=2$ ) en pastizales de pastos altos y desiertos (Sims et al. 1978). Liang et al. (1989) señalan un rango entre 3 y 25 para comunidades de la estepa de pastos cortos en EE UU. Los pastizales se ubican hacia el extremo superior del rango y el extremo inferior corresponde a arbustales. En pastizales tropicales el mismo cociente se reduce a un rango entre 0,5 y 1 (Long et al. 1989). Aunque existe una gran variación en los valores referidos, existiría una tendencia dada por mayores cocientes en los sitios más fríos comparados con los de de zonas más cálidas. Esta generalización no se contradice con los resultados del presente estudio a nivel local, donde el sitio más frio presenta la mayor relación subterráneo:aéreo, tanto si se tiene en cuenta sólo la biomasa viva o el material vivo + muerto.

Sin embargo, lo dicho en el párrafo anterior no invalida que en un determinado sitio, una reducción en la disponibilidad de agua tenga como consecuencia el incremento en la relación raíces:aéreo. En caso de stress hídrico, la principal respuesta de las plantas es la disminución del crecimiento aéreo, por lo cual dicha relación aumenta (Schulze et al. 1987, Sisson 1987). El mismo cociente de plantas de cultivo a menudo se incrementa en condiciones de sequía (Noy-Meir 1973), probablemente como un mecanismo de ajuste del suministro de agua a la demanda.

Una interpretación multifactorial de las causas de la distribución aérea y subterránea de la masa vegetal parece ser la explicación más adecuada de la misma.

\section{Distribución de la materia seca en compartimientos, en los pastizales situados a diferente altitud}

La biomasa subterránea se distribuye en profundidad en la misma proporción en los tres pastizales. En los primeros $10 \mathrm{~cm}$ de profundidad se concentran más de los $2 / 3$ de la materia seca total de raíces y aproximadamente la mitad de las raíces vivas, el resto ocupa $10510 \mathrm{~cm}$ de profundidad siguientes. 
En cada uno de los sitios estudiados, el porcentaje representado por los distintos compartimientos considerados (raíces finas vivas y muertas y, raíces gruesas vivas y muertas), con respecto a la materia seca total de cada estrato muestreado $(0-10$ y $10-20 \mathrm{~cm}$ de profundidad) mostró una distribución muy similar (Tabla VI.1.5). A mayor profundidad, aunque la materia seca en el estrato es menor, la distribución proporcional de esa materia seca en los distintos compartimientos, es semejante a la de la zona más superficial, dentro de un mismo pastizal. A su vez estas proporciones difieren entre los pastizales ubicados a mayor altitud (1025 y $850 \mathrm{~m} \mathrm{sm}$ ) y el pastizal inferior.

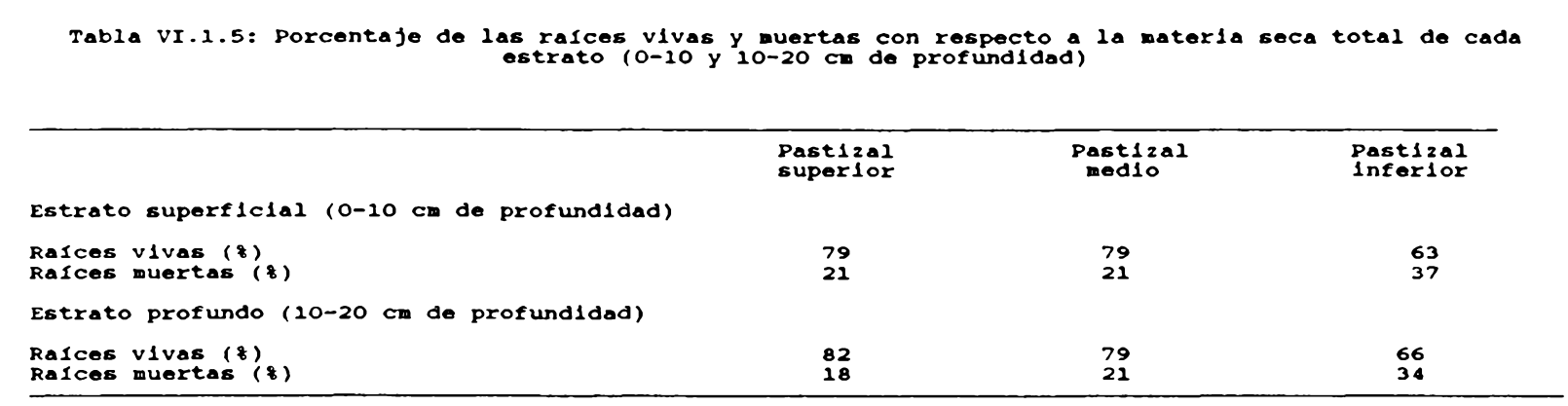

Singh y Coleman (1974) en un pastizal de pastos cortos de EEUU, dominado por Bouteloua gracilis usaron $\mathrm{C}^{14}$ para para estudiar la actividad, localizacion, y tamaño del destino del $\mathrm{C}$ en las raíces. Hallaron que el 67 a $76 \%$ de la biomasa total de las raíces se concentró en los primeros $20 \mathrm{~cm}$ de profundidad. Los mismos autores destacan la constante proporción de raíces que es involucrada en la distribución de $\mathrm{C}$ asimilado a través de la mayor parte de la estación de crecimiento, lo cual indica que existe en el sistema un eficiente mecanismo para el ajuste debido al crecimiento de las raíces y su mortalidad.

Las raíces vivas predominan sobre las muertas en los tres pastizales, pero en los pastizales superior y medio constituyen el $80 \%$ de la materia seca subterránea, mientras que en el inferior este compartimiento representa el $65 \%$ de la materia seca subterránea.

Las proporciones normalizadas de los compartimientos vivos (verde de gramíneas, raíces finas y raíces gruesas vivas) con respecto a la biomasa total (Tabla VI.1.6), varían entre los pastizales de distinta ubicación altitudinal, siendo mayor la proporción del verde a medida que disminuye la altitud, en tanto que la proporción de raíces finas vivas aumenta en ese sentido. 
A su vez el porcentaje que representan las raíces gruesas vivas es mayor en el pastizal inferior, con respecto a los ubicados sobre el cerro. Dicho de otro modo, la proporción de raíces finas se incrementa a medida que aumenta la altitud, pero de todos modos es siempre superior al porcentaje de raíces gruesas en los tres pastizales analizados.

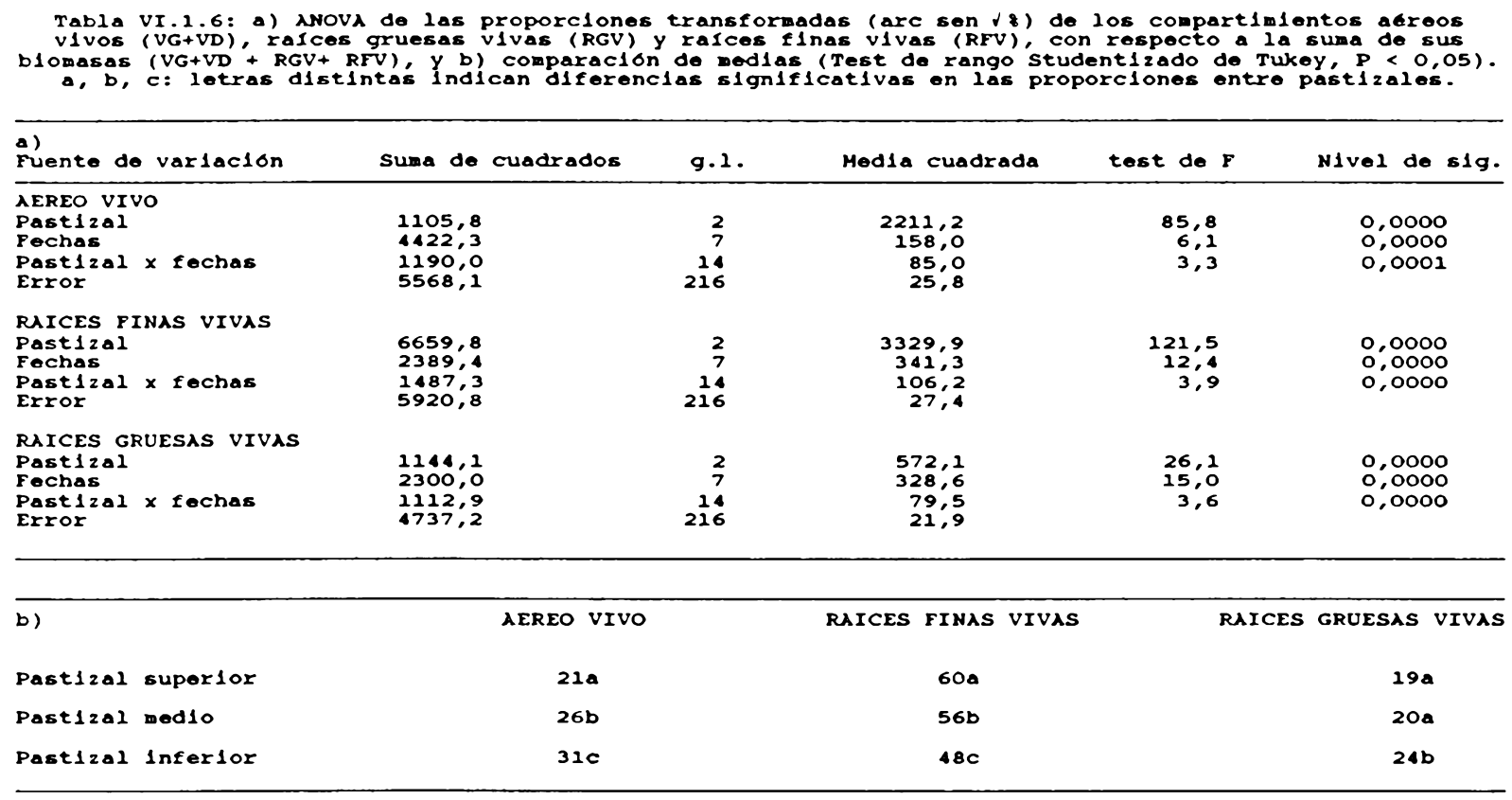

Körner y Renhardt (1987) compararon la distribución de materia seca en dicotiledóneas herbáceas perennes de dos sitios ubicados a diferente altitud en los Alpes Centrales, y señalan que la mayor fracción subterránea a mayor altitud resulta de una reducción en los tallos y un proporcional incremento en las raíces finas. Estos autores expresan que la asociación micorrícica podría influir en tales diferencias. Basándose en que las plantas que la desarrollan tienen menor materia seca subterránea y en que dicha simbiosis decrece a mayor altitud, plantean que un extendido sistema de raíces finas en zonas elevadas sería un sustituto funcional de las asociaciones micorrícicas, comunes a baja altitud. En los pastizales serranos estudiados es probable que la mayor proporción de raíces finas en los sitios de mayor altitud (850 y $1025 \mathrm{~m} \mathrm{sm)} \mathrm{esté} \mathrm{relacionada} \mathrm{principalmente} \mathrm{con} \mathrm{las} \mathrm{necesidades} \mathrm{hídricas} \mathrm{de} \mathrm{las}$ plantas, condicionadas por el menor desarrollo en profundidad del suelo, respecto del pastizal ubicado en la base del cerro. 


\section{Asociaciones micorrícicas en los pastizales serranos}

En numerosos trabajos se destaca la importancia de las micorrizas en sistemas de pastizal (Coleman 1976, Allen y Allen 1980, Newman et al. 1986, Stanton 1988, McNaughton y Oesterheld 1990). En los pastizales predominan las micorrizas vesículo-arbusculares (MVA), que son simbiontes intracelulares obligados (Stanton 1988).

Las micorrizas vesículo-arbusculares son asociaciones simbióticas mutualistas que se desarrollan entre las raíces de la mayoria de las especies vegetales y ciertos hongos del suelo. Se trata de una simbiosis que alcanza a la numerosas especies vegetales y se da en la mayoría de los habitats naturales (Barea et al. 1984). Estos autores destacan el importante papel de las micorrizas en la evolución y supervivencia de las plantas, así como una contribución significativa en la producción vegetal, basado principalmente en su efecto sobre el ciclado del P. También se ha demostrado la intervención de las micorrizas en la obtención de micronutrientes (cobre, aluminio, hierro) (Clarkson 1985). Los hongos de la micorriza por medio de su red de hifas externas capta nutrientes, principalmente fosfato, desde un volumen mucho mayor de suelo que el que puede ser explorado por la planta sola y transfiere estos iones a la planta hospedadora, la cual provee energia en forma de carbohidratos al hongo (Barea et al. 1984, Griffiths et al. 1990).

Se sabe que las propiedades del suelo, entre ellas el nivel de macro y micronutrientes ejercen una influencia selectiva sobre distintas especies de hongos presentes en él (AzconAguilar et al. 1984). En pastizales del Serengeti (Tanzania), Mc Naughton y Oesterheld (1990) hallaron que la longitud de las hifas de MVA presentes en el suelo estaba negativamente correlacionada con el contenido de materia orgánica del suelo, y el contenido total de nutrientes del mismo a lo largo de un gradiente de fertilidad de los suelos. Estos autores proponen que las asociaciones micorrícicas ayudarían a mantener la concentración de nutrientes en las plantas dentro de estrechos niveles comparado con la variación de los suelos y por lo tanto disminuirían el potencial stress nutricional tanto de las plantas como de los herbívoros.

En término generales no existe una marcada especificidad en la relación planta-hongo 
(Azcon-Aguilar et al. 1984). Aunque puede existir mayor o menor compatibilidad en las distintas combinaciones de una planta con un hongo. Hetrick et al. (1988) mostraron que los pastos de estación cálida $\left(\mathrm{C}_{4}\right)$ e hierbas dicotiledóneas $\left(\mathrm{C}_{3}\right)$ tuvieron una mayor dependencia de la colonización por micorrizas para su crecimiento que los pastos de estación fría $\left(\mathrm{C}_{3}\right)$. Los primeros tienen raíces más gruesas, menos ramificadas, que los pastos de estación fria, sosteniendo la hipótesis de que la micorrización depende de la morfología de las raíces, más que del tipo de mecanismo fotosintético. Al respecto, Reinhardt y Miller (1990) señalan que las raíces susceptibles de ser micorrizadas son aquellas menores de $1 \mathrm{~mm}$, consideradas raíces finas. Los mismos autores hallaron que dentro de las raíces finas, las clases diamétricas más gruesas son colonizadas en mayor proporción. A partir de lo cual sugieren que en comunidades de pastizal el grado de colonización por hongos micorrícicos depende principalmente de la distribución de las raíces finas en tamaños de clase de diámetro más que en la composición específica de la comunidad.

En el pastizal superior el $57 \%$ de la longitud de raíz está colonizada por endófitos formadores de micorrizas vesículo-arbusculares (MVA), encontrándose 14 esporas cada 25 $\mathrm{g}$ de suelo rizosférico; a media ladera el porcentaje de longitud de raiz colonizada es de 45 $\%$, y se contabilizaron 19 esporas cada $25 \mathrm{~g}$ de suelo y en el pastizal inferior el porcentaje de infección es $40 \%$, habiendo 20 esporas cada $25 \mathrm{~g}$ de suelo (Marta Cabello com. pers.). Estos resultados surgen de analizar muestras obtenidas a mediados de la primavera durante la realización del presente estudio. Aunque el grado de colonización con micorrizas puede variar con el estado de desarrollo de las plantas a lo largo del año (Allen y Allen 1980, Cabello 1988), se observa una tendencia creciente en el porcentaje de infección desde el pastizal inferior al superior. El mayor porcentaje de infección y menor número de esporas en los pastizales de mayor altitud indicaría mayor actividad de las micorrizas, probablemente favorecidas por una alta proporción de raíces finas vivas en los pastizales superior y media ladera, con respecto al inferior.

Por otra parte los porcentajes de micorrización hallados en estos pastizales serranos se encuentran dentro de los valores señalados en otros trabajos para sistemas de pastizal. Jastrow y Miller (1993) muestran que en Andropogon gerardii, el porcentaje de longitud de raiz colonizada varía entre 15 y $20 \%$ según las especies que crezcan en su proximidad. En 
pastizales no disturbados, dominados por Andropogon smithii, Allen y Allen (1980) señalan que el porcentaje de micorrización varió entre 81 y $95 \%$, según la época del año. Newman et al. (1986), en sabanas africanas encontraron que el grado de infección variaba entre 30 y $60 \%$, segun las especies y los tipos de suelo.

La hipótesis planteada por Körner y Renhardt (1987) en cuanto a que el aumento con la altitud de la proporción de raíces finas en hierbas dicotiledóneas sería un sustituto funcional de las asociaciones micorrícicas, más comunes a menor altitud, no concuerda con los resultados de los porcentajes de colonización por MVA de los pastizales de este trabajo. Sin embargo, no debe dejarse de lado que el clima de estos sitios es relativamente benigno, comparado con las altas cumbres alpinas a las que hacen referencia los mencionados autores, siendo la temperatura del suelo un factor destacable que influye en el desarrollo de las micorrizas. Hasta los $30^{\circ} \mathrm{C}$ el grado de micorrización presenta una relación directa con el aumento de la temperatura. A partir de esa temperatura la infección decrece y por encima de los $40^{\circ} \mathrm{C}$ se inhibe por completo (Azcon-Aguilar et al. 1984). Es probable que en ausencia de un factor como pueden ser temperaturas extremas, otros factores adquieran mayor importancia en la formación de esta simbiosis. En los pastizales analizados en el presente trabajo, los de mayor altitud tienen una proporción más alta de raíces finas vivas con respecto al inferior, y en los mismos el porcentaje de infección también es mayor. Estos resultados no son contradictorios con la hipótesis planteada en cuanto a que el grado de colonización por MVA depende de la morfología de los sistemas radicales de la plantas más que de las especies (Hetrick et al. 1988, Reinhardt y Miller 1990).

\section{El esfuerzo reproductivo en los pastizales serranos}

En numerosos trabajos se han analizado a nivel intraespecífico esfuerzos reproductivos y patrones de translocación de energía hacia órganos fotosintéticos y no fotosintéticos (Harper y Ogden 1970, Hickman y Pitelka 1975, Kawano y Masuda 1980, King y Roughgarden 1983, Reekie y Bazzaz 1987). En el presente estudio se considera en forma comparativa la proporción de la productividad neta total destinada a las estructuras involucradas en la reproducción sexual de las gramíneas, en comunidades multiespecíficas. 
Frangi et al. (1980a) estimaron el esfuerzo reproductivo en pastizales como el porcentaje de la productividad invertido en estructuras reproductivas, suma de las cosechas en pie máximas de las mismas durante la primavera y fines del verano. Los mismos autores señalan que el pico primaveral representa el $98 \%$ del esfuerzo reproductivo total. Este porcentaje es coincidente con el estimado en el presente estudio. A su vez las biomasas pico primaverales de las estructuras reproductivas no presentan diferencias entre los pastizales superior y medio siendo respectivamente $10,5 \pm 1,6 \mathrm{~g} / \mathrm{m}^{2}$ y $12,9 \pm 2,1 \mathrm{~g} / \mathrm{m}^{2}$. El pastizal inferior presenta mayor biomasa de estructuras reproductivas $\left(24 \mathrm{~g} / \mathrm{m}^{2}\right)$ con respecto a los otros dos sitios, pero la mayor proporción de la misma corresponde a la especie anual Vulpia dertonensis (16 $\left.\mathrm{g} / \mathrm{m}^{2}\right)$, que refleja aún el efecto de tensiones sufridas por el pastizal. Si se refiere sólo a las perennes $\left(7,6 \pm 1 \mathrm{~g} / \mathrm{m}^{2}\right)$, entonces se destaca que hay un esfuerzo similar en todo el gradiente. La especie anual mencionada es probable que haya aumentado su importancia en el pastizal a partir de la ocupación de espacios de suelo desnudo provocados por el incendio de 1987. Este factor ha actuado en toda la reserva, pero posiblemente con mayor intensidad en el pastizal inferior, comparado con los otros dos sitios considerados, por presentar mayor material combustible. Además es probable que en dicho pastizal se haya sumado una mayor intensidad de pastoreo post-quema por caballos salvajes. En los otros pastizales la aparición de Vulpia dertonensis es mínima. Por otra parte, el comportamiento típico de las anuales es destinar una elevada porción de su biomasa a estructuras reproductivas en un corto período (Harper y Odgen 1970, Hickman 1975, Schulze 1982, King y Roughgarden 1983, Wilson y Thompson 1989).

Kawano y Masuda (1980), hallaron que poblaciones de una liliácea, Heleniopsis orientalis, destinan en forma creciente mayor energía a la reproducción en respuesta al incremento en la elevación y acortamiento de la estación de crecimiento. En cambio, Körner y Renhardt (1987) en comparaciones interespecíficas de herbáceas situadas a distinta altitud, no encontraron diferencias en las proporciones de energía destinadas a estructuras reproductivas.

De acuerdo con los resultados del presente estudio, las diferencias entre pastizales, en las proporciones de materia seca destinadas a las estructuras reproductivas, con respecto a la productividad primaria neta total, son pequeñas (Tabla VI.1.7), de modo que en las distintas altitudes se observa un mismo patrón en la distribución de fotosintatos hacia órganos 
reproductivos, quizás a consecuencia de un gradiente altitudinal de aproximadamente 500 metros de desnivel que no presenta condiciones extremas en los elementos del clima sobre las laderas de solana (Kristensen, com. pers.) y se encuadra en un macroclima relativamente benigno, especialmente si se tienen en cuenta las estaciones favorables del año. Las gramíneas perennes, que son las dominantes en los pastizales estudiados, tienen en su mayoría macollos o rizomas, los cuales constituiyen un complemento y alternativa de importancia en la propagación de los individuos.

\begin{tabular}{|c|c|c|}
\hline PASTIZALES & ESFUERZO & REPRODUCTIVO ( 8 ) \\
\hline SUPERIOR ( $1025 \mathrm{msm})$ & & 0,9 \\
\hline MEDIO ( $850 \mathrm{msm})$ & & 1 \\
\hline INFERIOR (550 $\mathrm{msm})$ & 2* & $0,7 \star \star$ \\
\hline
\end{tabular}

\section{Hojarasca}

La necromasa media anual de la hojarasca, en valor absoluto, es semejantes en los tres sitios (Tabla VI.1.8). Sin embargo la acumulación de hojarasca en el pastizal superior a principios de julio de 1989 es aproximadamente el doble que en el año anterior, en el pastizal medio no varía de un año a otro y, aumenta en un $50 \%$ en el pastizal inferior. Si bien este compartimiento de la materia seca aérea es bastante variable espacialmente (coeficientes de variación superiores al $30 \%$ en la mayoría de los muestreos) y temporalmente, el aumento en la hojarasca en el curso del período de muestreo se relaciona con una acumulación de materia seca post-fuego. Por otra parte, la variabilidad tanto espacial como temporal de la hojarasca ya ha sido señalada por otros autores (Sims y Singh 1978a, Swift et al. 1979).

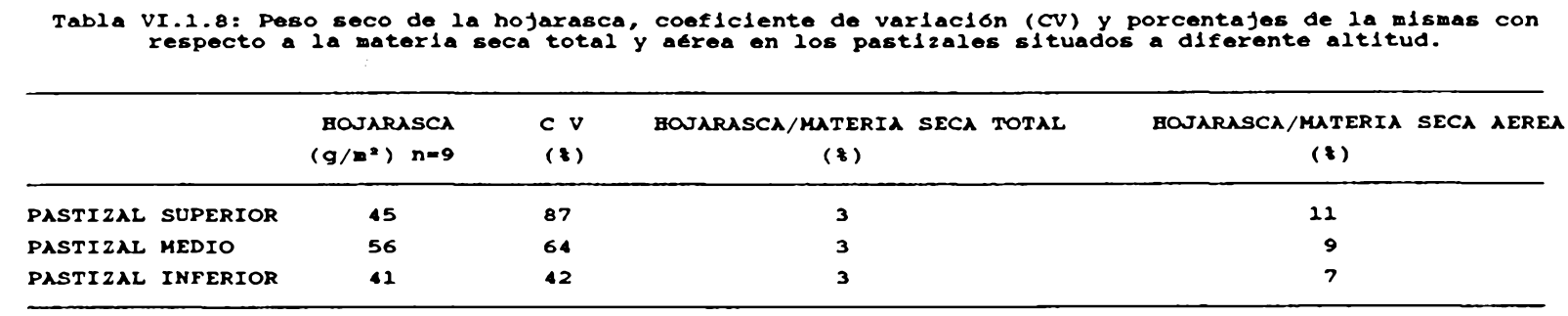


La hojarasca, en los tres pastizales estudiados, representa aproximadamente la misma proporción de la materia seca total (Tabla VI.1.8). Sin embargo, cuando se refiere dicho compartimiento a la materia seca aérea solamente, se observa una tendencia decreciente en tal porcentaje desde la cumbre hacia la base del cerro.

\section{VI.2- TENDENCIAS ESTACIONALES EN LA MATERIA SECA Y HOJARASCA}

En los tres sitios estudiados se observan tendencias similares en las variaciones de la materia seca y la hojarasca a lo largo del año: los compartimientos aéreos y las raíces vivas aumentan durante la primavera y el otoño temprano, a la vez que disminuyen las raíces muertas y la hojarasca. Durante el verano y el invierno se incrementan los compartimientos muertos y disminuyen los compartimientos vivos.

La materia seca aérea en pie presenta durante la primavera una tendencia creciente, coincidente con el aumento en las temperaturas y en las precipitaciones, pero alcanzan valores máximos en diferentes momentos de acuerdo con la altitud de los pastizales.

El pico primaveral ocurre antes en el pastizal inferior que en los otros dos sitios de mayor altitud. Kristensen y Frangi (1995) en sus estudios mesoclimáticos de estos pastizales ha definido a la cumbre como un sitio frío, al pastizal ubicado a media ladera como un sitio fresco, con temperaturas extremas poco mayores que las de la cumbre, resultando los sitios basales relativamente más cálidos que los anteriores. Estas características térmicas permitirían explicar el retraso en el pico de materia seca en los pastizales de mayor altitud, con respecto al inferior. Körner y Woodward (1987) han hallado que las tasas de extensión foliar de varias especies de gramíneas responden estrechamente a la marcha diaria de la temperatura a lo largo del día. Dichas tasas son más elevadas en los sitios de menor altitud que en aquellos ubicados a grandes alturas. Estos autores señalan que la disparidad en el crecimiento entre las plantas alpinas y las ubicadas a baja altitud no puede atribuirse a diferencias en características tales como capacidad fotosintética de las plantas, contenido de nutrientes del suelo o regimen hídrico y sugieren que la temperatura, a través de su estrecha relación con las tasas de extensión foliar, estaría determinando esas diferencias. En el presente estudio el rango altitudinal entre los sitios no es tan marcado, pero sin embargo el pico anticipado en el sitio 
más cálido (pastizal inferior) no es contradictorio con la hipótesis de Körner y Woodward (1987), especialmente si se tiene en cuante que las temperaturas primaverales tienen un efecto de arrastre del invierno anterior (Kristensen y Frangi 1995), el cual implica que las temperaturas favorables al crecimiento se alcancen más tarde a mayor altitud.

En los tres sitios la materia seca aérea desciende durante el verano. El pastizal superior, considerado más húmedo y con bajo déficit de saturación del aire (Kristensen y Frangi 1995) presenta bajos valores de materia seca aérea a fines de diciembre, pero durante el resto del verano la tendencia de la parte aérea es creciente, debido a que durante esos meses las lluvias fueron importantes, combinándose con su condicion de sitio relativamente más frio y húmedo. En los otros dos pastizales, en cambio, la tendencia decreciente de diciembre continúa durante gran parte del verano, respondiendo a condiciones hídricas menos favorables que las de la cumbre.

A fines de verano-principios de otoño, un balance más favorable entre precipitaciones y evapotranspiración y temperaturas benignas, permiten un aumento en la materia seca aérea, que es coincidente, temporalmente, en los tres sitios.

A principios del invierno la biomasa de los compartimientos vivos disminuye, y aumenta el seco en pie, respondiendo al descenso en las temperaturas. En los pastizales ubicados a menor altitud la disminución en los compartimientos vivos es menos marcada que en la cumbre, posiblemente porque el descenso térmico y las heladas en dichos sitios son relativamente menores.

En los sitios estudiados las raíces que ocupan la porción superior del perfil constituyeron el componente más dinámico de la materia seca subterránea, mientras que las raíces que ocupan los $10 \mathrm{~cm}$ más profundos presentan pocas variaciones de su materia seca, principalmente en los pastizales superior y media ladera. La menor variabilidad en la masa de las raíces más profundas se atribuiría a que las condiciones térmicas e hídricas en ese estrato son más constantes que en la parte superficial. Otros autores también destacan la mayor constancia en las raíces de los estratos más profundos (Dahlman y Kucera 1967, Fernández y Caldwell 1975). 
Las raíces finas vivas constituyen el componente más dimámico de la materia seca subterránea. En los tres sitios éstas aumentan cuando las condiciones hídricas y térmicas son favorables, a comienzos de primavera y de otoño, pero su crecimiento también es importante durante períodos de sequía, aunque en ese caso la mortalidad es elevada, lo que determina el aumento del compartimiento de las raíces finas muertas durante la primavera tardía y el verano. En el invierno, la reducción de la biomasa verde en un período limitativo de la fotosíntesis por bajas temperaturas se asocia a la reducción en la biomasa de raíces vivas.

Sims et al. (1978a) en sus estudios de de diez pastizales norteamericanos hallaron que la variabilidad en la materia seca subterránea anual es mejor explicada por la radiación solar o la temperatura. En el presente trabajo, el sitio más frío (pastizal superior) es el de mayor materia seca subterránea y mayor cociente raíces/aéreo; en el pastizal inferior, que es el más cálido de los tres, se hallaron los valores más bajos y el pastizal ubicado a media ladera con temperaturas intermedias entre los dos extremos de este gradiente presenta también valores intermedios de materia seca subterránea y del cociente raices/aéreo.

\section{VI.3- LOS SUELOS SERRANOS Y SU RELACION CON LA BIOMASA VEGETAL}

Los suelos de los pastizales del presente estudio se enmarcan dentro de caracterizaciones de suelos de la zona, realizadas sin detalle. Capannini et al. (1971), señalan que los suelos del ambiente serrano, se han desarrollado a partir de sedimentos loessicos de origen eólico, tienen textura franca y elevado contenido de materia orgánica, que los hace estables a la erosión, pese a que ocupan pendientes del orden del $5 \%$ a superiores. De acuerdo con el Mapa de suelos de la provincia de Bs As (1989), los hapludoles líticos serían los suelos más difundidos en las Sierras del sistema de Ventania. En el Atlas de condiciones de los Suelos (1966) para el área en que se encuentran los pastizales del presente estudio, los suelos en su horizonte superficial son ricos en materia orgánica (3,2 a 4,9\%), normalmente provistos de Ca (81 a más $150 \mathrm{mgCa} / 100 \mathrm{~g}$ de suelo), bien provistos a muy ricos en $\mathrm{Mg}$ y $\mathrm{K}$ asimilables (41 a más de $80 \mathrm{mgMg} / 100 \mathrm{~g}$ de suelo y 31 a más de $60 \mathrm{mgK} / 100 \mathrm{~g}$ de suelo), pobres en $\mathrm{P}$ ( 1 a $4 \mathrm{mg} / 100 \mathrm{~g}$ de suelo) y cuyo $\mathrm{pH}$ es débil a moderadamente ácido, con pH netamente ácidos sobre las sierras $(5,0$ a 5,4$)$. 
Los suelos de los sitios de pastizal estudiados en el presente trabajo son someros, en contacto con la roca subyacente, y sin horizonte B. La profundidad de los mismos varía; sobre la sierra alcanza los $20 \mathrm{~cm}$, y 30 a $40 \mathrm{~cm}$ en el pie de monte. Son suelos bien drenados, de textura franca-arenosa a franca, con presencia de gravas y gravillas.

Se observa una tendencia creciente en el porcentaje de arcillas desde la cumbre hacia la base $(9,6$ a $23,4 \%)$. La tendencia opuesta se evidencia en el porcentaje de carbono orgánico, siendo 1,7 veces menor en el pastizal inferior que en los otros ubicados a mayor altitud (6,3 a $3,8 \%$ ). El mayor contenido de arcilla en uno y de materia orgánica en los otros, respectivamente, se relaciona con la similitud en la capacidad de intercambio catiónico en los tres sitios (23,6 en el pastizal superior, 25,4 en el pastizal medio y 24,5 en el pastizal inferior). En el mismo sentido en que decrece la materia órganica de los suelos, también decrece la concentración de $\mathrm{N}$ y $\mathrm{P}$. El contenido de $\mathrm{N}$, en cambio difiere del patrón seguido por la concentración, ya que el mismo es ligeramente mayor en el pie de monte, con respecto a la situación a media ladera.

El mayor contenido de cationes de intercambio y el aumento como consecuencia del porcentaje de saturación con bases, junto con la mayor proporción de arcillas, desde la cumbre hacia el pie de monte estaría vinculado a los procesos intervinientes en la evolución de los suelos, en los que el lavado y arrastre desde las zonas más elevadas hacia las partes bajas de la sierra tendría una importancia destacada. La tendencia creciente en el porcentaje de saturación con bases en los suelos desde el pastizal superior al inferior también es seguida por el $\mathrm{pH}$, cuya acidez disminuye en ese sentido $(4,3$ a 5,4$)$. En relación con lo anterior, el pastizal inferior presenta valores de $\mathrm{Ca}, \mathrm{Mg} \mathrm{y} \mathrm{K}$, que se ubican en el extremo superior del rango señalado por el Atlas de condiciones de suelos (1966) $(208 \mathrm{mgCa} / 100 \mathrm{~g}$ de suelo, 102 $\mathrm{mgMg} / 100 \mathrm{~g}$ de suelo, $113 \mathrm{mgK} / 100 \mathrm{~g}$ de suelo). Los pastizales ubicados a mayor altitud, en cambio, tienen concentraciones de $\mathrm{Mg}$ cercanos al extremo inferior en el caso del pastizal medio (43 mgMg/100 $\mathrm{g}$ de suelo), o aún por debajo del mismo en el caso del $\mathrm{Mg}$ y el $\mathrm{K}$ en el pastizal superior ( $34 \mathrm{mgMg} / 100 \mathrm{~g}$ de suelo, $16 \mathrm{mgK} / 100 \mathrm{~g}$ de suelo) y de $\mathrm{K}$ en el pastizal medio ( $20 \mathrm{mgK} / 100 \mathrm{~g}$ de suelo). Con respecto al calcio, el mismo se ubica cercano al extremo superior del rango en ambos pastizales serranos $(115 \mathrm{mgCa} / 100 \mathrm{~g}$ de suelo en el pastizal superior y $170 \mathrm{mgCa} / 100 \mathrm{~g}$ de suelo en el pastizal medio). 
Otras descripciones de suelos en la zona, a nivel de sitio, son las realizadas por Frangi et al. (1980a) en el pastizal inferior y por Ricci (1992) en un flechillar a $450 \mathrm{~m}$ sm y en un pastizal de Sorghastrum pellitum a $850 \mathrm{~m} \mathrm{sm}$, sobre la vertiente oriental del Cerro Napostá. Los porcentaje de $\mathrm{C}$ orgánico, materia orgánica y $\mathrm{N}$ del horizonte $\mathrm{A} 1$ del perfil $\mathrm{N}^{0} 1$ señalados por Frangi et al. (1980) son similares a las estimaciones realizadas en el mismo sitio en el presente trabajo. Ricci (1992), señala que los suelos del flechillar por ella estudiado, el cual se corresponde topográficamente con el pastizal inferior, presenta menores contenidos de $\mathrm{C}$, materia orgánica y $\mathrm{N}$. La autora sugiere que estas diferencias estan relacionadas con la menor cobertura vegetal en dicho pastizal debido al efecto del pastoreo.

El pastizal medio se corresponde topográficamente con el pastizal de Sorghastrum pellitum cuyo perfil del suelo es descripto por Ricci (1992). Las diferencias más notables entre ambos es el mayor desarrollo de este último, que supera los $50 \mathrm{~cm}$ de profundidad y en el cual se evidencian, por debajo del A1, los horizontes de iluviación B1, B12t y B22t. La presencia de los horizontes B textural está en relación directa con el mayor porcentaje de arcillas en estos suelos con respecto al pastizal medio e incluso con respecto al flechillar que se ubica en el pie de monte, sobre la misma ladera del Cerro Napostá. Otra diferencia entre los suelos de ambos sitios está dada por el mayor contenido de $\mathrm{C}$, materia orgánica y $\mathrm{N}(8,3 \% ; 14,3 \%$ y $0,75 \%$ respectivamente), en el horizonte superficial del perfil descripto por Ricci. Las diferencias entre perfiles de suelos a similar altitud no llaman la atención en un ambiente tan heterogéneo como el serrano, donde la topografía y el sistema de plegamiento asociado juegan un importane papel en esa heterogeneidad. La permeabilidad moderadamente lenta que caracteriza al mismo podría contribuir a la acumulación de materia orgánica en la parte superficial del suelo. Dado que la vegetación es la principal fuente orgánica del suelo, la distribución de la materia seca de las plantas en orgános aéreos y subterráneos podria influir en su aporte al mismo. La materia orgánica del suelo puede derivar primariamente de los detritos de las raíces, dada la magnitud relativa de la biomasa aérea y subterránea (Schimel et al. 1985). En el presente trabajo se puso de manifiesto la importancia de las raíces, comparadas con el material aéreo, en cuanto a su contribución a la materia orgánica del suelo, dada por su elevada biomasa, producción y rápida desaparición. La importante masa de raíces en el sorghastral ubicado sobre el Napostá $\left(950 \mathrm{~g} / \mathrm{m}^{2}\right.$, de Wysiecki y Pérez 
inédito), junto con impedimentos en el drenaje son consistentes con la elevada concentración C y $\mathrm{N}$ orgánico en el primer sitio mencionado. Comparando los pastizales del presente estudio entre sí, la relación raíces/aéreo de los mismos aumenta a medida que se asciende y la misma tendencia se observa en la materia orgánica del suelo, mientras que el cociente $\mathrm{C} / \mathrm{N}$ disminuye. Schimel et al. (1985) sostienen que dicho cociente esta correlacionado inversamente con el porcentaje del $\mathrm{N}$ total del suelo que es mineralizado anualmente. $\mathrm{El}$ cociente $\mathrm{C} / \mathrm{N}$ estaría directamente vinculado con un creciente ingreso de $\mathrm{C}$ al sistema, lo que puede llevar a una alta inmovilización de $\mathrm{N}$, disminuyendo su mineralización relativa.

Con respecto al $\mathrm{P}$, la concentración del mismo en el suelo del pastizal superior es 2 veces mayor que en el pie de monte. A su vez, comparado con el pastizal pastoreado de Sorghastrum estudiado por Ricci (1992), en el pastizal medio la proporción de P es 4 veces mayor. De todas maneras estas concentraciones son consideradas bajas $(0,7 \mathrm{mg} / 100 \mathrm{~g}$ de suelo en el pastizal inferior, $0,5 \mathrm{mg} / 100 \mathrm{~g}$ de suelo en el pastizal medio y $0,34 \mathrm{mg} / 100 \mathrm{~g}$ de suelo el pastizal inferior). La interacción entre los nutrientes $\mathrm{C}, \mathrm{N}$ y $\mathrm{P}$ en los procesos de descomposición y mineralización de la materia orgánica en el suelo es un factor destacable en el ciclado de los mismos. Los ciclos del C, N y P están interrelcionados y la interacción de los nutrientes toma lugar desde el nivel individual, al de ecosistema, en la producción primaria, en los procesos de descomposición y en el ciclo de los nutrientes (Stewart et al. 1983, McGil y Christie 1983, Hunt et al. 1983). Coleman et al. (1983) destacan que la mayor parte de los nutrientes se encuentran en forma inactiva y sólo una pequeña porción, biologicamente activa, circulando rápidamente, constituye la principal fuente de $\mathrm{N}$ y $\mathrm{P}$ necesario para las plantas. A su vez la tasa de mineralización del $\mathrm{P}$ orgánico está influenciada por el $\mathrm{P}$ soluble y por el cociente C:P de los microorganismos (Stewart et al. 1983). La liberación de un nutriente ocurre cuando el cociente $C$ :nutriente cae a niveles similares a los de los organismos descomponedores (Swift et al. 1979). Ruess y Seagle (1994) consideran que en el Serengeti, la menor tasa de mineralización del $\mathrm{N}$ no se corresponde con la masa microbiana presente en el mismo, sugiriendo que el contenido de $\mathrm{C}$ relativo al $\mathbf{P}$ total puede ser más importane que el $\mathrm{C}: \mathrm{N}$ en la renovación del $\mathrm{N}$ y el $\mathrm{C}$. De acuerdo con estas consideraciones, la baja disponibilidad de $\mathrm{P}$ en los suelos de los pastizales estudiados podría tener un rol preponderante en los procesos de inmovilización y mineralización de nutrientes, y como consecuencia en su disponibilidad para las plantas. 
Con respecto a la reacción del suelo, los bajos valores del mismo en los pastizales del presente estudio han sido también señalados por Ricci (1992), siendo 4,3 y 4,8, en los pastizales ubicados a 450 y $850 \mathrm{~m}$ sm respectivamente. Swift et al. (1979) puntualizan que el $\mathrm{pH}$ de los suelos resulta de la interacción de un complejo de factores, tales como las características del material originario, las precipitaciones, el contenido de materia orgánica y la proporción de bases de intercambio. Como se dijo, en el presente trabajo el aumento del pH desde la cumbre hacia la base es consistente con el aumento en el porciento de saturación con bases y con una menor proporción de materia orgánica. Swift et al. (1979), consideran que el efecto del $\mathrm{pH}$ del suelo sobre los organismos del mismo tiene mayor influencia sobre la microflora y microfauna, siendo las bacterias más afectadas que los hongos. En suelos de extrema acidez, con pH menores que 3 la descomposición puede ser llevada a cabo sólo por hongos (Coleman et al. 1983). En cuanto a la fijación de $\mathrm{N}_{2}$ atmosférico, se han registrado asociaciones simbióticas con leguminosas en la sabana de Trachypogon, en Venezuela, con pH del suelo entre 4,2 y 5,1 (Izaguirre Mayoral y Mallorca 1993) y a pH 4,8 en pasturas de leguminosas en Colombia (Thomas y Asakawa 1993), por lo cual la acidez podría influir en la composición específica de los fijadores biológicos de nitrógeno atmosférico, pero no necesariamente inhibir su presencia.

\section{El almacenaje de carbono en los suelos}

El suelo, visto como un almacenaje de carbono a escala global, ha cobrado importancia en los últimos años ante la evidencia de la creciente concentración de $\mathrm{CO}_{2}$ atmósferico (Scheiner 1989). Post et al. (1982), basandose en perfiles de suelo del mundo en relación con el sistema de zonas de vida de Holdridge, señalan que la densidad de carbono en el suelo aumenta con las precipitaciones y con el descenso en las temperaturas, para todos los niveles de precipitación. Dada la estrecha relación entre el clima y el almacenaje de carbono en el suelo, se esperaría que cambios en el primero pueden llevar consigo alteraciones en el segundo.

La posible acumulación de carbono en el suelo, como consecuencia del incremento atmósferico de $\mathrm{CO}_{2}$, está mediada por el efecto de dicho incremento sobre la vegetación. 
Evidencias acerca del efecto del incremento atmósferico de $\mathrm{CO}_{2}$ sobre la vegetación son claras a nivel de individuo, sin embargo, las mismas pueden ser modificadas por numerosos factores y no predecir las respuestas de la comunidad (Bazzaz 1990). El mismo autor señala que, aunque las respuestas al incremento de $\mathrm{CO}_{2}$ atmosférico a nivel fisiologico varían según las especies, en numerosos casos dicho incremento genera 1) un aumento en la tasa fotosintética, principalmente en las plantas $\mathrm{C} 3$, cuando otros factores y recursos ambientales están presentes en forma adecuada; 2) una menor conductancia estómatica, lo que lleva a reducir la tasa transpiratoria y a aumentar la eficiencia en el uso del agua y 3) una mayor alocación de biomasa hacia las raíces. A nivel de comunidad, es probable que el impacto sobre la productividad, a raiz del aumento de los niveles de $\mathrm{CO}_{2}$, este dado principalmente por cambios en la composición de especies debido a las respuestas diferenciales de las plantas a elevados niveles de $\mathrm{CO}_{2}$ (Bazzaz 1990).

Las consecuencias sobre el ciclo de carbono en ecosistemas terrestres, al incrementarse el nivel de $\mathrm{CO}_{2}$ en la atmósfera, es altamente dependiente del patrón de translocación de carbono en las plantas y su subsecuente transformación en el suelo por los microorganimos (van Veen et al. 1991). Los mismos autores, en el terreno de las especulaciones, consideran que con una elevacion del $\mathrm{CO}_{2}$ atmosférico, el incremento en la producción vegetal junto con mecanismos de preferencia de sustratos de los microbios del suelo, y una menor degradabilidad de los residuos vegetales al aumentar el cociente $\mathrm{C} / \mathrm{N}$ puede llevar a que los materiales más recalcitrantes puedan acumularse, aumentando los niveles de materia orgánica del suelo. Rastetter et al. (1992), a partir de modelos de simulación señalan que el aumento en el $\mathrm{CO}_{2}$ atmosférico podría llevar a un aumento en el almacenaje de $\mathbf{C}$ en sistemas no leñosos a través del incremento del cociente $\mathrm{C}: \mathrm{N}$ en la vegetación. A partir de balances globales de $\mathrm{C}$, Johnson (1992) expresa que los suelos forestales podrían ser una gran fuente de emisión o de acumulación de carbono, dependiendo de las prácticas de manejo.

En los pastizales estudiados en el presente trabajo, varias de sus características llevan a suponer que los mismos serían centros potenciales de acumulación de $\mathrm{C}$. La flexibilidad en los patrones de asignación de la biomasa a estructuras aéreas y subterráneas, en respuesta a variables ambientales, y en el cociente $\mathrm{C}: \mathrm{N}$ en la vegetación, junto con la elevada producción de raíces, las cuales constituyen la via principal de ingreso de carbono orgánico al suelo, pone 
de manifiesto la importancia de estos sistemas como posibles receptores de carbono. Debe enfatizarse que el manejo de los ecositemas y en particular de los pastizales, es de importancia extrema ya que aquellos que potencialmente podrían ser centros de acumulación de carbono, debido a un uso inadecuado pueden convertirse en centros de emisión, a partir de la degradación de la vegetación y del suelo. En relación con lo anterior, la carga animal y el tiempo de permanencia en los potreros, como así también el uso del fuego como medio frecuentemente utilizado para mejorar el valor forrajero de los pastizales deben adecuarse en magnitud y frecuencia a fin de permitir su uso sostenido en el tiempo. 


\section{VI.4-PROCESOS FUNCIONALES EN LOS PASTIZALES SERRANOS}

\section{Productividad, Mortalidad, Caída a la hojarasca y Desaparición}

La productividad primaria neta total anual es similar en los tres pastizales ubicados a lo largo del gradiente altitudinal. El pastizal superior se diferencia de los otros dos en que asigna una mayor proporción del crecimiento neto anual a las raíces (Tabla VI.4.1).

La tasa de recambio de las raíces del pastizal superior es la mitad de la correspondiente al pastizal inferior. Esto sugiere que las condiciones hídricas favorables en el suelo de los pastizales superiores se extienden por periodos más largos que en los pastizales basales. Este aspecto resulta relevante para comprender porque los pastizales de altura, de menor biomasa aérea - y casi con seguridad área foliar-, realiza una producción total similar a los pastizales basales. Asumiendo que la tasa de fotosíntesis por unidad de área foliar es similar en los distintos pastizales, la productividad total semejante tiene que derivar de una combinación distinta del aporte del índice de área foliar y del período de producción, en cada pastizal. En la parte superior de los cerros un mayor período hídricamente favorable se combina con una menor masa fotosintética; en tanto en los basales una mayor alternancia de periodos secos y húmedos del suelo se asocia a una mayor biomasa verde.

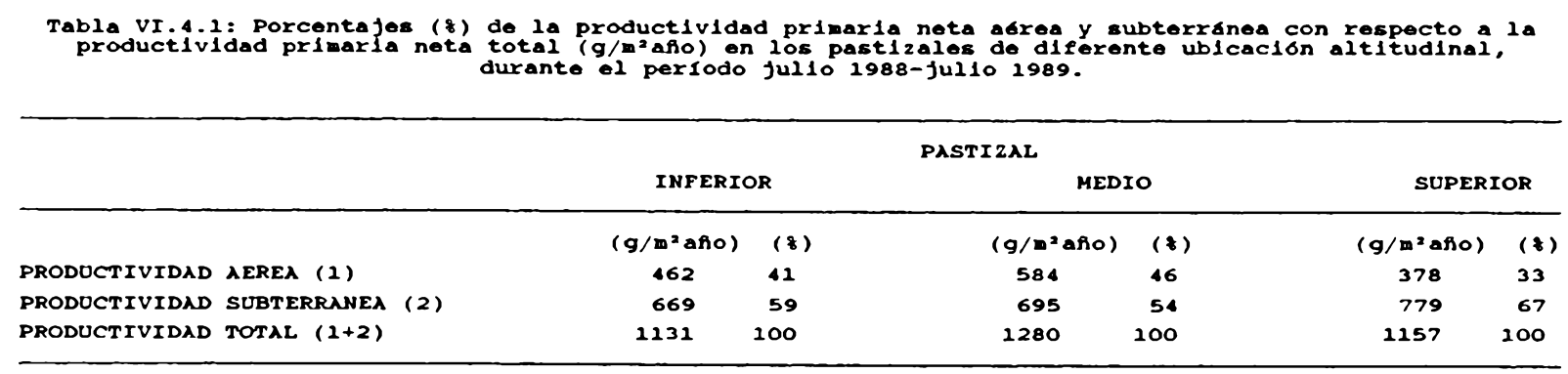

En estos pastizales durante el invierno el crecimiento es activo, principalmente a media ladera, destinándose en este sitio y en la cumbre una mayor parte de los fotoasimilados hacia las raíces. En la base, en cambio, la productividad invernal es asignada principalmente a los órganos aéreos Tabla VI.4.2). 


\begin{tabular}{|c|c|c|c|c|c|c|c|}
\hline Perlodo & Ne de dlas & $\begin{array}{c}\text { PRODUCTIUIDAD } \\
\text { super1or }\end{array}$ & $\begin{array}{l}\text { AEREA NETA } \\
\text { Past12al } \\
\text { modio }\end{array}$ & $\begin{array}{l}\left(g / n^{2} \cdot d 1 a\right) \\
\text { Inferlor }\end{array}$ & $\begin{array}{r}\text { PRODOCTIVIDAD } \\
\text { supex10x }\end{array}$ & $\begin{array}{l}\text { SUBTERRANEA } \\
\text { Past1zal } \\
\text { medio } 1\end{array}$ & $\begin{array}{l}\text { A Neta }\left(g / m^{2} \cdot d 1 a\right) \\
\text { inferlor }\end{array}$ \\
\hline $\begin{array}{l}j 1-s e \\
\text { se-oc } \\
o c-d 1 \\
d 1-f e \\
f e-a b \\
a b-m y \\
a b-m y \\
m y-j l\end{array}$ & $\begin{array}{l}82 \\
30 \\
41 \\
17 \\
52 \\
45 \\
54 \\
45\end{array}$ & $\begin{array}{l}1,0 \\
1,6 \\
3,3 \\
0,5 \\
0,4 \\
1,6 \\
0,1 \\
0,0\end{array}$ & $\begin{array}{l}1,2 \\
1,2 \\
2,4 \\
4,4 \\
0,0 \\
2,4 \\
2,6 \\
0,8\end{array}$ & $\begin{array}{l}1,0 \\
2,8 \\
0,2 \\
0,2 \\
0,0 \\
3,7 \\
2,2 \\
0,0\end{array}$ & $\begin{array}{l}1,6 \\
4,3 \\
4,5 \\
1,3 \\
1,3 \\
5,4 \\
0,0 \\
0,0\end{array}$ & $\begin{array}{l}3,8 \\
4,3 \\
1,7 \\
0,0 \\
0,0 \\
0,0 \\
0,1 \\
1,2\end{array}$ & $\begin{array}{l}0,5 \\
5,1 \\
2,4 \\
3,2 \\
3,2 \\
3,5 \\
0,0 \\
0,0\end{array}$ \\
\hline
\end{tabular}

En los tres sitios la tasa diaria de crecimiento neto es elevada durante la primavera. La ganancia neta de materia seca durante este período representa casi la mitad de la productividad total anual en los pastizales medio y superior y aproximadamente un tercio en el pastizal inferior, en el que la productividad durante el otoño es tan elevada como en la primavera.

La productividad primaveral es destinada en mayor proporción hacia las raíces en los tres sitios.

En los pastizales ubicados a mayor altitud (1025 m sm y $850 \mathrm{~m} \mathrm{sm})$ la tasa de productividad subterránea presenta un pico a principios de la primavera. Estos altos valores se mantienen a mediados de dicha estación, coincidiendo con el pico en la tasa de productividad aérea. En el pastizal inferior los picos en la productividad aérea y subterránea son coincidentes y ocurren a principios de primavera, descendiendo hacia mediados de la misma (Tabla VI.4.2).

La asincronía en el pico de crecimiento aéreo entre los pastizales ubicados a mayor altitud con respecto al inferior, se relaciona con el gradiente térmico altitudinal. En la base se tienen más tempranamente condiciones térmicas más favorables que a mayor altitud.

La mortalidad (Tabla VI.4.3) es baja a fines del invierno y principios de primavera. Los valores máximos son alcanzados a mediados y a fines de esta estación, relacionándose el aumento en la tasa de mortalidad con un período hídricamente desfavorable y con la finalización del ciclo reproductivo de las especies microtérmicas. 


\begin{tabular}{|c|c|c|c|c|c|c|c|c|c|c|c|}
\hline \multirow[b]{2}{*}{$\begin{array}{l}\text { Perlodo } \\
j 1-s e \\
\text { se-oc } \\
o c-d 1 \\
d 1-f e \\
f a-a b \\
a b-m y \\
a b-a y \\
m y-j l\end{array}$} & \multirow[b]{2}{*}{$\begin{array}{l}\mathrm{N}^{\circ} \\
82 \\
30 \\
41 \\
17 \\
52 \\
45 \\
54 \\
45\end{array}$} & \multirow[b]{2}{*}{ de dias } & \multicolumn{3}{|c|}{$\begin{array}{c}\text { MORTALIDAD AEREA } \\
\text { (g/a'd dia) } \\
\text { Pastizal }\end{array}$} & \multicolumn{3}{|c|}{$\begin{array}{c}\text { CAIDA } \lambda \text { LA BOJARASCA } \\
\left(g / m^{2} \text { dial }\right) \\
\text { Pastizal }\end{array}$} & \multicolumn{3}{|c|}{$\begin{array}{c}\text { MORTALIDAD SUBTERRANEA } \\
\text { (9/"'dia) } \\
\text { Pastizal }\end{array}$} \\
\hline & & & $\begin{array}{c}\text { super } 1 \text { or } \\
1,0 \\
0,0 \\
2,9 \\
1,6 \\
0,3 \\
0,3 \\
0,9 \\
0,3\end{array}$ & $\begin{array}{r}\operatorname{med10} \\
1,1 \\
0,2 \\
1,2 \\
6,3 \\
0,3 \\
0,9 \\
2,5 \\
0,6\end{array}$ & $\begin{array}{c}\text { Infer } 1 \text { or } \\
0,6 \\
1,7 \\
0,2 \\
2,5 \\
0,8 \\
2,1 \\
2,2 \\
0,6\end{array}$ & $\begin{array}{c}\text { super } 1 \text { or } \\
1,6 \\
4,3 \\
4,5 \\
1,3 \\
1,3 \\
5,4 \\
0,0 \\
0,0\end{array}$ & $\begin{array}{r}\operatorname{med10} \\
3,8 \\
4,3 \\
4,7 \\
0,0 \\
0,0 \\
0,0 \\
0,1 \\
1,2\end{array}$ & $\begin{array}{r}\text { Infer } 10 x \\
0,0 \\
0,0 \\
0,2 \\
2,5 \\
0,8 \\
0,0 \\
0,0 \\
0,3\end{array}$ & $\begin{array}{c}\text { super } 1 \text { or } \\
0,0 \\
0,0 \\
4,5 \\
1,3 \\
1,3 \\
0,0 \\
0,5 \\
8,6\end{array}$ & $\begin{array}{r}\operatorname{mod10} \\
0,0 \\
0,6 \\
1,7 \\
0,0 \\
0,0 \\
0,0 \\
0,1 \\
1,2\end{array}$ & $\begin{array}{c}\text { Inferlor } \\
0,0 \\
0,3 \\
8,9 \\
0,9 \\
0,9 \\
0,0 \\
1,8 \\
3,3\end{array}$ \\
\hline
\end{tabular}

A fines de la primavera, en los tres sitios, la caída (Tabla VI.4.3) a la hojarasca es máxima. La tasa de caída es mucho más elevada en el pastizal de la cumbre que en los otros dos. En el primer sitio mencionado la tasa pico de mortalidad aérea antecede a la de caída, mientras que en los otros sitios son simultáneas.

La desaparición (Tabla VI.4.4), tal como es estimada en el presente estudio, contempla las mayores vias tróficas del subsistema suelo: herbivoría y descomposición (Stanton 1988). Las vías más importantes que sigue la materia muerta son: respiración microbiana, consumo por meso y macrofauna, y transferencia a la materia orgánica del suelo (Swift et al. 1979, McClaugherty et al. 1982). Los procesos que conducen a la desaparición de material aéreo y subterráneo, en los sitios de la cumbre y pie de monte, son más activos a principios de primavera y a principios de otoño. Las tasas de desaparición subterránea son más elevadas que las aéreas, favorecidas, posiblemente, por la calidad orgánica de las raíces finas y las condiciones más favorables de humedad y temperatura del suelo. A media ladera, la tasa máxima de desaparición, tanto aérea como subterránea se observa en el verano.

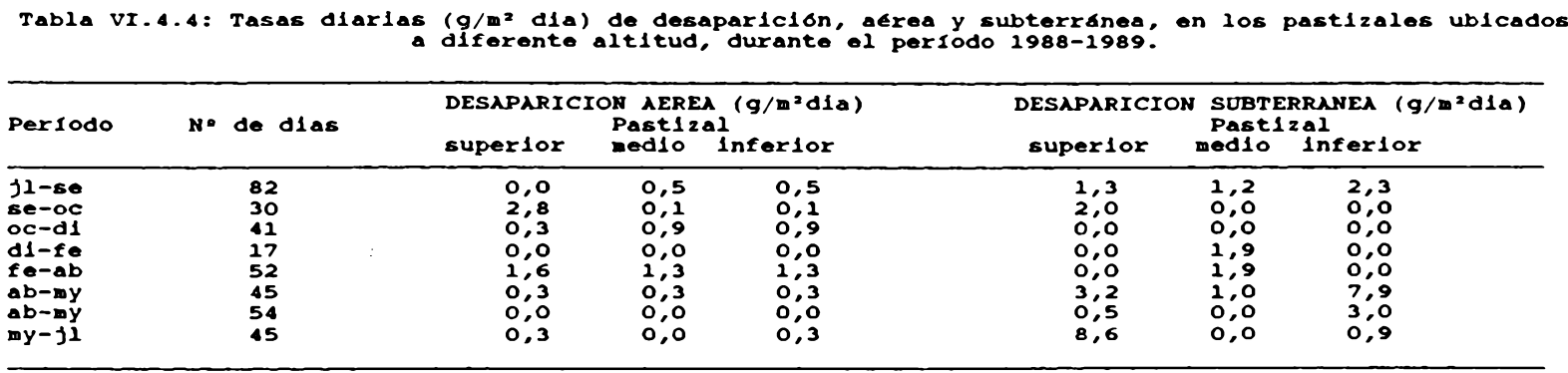


Durante el verano, a media ladera el crecimiento es nulo, y bajo en el pastizal superior. En el pastizal inferior se observan tasas de productividad importantes, que se deben exclusivamente al crecimiento subterráneo.

En el verano se observa la tasa pico de desaparición de la hojarasca, en los tres sitios. Aunque esta sea una época relativamente seca si se considera la relación precipitación evaporación, las lluvias en enero de 1989 fueron importantes (Gráfico II.2), por lo cual deben haber existido dias con condiciones de humedad y temperaturas favorables para los procesos de descomposición. La mayor desaparición después del pico de caída a la hojarasca estaría de acuerdo con lo expresado por varios autores (Hunt 1977, Andren y Paustian 1987, Gallardo y Merino 1993, Rustad 1994), en cuanto a que en los procesos de descomposición inicialmente existe una importante degradación de los compuestos más solubles. Además, probablemente, la particulación de este material por la acción de factores climáticos (viento, altas temperaturas) y por el consumo de la meso y macrofauna del suelo (Swift et al. 1979, Stanton 1988, Scott 1979, French 1979), favorezca su dispersión e incorporación al suelo. La combinación de tales factores contribuíria a que las tasas de desaparición sean elevadas. Thurrow (1989) en una sabana al sur de Somalía, utilizando bolsas de descomposición de hojarasca no halló una correlación evidente entre las lluvias y la pérdida de peso de las bolsas. En dicho trabajo se señala que luego de ocurrida la senescencia, la descomposición fue más rápida, a pesar de que durante esos meses las precipitaciones fueron muy escasas, en parte debido a la importancia de las termitas como agentes fraccionadores durante la estación seca. En los pastizales en estudio, es frecuente la presencia de hormigas cortadoras y hormigueros de tamaño importante, cuyas implicancias en el funcionamiento de los pastizales no ha sido evaluada.

En el otoño se registran tasas de crecimiento elevadas a lo largo del gradiente altitudinal. Del crecimiento otoñal, una mayor porporción es destinada a las raíces en el pastizal superior, mientras que en los otros dos sitios la mayor parte de la productividad de este período se asigna a los órganos aéreos. Las tasas de productividad aérea y subterránea alcanzan un pico a principios de otoño en los tres sitios. 
La mortalidad a fines del otoño-principios del invierno se asocia con la finalización del ciclo productivo de las especies mesotérmicas y la aparición de las primeras heladas. En los pastizales superior y inferior, son llamativas las elevadas tasas de mortalidad y desaparición subterráneas a principios del invierno en el primer sitio y a principios del otoño en el segundo. La calidad del material que constituye a las raíces facilitaría su incorporación a la vías tróficas de descomposición o herbivoría bajo condiciones ecológicas estacionales no limitativas para estos procesos.

De acuerdo con lo dicho hasta ahora, en los pastizales de media ladera y cumbre la mayor parte del crecimiento invernal tardío es subterráneo. En la cumbre, independientemente de la época del año, siempre la asignación de fotoasimilados es principalmente hacia las raíces, mientras que en los otros dos sitios el patrón de distribución de la productividad cambia estacionalmente. En los pastizales situados a media ladera y en el pie de monte la mayor parte de la productividad primaveral se destina a las raíces. En el último sitio mencionado la totalidad del crecimiento estival es subterráneo, pero durante el otoño la productividad neta en ambos sitios se asigna principalmente a la parte aérea.

Estas diferencias en la asignación de fotoasimilados entre los sitios se relacionaría con las condiciones mesoclimáticas de los mismos. El pastizal superior es considerado un sitio fresco, ventoso y térmicamente poco variable diaria y estacionalmente (Kristensen y Frangi 1995). Los mismos autores en cambio, consideran a los pastizales basales son, como sitios relativamente más cálidos, con mayores variaciones térmicas diarias y estacionales. El sitio de media ladera es intermedio tambien en sus condiciones ambientales, con temperaturas invernales semejantes a las de la cumbre, más fresco que los pastizales basales durante el verano y con más semejanzas con éste durante el otoño (Kristensen y Frangi 1995). En el presente trabajo tanto la productividad como la materia seca subterránea son mayores en los sitios más frios (pastizales superior y media ladera), y la cumbre, el más frio de ellos, asigna una mayor proporción de productividad subterránea durante todo el año. En los pastizales de media altitud y inferior, más cálidos durante el otoño que en la primavera, el crecimiento otoñal es destinado en mayor proporción a los órganos aéreos.

Además, el agua actua como la más importante conección entre la energia y el carbono, 
dado que el estado hídrico de la planta, a través del control estomático influencia la tasa de fotosintesis y transpiración (Noy-Meir 1973, Schulze 1982, 1987). El año 1988 fue particular en cuanto a la alternancia de períodos prolongados con escasas lluvias y períodos breves con lluvias abundantes (Gráfico II.2). Tanto la cantidad como la distribución de las precipitaciones resultan fundamentales en la dinámica de la vegetación (Walter 1977, Larcher 1980, Sala et al. 1982). Se ha señalado que las condiciones de sequía promueven un mayor crecimiento de raíces, como son las raíces finas (Sisson 1989, Schulze et al. 1987, Schulze 1982, Stock et al. 1987, San José et al. 1982). En relación con este importante factor se observa que durante la primavera temprana, que fue desfavorable desde el punto de vista hídrico, la mayor parte de la productividad de ese período es asignada a las raíces. En el pastizal inferior, que sería un sitio con elevado déficit de saturación del aire durante el verano, la productividad es destinada totalmente al crecimiento de las raíces. La escaces de agua reduce la captación de carbono a través del cierre de los estomas, el carbono asimilado y la proporción del mismo canalizada a las hojas (Schulze y Chapin 1987). Además Sala et al. (1982) señalan que una sequía prolongada disminuye la conductancia estomática durante varios días en el período húmedo siguiente, disminuyendo de ese modo la captación de $\mathrm{CO}_{2}$ y por lo tanto la productividad neta total. Este efecto no sólo depende del grado de stress hídrico, sino también de la duración del período seco (Sala et al. 1982).

\section{La productividad primaria neta en los pastizales templados}

Laurenroth (1979) a partir de datos de 52 pastizales provenientes de todo el mundo señala que los sitios más productivos son aquellos cuya precipitación media anual es de $800 \mathrm{~mm}$ y cuya temperatura media anual es superior a los $15^{\circ} \mathrm{C}$. Esos sitios fueron agrupados por el autor, de acuerdo a las caracteristicas macroclimáticas, teniendo en cuenta la distribución proporcional de condiciones de humedad y sequia. De este análisis resultaron seis grandes grupos. Los pastizales del presente trabajo, por sus características climáticas se encontrarian dentro del grupo 6, que incluye a los pastizales más productivos del mundo, desde semiáridos a húmedos, y los tipos climáticos desde tropical húmedo a templado continental. La caracteristica distintiva que los reúne es la ausencia un período significativo de sequía durante el año. La PPAN dentro de dicho grupo presenta un rango entre 160 y $1387 \mathrm{~g} / \mathrm{m}^{2}$ año, con una media de $525 \mathrm{~g} / \mathrm{m}^{2}$ año. La PPAN de los pastizales serranos actualmente estudiados se 
encontrarían cerca de ese valor medio ya que la misma es $378 \mathrm{~g} / \mathrm{m}^{2}$.año en pastizal superior, $584 \mathrm{~g} / \mathrm{m}^{2}$.año en el pastizal medio y $462 \mathrm{~g} / \mathrm{m}^{2}$.año en el inferior. Coincidentemente, Gómez y Gallopín (1991) mostraron los rangos en la PPAN de los principales biomas latinoamericanos, correspondiendo a los pastizales pampeanos un rango entre 400 y 600 $\mathrm{g} / \mathrm{m}^{2}$.año. En ausencia de pastoreo, otras estimaciones de la PPAN realizadas en pastizales pampeanos se encuentran dentro de dicho rango. Para un flechillar $(550 \mathrm{~m} \mathrm{sm}) \mathrm{sin}$ pastoreo, de la Sierra de la Ventana, Frangi et al. (1980a) estimó una PPAN de $700 \mathrm{~g} / \mathrm{m}^{2}$.año. Sala et al. (1981) estimaron $532 \mathrm{~g} / \mathrm{m}^{2}$ año de PPAN en un pastizal de la depresión del Salado en condiciones de clausura. La PPAN media de tres años de estimaciones realizadas por de Wysiecki (1993) en un pastizal natural de la provincia de La Pampa, clausurado al pastoreo, es $410 \mathrm{~g} / \mathrm{m}^{2}$ año. El rango en la PPAN estimado por Sims y Singh (1978b) para los pastizales no pastoreados de EE UU es $416 \mathrm{~g} / \mathrm{m}^{2}$ año, en un pastizal de pastos altos (Osage) a $82 \mathrm{~g} / \mathrm{m}^{2}$ año, en un pastizal con arbustos (Ale). De acuerdo con ello, los mismos serían menos productivos que los pastizales pampeanos. Al respecto Lauenroth (1979) señala que, a nivel global, los pastizales de América del Norte se encuentran dentro del menor tamaño de clase de producción.

La productividad primaria neta subterránea (PPNS) de pastizales no pastoreados de América del Norte, a partir de estimaciones realizadas por Sims y Singh (1978b), presenta un rango entre $304 \mathrm{~g} / \mathrm{m}^{2}$ año en Cottonwood, a $1062 \mathrm{~g} / \mathrm{m}^{2}$ año en Hays, ambas praderas mixtas. De acuerdo con estas estimaciones, la PPNS representa entre el $60 \%$ de la productividad primaria neta total en un pastizal de montaña y en un pastizal de pastos altos, a más del $70 \%$ en praderas mixtas y de pastos cortos. La tasa de acumulación de materia seca subterránea generalmente aumenta con un decrecimiento de la temperatura media anual y dentro de un régimen particular de temperatura, la tasa se incrementa con el aumento en la aridez (Sims y Singh 1978c). Estos autores señalan que en pastizales templados la productividad subterránea es usualmente mayor que en pastizales tropicales y la situacion inversa se da en la productividad neta aérea. A partir de estimaciones relizadas por Long $e t$ al. (1989) en pastizales tropicales, la PPNS presenta un rango entre $431 \mathrm{~g} / \mathrm{m}^{2}$ año, en Nairobi (Kenya) a $678 \mathrm{~g} / \mathrm{m}^{2}$ año, en Montecillos (México). De acuerdo con dichas estimaciones, la PPNS de los pastizales tropicales muestra valores similares a los obtenidos por Sims y Singh (1978b) en pastizales templados. Sin embargo, la diferencia que se observa 
entre ambos tipos de pastizal, es que en los tropicales la PPNS alcanzó sólo el $39 \%$ de la productividad primaria neta total en Montecillos, $35 \%$ en Nairobi y $28 \%$ en Thailandia. En sabanas venezolanas San José et al. (1982) estimaron valores mucho menores de PPNS, 195 $\mathrm{g} / \mathrm{m}^{2}$ año, pero el mismo significa el $35 \%$ de la PPNTotal. Otras estimaciones de la PPNS en pastizales templados coinciden con las de Sims y Singh (1978b) en lo referente al porcentaje que las mismas representan con respecto a la productividad primaria neta total del sistema. Dichos porcentajes son mayores que los señalados para pastizales tropicales. Kucera et al. (1967) hallaron en pastizales de pastos altos de EE. UU., que la productividad primaria neta total fue $992 \mathrm{~g} / \mathrm{m}^{2}$.año, correspondiendo al crecimiento de las raíces aproximadamente el 50\%. Aerts et al. (1989) en Holanda, en pastizales dominados por Molinia caerulea obtuvieron una PPSN de $1080 \mathrm{~g} / \mathrm{m}^{2}$.año, la cual representa el $52 \%$ de la asimilación neta total del pastizal. Distel y Fernández (1986) en la región semiárida central de Argentina estimaron una productividad primaria neta subterránea de $902 \mathrm{~g} / \mathrm{m}^{2}$ año para Stipa tenuis y Piptochaetium napostaense, la cual representó respectivamente el 91 y el $93 \%$ de la productividad primaria neta total de esas especies. Montani y Fernández (1986) en la misma zona que la señalada anteriormente, muestran que la productividad subterránea en pasturas de Eragrostis curvula fue $1426 \mathrm{~g} / \mathrm{m}^{2}$ año, la cual significa el $68 \%$ de la productividad total de esa planta. de Wysiecki y Pérez (inédito) hallaron que la productividad de las raíces en un pastizal de Sorghastrum pellitum $(850 \mathrm{~m} \mathrm{sm})$ en Sierra de la Ventana alcanzó los 1250 $\mathrm{g} / \mathrm{m}^{2}$ año, representando el $86 \%$ de la PPNTotal. La productividad primaria neta subterránea anual en los pastizales serranos actualmente estudiados tiene su mayor valor en el pastizal superior, $778 \mathrm{~g} / \mathrm{m}^{2}$.año, en el pastizal medio la misma es de $696 \mathrm{~g} / \mathrm{m}^{2}$ año y el valor más bajo corresponde al pastizal inferior, $669 \mathrm{~g} / \mathrm{m}^{2}$ año. Las mismas representan respectivamente el $67 \%, 54 \%$ y $59 \%$ de la productividad primaria neta total. Estos valores y las proporciones que los mismos representan se encuentran dentro de los rangos observados en otros pastizales templados.

\section{La productividad primaria neta en relación con las variables abióticas}

La productividad primaria neta aérea (PPAN) se relaciona principalmente con las precipitaciones. El agua es el más importante vínculo entre el flujo de energía y Carbono, dado que el estado hídrico de la planta, a través de mecanismos de control estomático, 
influencia tanto a la tasa de fotosíntesis como de transpiración (Noy-Meir 1973)

A escala global, Rosenzweig (1968) relacionó la PPAN con la evapotranspiración real, señalando que ésta es un predictor altamente significativo de PPAN debido a que mide simultáneamente la disponibilidad de agua y energía solar, los cuales son los más importantes recursos limitantes en la fotosíntesis. De acuerdo con Gómez y Gallopín (1991) el modelo propuesto por Rosenzweig no se ajusta a datos más recientes, sin embargo señalan que a nivel global las únicas variables que se relcionan en forma significativa con la PPAN son la precipitación y la evapotranspiración. A esto, Sala et al. (1988) agrega que la producción primaria neta aérea de pastizales está fuertemente influenciada no sólo por la cantidad sino también por la distribución de la precipitación anual.

Lauenroth (1979) comparó la PPAN de 52 pastizales de distintas partes del mundo, teniendo en cuenta las precipitaciones y la temperatura. Este autor señala que esas dos variables son importantes determinantes de la producción anual de los pastizales, aunque la variación entre sitios se incrementa hacia el extremo más húmedo del espectro, lo cual indica que cuando disminuyen las restricciones impuestas por la aridez, adquieren mayor importancia otros factores característicos de esos sitios. Para pastizales templados del mundo, Gómez y Gallopin (1991), hallaron que la productividad primaria neta aérea aumenta linealmente con la precipitación y la evapotranspiración, únicas variables estadísticamente significativas .

Sims y Singh (1978b) en pastizales de EE UU, encontraron un aumento lineal de la PPAN con las precipitaciones hasta los $500 \mathrm{~mm}$. Los mismo autores indican que también es lineal la relación de la PPAN con la evapotranspiración real anual y de la estación de crecimiento. Webb et al. (1983), a partir de datos de biomasa aérea y PPAN de Sims et al. (1978) y Sims y Singh (1978b) realizaron un modelo altamente predictivo de la PPAN para desiertos y pastizales de pastos cortos de EE UU, en términos de cosecha en pie foliar, disponibilidad de agua (evapotranspiración potencial menos precipitación anuales) y temperatura. Sala et al.(1988) relacionaron la PPAN de pastizales de la Región Central de EE UU, señalando que a nivel regional sólo una variable (la precipitación anual), es necesaria para explicar una gran fracción de la variabilidad en la producción, mientras que a escalas de análisis más finas, un modelo necesitará incluir un mayor número de variables para explicar el patrón del mismo 
proceso. Estos autores hallaron que a nivel de sitio la produccion aérea fue explicada por la precipitación anual, la capacidad de retención de agua del suelo y por la interacción entre ambos factores. Por otra parte, Knapp et al. (1992) muestran que a lo largo de una vertiente, la PPAN de los sitios de diferente ubicación topográfica está fuertemente correlacionada con el contenido de agua del suelo.

Teniendo en cuenta las variciones a lo largo del año, Robertson (1988) analizó la influencia de las lluvias sobre el crecimiento y disminución de la biomasa aérea en 313 sitios, en pasturas de Australia, temporariamente clausuradas al pastoreo, realizando estimaciones trimestrales a lo largo de cuatro años. Este autor halló que las estimaciones trimestrales de crecimiento y decrecimiento de la biomasa fueron explicadas en un $86 \%$ por las lluvias caídas en esos tres meses y la biomasa inicial al comienzo de cada período. De las dos varibles independientes, las lluvias resultaron con mayor poder predictivo, ya que explicaron el $72 \%$ de la varianza.

Para analizar la relación existente entre la variación estacional de la materia seca aérea en los tres pastizales estudiados, y las precipitaciones registradas en cada uno de ellos, a escala de detalle, durante el período de muestreo, se aplicó el modelo de la recta de regresión lineal (gráfico VI.4.1). Como la variable dependiente se utilizaron las diferencias significativas (positivas o negativas, test $t$ de Student, $\mathrm{P}<0,05$ ) de la materia seca en pie aérea, teniendo en cuenta los extremos de tendencias crecientes o decrecientes de la misma, desde julio de 1988 a julio de 1989. De este modo se obtuvo una tasa diaria $\left(\mathrm{g} / \mathrm{m}^{2}\right.$.dia) de crecimiento, cuando la tendencia fue positiva, o de decrecimiento, cuando la tendencia fue negativa. La variable independiente fue la precipitación diaria de cada período, expresada en $\mathrm{mm} / \mathrm{dia}$. (Tabla VI.4.5)

Las precipitaciones diarias explicaron el $89 \%$ de la variación en las tasas diarias de crecimiento y decrecimiento de la materia seca aérea en pie en los tres pastizales muestreados en un ciclo anual. La dinámica de la materia seca aérea está condicionada en gran parte por las características hídricas prevalecientes en cada sitio. Teniendo en cuenta la ecuación de la recta de regresión entre las dos variables señaladas (pendiente significativa, $P=0,001$ ), se obtiene que el crecimiento aéreo, para el año de estimaciones, fue igual a cero cuando las 
precipitaciones fueron aproximadamente $2 \mathrm{~mm} / \mathrm{dia}$. Por debajo de este valor la biomasa decreció y por encima del mismo ocurrió crecimiento.

\begin{tabular}{|c|c|c|c|c|}
\hline Past1zal & Perlodo & $\begin{array}{l}\text { Intervalo } \\
\text { (node dlas) }\end{array}$ & $\begin{array}{r}\text { B1omasa/d1a } \\
\left(g / m^{2} . d 1 a\right)\end{array}$ & $\begin{array}{c}\text { Lluvias/dia } \\
(m \infty / d i a)\end{array}$ \\
\hline Superior & Jullo-diclembre & 153 & 1,1 & 2,4 \\
\hline Med10 & Jul10-d1clembre & 153 & 1,4 & 2,2 \\
\hline Inferior & jul10-octubre & 112 & 1,5 & 2,2 \\
\hline Superior & diclembre,20-d1c, 27 & 17 & $-7,9$ & 0,3 \\
\hline Med10 & alclembre-febrero & 69 & $-2,0$ & 1,9 \\
\hline Inferlor & octubre-febrero & 110 & $-1,5$ & 1,7 \\
\hline Superlor & diclembre-mayo & 151 & 0,7 & 2,7 \\
\hline Medio & febrero-jullo & 144 & 2,9 & 2,2 \\
\hline Inferlor & febrero-mayo & 99 & 2,8 & 2,6 \\
\hline
\end{tabular}

Las variaciones estacionales observadas en la materia seca aérea permiten destacar diferencias en la duración de las tendencias crecientes o decrecientes entre los sitios. En los dos pastizales de mayor altitud la tendencia creciente aérea se extendió desde julio hasta principios de diciembre, mientras que en el pastizal inferior, este período fue menor, extendiéndose desde julio hasta fines de octubre. Esto podría deberse a las diferecias mesoclimáticas entre los mismos, señaladas por Kristensen y Frangi (1995), generadas por la distinta ubicación topográfica de los mismos. Durante el período primaveral predominó la acumulación de materia seca en pie con respecto a la la caída, en los tres sitios. El período de decrecimiento de la materia seca aérea en pie, a partir de un balance negativo entre la productividad y la caida a la hojarasca, fue más breve en el pastizal superior que en los otros dos sitios, pero la magnitud de esta disminución fue la mayor de los tres. En el pastizal superior, con respecto a los otros sitios las temperaturas son menores, pero la velocidad del viento es mucho mayor. Este factor actuaría incrementando la evaporación, lo cual intensificaría los momentos de déficit hídrico marcado. El período de crecimiento estivo-otoñal en el sitio cercano a la cumbre, comenzó a principios del verano. Esto se relacionaría con las importantes lluvias ocurridas en enero de 1989 y las temperaturas relativamente menores que caracterizan a este sitio, permitiendo que los compartimientos aéreos comiencen antes a mostrar una tendencia creciente. En el pastizal medio, el mismo período de crecimiento se extendió hasta principios del invierno, probablemente favorecido 
por ser más cálido que los otros tres durante dicha época (Kristensen y Frangi 1995).

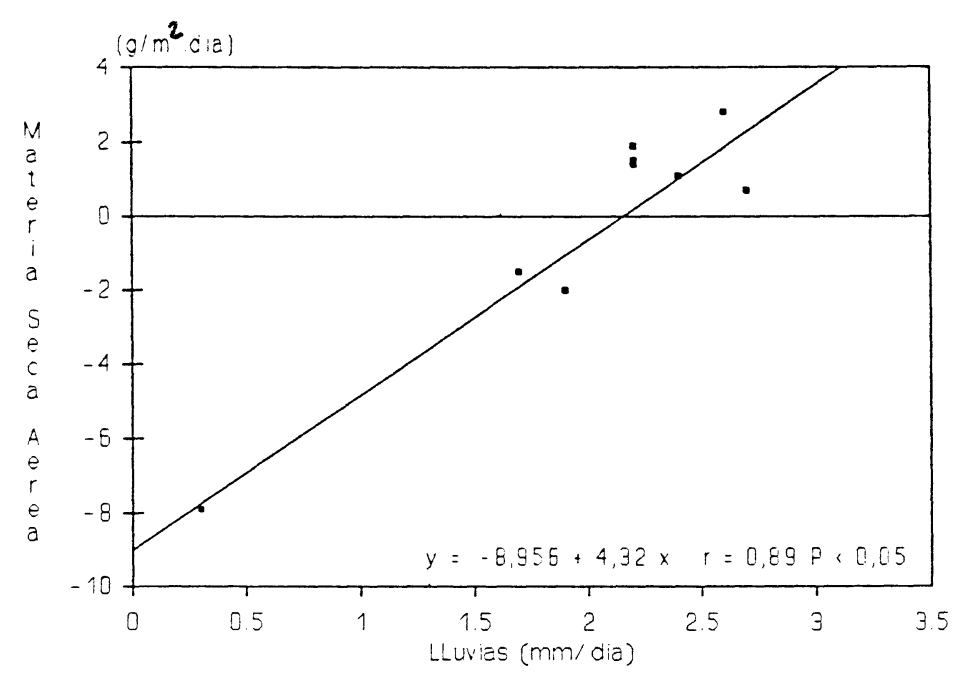

Graflco VI.4.1: Recta de regresion entre las diferencias signiflcativas (crecimlento o decrecimlento) de la materla seca aerea y las liuvias en los mismos perlodos, durante jullo de $1988-j u l 10$ de
pastizales serranos (ambas variables dividido el numero de dias del intervalo).

Estrategias fotosintéticas y eficiencia en el uso del agua en los pastizales serranos.

La eficiencia en el uso del agua (EUA) frecuentemente se refiere al cociente entre la productividad primaria neta aérea y la evapotranspiración real o potencial (Sims y Singh 1978b, Webb et al. 1978, Sala et al. 1988, Gómez y Gallopín 1991). Este índice une la acumulación de energía en los ecosistemas a un importante componente del ciclo hidrológico (Webb et al. 1978) y depende del tipo de ecosistema y de las condiciones edáficas (Sala et al. 1988, Gómez y Gallopín 1991). De acuerdo con los últimos autores citados, los pastizales templados exhiben los menores valores de EUA (Rango 0,21 - 0,84; Media=0,57), con respecto a otros ecosistemas. La EUA estimada por Sala et al.(1988) para los pastizales de la Región Central de los Estados Unidos es $0,6 \mathrm{~g} / \mathrm{m}^{2} . \mathrm{mm}$. Ambas estimaciones son a nivel regional, a nivel local, factores edáficos y la ubicación de los sitios, entre otros, reducen el poder predictivo de las mismas. Sin embargo, la EUA de los pastizales estudiados en el presente trabajo, son cercanas a las señaladas anteriormente $(0,6$ en el pastizal superior, 0,9 en el pastizal medio y 0,7 en el basal) (Tabla VI.4.7). 
Aunque el significado ecológico de las plantas $C_{3}$ y $C_{4}$ no es claro (Risser 1985), una de las principales diferencias entre las especies con uno u otro mecanismo fotosintético, en condiciones de laboratorio, es la mayor eficiencia hídrica de las $\mathrm{C}_{4}$ con respecto a las $\mathrm{C}_{3}$. De acuerdo con Pearcy y Ehleringer (1984) esta mayor eficiencia de un mecanismo con respecto al otro, en general no se debe a una mayor capacidad fotosintética de las $\mathrm{C}_{4}$, sino a que las mismas alcanzan niveles de saturación intracelular de $\mathrm{CO}_{2}$ a bajas concentraciones atmosféricas del mismo. Esta diferencia implica que, bajo condiciones de disponibilidad de agua y temperaturas moderadas, las $\mathrm{C}_{4}$ alcanzan concentraciones de $\mathrm{CO}_{2}$ de saturación de la fotosíntesis neta con una apertura estomática menor que las $C_{3}$ y por lo tanto transpiran menos. Ademá en las $\mathrm{C}_{4}$, en virtud de su mecanismo de captación de $\mathrm{CO}_{2}$, la fotosíntesis aumenta con la temperatura, dentro de un cierto rango (de 20 a $40^{\circ} \mathrm{C}$ ). En cambio, en las $\mathrm{C}_{3}$ esas variables son independientes, a concentraciones atmosféricas de $\mathrm{CO}_{2}$, debido al efecto inhibitorio del $\mathrm{O}_{2}$ sobre la RubPcarboxilasa. Sin embargo, Caldwell (1973), a partir del análisis comparativo de 50 pastizales de todo el mundo, señala que las supuestas ventajas de las $\mathrm{C}_{4}$ no siempre se ponen de manifiesto en ambientes naturales y no implican mayor tolerancia a la sequía en las $C_{4}$, con respecto a las $C_{3}$ (Pearcy y Ehleringer 1984), sino que probablemente, la elevada producción de biomasa que se atribuye a las $\mathrm{C}_{4}$ solo se expresa en condiciones de altas temperaturas y disponibilidad de agua (Liang et al. 1989). Los mismos autores señalan que la efieciencia en el uso del agua está más relacionada con las formas de vida que con los mecanismos fotosintéticos de las especies presentes en las comundades. Los mecanismos fotosintéticos, $\mathrm{C}_{3} \mathrm{y}_{4} \mathrm{C}_{4}$, constituyen sólo una parte de un gran número de caracteres fisiológicos y morfológicos, los cuales en su conjunto contribuyen a la adaptación de una planta a su medio (Pearcy y Ehleringer 1984).

En cuanto a la abundancia de especies con uno $\mathrm{u}$ otro mecanismo productivo en determinado ambiente, varios autores (Teeri y Stowe 1976, Boutton et al. 1980) señalan que la proporción de especies $\mathrm{C}_{4}$ mantiene una estrecha relación con la temperatura del lugar. Los últimos autores citados hallaron que a lo largo de una transecta altitudinal en Wynoming (EE $\mathrm{UU})$, la contribución relativa de las $\mathrm{C}_{4}$ a la materia seca aérea disminuía con la altitud en relación directa con el descenso térmico altidudinal. En el presente trabajo se halló que en el pico reproductivo primaveral prevalecieron especies de régimen microtémico mientras que en el estival estuvieron mejor representadas las especies megatérmicas a lo largo de todo el 
gradiente. Si bien no puede asignarse una relación directa entre un mecanismo fotosintético determinado y uno u otro grupo de especies, es probable que las microtérmicas sean predominantemente $C_{3}$ y las megatérmicas $C_{4}$. A su vez, teniendo en cuenta los gradientes térmicos altitudinales en los pastizales serranos $\left(6,9^{\circ} \mathrm{C} / 100 \mathrm{~m}\right.$, Kristensen y Frangi 1995), es probable que la abundancia relativa de las megatérmicas en los mismos disminuya con la altitud. Debe resaltarse que aunque en el período estivo-otoñal las especies que fructifican son megatérmicas, existe un reverdecimiento de las primaverales, y ambas contribuyen a la biomasa de los pastizales. En tal sentido, para la depresión del Salado, Deregibus y Cahuépé (1983), señalan que el período productivo de las especies $C_{3}$ se extendería a lo largo de todo el año, siendo óptimos la primavera y el otoño, mientras que para las $\mathrm{C}_{4}$ las condiciones adecuadas se restringirían al período octubre-marzo. Es posible que exista un aumento en la importancia de las megatérmicas en el pastizal inferior con respecto a los ubicados en lo que correspondería al piso montano de la provincia de Buenos Aires (Kristensen y Frangi 1995). En relación con lo cual se observa que el porcentaje de la productividad primaria neta aérea y total correspondiente al período estivo-otoñal es similar al inverno-primaveral en el pie de monte, mientras que sobre el cerro la mayor parte de la productividad anual ocurre durante el último período mencionado, pese a que las lluvias en la primavera fueron inferiores a las otoñales. Si se considera la eficiencia en el uso de las lluvias, la misma muestra un mayor valor en el período inverno-primaveral con respecto al estivo-otoñal, pero esta diferencia disminuye en el pastizal inferior, con respecto a los de mayor altura.

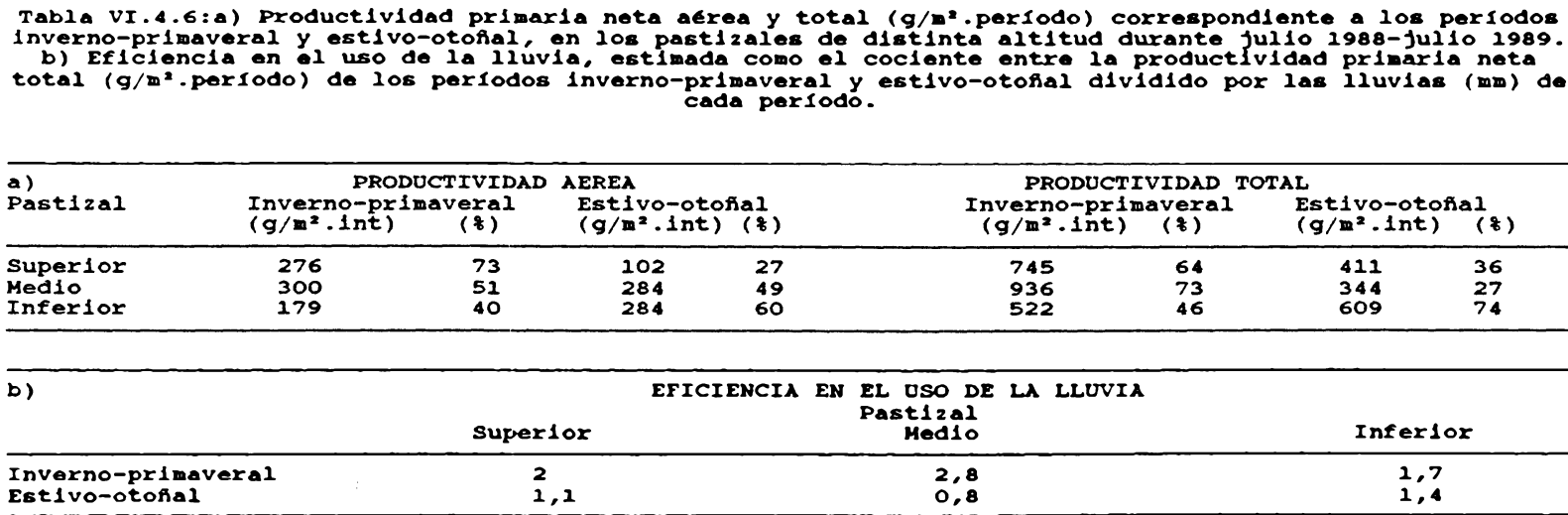

Aunque la EUA estimada a partir de la evapotranspiración constituye una medida más realista, ya que ésta última tiene en cuenta además de las precipitaciones, a las temperaturas, a partir de los datos disponibles se estimó la eficiencia anual en el uso de la lluvia, teniendo 
en cuenta la productividad primaria neta aérea y total de pastizales de varios sitios del mundo (tabla VI.4.7). En dicha tabla existe un sesgo, ya que los pastizales dominados por especies C4 están mejor representados, pero puede verse claramente que éste índice muestra un amplio rango de variación. Esto coincide con lo expresados por otros autores con respecto a que no puede trazarse una relación estrecha entre el mecanimo fotosintético y la eficiencia en el uso del agua. Las eficiencias en el uso de la lluvia obtenidas a partir de datos bibliográficos fueron ordenadas de menor a mayor de acuerdo con la estimación realizada a partir de la PPAN. Se destaca que la misma no refleja la eficiencia hídrica de todo el pastizal, ya que cuando se incluye la productividad de raíces se obtiene un orden diferente.

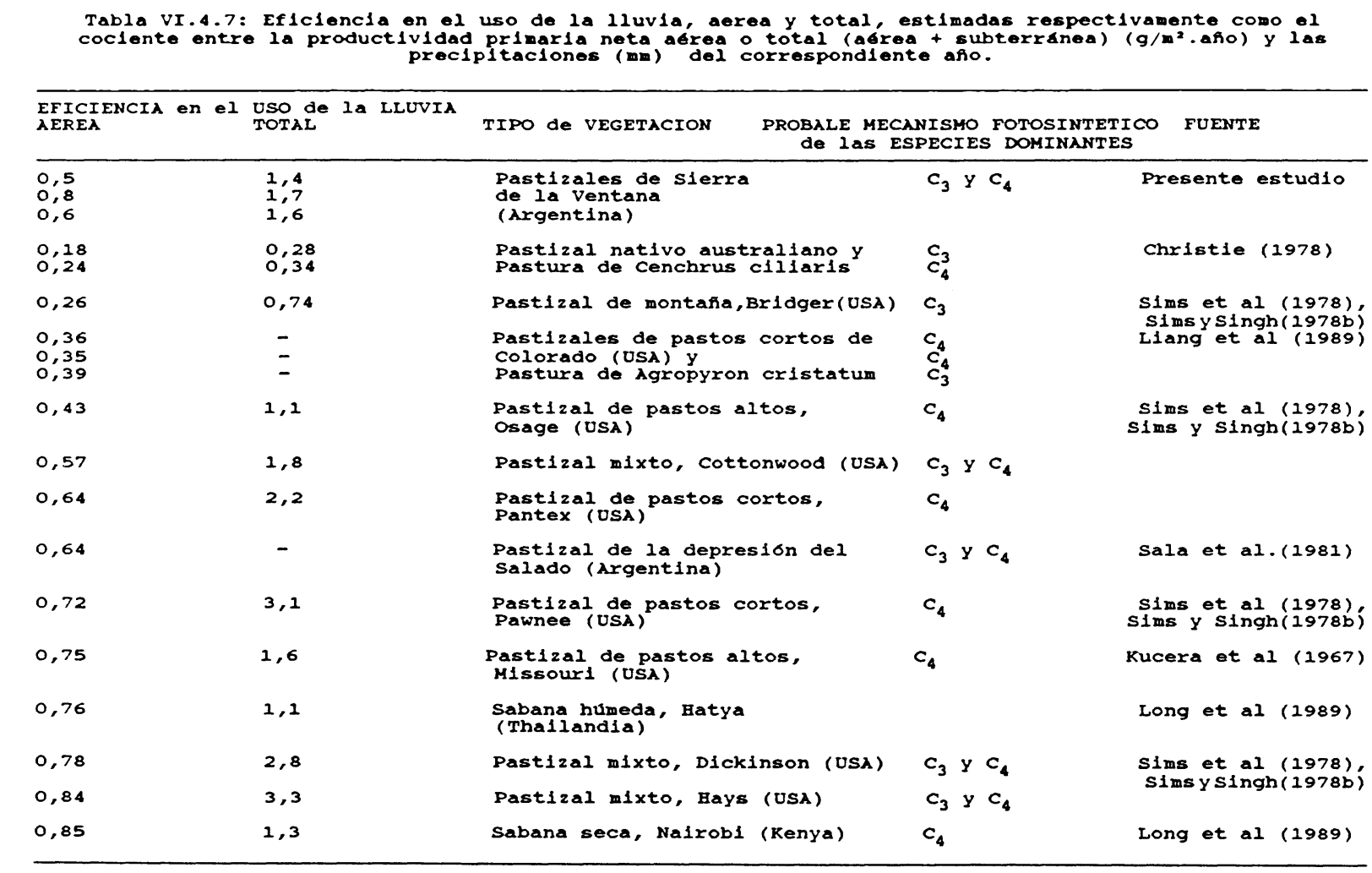

Siempre de acuerdo con los datos consignados en la tabla antes mencionada, se observa que las mayores eficiencias en el uso de las lluvias corresponden a los pastizales con abundancia de $\mathrm{C}_{3}$ y $\mathrm{C}_{4}$.

La eficiencia en el uso de la lluvia de los pastizales serranos presenta valores intermedios, de acuerdo con los presentados en la tabla VI.4.7. Comparados entre sí, se destaca que las diferencias son pequeñas, siendo menos eficiente el pastizal superior, debido a que este sitio 
recibió durante el período de estimaciones más milímetros de lluvia que los otros dos, que no se reflejaron en mayor productividad, principalmente durante el verano y el otoño.

\section{Tasas de renovación de la biomasa y del material muerto}

Dadas las diferencias estructurales y funcionales de los órganos aéreos y subterráneos, la renovación de la biomasa también opera a tasas diferentes. Además la tasa de renovación puede variar según la forma de cálculo: productividad dividido la media anual de biomasa (Frisel 1981) o materia seca, o bien la productividad dividido el pico de biomasa o materia seca (Dahlman y Kucera 1965). La primera de ellas es la que se emplea en el presente trabajo. Para los tres pastizales estudiados, las tasas de renovación aéreas (rango 2,9 año ${ }^{-1}$ 4,3 año $^{-1}$ ) son más elevadas que las subterráneas (rango 0,9 año ${ }^{-1}-1,6 \mathrm{año}^{-1}$ ). La mayor rapidez en el recambio de los tejidos aéreos con respecto a los subterráneos, en pastizales, es demostrado en otros trabajos (Dahlman y Kucera 1965, Sims y Singh 1978b, Aerts et al. 1989, Soriano et al. 1990).

Altitudinalmente las tasas de renovación subterráneas aumentan desde la cumbre hacia el pie de monte. La renovación de la biomasa aérea es más rápida a media ladera, seguida en importancia por el pastizal inferior, siendo el pastizal superior el de menor tasa de renovación (mayor tiempo de renovación) con respecto a los otros dos sitios. En el pastizal superior, donde las condiciones ambientales son relativamente más limitantes, la renovación de la biomasa (aérea y subterránea) es más lenta comparada con los otros sitios.

Las tasas de renovación de la materia seca (material vivo + muerto), aérea y subterránea de los pastizales estudiados (tabla VI.4.8) se encuentran dentro de los rangos observados para otros pastizales templados. Dahlman y Kucera (1965) estimaron una tasa de renovación de 0,5 año $^{-1}$ para la materia seca aérea y 0,25 año $^{-1}$ para la subterránea, en pastizales de pastos altos (Missouri, EEUU). Sims y Singh (1978b), en pastizales de EE UU, señalan que el rango para la renovación de la materia seca aérea es 0,9 a 1,7 año ${ }^{-1}$ y para las raíces es 0,2 a 0,7 año $^{-1}$. En ambos trabajos estas tasas fueron calculadas a partir del valor pico en la 
materia seca. En matorrales de Holanda, Aerts et al. (1989), en los sitios dominados por la gramínea Molinia caerulea, la tasa de renovación aérea es 3,3 año $^{-1}$ y la de las raíces es 1,3 año ${ }^{-1}$ y en sabanas venezolanas la tasa de renovación subterránea varía entre 0,8 a 1,1 año ${ }^{-1}$, en ambos trabajos las tasas fueron estimadas a partir de la media anual de materia seca. En los pastizales serranos estudiados, la renovación aérea es 1/año o cercana a ese valor, coincidiendo con lo señalado por Webb et al. (1983), a través del análisis de numerosos pastizales templados. Las tasas de renovación subterráneas son cercanas al límite superior del rango señalado para otros pastizales $\left(0,25-1,3\right.$ año $\left.^{-1}\right)$. Para pastizales de la depresión del Salado, Soriano et al. (1991) estimaron la tasa de renovación aérea y subterránea como el cociente entre la productividad y el pico de materia seca, obteniendo, en las raíces, valores mucho menores que los estimados para pastizales serranos $\left(0,23\right.$ año $^{-1}$ para las raíces $)$ y 0,62 $a_{n ̃ o}{ }^{-1}$ para la parte aérea (estimado a partir de datos de los autores). Recalculando dichas tasas para hacerlas comparables con las del presente trabajo, se obtiene una tasa de renovación aérea similar $\left(0,82\right.$ año $\left.^{-1}\right)$ a la de los pastizales en estudio, mientras que las variaciones son poco marcadas con respecto a la renovación subterránea $\left(0,25\right.$ año $\left.^{-1}\right)$, poniendo en evidencia el mayor dinamismo de los pastizales serranos.

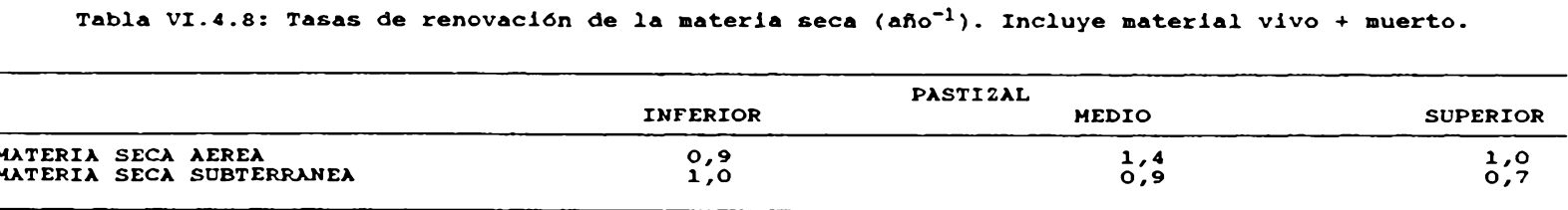

La renovación de la necromas aérea (desaparición aérea/(seco en pie + hojarasca) es más rápida en los pastizales ubicados sobre el cerro $\left(0,7 \mathrm{año}^{-1}\right)$ que en el pie de monte $\left(0,2 \mathrm{año}^{-1}\right)$. A su vez, las tasas de renovación de las raíces muertas (desaparición subterránea/raíces muertas) son mayores que las aéreas, lo cual destaca la importancia del aporte subsuperficial de las raíces a la materia orgánica del suelo. Las tasas de renovación de raíces muertas alcanzan valores similares en los pastizales superior e inferior $\left(3,2 \mathrm{año}^{-1}\right)$, mayores a su vez que. los del pastizal medio $\left(1,6 \mathrm{año}^{-1}\right)$. 


\section{VI.5-LOS CICLOS DE NUTRIENTES EN PASTIZALES DE LAS SIERRAS AUSTRALES}

Las concentraciones de nutrientes en los pastizales serranos

Las mayores concentraciones de los nutrientes considerados se encuentran en la biomasa aérea. Por tratarse de tejidos diferentes en su composición y función, se compararon las concentraciones en los compartimientos aéreos y subterráneos por separado.

La concentración de $\mathrm{P}$ y $\mathrm{N}$ es similar entre los compartimientos aéreos vivos y es a su vez mayor que en los muertos, entre los cuales no se detectaron diferencias significativas. La concentración de $\mathrm{K}$ en los compartimientos aéreos se ordena del siguiente modo: dicotiledóneas $=$ gramíneas $>$ estructuras reproductivas $>>$ seco en pie $>$ hojarasca. La concentración de $\mathrm{Ca}$ es mayor en las dicotiledóneas que en la hojarasca y ambas superan a los restantes compartimientos aéreos, los cuales presentan valores similares. En las raíces, las concentraciones de los nutrientes analizados son mayores en las finas muertas, le siguen en orden de importancia las finas vivas, y las gruesas vivas. Las raíces gruesas muertas presentan valores cercanos a las de las finas muertas.

A partir del ANOVA de la concentración de nutrientes en la parte aérea y subterránea (Tabla VI.5.1) y la comparación de medias (Gráfico VI.5.1) se establecen diferencias entre los pastizales. En los tejidos aéreos, las mayores concentraciones de los nutrientes analizados, se observan en el pastizal inferior. En las raíces finas no se detectan diferencias en las concentraciones entre pastizales, mientras que en las raíces gruesas vivas, las concentraciones de $\mathrm{P}, \mathrm{K}$ y $\mathrm{Ca}$ son mayores en el pastizal inferior. $\mathrm{El} \mathrm{N}$ en dicho compartimiento no muestra diferencias significativas entre pastizales. 
Tabla VI.5.1: ANOVA de dos factores (pastlzales y fechas), sin repllcaclones, de las concentraclones de nutrientes en $10 s$ compartinientos abreos y subterraneos de los pastizales serranos durante el periodo de muestreo.

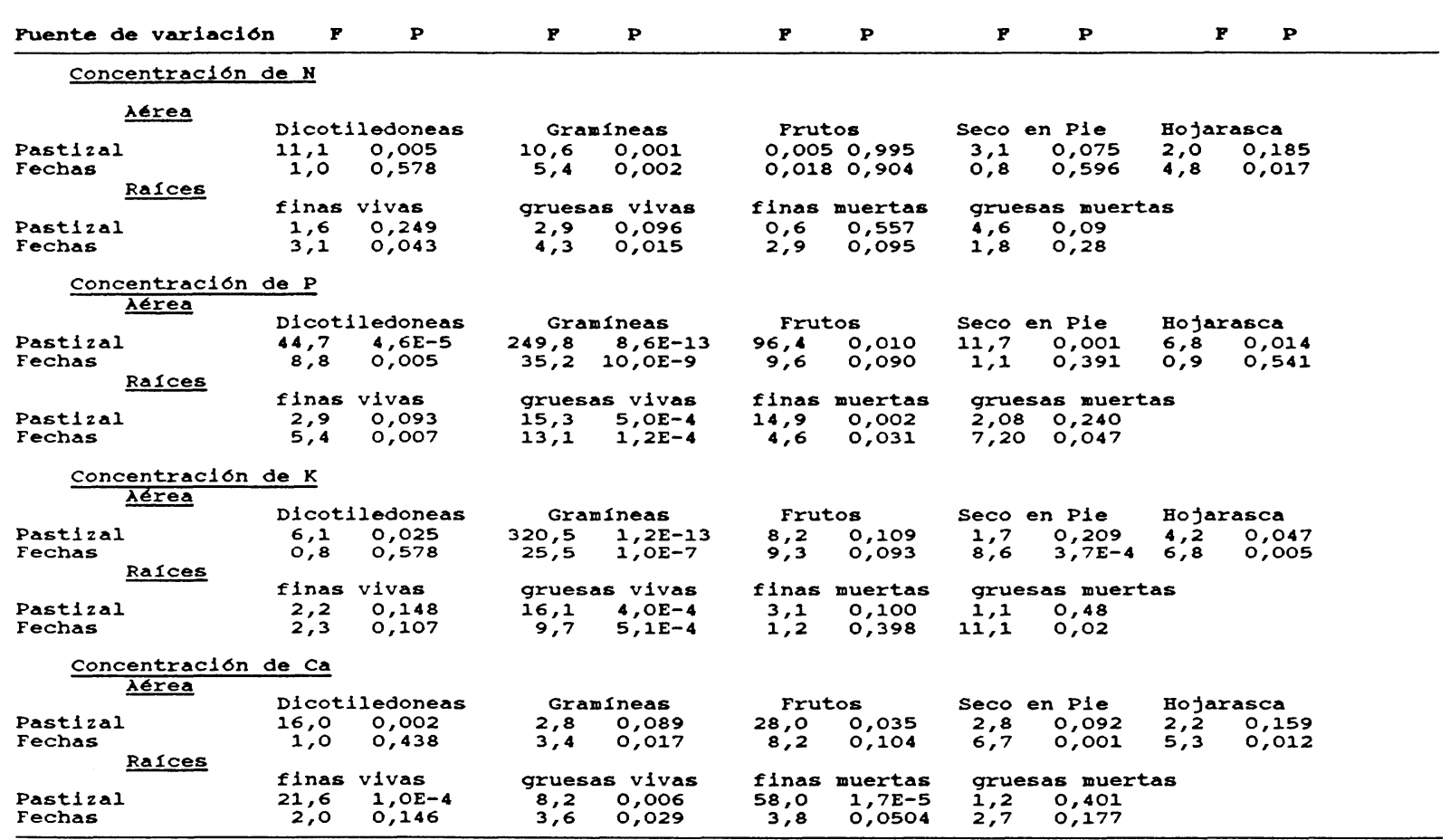

Teniendo en cuenta las concentraciones, se desprende que la vegetación en el pastizal inferior es la más rica en nutrientes, mientras que la del pastizal medio es la más pobre. Es probable que las bajas concentraciones en este pastizal estén en relación con el importante aumento de la materia seca del mismo durante el año de estudios. Dicho aumento en el pastizal medio es del $90 \%$, con respecto a los valores hallados al comienzo del muestreo, en los otros pastizales este aumento no supera el $15 \%$. Se sugiere que en el pastizal medio la dilución de los nutrientes en la biomasa fue más acentuada que en los otros sitios, por lo cual la misma presenta menores concentraciones. 

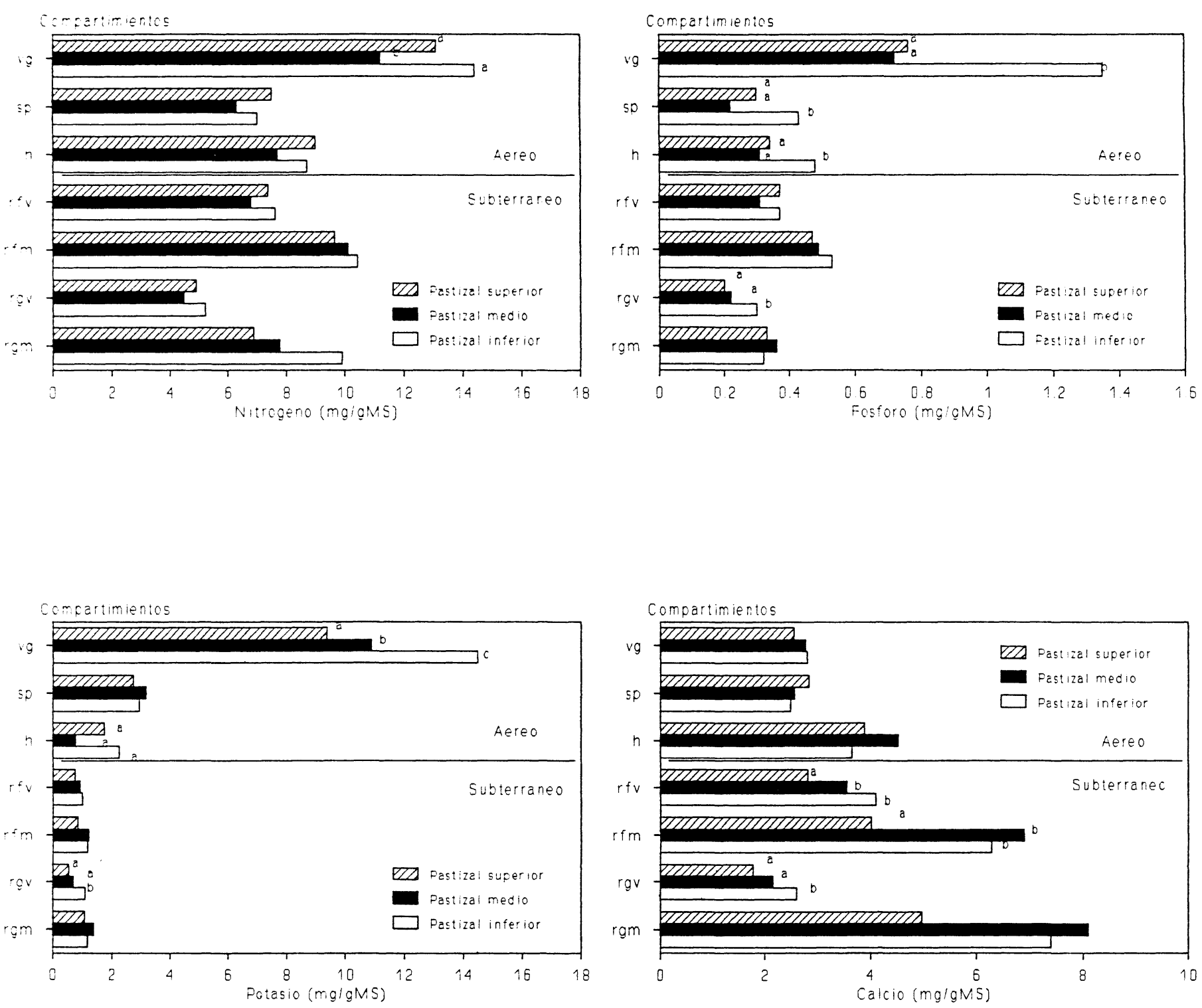

vg: verde de gramineas

sp : seco en ple

rfv: rajces finas vivas

rgv: ralces gruesas vivas

rgi: ralces gruesas muertas

Graflco VI.5.1: Concentracion de nutrientes (mg/gMs) en $20 s$ tejldos aereos y subterraneos, en los pastizales sltudados a diferente altitud, durante el periodo Jullo de 1988-jul10 de 1989.a, b, c: diferencias significativas, test de tukey $P<0,05$, cuando los resultados del ANovi fueron

significativos 
Körner (1989) realizó comparaciones que se basan en los niveles de $\mathrm{N}$ en comunidades que han evolucionado en contrastantes altitudes, en diferentes partes del mundo. En dicho trabajo señala que las plantas herbáceas que viven a mayor altitud presentan mayores concentraciones de nitrógeno en las hojas (en algunas especies hasta $40 \mathrm{mgN} / \mathrm{g}$ ), que las de baja altitud. Sin embargo, los resultados del presente trabajo son opuestos a los obtenidos por dicho autor, ya que tanto el contenido como la concentración de nitrógeno en las hojas de gramíneas y dicotiledóneas son mayores en el pie de monte. Probablemente, esta discordancia se deba a que Körner hace referencia a un rango altitudinal mucho mayor que la del presente estudio. Por otra parte, y en coincidencia con Körner (1989) en lo referente al $N$ en comunidades herbáceas, se destaca que en los pastizales estudiados los contenidos de los nutrientes $\mathrm{N}$ y $\mathrm{P}$ reflejan en gran medida la distribución de la materia seca, siendo los sitios más elevados, los que tienen mayor la proporción de esos nutrientes en las raíces con respecto a la parte aérea (tabla VI.5.2). En cambio, este patrón es opuesto, en el caso del K, el cual se almacena mayoritariamente en los tejidos aéreos. Este resultado estaría de acuerdo con la conclusión a la que arriban Abrahamson y Caswell (1982), quienes compararon tres poblaciones de Verbascum thapsus y señalan que el patrón en la asignación de la biomasa no siempre es coincidente con el de los nutrientes.

\begin{tabular}{|c|c|c|c|c|c|c|c|c|c|c|c|c|}
\hline & \multirow[b]{2}{*}{$\mathbf{N}$} & \multicolumn{3}{|c|}{ INFERIOR } & \multicolumn{4}{|c|}{$\begin{array}{l}\text { PASTIZAL } \\
\text { MEDIO }\end{array}$} & \multirow[b]{2}{*}{$\mathbf{N}$} & \multicolumn{3}{|c|}{ SUPERIOR } \\
\hline & & $\mathbf{P}$ & $\mathbf{K}$ & $\mathrm{Ca}$ & $\mathbf{N}$ & $\mathbf{P}$ & $\mathbf{k}$ & $\mathrm{Ca}$ & & $\mathbf{P}$ & $\mathbf{K}$ & $\mathrm{Ca}$ \\
\hline $\begin{array}{l}\text { TEJIDOS AEREOS ( }(\xi) \\
\text { RAICES }(\xi)\end{array}$ & $\begin{array}{l}46 \\
54\end{array}$ & $\begin{array}{l}56 \\
44\end{array}$ & $\begin{array}{l}83 \\
17\end{array}$ & $\begin{array}{l}32 \\
68\end{array}$ & 44 & $\begin{array}{l}44 \\
56\end{array}$ & $\begin{array}{l}79 \\
21\end{array}$ & $\begin{array}{l}36 \\
64\end{array}$ & $\begin{array}{l}33 \\
67\end{array}$ & $\begin{array}{l}31 \\
69\end{array}$ & $\begin{array}{l}71 \\
29\end{array}$ & $\begin{array}{l}30 \\
70\end{array}$ \\
\hline TOTAL $\left(g / m^{2}\right)$ & 11 & 0,7 & 4 & 5 & 9,1 & 0,4 & 3,4 & 4,6 & 12,4 & 0,6 & 3 & 4,9 \\
\hline
\end{tabular}


El contenido de nutrientes en los pastizales serranos

Los contenidos totales de nutrientes varían dentro de un estrecho margen entre los pastizales estudiados (tabla VI.5.2).

Las proporciones en que se reparte ese almacenaje mineral entre los tejidos vivos y muertos es similar en los pastizales de mayor altitud, siendo mayor la proporción en el vivo (rango entre el $57 \%$ y el $66 \%$ según el nutriente considerado). En el pastizal inferior, a diferencia de los otros, la distribución de los nutrientes es similar entre tejidos vivos y muertos. En el mismo, la mineralomasa un rango entre $41 \%$ y $63 \%$, de acuerdo al nutriente. El pastizal inferior tiene una mayor proporción de necromasa (50\%), que los otros dos sitios (38\%), lo cual se reflejaría en los contenidos de los nutrientes.

Como ya fue señalado, la distribución del almacenaje de nutrientes entre órganos aéreos y subterráneos mostró una tendencia altitudinal semejante a la observada en la materia seca, en los nutrientes P y N (Tabla VI.5.2). El porcentaje de esos elementos almacenados en las raíces aumenta desde el pastizal inferior al superior. En el caso del $\mathrm{K}$, dado que este elemento no forma parte de compuestos estructurales, sino que principalmente es activador de enzimas, se encuentra en los tejidos donde la función de síntesis es más activa, por lo cual son los tejidos fotosintéticos los que capitalizan este nutriente. El calcio esta almacenado principalmente en las raíces. En este caso tampoco se puede señalar una tendencia altitudinal similar a la seguida por la materia seca.

\section{Dinámica estacional de los nutrientes en los pastizales serranos.}

Las concentraciones y contenidos de los nutrientes en los tres sitios analizados mostraron un patrón similar en su variación estacional.

En los tejidos vivos, tanto aéreos como subterráneos se observa en los tres sitios que las concentraciones de los nutrientes al comienzo de la primavera son mayores que hacia el final de la misma, lo cual se debe a la dilución de los mismos en el pico de biomasa. El proceso de dilución es frecuentemente señalado en la dinámica de los nutrientes en pastizales (Christie 
1987). En la biomasa aérea los cocientes $\mathrm{C} / \mathrm{N}$ a fines de la primavera fueron de 40 , en los pastizales medio e inferior, y 37 en el superior, mientras que en el otoño, estos cocientes se reducen en más del $30 \%$ (27, 29 y 25, en los pastizales superior, medio e inferior, respectivamente). Chapin (1991) plantea la existencia de un mismo tipo de mecanismo fisiológico de respuesta a distintos tipos de stress, mediado a través del control hormonal sobre el crecimiento, que involucra un cambio integrado en el balance de agua, nutrientes y carbono en las plantas. Un proceso clave por el cual las plantas responden a cambios en su ambiente es la partición de recursos en nuevos órganos (Schulze y Chapin 1987). A partir de lo cual, la existencia de una disminución en la disponibilidad de agua en las plantas condicionaría la nutrición de las mismas y la asignación de biomasa principalmente hacia los tejidos de absorción. Excepto en el pastizal superior, en el cual las características ambientales generadas en parte por su ubicación topográfica parecen favorecer siempre la asignación de fotoasimilados hacia las raíces, en los otros dos sitios la productividad otoñal fue destinada en mayor proporción a los tejidos aéreos. Surge la duda de si estas diferencias son inherentes a la composición florística dominante en los pastizales en la primavera y en el otoño, o bien si se trata de respuestas a diferencias en las condiciones ambientales, que a su vez influyen sobre la disponibilidad de los recursos. La existencia de patrones de respuestas similares en plantas pertenecientes a diferentes especies y ambientes, sugiere que la última explicación propuesta es más probable.

En las raíces gruesas vivas, se observa que tanto sus concentraciones como su biomasa disminuyen en los períodos de mayor productividad del pastizal y ambas variables aumentan cuando dicho proceso es menos activo, y las concentraciones en las hojas disminuyen. De este modo, las mayores concentraciones de nutrientes en las raíces gruesas vivas ocurren en el verano y a principios del invierno. La repetición de este patrón en los tres pastizales muestreados y dado que las raíces gruesas han sido señaladas como organos de reserva (Ares 1976), se piensa que el aumento de las concentraciones en las mismas, cuando disminuye en las hojas, se debería a un proceso de circulación interna dentro de la planta. De este modo, parte de los nutrientes se recuperarian desde las hojas senescentes transfiriéndose hacia las raíces, principalmente a las que se engrosan. La disminución de nutrientes desde las hojas a la vez que aumentan en las raíces gruesas ha sido señalada en otros pastizales (Medina et al. 1977, Aerts y Berendse 1989, Bobbink et al. 1989). Esta estrategia permitiría a las plantas 
obtener rápidamente nutrientes cuando se reanudan condiciones ambientales favorables para el activo crecimiento. Otra evidencia en favor de este planteo es que las concentraciones en las raíces gruesas vivas decrecen cuando la productividad aumenta.

En sistemas cuyas poblaciones están sometidas a una presión selectiva favorable para economizar ciertos nutrientes, la selección natural ha favorecido mecanismos de reciclado interno, que permiten a los individuos reutilizar indefinidamente los nutrientes que ha absorvido la planta (Sarmiento 1984). La retranslocación de los nutrientes desde los tejidos senescentes constituye un mecanismo de rápido acceso a los mismos, además de evitar su pérdida del sistema, a través de distintas vias como puede ser el lavado, la captación por organismos del suelo o la formación de compuestos que los hagan inaccesibles para la planta. En los pastizales estudiados, la retranslocación de los nutrientes es puesta en evidencia a través de la diferencias que existen en las concentraciones entre los tejidos aéreos vivos y el seco en pie (las concentaciones en el verde son entre dos y cuatro veces superiores a las del seco en pie, según el nutriente y el pastizal). Aunque una proporción puede ser lavada desde los órganos aéreos, incorporándose directamente a los nutrientes en la solución del suelo, parte de esa diferencia es debida a la retranslocación. Al no poder discriminar que proporción es atribuída al lavado, se hace dificil comparar los sitios en cuanto a la eficiencia en este mecanismo. Aparentemente la retranslocación es mayor en los pastizales de menor altitud (Tabla VI.5.3). Estos pastizales comparados con el superior tienen mayor biomasa aérea, por lo cual se esperaría que recuperen más nutrientes. Sin embargo también es cierto que en estos sitios existiría mayor proporción de tejidos expuestos a la acción del lavado por la lluvia. Jones y Woodmansee (1979), señalan para el P, que dado que este nutriente se encuentra formando parte de compuestos solubles en agua, la exposición de los tejidos aéreos en pie a un lavado continuo, equivalente a $125 \mathrm{~mm}$ de lluvia, durante $96 \mathrm{~h}$ pueden remover hasta el $60 \%$ de dicho elemento.

La dinámica estacional de los nutrientes en el seco en pie es similar en los tres sitios. El aumento en las concentraciones de los nutrientes coinciden con los picos de mortalidad aéreos. El posterior descenso en las mismas se asocia al lavado por la lluvia.

Los nutrientes en la hojarasca, en los tres pastizales analizados muestra una variación estacional similar. El peso seco de este compartimiento, junto con las concentraciones de $\mathbf{P}$ 
y $\mathrm{K}$ disminuyen en la primavera y en el otoño. El descenso en el peso seco, expresado a través de su tasa instantánea de desaparición no muestra difencias estacionales, en el pastizal superior, pero es más importante durante el período estivo-otoñal, en los otros dos sitios. A su vez, en el período inverno-primaveral, la velocidad de desaparición es mayor en el pastizal superior (13 mg/g.dia) que en los sitios ubicados a menor altitud $(4,5 \mathrm{mg} / \mathrm{g}$.dia). En el otoño dichas tasas muestran mayores valores en los pastizales situados sobre el cerro que en el pie de monte (12 y $8 \mathrm{~m} / \mathrm{g}$. día respectivamente). En ambos períodos las tasas instantáneas de mineralización de los nutrientes fueron similares a las de la materia seca, excepto durante el estivo-otoñal en el pastizal superior, en el cual la tasa de desaparición fue marcadamente mayor que la de mineralización (12 y $3 \mathrm{mg} / \mathrm{g}$.dia, respectivamente). En la primavera y en el otoño, la temperatura y humedad resultarían más favorables para los organismos que intervienen en los procesos de descomposición y mineralización. Analizando el comportamiento de la hojarasca en un ciclo anual, se advierte que la diferencia estacional en las tasas instantáneas de descomposición podría estar en relación con la concentración de nutrientes de la materia seca. El material presente en el otoño procede en su mayor parte de la hojarasca caída a fines de diciembre, inicialmente podría existir una pérdida de los materiales más solubles, prevaleciendo luego procesos de enriquecimiento microbiano que permitirían su degradación en la primavera siguiente. A medida que la descomposición ocurre, compuestos solubles y de relativamente fácil degradación, tales como azúcares, almidón y proteinas pueden ser rápidamente utilizadas por los descomponedores, mientras que otros más recalcitrantes tales como la celulosa, grasas, ceras, taninos y ligninas son perdidas a tasas relativamente más lentas (Wieder y Lang 1982). Por otra parte, la velocidad de descomposición y la mineralización de los nutrientes esta en relación directa con las calidad del material, la cual se expresa a través del cociente C:elemento. Habitualmente el cociente más utilizado es el $\mathrm{C}: \mathrm{N}$, y los procesos involucrados en las variaciones del mismo son la inmovilización y la mineralización del nitrógeno en los tejidos muertos. Los nutrientes son inmovilizados cuando son incorporados y mantenidos en la forma orgánica. Esto ocurre cuando nutrientes inorgánicos son tomados por las raíces de las plantas, o por microorganismos u otros animales descomponedores (Swift et al. 1979), sin embargo de acuerdo con Frioni (1990), dicho término se aplicará solo al proceso en el que participan microorganismos. La clave en la disponibilidad de nutrientes está en la mineralización neta, es decir cuando la mineralización excede a la inmovilización (Swift et al. 1979). De acuerdo 
con lo expresado por estos autores, la mineralización neta de cualquier elemento esta en relación directa con su disponibilidad para con los organismos descomponedores, siendo el P y $\mathrm{N}$ habitualmente los nutrientes que pueden limitar la descomposición. En tal caso el elemento limitante es retenido (inmovilizado), por los microorganismos hasta que alcanza un nivel a partir del cual la mineralización prevalece sobre la inmovilización. Una expresión de ese nivel crítico es el cociente C:nutriente. Los valores del cociente en el nivel crítico son variables de acuerdo a los materiales y múltiples factores tales como humedad, $\mathrm{pH}$, temperatura, que pueden afectar la composición y dinámica de los microorganismos descomponedores (Berg y Ekbohm 1983). Teniendo en cuenta los cocientes C/N en los tres sitios estudiados, los mismos decrecen desde fines de la primavera (cuando la caída a la hojarasca fue máxima) hasta el invierno siguiente, poniendo en evidencia el enriquecimiento de este mineral. Por lo cual es probable que, dadas las condiciones de temperatura y humedad del suelo favorables, la calidad mejorada del material que constituye la hojarasca aceleraría los procesos de descomposición y mineralización.

Los procesos de inmovilización y enriquecimiento microbiano y preferencia de sustratos permitirían explicar por qué las concentraciones de nutrientes en las raíces muertas son mayores que en las raíces vivas. Con respecto a los niveles de los minerales en los tejidos subterráneos, Stanton (1988) señala que se establecería competencia por los mismos entre los microorganismos del suelo, dado que las raíces en los pastizales se caracterizan por una alta proporción de polisacáridos estructurales y un relativamente bajo contenido de nutrientes (Heal e Ineson 1984 en Stanton 1988). A diferencia de lo que ocurre en la hojarasca, en las raíces, las mayores tasas instantáneas de descomposición y mineralización fueron otoñales. Durante el año de muestreo, las lluvias otoñales fueron más abundantes que en la primavera, lo cual se relacionaría con tasas más elevadas en el primer período mencionado.

La velocidad de descomposición y mineralización (mg/g.dia) de la hojarasca, en los dos períodos considerados, fue igual o menor que en las raíces. Al respecto, Ricci y de Wysiecki (com. pers.) estimaron las tasas instantáneas de descomposición de hojarasca y de raíces, en pastizales de la zona, empleando bolsas de descomposición, obteniéndo mayores valores en las raíces (4,6 mgMS/g.dia) que en la hojarasca y (1,5 mgMS/g.dia). Mayores velocidades en la mineralización de los nutrientes provenientes de las raíces son señalados en otros 
trabajos (Seastedt 1988, Berendse et al. 1989).

\section{Los ciclos de nutrientes en los pastizales serranos.}

El ingreso de los nutrientes al suelo, disponibles para las plantas, procede de distintas fuentes. La más importante la constituyen los nutrientes provenientes de la descomposición de los restos vegetales (Swift et al. 1979, Jones y Woodmansee 1979). Otra via de ingreso importante es la depositación atmosférica, seca o por medio de la lluvia. El ingreso de nutrientes por dicha via, para la cuenca en la que se encuentran los pastizales, fue durante el período junio de 1988- mayo de $19890,34 \mathrm{gK} / \mathrm{m}^{2}, 1 \mathrm{gCa} / \mathrm{m}^{2}, 0,04 \mathrm{gP} / \mathrm{m}^{2}$ y 0,19 gN/m² (Dascanio y Bianchi com. pers.). Jones y Woodmansee (1979) señalan ingresos de N y P a través de la lluvia similares a los hallados para estos pastizales, en pastizales anuales del valle central de California, cuyo rango varía entre 0,3 y $1 \mathrm{gN} / \mathrm{m}^{2}$ y entre $4 \times 10^{-3}$ y $0,05 \mathrm{gP} / \mathrm{m}^{2}$. En los pastizales estudiados el ingreso anual de $\mathrm{P}, \mathrm{K}$ y $\mathrm{Ca}$ a partir de la depositación atmosférica reviste importancia, ya que la misma presenta valores similares a los de la mineralización aérea de esos nutrientes. Otro ingreso de importancia es a partir del lavado de la vegetación, el cual representaría aproximadamente el $40 \%$ del P inórganico que ingresa al suelo desde la mineralización de tejidos vegetales y cerca del $50 \%$ en el caso del $\mathrm{K}$. En el caso del N y el Ca, esta via es menos importante. Sarmiento (1984), señala que los cationes que ingresan al suelo ya sea por mineralización de la necromasa o por pluviolavado son retenidos en gran cantidad por el complejo coloidal organomineral, lo que facilita su reciclado entre el suelo y la biota. En el caso del $\mathrm{N}$ y el $\mathrm{P}$ su liberación a la solución del suelo a partir de la degradación de la materia orgánica del mismo, o en el caso del $\mathrm{P}$, la lixiviación desde minerales primarios o secundarios ocurre a tasas muy lentas (Swift et al. 1979, Jones y Woodmansee 1979, Stewart et al. 1983). La fijación atmosférica de nitrógeno puede también significar un importante ingreso de ese elemento que aumentaría la disponibilidad del mismo en el suelo. No se dispone de estimaciones en los sitios de estudio. Jones y Woodmansee (1979) señalan que el ingreso anual de $\mathbf{N}$ por esta via, en pastizales del centro de California, varía entre 0,5 y $5 \mathrm{gN} / \mathrm{m}^{2}$. El balance de los nutrientes en la cuenca serrana realizado por Dascanio y Bianchi (com. pers.), fue positivo para el $\mathrm{K}$, balanceado para el $\mathrm{P}$ y negativo, pero en pequeña magnitud para el $\mathrm{N}$ y $\mathrm{Ca}$ (en el caso del $\mathrm{N}$ este resultado podría variar si se considerara la fijación atmosférica). Esto pone de manifiesto la 
efectividad de los pastizales serranos en la conservación de los nutrientes.

Los requerimientos de nutrientes difieren entre pastizales. Los mayores en cuanto a $\mathrm{P}$, $\mathrm{N}$ y K corresponden al pastizal inferior, y decrecen con la altitud, siendo el pastizal superior el que emplea menos cantidad de nutrientes en la productividad primaria neta anual. Esta diferencia se relaciona con la diferente asignación de la asimilación neta en órganos aéreos y subterráneos en los pastizales situados a diferente altitud. Como fue señalado, los tejidos fotosintéticos presentan concentraciones mucho mayores de nutrientes que las raíces vivas, por lo cual se esperarían mayores requerimientos en aquellos pastizales que asignan una mayor proporción de la asimilación neta a la formación de tejidos aéreos. El Ca en cambio se concentra principalmente en las raíces, por lo cual no se observan diferencias en los requerimientos entre los pastizales. Si bien los mismos tienen una productividad primaria neta anual similar, la inversión de la misma en la formación de tejidos fotosintéticos y no fotosintéticos en diferentes proporciones tiene importantes implicancias en el flujo de nutrientes, disminuyendo la cantidad de nutrientes circulando en el sistema desde el pie de monte hacia la cumbre, en correspondencia con una mayor asignación de recursos hacia las raíces en ese mismo sentido.

En cuanto a la adquisición de nutrientes, las plantas desarrollarían un activo papel a través de su sistema radical, modificando propiedades del suelo, formando asociaciones simbióticas, y a partir del crecimiento diferencial en zonas con mayor disponibilidad de nutrientes.

Las raíces de las plantas pueden cambiar sustancialmente las propiedades del suelo en su vecindad y promover la liberación de nutrientes desde sustancias minerales del mismo (Clarkson 1985). Diversos autores ( Swift et al. 1979, Chapin 1980, Clarkson 1985, Stanton 1988) señalan que a partir de exudados orgánicos desde las raíces, los cuales pueden representr aproximadamente un 20\% de la fotosíntesis total (Clarkson 1985), las plantas modificarían su entorno: 1) mediante la secreción de polisacárido pueden mejorar o mantener la porosidad del suelo, incrementando el contacto entre este y las raíces; 2) a través de excreción de $\mathrm{H}^{+}$, pueden disminuir el $\mathrm{pH}$ aumentando la disponibilidad de $\mathrm{P}$ en el suelo y; 3) mediante la liberación de la enzima fosfatasa, en suelos deficientes en fósforo, mejorando la disponibilidad de ese nutriente. Los mismos autores señalan la importancia de las 
asociasiones micorrícicas en la obtención de nutrientes del suelo.

Otra forma en que las plantas pueden mejorar la adquisición de los nutrientes es a partir de la mayor proliferación de raíces en micrositios del suelo más ricos en agua y nutrientes (Eissenstat y Caldwell 1988, 1989, Caldwell et al. 1991). Existe una respuesta integrada, morfológica y fisiológica, de las plantas a cambios en la quimica del suelo de los micrositios enriquecidos, resultando en un incremento en la captación de nutrientes por parte de las plantas (Black et al. 1994).

En los tres sitios, pese a que los requerimientos aéreos son mayores, el retorno de materia orgánica y nutrientes al suelo desde la vegetación ocurre principalmente a través de la mortalidad de las raíces. Esto se debe a que en el material aéreo los requerimientos de nutrientes son satisfechos en parte por la retranslocación y por otro lado a que el material seco en pie se acumula, actuando como un sumidero nutritivo, por lo que el pluviolavado y una menor fracción de materia seca caída y descompuesta retoran nutrientes al suelo. Sumado a esto, durante el período en que se realizó este estudio, los pastizales se encontrarían en una etapa de recuperación de su estructura aérea posterior al incendio ocurrido a principios de 1987, por lo cual no sólo se verifica la diferencia en las vias mencionadas (aérea y subterránea) sino que el almacenaje de nutrientes en el seco en pie se debe al incremento en materia seca.

La eficiencia en el uso de los nutrientes en los tres pastizales fue estimada como el cociente entre la productividad primaria neta total de materia seca (aérea + subterránea) dividido por la mineralomasa total (Chapin 1980) (Tabla VI.5.4). Aunque las diferencias entre pastizales no son marcadas para un mismo nutriente, se evidencia una relación inversa entre este índice y el contenido de nutrientes disponibles en el suelo (Gráfico VI.5.2). El concepto de eficiencia en el uso de los nutrientes ha sido objeto de una amplia revisión realizada por Grubb (1989), quien señala que el más adecuado, a su criterio, es el formulado por Hirose (1971 fide Grubb 1989) que considera la tasa de productividad neta (aérea + subterránea) y la tasa de captación de nutrientes. Esta forma de estimación de la eficiencia contempla la retranslocación, el lavado de elementos y eventualmente la herbivoría. En el presente estudio se calculó el cociente entre la tasa de productividad neta total de materia seca 
dividido la tasa de absorción de nutrientes (Tabla VI.5.4). Comparando las mencionada formas de estimación, ambas coinciden en que decrecen a medida que aumenta el contenido de nutrientes disponibles en el suelo de los pastizales. Sin embargo, en el caso del potasio, la eficiencia estimada según el último cociente señalado es similar en los pastizales superior e inferior, a pesar de que en éste, su contenido en el suelo es nueve veces mayor. Tal diferencia se explica por la elevada retranslocación de postasio en el pastizal inferior comparado con el superior, que no es tenida en cuenta cuando se utiliza la mineralomasa en el denominador. En el caso del potasio, esta relativa mayor eficiencia del pastizal inferior se relaciona con los altos requerimientos del mismo. Dado que en este sitio la alocación de fotosintatos es mayor hacia estructuras aéreas, comparado con los pastizales ubicados sobre el cerro, y son esos tejidos los que poseen mayor concentración y necesidad de potasio, la eficiencia con respecto a ese nutriente aumenta a pesar de su mayor disponibilidad en el suelo. 


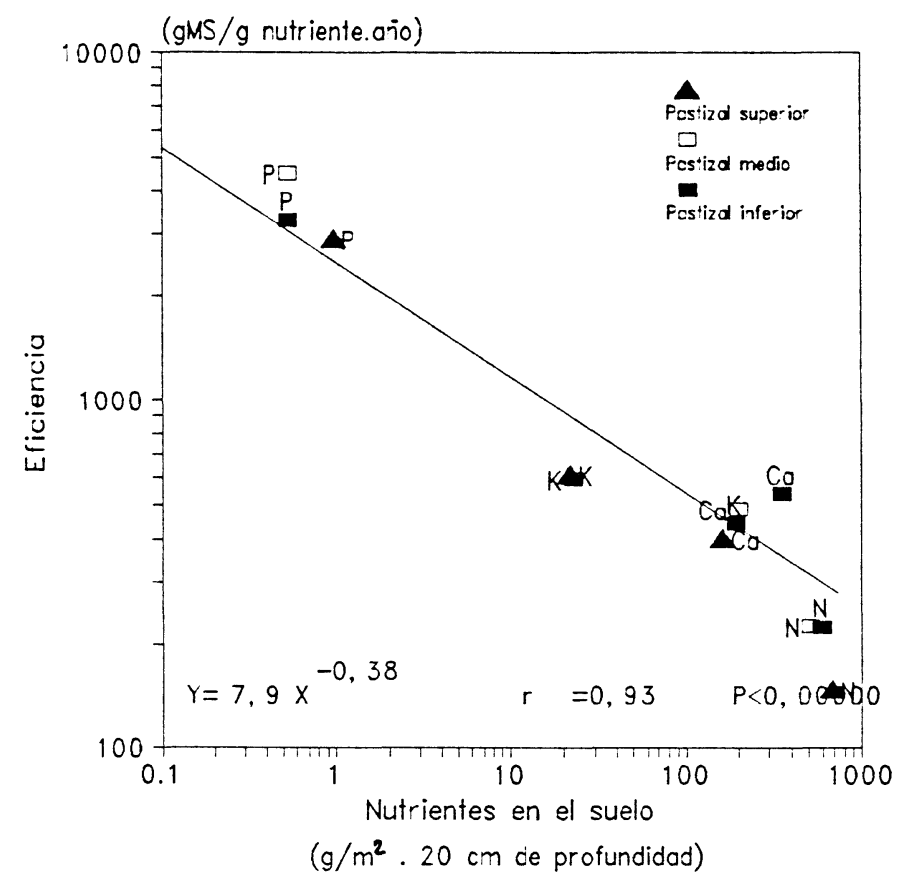

Graflco vI.5.2: Regresion entre la eficiencia en el uso de nutrientes (produccion total de
MS/mineralomasa total) y el contenldo de nutrientes disponibles del suelo en los pastizales ubicado a

La tasa de recambio de órganos de las plantas (en términos de materia seca) es relativo al tiempo de vida de los mismos (Shaver y Billings 1975). Hendrick y Pregitzer (1992) estiman la vida media de las hojas y de las raíces como aproximadamente igual a la mitad del tiempo de renovación. De acuerdo con ello, la masa de hoja en los pastizales tendrían una vida media de aproximadamente 2 meses, en cambio en las raíces la misma podría ser cercana a los seis meses en los pastizales ubicados sobre el cerro, y tres meses, el pastizal inferior.

Por otra parte, la renovación de los nutrientes en la vegetación (requerimientos/mineralomasa), presenta velocidades diferentes según se trate de tejidos aéreos o subterrános (Tabla VI.5.4). En los tres sitios, la renovación tanto de la materia seca como de los nutrientes que integran los tejidos aéreos vivos es mayor que la renovación en los tejidos subterráneos. Evans (1989) señala que en plantas con elevadas tasas fotosintéticas, dado que la misma decrece con el envejecimiento de las hojas, la única forma de mantener esas tasas es a partir de la constante renovación foliar. A su vez, la tasa de renovación de nutrientes dividida por la tasa de renovación de materia seca (Tabla VI.5.4) es un estimador de la eficiencia en el uso los nutrientes que permite la comparación de comunidades con 
diferente contenido de nutrientes en la vegetación, porque es independiente de las concentraciones (Gray 1983). De acuerdo con el mismo existiría una relación óptima entre la circulación de materia seca y de nutrientes, que se mantiene a lo largo del gradiente estudiado. Se destaca que los nutrientes circulan a una velocidad poco mayor que la de la materia seca, con excepción del potasio que que circula a mayor velocidad que el resto de los nutrientes y al doble que la materia seca en los pastizales ubicados sobre el cerro. El pastizal inferior sería más conservativo comparado con los de mayor altura, con respecto a dicho nutriente. Esto se relaciona también con la elevada tasa de retranslocación de potasio en el pastizal de menor altitud.

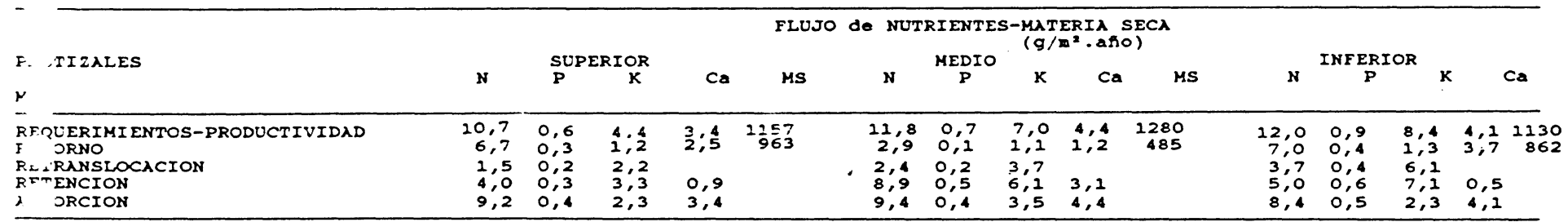

\begin{tabular}{|c|c|c|c|c|c|c|c|c|c|c|c|c|c|c|c|}
\hline \multirow[t]{2}{*}{ PASTIZALES } & \multicolumn{15}{|c|}{$\begin{array}{l}\text { INDICES de EFICIENCIA } \\
\text { MEDIO }\end{array}$} \\
\hline & $\mathbf{N}$ & $\mathbf{P}$ & $\kappa$ & $\mathrm{Ca}$ & MS & $\mathbf{N}$ & $\mathbf{P}$ & $\mathbf{K}$ & $\mathrm{Ca}$ & MS & $\mathbf{N}$ & $\mathbf{P}$ & $\mathbf{x}$ & $\mathrm{Ca}$ & MS \\
\hline \multicolumn{16}{|l|}{ - $\frac{\text { Productividad total MS }}{\text { Mineralomasa. }}$} \\
\hline$\frac{\text { Productividad total MS }}{\text { Absorcion }}$ & 0,4 & 8,5 & 1,6 & 1,1 & & 0,4 & 9,7 & 1,2 & 0,9 & & 0,4 & 7,2 & 1,6 & 0,8 & \\
\hline $\begin{array}{l}\text { He retranslocacion: } \\
\text { retranslocacion/requerimientos }\end{array}$ & 14 & 27 & 49 & - & & 20 & 35 & 52 & - & & 31 & 47 & 73 & - & \\
\hline \multicolumn{16}{|l|}{$\begin{array}{l}\text { Taia de renovacion: } \\
\text { raruerimiento-productividad } \\
\text { Ineralomasa-biomasa }\end{array}$} \\
\hline $\begin{array}{l}\text { Atrea } \\
\text { Subterranea } \\
\text { Total }\end{array}$ & $\begin{array}{l}2,9 \\
0,9 \\
1,4\end{array}$ & $\begin{array}{l}3,3 \\
0,9 \\
1,5\end{array}$ & $\begin{array}{l}3,1 \\
0,9 \\
2,4\end{array}$ & $\begin{array}{l}2,4 \\
0,9 \\
1,2\end{array}$ & $\begin{array}{l}3,0 \\
0,9 \\
1,1\end{array}$ & $\begin{array}{l}4,0 \\
1,2 \\
2,1\end{array}$ & $\begin{array}{l}4,1 \\
1,2 \\
2,3\end{array}$ & $\begin{array}{l}4,1 \\
1,0 \\
3,3\end{array}$ & $\begin{array}{l}3,1 \\
1,2 \\
1,7\end{array}$ & $\begin{array}{l}4,3 \\
1,1 \\
1,7\end{array}$ & $\begin{array}{l}3,5 \\
1,7 \\
2,4\end{array}$ & $\begin{array}{l}3,5 \\
1,7 \\
2,7\end{array}$ & $\begin{array}{l}3,7 \\
1,4 \\
3,3\end{array}$ & $\begin{array}{l}3,0 \\
1,7 \\
2,0\end{array}$ & $\begin{array}{l}3,2 \\
2,6 \\
2,0\end{array}$ \\
\hline$i \frac{\text { renovacion total nutrientes }}{\text { renovacion de la blomasa total }}$ & 1,3 & 1,4 & 2,2 & 1,1 & - & 1,3 & 1,2 & 1,9 & 1,0 & - & 1,2 & 1,3 & 1,6 & 1,0 & - \\
\hline
\end{tabular}

Chapin et al. (1986) señalan que el concepto agronómico de suministro limitado de nutrientes no puede ser transferido directamente a las comunidades naturales, debido a que la escasa disponibilidad de nutrientes no implica la limitación de los mismos en la comunidad, dadas las distintas estrategias desarrolladas por las plantas adaptadas a diferentes condiciones 
de fertilidad de los suelos. En los pastizales estudiados, la concentración de los nutrientes $\mathbf{N}$ y $\mathrm{P}$ en los tejidos vegetales sigue un patrón altitudinal opuesto a la concentración y contenido de los mismos en el suelo. El pastizal inferior presenta las mayores concentraciones de los nutrientes mencionados, comparado con el sitio ubicado a mayor altitud, siendo el suelo del mismo más pobre en concentración y contenido de estos nutrientes con respecto al pastizal cercano a la cumbre. En relación con dichas estrategias, Chapin (1980) en concordancia con Grime $(1977,1979)$ expresa que las especies de habitat favorables muestran mayor plasticidad en los patrones de alocación que las especies de ambientes restrictivos. En varios estudios (Chapin et al. 1982, Kachi y Rorison 1990) se muestra que existe menor plasticidad en los patrones de distribución de la biomasa en especies que crecen en ambientes relativamente pobres en nutrientes, con respeto a otras, similares en su forma de crecimiento, que habitan ambientes más ricos. En ambientes pobres, donde la absorción esta limitada por la difusión tiene más valor una gran biomasa de raíces de mayor longevidad que una capacidad de absorción elevada (Chapin 1980). Nadelhoffer et al.(1985), a partir de la comparación de sitios en bosques templados con diferente disponibilidad de nitrógeno en el suelo, demostraron que la renovación de las raíces finas es mayor en sitios ricos en recursos, que en sitios pobres. Hobbie (1992) muestra que existe una serie de rasgos contrastantes en las especies que crecen en ambientes con diferente suministro de nutrientes. En ambientes donde la disponibilidad de nutrientes es baja, las plantas crecen más lentamente, usan eficientemente los nutrientes, minimizando las pérdidas y demandas de los mismos. Estos rasgos resultan en un lento ciclado de los nutrientes. En cambio, en dicho trabajo se señala que las plantas de ambientes con alta disponibilidad de nutrientes crecen relativamente rápido, tienen altas tasa de renovación y usan los nutrientes ineficientemente, promoviendo un rápido ciclado de los mismos.

Esta caracterización de las especies vegetales que viven en ambientes relativamente ricos en cuanto a la disponibilidad de nutrientes concuerda con los rasgos más sobresalientes de las plantas en los pastizales estudiados. Las mismas mantienen tasas elevadas de productividad durante gran parte del año; a partir de cambios en las condiciones hídricas del suelo, y por lo tanto, también en la disponibilidad de los nutrientes, se observan rápidos cambios en la distribución de la biomasa, expresada a través de la relación biomasa subterránea/biomasa aérea, la cual presenta amplios rangos en los pastizales ( 6 a 12 en el superior, 3 a 9 en el medio y, 1 a 5 en el inferior); y el tiempo de renovación, tanto de nutrientes como de 
biomasa es elevado (anual o menor que un año).

Las plantas refuerzan los patrones de disponibilidad de nutrientes en los ecosistemas naturales (Hobbie 1992). Las implicancias que tendrían estos mecanismos de retroalimentación postitiva sobre los ciclos biogeoquímicos y la incorporación de materia orgánica al suelo, la cual actua directamente sobre la estabilidad y cohesión de los mismos, deben considerarse cuando los sistemas naturales son sometidos a perturbaciones. La implantación de comunidades artificiales con tasas de captación y renovación de recursos que operan a diferente velocidad que las de las comunidades naturales podrían conducir a importantes alteraciones y deterioro del suelo. Estos efectos negativos pueden intensificarse si se considera la importancia de los pastizales en cuanto a la función protectora de las zonas con fuertes pendientes.

\section{VI.6 - EFECTOS DEL FUEGO y PASTOREO EN LOS PASTIZALES SERRANOS}

El pastoreo es uno de los factores bióticos más importantes en sistemas de pastizal. Un completo entendimiento de las respuestas de la vegetación a la herbivoría debe incluir procesos desde el nivel individual al de ecosistemas (McNaughton 1985).

A nivel individual, McNaughton (1979) considera que el crecimiento compensatorio constituye una respuesta indirecta a la defoliación parcial, la cual puede aumentar la tasa fotosintética por unidad de área foliar remanente, al aumentar la demanda de fotosintatos en los meristemas no dañados, además al remover los tejidos viejos, permite un uso más eficiente de la luz, mejora el estado nutricional de los tejidos y el estado hídrico de la planta, al reducir la superficie transpirante (McNaughton 1985).

Las plantas responden como un todo a un complejo de factores ambientales, de los cuales la herbivoría es sólo uno (McNaughton 1979). El impacto de la herviboría sobre una planta depende de la interacción de múltiples factores tales como la presencia o ausencia de plantas vecinas, la disponibilidad de nutrientes y agua en el suelo, el grado de defoliación y la longitud de tiempo que una planta tiene para recomponerse luego de un evento de pastoreo, (Maschinski y Whitham 1989, Georgiadis et al. 1989, Oesterheld y McNaughton 1991). La 
alocación y las respuestas fisiológicas al stress pueden afectar positiva o negativamente la respuesta al pastoreo y el pastoreo puede aliviar o agravar los efectos de distintos tipos de stress (Oesterheld y McNaughton 1991).

A nivel de ecosistemas, el pastoreo de grandes herbívoros, tiene efectos directos tales como el consumo, pisoteo, reciclado de las excretas y generalmente la remoción del producto animal (Floate 1981), los cuales generan cambios de diferente magnitud en los sistemas de pastizal condicionados por la historia de pastoreo de los ambientes, las características del clima y las prácticas de manejo.

En pastizales de América del Norte, Sims et al (1978) señalan que dado que los pastizales y los grandes herbívoros han coevolucionado, la consideracion de los pastizales sin la interacción con los herbívoros sería una situación artificial. Mack y Thompson (1982) consideran que la morfología de pastos rizomatosos y cespitosos refleja los dos extremos a los que han evolucionado los pastos perennes en respuesta, a la continua y alta versus la baja presión de pastoreo por grandes manadas de mamíferos. Dado que las gramíneas y los grandes herbívoros evolucionaron juntos, varios rasgos que son ventajosos en habitat semiáridos tienen un efecto beneficioso sobre las plantas pastoreadas (Coughenour 1985). En el Serengeti (Kenya) el pastoreo modifica la composición y diversidad de la vegetación y estimula la productividad aérea (McNaughton 1983, 1985). Sin embargo MacNaughton (1983) señala que el aumento de la diversidad en los parches pastoreados ocurre a partir del ingreso de especies de gramineas nativas de tipo rizomatoso, al reducirse la competencia por la luz generada por las gramineas cespitosas dominantes en los parches no pastoreados. En pastizales de la depresion del Salado, Sala (1988) destaca que el pastoreo produce profundos cambios en la estructura y composición florística de las comunidades. La diversidad en las áreas pastoreadas es mayor que en las no pastoreadas por el ingreso hierbas de hoja ancha y de especies de gramíneas exóticas, más tolerantes al pastoreo que las nativas. Milchunas et al. (1989), en pastizales semiáridos de América del Norte, muestran que el pastoreo no constituye un disturbio a nivel población, ni a nivel comunidad.

Al respecto, Milchunas et al. (1988) desarrollaron un modelo que explica esas diferentes respuesta al pastoreo en pastizales, en función de dos variables, la humedad ambiental y la 
historia de pastoreo de las comunidades de pastizal, en tiempos evolutivos. La respuesta de las comunidades vegetales al pastoreo depende de la interacción de presiones de selección convergentes o divergentes a lo largo de un gradiente de humedad, y factores relativos a la tolerancia o intolerancia del pastoreo a lo largo de un gradiente de historia evolutiva de pastoreo (Milchunas et al. 1988). Sala (1988) señala que los pastizales pampeanos se encuadrarían dentro de uno de los de los cuatro casos extremos ejemplificados por los autores del modelo, los pastizales subhúmedos con corta historia de pastoreo, los cuales son potencialmente más suceptibles de ser alterados por el mismo.

En pastizales de Sierra de la Ventana, Ricci (1992) realizó estudios de la vegetación en relación con las actividades del hombre en la zona, señalando que las áreas serranas propiamente dichas y los valles intraserranos se dedican principalmente al uso pastoril. A partir de este estudio se establece que las comunidades serranas de pastizal son modificadas por el pastoreo en distinto grado segun la topografía, pendiente y rocosidad. Dentro de las comundiades ubicadas en el pie de monte, las dominadas por pastos del tipo tussock fueron más alteradas por el pastoreo en su composición florística, debido a la introducción de especies exóticas, que las comunidades dominadas por flechillas. En ausencia de pastoreo, estas últimas tienen mayor diversidad específica comparadas con las primeras. Ricci (1992) sugiere que los flechillares tendrían mayor variedad de estrategias en las especies nativas que le permiten tolerar el disturbio, por lo cual el ingreso de especies exóticas ocurre en menor grado que en las comunidades del tipo tussock. Otro efecto del pastoreo en las comunidades serranas, señalado por Barrera (1991) esta dado por favorecer el establecimiento de arbustos. En los flechillares y pastizales de Sorghastrum, situados sobre la sierra los cambios causados por el pastoreo suave a moderado tienden a ser más cuantitativos que cualitativos (Ricci 1992). Con respecto a las modificaciones en la estructura de los pastizales Ricci (1992) determinó que el pastoreo reduce la biomasa aérea total de los pastizales y en particular la de los compartimientos muertos, seco en pie y hojarasca, con respecto a la situación no pastoreada. La productividad primaria aérea neta también se ve disminuída en las áreas pastoreadas con respecto a las no pastoreadas.

Frangi y Bottino (1995) señalan con respecto a la composición florítica, que en las Sierras Australes confluyen especies de distinto origen fitogeográfico, por la gran heterogeneidad de 
ambientes generados como consecuencia de su historia geologica y climatica y por su condición de isla ambiental. De este modo los autores destacan la existencia en los distintos ambientes serranos de especies de origen autrobrasileño-uruguayo, del Monte, del Espinal, Subantártico, Patagónico y especies endémicas de estirpe microtémica. Por otra parte dado que los pastizales naturales han sido modificados, en la mayoria de los casos profundamente, por ser las zonas que actualmente sostienen la mayor parte de las actividades agropecuarias, resulta de gran importancia la existencia de áreas de Reserva Natural. En la actualidad, en el Parque Provincial E. Tornquist, existe una creciente población de caballos salvajes en la zona de la reserva. Dado los antecedentes mencionados a cerca de la influencia que el pastoreo de grandes herbivoros ejerce sobre estos pastizales, y ante la ausencia control por enemigos naturales o de manejo de la población de caballos, es de esperar que la densidad de los mismos provoque cambios profundos e indeseables en áreas que además de ser valiosas desde el punto de vista de las especies que albergan, ejerce la función de protección de los suelos. Las mismas permitirian mantener especies nativas que de otro modo pueden desaparecer debido a los diferentes usos de otros pastizales y cuyas potenciales aplicaciones aun no han sido investigadas. Los pastizales como unidades en sí mismas pueden ser objeto de múltiples estudios, los cuales pueden a su vez permitir un mejor manejo de las zonas destinadas a la producción agrícola-ganadera. Por lo cual, en el Parque Provincial E. Tornquist, el uso pastoril de áreas que en otro momento fueron designadas como reserva intangible para la preservación de pastizales, resulta incompatible con tal fin.

El efecto que tiene el pastoreo sobre los ciclos de nutrientes, en la mayoría de las investigaciones se han centrado en el ciclo del nitrógeno. El pastoreo acelera el flujo de nitrógeno en los pastizales, incrementando su concentración en los tejidos aéreos que rebrotan, al aumentar la tasa de mineralización de este nutriente a partir de la orina y las heces (Woodmansee 1979, Floate 1981, Risser y Parton 1982, McNaughton 1985, Ruess y Seagle 1994) y por una menor alocación de carbono hacia tejidos subterráneos, lo cual influye en la relación C:N en el suelo, prevaleciendo la mineralización sobre la inmovilización de dicho nutriente (Holland y Detling 1990). Sin embargo las pérdidas de nitrógeno desde las excretas animales, principalmente como amoníaco, pueden tener severos efectos sobre los pastizales, dependiendo de la intensidad del pastoreo, como así también de la aridez de los ambientes (Woodmansse 1979, Floate 1981). El pastoreo intenso podría llevar a que se 
acumulen grandes cantidades de nutrientes en su forma inorgánica, y si no existe una adecuada captación de los mismos por parte de las plantas y de los microorganismos del suelo, el mismo puede ser lixiviado o perderse como amoníaco (Woodmansee 1979, Floate 1981, Hobbie 1992).

El efecto que el pastoreo puede ejercer sobre las raíces no ha sido evaluado aún en los pastizales serranos. Los estudios realizados al respecto, en otros sitios, coinciden en que la defoliación intensa disminuye el crecimiento y la biomasa subterránea, aunque en distinto grado de acuerdo a la interacción de la herbivoría con otros factores (Weaver 1958, Harradine y Whalley 1981, Stanton 1983, Coughenour 1985, Jaramillo y Detling 1988, Trlica y Orodho 1989, Holland y Detling 1990). En otros estudios en cambio se destaca que la biomasa de las raíces no decrece con el pastoreo, siendo la aridez un factor destacable en tal respuesta (van der Maarel y Titlyanova 1989, Milchunas y Lauenroth 1989, Oesterheld y McNaughton 1991).

Los resultados del presente estudio permiten señalar que el ingreso de materia orgánica y nutrientes al suelo es mediado en su mayor parte por las raíces. Por otra parte, a partir de los estudios de Dascanio y Bianchi (com. pers.) ha podido establecerse que no existe perdida de sedimentos, ni de nutrientes en la cuenca serrana en la que se encuentran los pastizales en estudio. Los mismos, a través de su sistema radical actuarían como una densa red, contribuyendo a la estructura y cohesión del suelo y captando los nutrientes que de otro modo podrían lixiviarse, perdiéndose del sistema. En las zonas con pendientes, la erosión que podría provocar el pastoreo al dejar parte del suelo sin su cobertura vegetal, afectaría negativamente tanto a los suelos en si mismos como a la calidad del agua para consumo humano, ya que estos pastizales de la reserva se encuentran en las nacientes del arroyo Sauce Grande, que provee de agua potable a la ciudad de Bahia Blanca.

Ricci (1992) señala que como consecuencia del manejo de los rodeos en la zona, los pastizales de la parte baja de las sierra reciben mayor carga animal en la primavera y en el verano, mientras que en el invierno el ganado es trasladado a los pastizales ubicados a mayor altitud. Estos traslados están en relación con la mayor disponibilidad de agua en el primer caso y de forraje, en el segundo. 
En este estudio se comprobó la existencia de productividad inverno-primaveral en los tres pastizales ubicados a diferente altitud sobre la sierra. Sin embargo, la alta proporción de la misma que es asignada a las raíces en todos los sitios, coincidiendo con un período relativamente seco, lleva a señalar que la carga animal debe ser adecuada a la disponibilidad de forraje, teniendo en cuenta la variaciones interanuales en la biomasa como respuesta a las precipitaciones.

A fines del verano-principios de otoño, la productividad aérea mostró una tendencia decreciente con el aumento en la altitud. Este período fue más húmedo, con respecto a la primavera, y la proporción de la productividad destinada a los tejidos fotosintéticos se incrementó desde la cumbre hacia el pie de monte. La presencia de ganado en esta época en los pastizales de la sierra baja sería acorde con las tendencias mostradas por la vegetación en cuanto a la disponibilidad de forraje.

En cuanto a la calidad del forraje, teniendo en cuenta la concentración de nutrientes en los tejidos aéreos, la misma es mayor en el pastizal inferior. Estacionalmente se vio que dichas concentraciones, en los tres sitios, fueron mayores en la primavera temprana y a principios del otoño, al menos durante el período de muestreo. De acuerdo con esto, el movimiento y permanencia del ganado en la parte alta o baja de la sierra coincide siempre con los períodos en que los tejidos aéreos tienen mayores concentracionẹs de nutrientes.

El fuego es uno de los factores ambientales de mayor importancia en pastizales naturales (Daubenmire 1974, Hulbet 1969, Frangi et al. 1980b, Bazzaz y Parrish 1982, McNaugton y Rolhf 1984).

El fuego actúa reduciendo la cobertura vegetal aérea, provocando una rápida mineralización de los nutrientes presentes en la materia seca. A su vez aumenta el asoleamiento y las temperaturas del suelo, al quedar descubierto, por lo cual puede aumentar también la mineralización de la materia orgánica en el mismo. A corto plazo, como respuesta a este factor, ocurre un aumento en la productividad (Hulbert 1969, McNaughton 1985, Knapp y Seastedt 1986, Hulbert 1988, Niering y Dreyer 1989) y diversidad de los pastizales (Frangi et al. 1980b, Collins 1987). El fuego generalmente no afecta las raíces y rizomas de 
los pastos perennes (Knapp y Seasted 1986, Collins 1987) y al disminuir la cobertura de las especies dominantes, del seco en pie y de la hojarasca, permite el ingreso de otras especies, principalmente dicotiledóneas (Frangi et al. 1980b), estimulando también la germinación de semillas al aumentar la insolación y temperaturas del suelo (Collins 1987, Tilman 1993). Hulbert (1988) estableció que las causas del aumento en la productividad post-fuego, en pastizales de pastos altos de Kansas (EEUU), se debe al aumento del nitrógeno disponible en el suelo, a través de la mineralización de la materia seca aérea y a la mayor insolación y temperaturas en la superficie, las cuales probablemente indirectamente aumenten la disponibilidad de este nutriente en el suelo.

Por otra parte el fuego puede intensificar el stress hídrico, al aumentar la evaporación directa desde las superficies de suelo desnudo (Hulbert 1969, Knapp y Seasted 1986) y volatilizar importantes cantidades de nitrógeno (Seastedt 1988), por lo cual los incendios periódicos pueden disminuir, a largo plazo, la productividad de las comunidades vegetales. Abrams et al. (1986), en un estudio llevado a cabo durante diez años en pastizales de pastos altos en EEUU, detectaron un aumento de la productividad en los pastizales ubicados en partes bajas del terreno, con respecto a los no quemados. Sin embargo en pastizales ubicados a mayor altitud no registraron el mismo efecto, atribuyendo esta diferencia con las depresiones, a que en las tierras altas, con suelos someros y por lo tanto con menos disponibilidad de agua, la evaporación de la misma aumentó, debido a la reducción en la cobertura vegetal, intensificando el déficit hídrico, con respecto a los sitios testigo. Seastedt (1988), en pastizales de pastos altos (Kansas, EEUU) estimó que la volatilización de nitrógeno debido al fuego es equivalente a dos años de depositación atmósferica de ese elemento, por lo cual la práctica de manejo de quema anual llevaría a dichos pastizales a un lento pero continuo agotamiento del nitrógeno en el suelo. En varios estudios se señala que el fuego puede tener distintos efectos sobre determinado grupo de especies, de acuerdo con la epoca del año en que ocurre (Orionte y Anderson 1978, Biondini et al. 1989).

La quema de los pastizales con la finalidad de aumentar su calidad como recurso forrajero es una práctica habitual en la zona de estudio. Sin embargo la misma podría tener distintos efectos sobre la productividad, de acuerdo a la ubicación topográfica de la comunidad, a la epoca del año en que se produce y a la frecuencia con que una comunidad es sometida a 
incendio. En los pasizales de mayor altitud no sólo es probable que el fuego no lleve a un aumento en la productividad, según los antecedentes mencionados anteriormente, sino que la quema reiterada podría conducir a un deterioro del suelo, al dejar el mismo sin su cobertura vegetal, haciéndolo suceptible de erosión.

En cuanto a la pérdida de fertilidad del suelo, Seastedt (1988) señala que la volatilización de nitrógeno depende de la cantidad de material combustible, siendo en su estudio equivalente a la mitad del nitrogeno que ingresa al suelo por medio de la caída $\left(1,9 \mathrm{~g} / \mathrm{m}^{2}\right.$.año en pastizales no quemados) y de la depositación atmosférica $\left(1,3 \mathrm{~g} / \mathrm{m}^{2}\right.$.año). Suponiendo una volatilización equivalente en el pastizal inferior, la misma significaría una perdida de 0,8 $\mathrm{g} / \mathrm{m}^{2}$.año, la cual representaría el $0,1 \%$ del nitrógeno en los primeros $10 \mathrm{~cm}$ del suelo. Es probable que esta cantidad pueda ser compensada por la fijación de nitrogeno atmosférico, de la cual no se tienen estimaciones para la zona, pero que puede ser elevada, de a cuerdo con estimaciones en pasturas perennes $\left(1,5 \mathrm{Kg} / \mathrm{m}^{2}\right.$.año, Frioni (1990)), por lo cual, si estos cálculos fueran reales, el uso del fuego no afectaría negativamente al nitrógeno almacenado en el suelo. El efecto conjunto del fuego y pastoreo podría modificar estas especulaciones, ya que ambos constituyen vias alternativas en el ciclado de los nutrientes (McNaughton 1985), pero a una tasa mucho mayor que la que seguirían a través de los detritos, por lo cual podrían intensificarse las pérdidas, de acuerdo con la frecuencia del fuego, la carga animal y la permanencia del ganado en un mismo sitio.

Los pastizales estudiados en el presente trabajo se quemaron a principios de 1987, y a dos años del incendio se observa una tendencia a acumular materia seca, principalmente en el seco en pie y en la hojarasca. Comparando los valores de la materia seca en el inicio y en la finalización del muestreo, el verde se incrementó ( $48 \%$ en el pastizal superior, $86 \%$ en el pastizal medio), pero en una proporción menor que la necromasa. Estos incremento pueden adjudicarse, en parte, a las mejores condiciones hídricas en la segunda mitad del período de muestreo. En el mismo, en el pastizal superior el seco en pie aumentó un $37 \%$ y la hojarasca un $130 \%$, en el pastizal medio aumentó el seco en pie $180 \%$ y en el pastizal inferior aumentaron el seco en pie $88 \%$ y la hojarasca $50 \%$. De los tres pastizales, los de menor altitud, (y mayor biomasa aérea) podrían ser los más afectados por el fuego. En ellos el incremeto del seco en pie es mayor que el observado en el pastizal superior, en el que la 
acumulación se concentra en la hojarasca. Seastedt (1988) expresa que a causa del fuego, la caida a la hojarasca se reduce del $36 \%$ del pico de biomasa aérea, en áreas no quemadas, al 9\% en áreas quemadas. En los pastizales estudiados, el pico en la caída a la hojarasca representa aproximadamente el $30 \%$ de la materia seca aérea máxima en los pastizales ubicados sobre la sierra; mientras que en el pie de monte dicha proporción se reduce del $27 \%$ en ausencia de fuego (estimado a partir de los datos de Frangi et al. 1980a) al 8\%, a dos años del incendio. En resumen, en los pastizales serranos la recuperación post-fuego se produce rapidamente. A dos años del incendio, la materia seca subterránea alcanzaría niveles similares a los señalados por Barrera y Frangi (1994) en ausencia de fuego (Gráfico VI.1.1). En la materia seca aérea las diferencias son mayores entre ambos estudios, evidenciándose un proceso de acrecentamiento de la necromasa (Gráfico VI.6.1). 
a)

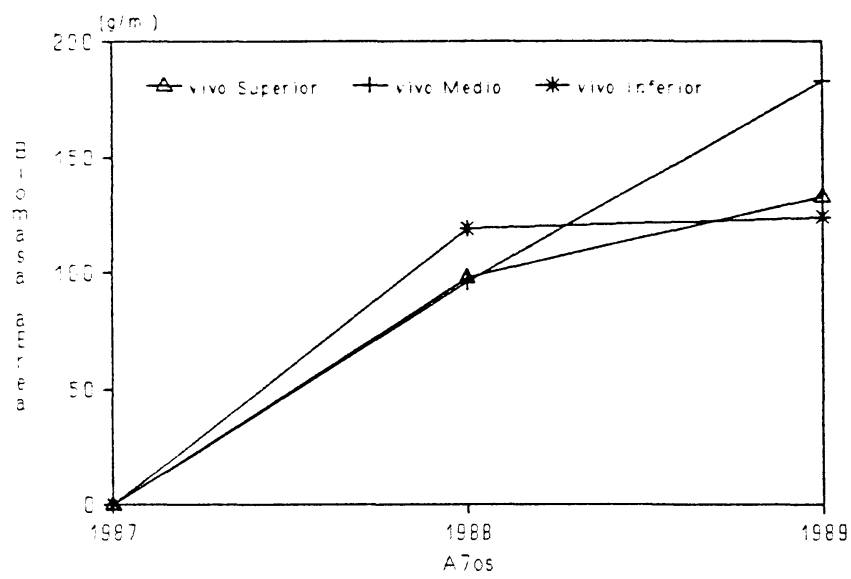

b)

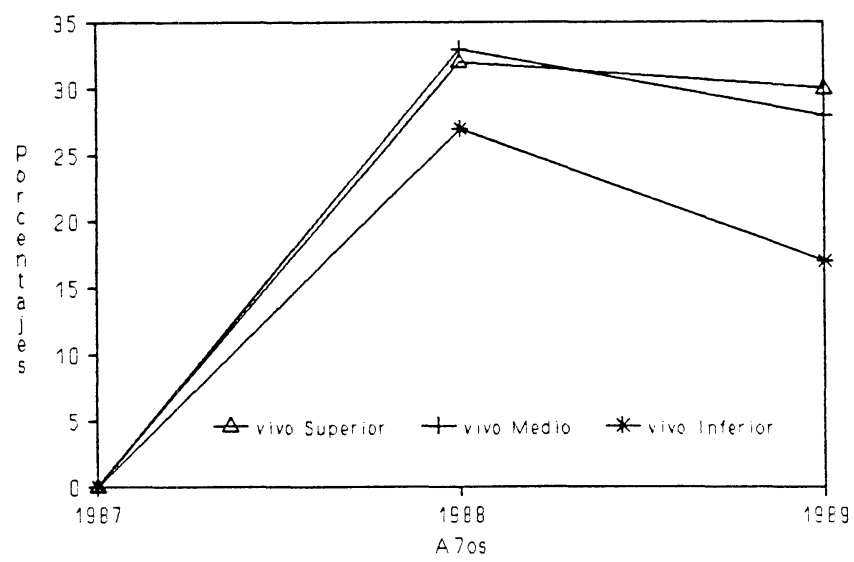

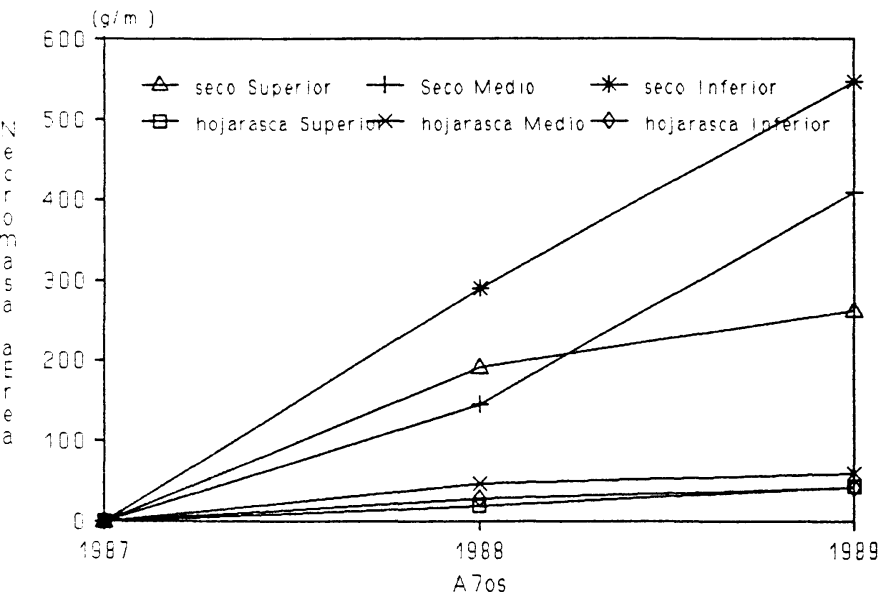

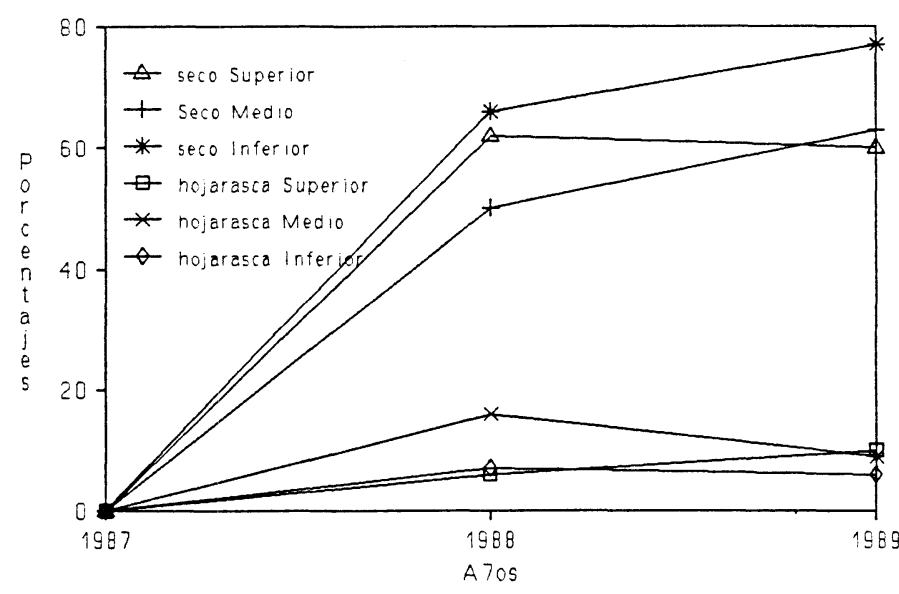

Graflco VI.6.1: a) Peso seco $\left(g / \mathrm{m}^{2}\right)$ de los compartimlentos aereos vivo, seco on ple y Bojarasca $y$ b) porcentaje de los mismos con respecto a la materia seca abrea en los dos anos sigulentes al incendio de 
CAPITULO VII: CONCLUSIONES 


\section{VII.-CONCLUSIONES}

En los pastizales serranos la materia seca total es mayor en el sitio cercano a la cumbre con respecto a ubicados a media ladera y en el pie de monte. Se verifica que con la altitud existe una diferente partición de la biomasa entre las estructuras aéreas y subterráneas. La proporción de raíces aumenta, en tanto que la materia seca aérea disminuye desde el pie de monte hacia la cumbre.

Como consecuencia de este gradiente de la biomasa, desde el punto de vista de su uso los pastizales de menor altitud poseen una mayor disponibilidad de forraje.

La dinámica de la biomasa y necromasa del pastizal presenta un marcado patrón estacional, poniendo en evidencia que los períodos favorables para el crecimiento de la vegetación, también lo son para los procesos de descomposición.

La via principal seguida por la materia seca aérea es la siguiente: Verde--seco en pie-hojarasca, mientras que en las raíces el pasaje de vivo a muerto y su incorporación al suelo es más directa.

Con la altitud, en los suelos más someros, aumenta la proporción de raíces finas, y con ello la superficie de absorción y el porcentaje de micorrización.

La productividad primaria neta total es similar en los pastizales de diferente altitud. Se verifica, en cambio, que la asignación de fotosintatos hacia los órganos subterráneos aumenta desde la base hacia la cima, a la vez que disminuye la proporción asignada a las estructuras aéreas.

La productividad total semejante tiene que derivar de una combinación distinta del aporte del índice de área foliar y del período de producción, en cada pastizal. En la parte superior de los cerros un mayor período hídricamente favorable se combina con una menor masa fotosintética; en tanto en los basales una mayor alternancia de periodos secos y húmedos del suelo se asocia a una mayor biomasa verde. 
La diferente partición de la biomasa y asignación de fotosintatos entre estructuras aéreas y subterráneas en los pastizales de diferente altitud constituye una respuesta adaptativa a las características ambientales asociadas con la altitud, tales como el descenso térmico, la mayor velocidad del viento en la cumbre y la menor profundidad de los suelos de los pastizales ubicados sobre el cerro.

Se verifica en los pastizales de solana la existencia de un patrón bimodal en la productividad tanto aérea como subterránea, que se relaciona con la existencia de especies de régimen micro y megatérmico.

La importancia de los períodos inverno-primaveral y estivo-otoñal en cuanto a su contribución a la productividad anual varía altitudinalmente. En los pastizales de mayor altitud, la mayor parte de la producción anual es inverno-primaveral, mientras que en el pie de monte, ambos períodos mencionados son igualmente productivos.

El patrón de distribución estacional de fotoasimilados entre tejidos aéreos y subterráneos varía altitudinalmente. En el pastizal superior, relativamente más frío y anualmente isotermo, la mayor parte de la productividad es asignada a la raíces, independientemente de la época del año. En los sitios de menor altitud, con una mayor amplitud térmica estacional, durante el período inverno-primaveral predomina la producción subterránea, y durante el otoño, la producción aérea.

El pico primaveral de la biomasa aérea es asincrónico, anticipándose en el sitio de menor altitud, más cálido, con respecto a los ubicados sobre el cerro.

El mayor esfuerzo reproductivo de estos pastizales ocurre a fines de la primavera. El manejo de los rodeos deberá adecuar la carga animal en los períodos de floración y fructificación de los pastizales naturales, a fin de permitir la resiembra de los mismos.

La cantidad y distribución de las precipitaciones a lo largo del año contribuyó a explicar la mayor parte de las variaciones intraanuales de la materia seca aérea en los pastizales estudiados. 
La eficiencia en el uso del agua varió estacionalmente en los pastizales situados a diferente altitud. Los pastizales de mayor altitud son más eficientes en el período inverno-primaveral, con respecto al estivo-otoñal. El pastizal situado en el pie de monte, en cambio, muestra similar eficiencia en ambos períodos.

En los pastizales serranos, la renovación de los tejidos aéreos y subterráneos opera a tasas diferentes, siendo menor el tiempo de renovación en los primeros que los últimos. A su vez, las tasas de renovación de la materia seca varían altitudinalmente. El pastizal superior, sometido a condiciones relativamente menos favorables muestra las menores tasas de renovación tanto aéreas como subterráneas.

La productividad del pastizal es sostenida en los aspectos nutricionales por mecanismos de absorción de nutrientes, de dilución de las concentraciones en la biomasa y por retranslocación. Las eficiencias en el uso de los nutrientes aumentan con la menor disponibiliad de los mismos en el suelo.

La partición de la materia seca en tejidos aéreos y subterráneos refleja en gran medida la distribución del stock de $\mathrm{N}$ y $\mathrm{P}$ en la vegetación, pero no ocurre lo mismo con el $\mathrm{K}$ y el Ca.

La variación altitudinal en la distribución de la materia seca tiene importantes implicancias en el presupuesto de nutrientes en los pastizales serranos. En concordancia con el aumento en la proporción de materia seca aérea hacia el pie de monte, la cantidad de nutrientes circulando en la vegetación aumenta en esa dirección.

Desde el punto de vista de su uso, el pastizal de menor altitud, además de ser más accesible para el ganado y presentar mayor disponibilidad de forraje, es de mejor valor nutricional, ya que presenta las mayores concentraciones de nutrientes en los tejidos aéreos.

Las concentraciones y contenidos de los nutrientes en los tres sitios analizados mostraron un patrón similar en su variación estacional. Los períodos primaveral y otoñal tempranos son los más favorables para los herbívoros desde el punto de vista de la concentración de nutrientes en la biomasa aérea. 
Las raíces constituyen la principal via de incorporción al suelo de la materia orgánica y de los nutrientes, tanto por ser el principal almacenaje de los mismos en la vegetación como por su rápida incorporación al suelo y descomposición.

Se evidencian diferentes vias de incorporación de nutrientes al suelo desde la vegetación, que operan a diferentes velocidades: el pluviolavado y la mineralización de detritos vegetales. El primero constituye un circuito rápido, mientras que el segundo pese a ser relativamente más lento tiene como ventaja el enriquecimiento microbiano.

La gran proporción de biomasa y productividad subterráneas es relevante para el suministro de materia orgánica y nutrientes al suelo, mantener su estructura y demás características propias del suelo que junto a la fitomasa aérea ayudan a reducir los riesgos erosivos que puedan causar el agua y el viento.

El manejo de los rodeos deberá considerar el valor protector de las cuencas altas que tiene la vegetación graminosa, capaz de restaurarse en pocos años luego de disturbios agudos como el fuego o los años secos, ya que el sobrepastoreo crónico provoca cambios más profundos que comprometen la recuperación de la estructura del pastizal y su función protectora.

En concordancia con el punto anterior, las cuencas altas serranas incluídas en Reservas Naturales con pastadores exóticos, tales como los caballos del Parque Provincial Ernesto Tornquist, carentes de control poblacional comprometen seriamente la función protectora de los pastizales naturales.

En esta zona, las razones de protección y conservación de los recursos naturales que son el objeto mismo de los Parques y Reservas, adquieren significado específico y concreto, ya que no sólo se conserva la biodiversidad nativa en sus distintas escalas, sino que se ayuda a preservar la calidad de los recursos hídricos que, procedentes de estas altas cuencas son embalsados en Paso de Piedras para su potabilización y consumo en Bahía Blanca. 
CAPITULO VIII: BIBLIOGRAFIA. 


\section{VIII.-BIBLIOGRAFIA}

Abrahmson, W.G. y H. Caswell. 1982. On the comparative allocation of biomass, energy and nutrients in plants. Ecology, 63 (4): 982-991.

Abrams M.D., Knapp, A.K. y L.C. Hulbert. 1986. A ten-year record of aboveground biomass in a Kansas tallgrass pririe: effects of fire, and topographic position. American Journal of Botany, 73 (10): 1509-1515.

Aerts, R. y N.M. Berendse. 1989. Above-ground nutrient turnover and net primary production of an evergreen and deciduous species in a heathland ecosystem. Journal of Ecology, 77: 343-356.

Aerts, R., Berendse, F., Klerk, N.M. y C. Bakker. 1989. Root production and root turnover in two dominant species of wet heathlands. Oecologia (Berlin), 81: 374-378.

Allen, B. y M. Allen. 1980. Natural re-estrblishment of vesicular-arbuscular mycorrhizae following stripmine reclamation in Wyoming. Journal of Applied Ecology 17:139-147.

Andrén, O. y K. Paustian. 1987. Barley Straw Decomposition in the Field: a Comparison of Models. Ecology, 68 (5):1190-1200.

Arens, P.L. y P.H. Etchevere. 1966. Norma de reconocimiento de suelos. Secretaría de Agricultura y Ganadería de la Nación. INTA-ISA. 169 pp.

Ares, J. 1976. Dynamics of the root system of blue grama. Journal of Range Managements, 29: 208-213.

Atlas de Condiciones de los Suelos. 1966. Estudio del desarrollo Agropecuario del Sud. Ministerio de Asuntos Agrarios-Consejo Federal de Inversiones-Ministerio de Relaciones Exteriores de Francia. 33 pp. 
Barea, J.M., Azcon-Aguilar, C .y B. Roldan-Fajardo. 1984. Avances recientes en el estudio de la micorrizas V-A. I.Funcionamiento y efectos en nutrición vegetal. Anales de Edafología y Agrobiología. XLII: 659-677.

Barrera, M.D. y J.L. Frangi. 1994. Estructura de la biomasa de pastizales en Sierra de la Ventana (Buenos Aires, Argentina). Revista del Museo de la Plata (NS), XIV(100): 243-262.

Bazzaz, F.A. 1990. The Response of Natural Ecosystems to the Rising Global $\mathrm{CO}_{2}$ Levels. Annual Review of Ecology and Systematic, 21:167-196.

Berg, B. y G. Ekbohm. 1983. Nitrogen Immobilization in Decomposing Needle Litter at Variable Carbon:Nitrogen Ratios. Ecology, 63 (1): 63-67.

Biondini, M., Lauenroth, W.K .y O.E. Sala. 1991. Correcting estimates of net primary production. Are we overestimating plant production in rangelands? Journal Range Management 44(3): 194-198.

Biondini, M.E., Steuter, A.A., y C. E. Grygiel. 1989. Seasonal fire effects on the diversity patterns, spatial distribution and community structure of forbs in the Northern Mixed Prairie, USA. Vegetatio, 85: 21-31.

Black, R.A., Richards, J. y J.H. Manwaring. 1994. Nutrient uptake from enriched soil microsites by three Great Basin perennials. Ecology, 75(1): 110-122.

Bobbink, R., den Dubbelden, K. y J.H. Willems. 1989. Seasonal dynamics of phytomass and nutrients in chalk grassland. Oikos, 55: 216-224.

BÖhm, W. 1979. Methods of studyng root systems. Ecological Studies 33. Springer-Verlag. Berlín. 188 pp. 
Boutton, T.W., Harrison, A.T. y B.N. Smith. 1980. Distribution of Biomass of species differing in photosynthetic pathway along an altitudinal transec in Southeastern Wyoming grassland. Oecologia (Berl.), 45: 287-298.

Bray y Kurtz. 1945. Determination of total organic and available forms of phosphorus in soil. Soil Science, 59: 39-45.

Burgos, J. 1968. El clima de la Provincia de Buenos Aires en relación con la vegetación natural y el suelo. En: Cabrera, A.L. (ed.), Flora de la Provincia de Buenos Aires. Colección Científica del INTA 4 (1): 34-97.

Burgos, J. y A. Vidal. 1951. Los climas de la República Argentina, según la nueva clasificación de Thornthwaite. Meteoros I (1): 3-33.

Burkart, A. 1975. Evolution of Grasses and Grasslands in South America. Taxon, 24 (1): 53-66.

Cabello, M.N. 1988. Mycorrizas vesiculo-arbusculares en un cultivo de Girasol. Revista de la Facultad de Agronomía-La Plata 63:46-52.

Cabrera, A.L. 1968. La vegetación de la Provincia de Buenos Aires. En: Cabrera, A.L. (ed.), Flora de la Provincia de Buenos Aires. Colección Científica del INTA, 4 (1): 101-126.

Caldwell, M.M. 1973. Primary Production of Grazing Lands. Cooper, J.(Ed.). Photosynthesis and productivity in different environments. IBP 3. Cambridge University Press. Cambridge.

Caldwell M.M., Manwaring, J.H. y R.B. Jackson. 1991. Explotation of phosphate from fertile soil microsites by three Great Basin perennials when in competition. Functional Ecology, 5: 757-764. 
Cappannini, D., Scoppa, C.O. y J.R Vargas Gil. 1971. Suelos de las Sierras Australes de la Provincia de Buenos Aires. En: C.I.C. (ed.), Reunión sobre la Geología de las Sierras Australes: 203-234. Comisión de Investigaciones Científicas, La Plata.

Clarkson, D.T. 1985. Factors Affecting Mineral Nutrient Adcquisition by Plants. Annual Review of Plant Physiology 36: 77-115.

Cole, D.W. y M. Rapp. 1981. Elemental cycling in forest ecosystems. En: Reichle, C.E. (Ed.). Dynamic Properties of Forest Ecosystems: 341-401. Cambridge University Press. Cambridge.

Coleman, D.C. 1976. A review of root production processes and their influence on soil biota in terrestrial ecosystems. En: Anderson, J.M. y A. Mac Fadyen (Eds.). The role of terrestrial and aquatic organisms in descomposition processes: 417-434. Blackwell Scientific Publications, Oxford.

Coleman, D.C, Reid, C.P.P. y C.V. Cole. 1983. Biological Strategies of Nutrient Cycling in Soil Systems. En McFadyen, A. y E.D. Ford (Eds.) Advances in Ecological Research, Vol. 13 Academic Press. NY. 382 pp.

Collins, S.L. 1987. Interaction of disturbances in tallgrass prairie: a field experiment. Ecology 68 (5): 1243-1250.

Coughenour, M.B. 1985. Graminoid responses to grazing by large herbivores: adaptations, exaptations, and interacting processes. Annual Missouri Botanic Garden,72: 852-863.

Chapin III, F.S. 1980. The mineral nutrition of wild plants. Annual Review of Ecology and Systematic, 11: 233-260.

Chapin III, F.S. 1991. Integrated Responses of Plants to Stress. BioScience, 41: 29-36. 
Chapin III, F.S, Follett, J.M. y K.F. O'Connor. 1982. Growth, Phosphate absortion, and phosphorus chemical fractions in two Chionochloa species. Journal of Ecology, 70: 305-321.

Chapin III, F.S., Vitousek, P.M. y K. Van Cleve. 1986. The Nature of Nutrient Limitation in Plant Communities. The American Naturalist, 127(1): 48-58.

Chapman, S.B. 1970. The nutrient content of the soil and root systems of dry heath ecosystem. The Journal of Ecology, 58(2): 445-452.

Christie, E.K. 1979. Ecosystem processes in semiarid grassland. I. Primary Production and Water Use of two Communities Possessing Different Photosynthetic Pathways. Australian Journal of Agricultural Research, 29 (4): 773-787.

Christie, E.K. 1979. Ecosystem processes in semiarid grassland. II. Litter production, decomposition and nutrient dynamics. Australian Journal of Agricultural Research, 30: 29-42.

Dahlman, R.C. y C.L. Kucera. 1965. Root productivity and turnover in native prairie. Ecology, 46 (1\&2): 84-89.

Dascanio, L. y G. Bianchi. Balance hidrológico y presupuesto de nutrientes en una cuenca serrana no disturbada. Informe CIC 1990.

Daubenmire. 1974. Plants and enviroment. Wiley International Edition.

Deregibus, V.A. y M.A. Cahuépé. 1983. Pastizales naturales de la Depresión del Salado: utilización basada en conceptos ecológicos. Revista de Investigaciones Agropecuarias, INTA, Bs.As., Argentina. vol 18(1): 47-78.

Detling, J.K. 1979. Processes controling Blue Grama production on the shortgrass prairie. En: French NR (Ed.). Perspectives in Grassland Ecology: 25-40. Springer-Verlag. N.Y. 
de Wysiecki, M.L. 1993. Productividad primaria neta aérea de un pastizal natural de la provincia de La Pampa, Argentina. Revista de la Facultad de Agronomía, La Plata, 69 (1): 23-29.

de Wysiecki, M.L. y C. Pérez. 1994. Producción de raíces de dos pastizales pastoreados de la Sierra de la Ventana, Provincia de Buenos Aires, Argentina. Ecología Austral, 4: 95-99.

Distel, R.A. y O.A. Fernández. 1986. Productivity of Stipa tenuis y Piptochaetium napostaense (Speg.) Hack in semiarid Argentina. Journal of Arid Environments, 11: 93-96.

Duchaufour. 1965. Precis de pedologie. Masson et Cie. Paris. 481 pp.

Eissentat, D.M. y M.M. Caldewell. 1988. Seasonal timing of root growth in favorable microsites. Ecology, 69: 870-873.

Eissentat, D.M. y M.M. Caldewell. 1989. Invasive root growth in to disturbed soil of two tussock grasses that differ in competitive effectiveness. Functional Ecology 3: 345-353.

Evans, J.R. 1989. Photosynthesis and nitrogen relationships in leaves of $\mathrm{C}_{3}$ plants. Oecologia 78: $9-19$

Fassbender. 1982. Química de suelos. IICA, Costa Rica. 398 pp.

Fernández, O.A. y M.N. Caldwell. 1975. Phenology and dynamics of root growth of three cool semi-desert shrubs under field conditions. Journal of Ecology 63: 703-714.

Fernández, O.A., Montani, T. y R.A. Distel. 1988. El sistema radical de especies de zonas áridas y semiáridas. Algunas estrategias de supervivencia. Interciencia, 13: 25-30.

Floate, M.J.S. 1981. Effects of Grazing by large herbivores on nitrogen cycling in agricultural ecosystems. En: Clark FE y T Rosswall (Eds.). Terrestrial Nitrogen Cycles. Ecoll. Bull. (Stoclhom), 33: 585-601. 
Forsythe, W. 1980. Física de suelos. IICA, Costa Rica. 211 pp.

Frangi, J.L. y O. Bottino. 1995. Las comunidades vegetales de la Sierra de la Ventana, Provincia de Buenos Aires, Argentina. Revista de la Facultad de Agronomía (UNLP), 71 (1): 93-133

Frangi, J.L., Sanchez, N., Rovetta, G. y R. Vicari. 1980 a. Dinámica de la biomasa y productividad primaria aérea neta de un pastizal de "flechillas" de Sierra de la Ventana (Buenos Aires, Argentina). Boletin de la Sociedad Argentina de Botánica, Vol. XIX (1-2): 203-228.

Frangi, J.L., Ronco, M. y N. Sánchez. 1980 b. Efecto del fuego sobre la composición y dinámica de la biomasa de un pastizal de Sierra de la Ventana.(Buenos Aires, Argentina). Darwiniana, vol XXII (4).

Frangi, J.L. 1987. Estudios de la estructura y función de ecosistemas de la Sierra de la Ventana. Proyecto de la Comisión de Investigaciones Científicas de la Provincia de Buenos Aires.

French, N.R. 1979. Principal subsystem interactions in grassland. En: French N.R. (Eds.). Perspectives in Grassland Ecology: 173-189. Springer-Verlag. N.Y.

Gadgil, M.D. y O.T. Solbrig. 1972. The concept of $r$ and $K$ selection: evidence from wild flowers and some theoretical considerations. American Naturalist, 106: 14-31.

Gallardo, A. y J. Merino. 1993. Leaf Decomposition in two Mediterranean Ecosystems of Southwest Spain: Influence of Substrate Quality. Ecology, 74 (1): 152-161.

Georgiadis, N.J., Ruess, R.W., McNaughton, S.J. y D. Western. 1989. Ecological conditions that determine when grazing stimulates grass production. Oecologia, 81: 316-322. 
Gómez, I.A. y G.C. Gallopin. 1991. Estimación de la productividad primaria neta de ecosistemas del mundo en relación a factores ambientales. Ecologia Austral 1 (1): 24-40.

Grabherr, G. 1989. On Community structure in high alpine grasslands. Vegetatio 83: 223227.

Gray, J.T. 1983. Nutrient use by evergreen and deciduous shrubs in southern California. I. Community nutrient cycling and nutrient use efficieny. Journal of Ecology, 71: 21-41.

Griffiths, R.P., Caldwell, B.A., Cromack, K.Jr. y R.Y. Morita. 1990. Douglas fir forest soils colonized by ectomycorrhizal mats. I. Seasonal variation in nitrogen chemistry and nitrogen cycle transformation rates. Canadian Journal Forest Reserch 20: 211-218.

Grime, J.P. 1979. Plants strategies \& vegetation processes. Wiley International Edition. NY. $222 \mathrm{pp}$.

Grubb, P.J. 1989. Minerals nutrients: a plant ecologist'view. En: Proctor, J. (Ed.). Mineral nutrients in tropical forest an savanna ecosystems: 416-439. Blackwell Scientific Publications. Oxford.

Harrington, H. 1947. Hojas geológicas 33 m y $34 \mathrm{~m}$, Sierras de Curamalal y de la Ventana, Pcia de Bs. As. Serv. Nac. Minero geológico. Bol. Nro. 61. Bs. As.

Harper, J.L. 1977. Population Biology of Plants. Academic Press, London.

Harper, J.L. y J. Ogden. 1970. The reproductive strategy of higher plants. The Journal of Ecology. Vol 58, (3): 681-698.

Hendrick, R.L. y K.S. Pregitzer. 1992. The demography of Fine Roots in a Northern Hardwood Forest. Ecology, 73 (3): 1094-1104. 
Hickman, J.C. 1975. Environmental unpredictability and plastic energy allocation strategies in the annual Poligonum cascadense (Polygonaceae). Journal of Ecology 63: 689-701.

Hickman, J.C. y L.F. Pitelka. 1975. Dry weight indicated energy allocation in ecological strategy analysis of plants. Oecologia (Berlin) 21: 117-121.

Hobbie, S.E. 1992. Effects of Plant Species on Nutrient Cycling. Trends in Ecology and Evolution, 7(10): 336-339.

Holland, E.A. y J.K. Detling. 1990. Plant response to hebivory and belowground nitrogen cycling. Ecology, 71(3): 1040-1049

Hulbert, L.C. 1969. Fire and litter effects in undisturbed bluestem prairie in Kansas. Ecology, 50(5): 874-877.

Hubert, L.C. 1988. Causes of fire effects in tallgrass paririe. Ecology, 69(1): 46-58.

Hunt, H.W. 1977. A Simulation Model for Decomposition in Grasslands. Ecology, 58: 469484.

Hunt, W.H., Stewart, J.W.B. y C.V. Cole. 1983. A conceptual Model for Interactions Among Carbon, Nitrogen, Sulphur, and Phosphorus in Grasslands. En: Bolin, B. y R.B. Cook (Eds.). The Major Biogeochemical Cycles and Their Interactions. SCOPE. Canada

Instituto Geográfico Militar. Carta Topográfica Sierra de la Ventana. Hoja 3963 6-1-3963 5 2. Equidistancia $100 \mathrm{~m}$. Escala 1: 10.000.

INTA. 1989. Mapa de Suelos de la Provincia de Buenos Aires. Escala 1:500.000. Secretaría de Agricultura, Ganadería y Pesca-Instituto Nacional de Tecnología Agropecuaria. 
Izaguirre-Mayoral, M.L. y M.S. Mallorca. 1993. Quantitative analysis of the symbiotic $\mathrm{N}_{2}-$ fixation in Native legume species collected in different savanna sites. En: Palacios, R., Mora, J. y W. Newton (Eds.). News Horizons in Nitrogen Fixation. Kluwer Academic Publishers. The Netherlands.

Jackson, R.B. y M.M. Caldwell. 1989. The timing and degree of root proliferation in fertile-soil microsites for three cold-desert perennials. Oecologia 81: 149-153.

Jastrow, J.D. y R.M. Miller. 1993. Neighbor influences on root morphology and mycorrhizal fungus colonization in tallgrass prairie plants. Ecology 74(2): 561-569.

Johnson, D. 1992. Effects of forest management on soil Carbon storage. En: Wisniewski, J. y Lugo, A. (Eds). 1992. Natural Sinks of $\mathrm{CO}_{2}$. Kluwer Academic Publishers. Dordrecht, Boston, London.466 pp.

Jones, M.B. y R.G. Woodmansee. 1979. Biogeochemical cycling in annual grassland ecosystems. Botanical Review, 45: 111-114.

Kachi, N. y I.H. Rorison. 1990. Effects of nutrient depletion on growth of Holcus lanatus L. y Festuca ovina L. and on the ability of their root to absorb nitrogen at warm and cool temperatures. New Phytology, 115: 531-537.

Kawano, S. y J. Masuda. 1980. The productive and reproductive biology of flowering plants. Oecologia (Berlin) 45: 307-317.

King, D. y J. Roughgarden. 1983. Energy allocation patterns of the California grassland annuals Plantago erecta and Clarkia rubicunda. Ecology, 64(1): 16-24.

Klein, D.A. 1977. Seasonal carbon flow and descomposer parametrer relationshisps in a semiarid grassland soil. Ecology, 58: 184-190. 
Knapp, A.K., Fahnestock, J.T., Hamburg, S.P., Statland, L.B., Seastedt, T.R. y D.S. Schimel. 1992. Landscape Patterns in Soil-Plant Water Relations and Primary Production in Tallgrass Prairie. Ecology 74(2): 549-460.

Knapp, A.K. y T.R. Seastedt. 1986. Detritus Acumulation Limits Productivity of Tallgrass Paririe. BioScience, 36(10): 662-668.

KÖrner, Ch. y V. Renhardt. 1987. Dry matter partitioning and root length/leaf area ratios in herbaceus perennial plants with diverse altitudinal distribution. Oecologia (Berlin), $\quad 74$ : 411-418.

Körner, Ch. y F.I. Woodwar. 1987. The dynamics of leaf extension in plants with diverse altitudinal ranges. II. Field studies in Poa species between 600 a $3200 \mathrm{~m}$ altitude. Oecologia (Berlin) 72: 279-383.

Kristensen, M.J. 1992. Características micro y mesoclimáticas de la Sierra de la Ventana y su relación con la vegetación. Tesis doctoral. Fac. Cs. Nat. y Museo, UNLP, 388 pp.

Kristensen, M.J. y J.L. Frangi. 1995. Mesoclimas de pastizales de la Sierra de la Ventana. Ecología Austral 5: 55-64.

Kucera, C.L., Dahlman, R.C. y M.R. Koelling. 1967. Total net productivity and turnover on an energy basis for tallgrass paririe. Ecology, Vol 48 (4): 536-541.

Lauenroth, W.K. 1979. Grassland primary production: North American grassland in perspective. En: French, N.R. (Ed.). Perspectives in grassland ecology: 3-21. SpringerVerlag. NY.

Larcher. 1980. Physiological Plant Ecology: 206-267. Springer Verlag. NY. 
Liang, Y.M., Hazlett, D.L. y W.K. Lauenroth. 1989. Biomass dynamics and water use efficiencies of five plant communities in the shortgrass steppe. Oecologia (Berlin) 80: 148-153.

Lieth, H. 1975. Primary productivity of the mayor vegetation units of the world. En: Lieth y Whittaker (Eds.). Primary productivity of the biosphere. Springer-Verlag. N. Y.

Long, S.P., García Moya, E., Imbamba, S.K., Kamnalrut, A., Piedade, M.T.F., Scurlock, J.M.O., Shen, Y.K. y D.O. Hall. 1989. Primary productivity of natural grass ecosystems of the tropics: A reappraisal. Plant and Soil 115: 155-166.

Lugo, A.E., Medina, E. y M.J. Sánchez. 1990. Nutrient and Mass in Litter and Top Soil of Ten Tropical Tree Plantations. Plant and Soil, 125: 263-280.

Mack, R.N. y J.N. Thompsons. 1982. Evolution in steppe with few large, hooved mammals. The American Naturalist, 119(6): 757-773.

Marschner, H. 1983. General Introducction to the Mineral Nutrition of Plants. En: Läuchli, A. y R.L. Bieleski. Encyclopedia of Plant Physiology. New Serie, Vol 15: 5-54. SpringerVerlag, Berlin, Heidelberg, New York.

Maschinski, J. y T.G. Whitham. 1989. The continuum of plant responses to herbivory: the influence of plant association, nutrient availability, and timing. The American Naturalist, 134(1): 1-19.

McClaugherty, C.A., Aber, J.D. y J.R. Melillo. 1982. The role of fine roots in the organic matter and nitrogen budgets of two forested ecosystems. Ecology 64 (5): 1481-1490.

McGil, W.B. y E.K. Christie. 1983. Biogeochemical Aspects of Nutrient Cycle Interactions in Soil and Organisms. En: Bolin B y RB Cook (Eds.). The Major Biogeochemical Cycles and Their Interactions. SCOPE. Canada. 
McNaughton, S.J. 1979. Grazing as an optimization process: grass-ungulate relationship in the Serengeti. The American Naruralist, 113(5): 691-703.

McNaughton, S.J. 1983. Serengeti grassland ecology: the role of composite environmental factors and contingency in community organization. Ecological Monographs, 53: 291-300.

McNaughton, S.J. 1985. Ecology of a grazing ecosystem: The Serengeti. Ecological Monographs, 55 (3): 259-294.

McNaughton, S.J. y M. Oesterheld. 1990. Extramatrical mycorrhizal abundance and grass nutrition in a tropical grazing ecosystem, the Serengeti National Park, Tanzania. Oikos 59: 92-96.

Medina, E., Mendoza, A. y R. Montes. 1977. Balance nutricional y producción de materia orgánica en las sabanas de Trachypogon de Calabozo, Venezuela. Boletín de la Sociedad Venezolana de Ciencias Naturales, 134: 101-120.

Menghi, M.M., de Solis, A.B., Galera, F.M., Herrera, M. y R. Lutti. 1978. Productividad primaria de los pastizales de altura de las Sierras Chicas de Córdoba. Ecología, 3: 96-101.

Milchunas, D.G., Sala, O.E. y W.K. Lauenroth. 1988. A generalized model of the effects of grazing by large herbivores on grassland community structure. The American Naturalist, 132(1): 88-105.

Milchunas, D.G. y W.K. Lauenroth. 1989. Three dimensional distribution of plant biomass in relation to grazing and topography in the shortgrass steppe. Oikos, 55: 82-86.

Milchunas, D.G., Lauenroth, W.K., Chapman, P.L. y M.K. Kazempour. 1989. Effects of grazing, topography, and precipitation on the structure of semiarid grassland. Vegetatio 80: 11-23. 
Milner, C. y R. Hughes. 1970. Methods for the measurement of the primary production of grassland. IBP Handbook Nro. 6

Montani, T., Delmastro, S.E. y O.A. Fernández. 1989. Biomasa radical y la dinámica de su crecimiento en Eragrostis curvula (Schrad.) Ness. Stvdia (Ecologica), 6: 79-96.

Nadelhoffer, K.L., Aber, J.D. y J.L. Melillo. 1985. Fine roots, net primary production, and soil nitrogen availability. A new hypotesisis. Ecology 66 (4): 1377-1390.

Newman, E.I., Child, R.D. y C.M. Patrick. 1986. Mycorrhizal infection in grasses of Kenyan savanna. Journal of Ecology 74: 1179-1183.

Niering, W.A. y G.D. Dreyer. 1989. Effects of prescribed burning on Andropogon scoparius in postagricultural grasslands in Connecticut. American Midland Naturalist, 122: 88-102.

Noy-Meir, I. 1973. Desert Ecosystems: Environment and Producers. Annual Review of Ecology and Sistematic, 4:25-51.

Odum, H.T. 1971. Energy, Power \& Society. J. Wiley, New York.

Oesterheld, M. y S.J. McNaughton. 1991. Effect of stress and time for recovery on the amount of compensatory growth after grazing. Oecologia (Berlin), 85:305-313.

Orionte, E. y D.L. Anderson. 1978. Influencia del fuego en un área reliquia del Sorghastral. Ecologia, 3: 11-17

Osmond, C.B., Winter, K. y H. Ziegler. 1982. Functional significance of different pathways of $\mathrm{CO}_{2}$ fixation in photosynthesis. En: Lange, O., Nobel, L., Osmond, C.B. y H. Ziegler. (Eds.). Encyclopedia of plant physiology. New Serie, vol 12B: 480-547. Springer-Verlag, Berlin, Heidelberg, New York. 
Parrish, J.A.D. y F.A. Bazzaz. 1982. Responses of plans from three successional communities to a nutrient gradient. Journal of Ecology, 70:233-248.

Pearcy, R.W. y J. Ehleringer. 1984. Comparative ecophysiology of $\mathrm{C}_{3}$ and $\mathrm{C}_{4}$ plants. Plant, Cell and Environment, 7:1-13.

Persson, H. 1979. Fine-root production, mortality and decomposition in forest ecosystems. Vegetatio, 41 (2): 101-109.

Persson, H. 1990. Methods of studying root dynamics in relation to nutrient cycling. En: Harrison, A.F., Ineson, P. y O.W. Heal (Eds.). Nutrient cycling in terrestrial ecosystems. Field methods, applications and interpretation: 198-219. Elsevier Applied Science.

Piper, J.K. 1989. Dristibution of dry mass between shoot and root in nine understory species. American Midland Naturalist, 122 (1): 114-119.

Post, W.M., Emanuel, W.R., Zinker, P.J. y A.G. Stangenberger. 1982. Soil carbon pools and world life zones. Nature, 298:156-159.

Rabassa, J. 1982. Variación regional y significado geomorfológico de la densidad de drenaje en la cuenca del Río Sauce Grande, Pcia de Bs Aires. Asociación Geológica Argentina, Revista 37(3): 268-284.

Rastetter, E., McKane, R., Shaver, G. y J. Melillo. 1992. Changes in C storage by terrestrial ecosystems: How $\mathrm{C}-\mathrm{N}$ interactions restrict responses to $\mathrm{CO}_{2}$ y temperature. En: Wisniewski, J. y Lugo, A. (Eds). 1992. Natural Sinks of $\mathrm{CO}_{2}$. Kluwer Academic Publishers. Dordrecht, Boston, London.466 pp.

Reekie, E.G. y F.A. Bazzaz. 1987. Reproductive effort in plants. 2. Does Carbon reflect allocation of other resources? The American Naturalist 129(6): 897-906. 
Reinhardt, D.R. y R.M. Miller. 1990. Size classes of root diameter and mycorrhizal fungal colonization in two temperate grassland communities. New Phytology, 116: 129-136.

Ricci, S. 1992. Relaciones entre la vegetación y la actividad agropecuaria en el área de Sierra de la Ventana. Tesis Doctoral, Fac. Cs. Naturales y Museo, UNLP, 171 pp.

Risser, P. 1985. Grasslands. En: Chabot, B. y B. Mooney B (Eds). Physiological Ecology of North American Plant Communities. Chapman and Hall. New York, London. 351 pp

Risser, P.G. y W.J. Parton. 1982. Ecosystem analysis of the tallgrass prairie: nitrogen cycle. Ecology 63 (5): 1342-1351.

Robertson, G. 1988. Effect of rainfall on biomass, growth and dieback of pastures in an arid grazing system. Australian Journal of Ecology, 13:519-528.

Rosenzweig, M.L. 1986. Net primary productivity of terrestrial communities: prediction from climatological data. The American Naturalist, 102 (923): 67-74.

Ruess, R. y S. Seagle. 1994. Landscape patterns in soil microbial processes in the Serengeti National Park, Tanzania. Ecology 75:892-904

Rustad, L. 1994. Element dynamica along decay continuum in a red spruce ecosystem in Maine, Usa. Ecology, 75:867-879.

Sala, O.E., Deregibus, V.A., Schlichter, T. y H. Alippe. 1981. Productivity Dynamics of a native temperate grassland in Argentina. Journal of Range Management, 34 (1):48-51.

Sala, O.E. 1988. The effect of herbivory on vegetation structure. En: Wergen, Van der Aare, Ovring y Verhoven (Eds.). Plant form and vegetation structure. SPB. Acad. Publ. The Hague. The Netherlands. 
Sala, O.E., Biondini, M.E. y W.K. Lauenroth. 1988. Bias in stimates of primary production: an analytical solution. Ecological Modelling, 44: 43-55.

Sala, O.E., Lauenroth, W.K. y W.J. Parton. 1982. Plant recovery following prolonged drought in a shortgrass steppe. Agricultural Meteorology, 27: 49-58.

Sala, O.E., Parton, W.J., Joyce, L.A. y W.K. Lauenroth. 1988. Primary production of the central grassland region of the United States. Ecology 69 (1): 40-45.

San Jose, J.J., Berrade, F. y J. Ramirez. 1982. Seasonal changes of growth, mortality and disapperance of belowground root biomass in the Trchypogon savanna grass. Acta Ecologica/Oecolia Plantarum, 3 (17): 201-206.

Sarmiento, G. 1984. Los ecosistemas y la ecósfera. Ed. Blume.

Scott, J.A. 1979. An ecosystem-level trophic-group Arthopod an Nematode bioenergetics model. En: French NR (Ed). Perspectives in grassland ecology: 107-115. Springer-Verlang.NY.

Shaver, G.R. y W.D. Billings. 1975. Root production and root turnover in a wet ecosystem, Barrow, Alaska. Ecology, 56:401-409.

Schimel, D., Stillwell, M.A. y R.G. Woodmansee. 1985. Biogeochemistry of C, N and P in a soil catena of the shortgrass steppe. Ecology, 66 (1): 276-282.

Schulze, E-D. 1982. Plant life forms and their carbon, water and nutrients relations. En: Pirson, A. y M.H. Zimmermann (Eds). Enciclopedia of plant physiology. New Series. Springer-Verlag. Vol 128: 615-677.

Schulze, E-D. y F.S. Chapin III. 1987. Plant specialization to enviroments of different resource availability. En: Shulzee y Zwöher (Eds.). Ecological Studies. Springer-Verlag. Vol 61: $120-148$. 
Schulze, E-D., Robichaux, R.H., Rundel, P.W., y J.R. Ehleringer. 1987. Plant water balance. BioScience, 37 (1): 30-37.

Singh, J.S. y D.C Coleman. 1974. Distribution of photoassimilated ${ }^{14}$ Carbon in the root system of a short grass prairie. Journal of Ecology, 62: 359-365.

Singh, J.S., Lauenroth, W.K. y R.K. Steinors. 1975. Review and assessment of various techniques for estimating net aerial primary production in grassland from harverst date. Bot. Rev. 41: 181-232.

Singh, J.S., Lauenroth, W.K., Hunt, H.W. y D.M. Swift. 1984. Bias and random errors in estimators of net root production: a simulation approach. Ecology 65 (6): 1760-1764.

Sims, P.L., Singh, J.S. y W.K. Lauenroth. 1978. The structure and function of ten western North American grasslands (I). Journal of Ecology, 66: 251-285.

Sims, P.L. y S. Singh. 1978 a. The structure and function of ten western North American grasslands (II). Journal of Ecology, 66: 547-572.

Sims, P.L. y S. Singh. 1978 b. The structure and function of ten western North American grasslands (III). Journal of Ecology, 66: 573-597.

Sisson, W.B.1989. Carbon balance of Panicum coloratum during drought and non-drought in the Northern Chihuahuan desert. Journal of Ecology, 77: 799-810.

SMN (Servicio Meteorológico NacionaL). 1916-1986. Estadísticas Meteorológicas. Fuerza Aéra Argentina.

SMN (Servicio Meteorológico NacionaL). 1981. Estadísticas Meteorológicas. Bol No 35. Fuerza Aéra Argentina. 
SMN (Servicio Meteorológico NacionaL). 1986. Estadísticas Meteorológicas. Bol No 36. Fuerza Aéra Argentina.

Snedecor, G.W. y W.G. Cochran. 1979. Métodos estadísticos. CECSA. 703 pp.

Sokal, R.R. y F.J. Rohlf. 1969. Biometry. The principles and practice of statistics in biological research. Freeman and company. 832 pp.

Soil Survey Staff. Keys to Soil Taxonomy. 1990. SMSS. Technical Monograph n ${ }^{0} 19$. Virginia Polytechnic Institute and State University.

Soriano, A., Alippe, H., Deregibus, V.A., Lemcoff, J.H., León R.J.C., Sala, O.E., Schlichter, T. y R. Trabucco. 1977. Ecología de los Pastizales de la Depresión del Salados. Academia Nacional de Agronomía y Veterinaria, Buenos Aires, 31:1-18.

Soriano, A., León, R.J.C., Sala, O.E., Lavado, R.S., Deregibus V.A., Cauhépé, M.A., Scaglia, O.A., Velázquez, C.A. y J.H. Lemcoff. 1990. Rio de la Plata Grasslands. En: Coupland, R.T. (ed). Natural grasslans. Ecosistems of the World 8 A. Eslevier. Amsterdam, London, New York, Tokyo. 409 pp.

Stanton, N.L. 1988. The underground in grasslands. Annual Review of Ecology and Systematic, 19: 573-589.

Stewart, J.W., Cole, C.V., y D.G. Maynard. 1983. Interactions of Biogeochemical Cycles in Grassland Ecosystems. En: Bolin, B. y R.B. Cook (Eds.). The Major Biogeochemical Cycles and Their Interactions. SCOPE. Canada.

Stock, W.D., Sommerville, J.E.M. y O.A.M Lewis. 1987. Seasonal allocation of dry mass and nitrogen in a fynbos endemic Restionaceae species Thamnochortus punctatus Pill. Oecologia (Berlin), 72:315-320. 
Suero, T. 1972. Compilación geológica de las Sierras Australes de la Provincia de Buenos Aires. LEMIT, serie II, Nro. 216.

Swift, M.J., Heal, O.W. y J.M. Anderson. 1979. Decomposition in Terrestrial Ecosystems. Studies in Ecology, Vol. 5. Blacwell Scientific Publications. Oxford London. 372 PP.

Teeri, J.A. y L.G. Stowe. 1976. Climatic patterns and the distribution of $\mathrm{C}_{4}$ grasses in North America. Oecologia, 23: 1-12.

Thomas, R.J. y N.M. Asakawa. 1993. Nitrogen fixation by three tropical forage legumes in an acid-soil savanna of Latin America. En: Palacios, R., Mora, J. y W. Newton (Eds.). News Horizons in Nitrogen Fixation. Kluwer Academic Publishers. The Netherlands.

Thorntnwaite, C.W. y J.R. Mather. 1957. Instrucciones y tablas para el cómputo de la evapotranspiración potencial y balance hídrico. Instituto Tecnológico de Drexel. Publicaciones de climatología, 10 (3) 68 pp.

Tilman, D. 1993. Species richness of experimental productivity gradient: how important is colonization limitation? Ecology, 74(8): 2179-2191.

Tilman, D. y A. El Haddi. 1992. Drought and biodiversity in Grasslands. Oecologia, 89:257264.

Tricart, J.L. 1968. La geomorfología de la Pampa deprimida como base para los estudios edafológicos. INTA (ISA) tirada interna, 102 pp. Buenos Aires.

Thurow, T.L. 1989. Decomposition of grasses and forbs in coastal savanna of southern Somalia. African Journal of Ecology 27: 201-206.

van Veen, J., Liljeroth, E., Lekkerkerk, J., van de Geijn. 1991. Carbon fluxes in plant-soil systems at elevated atmospheric $\mathrm{CO}_{2}$ levels. Ecological Applications, 1:175-181. 
Vargas Gil, J.R. y C. Scoppa. 1973. Suelos de las Sierras de la Provincia de Buenos Aires. Revista de Investigaciones Agropecuaria, Serie 3 Clima y Suelo, 10 (2): 57-79.

van der Marel E y A Titlyanova. 1989. Above-ground an below-ground biomass relations in steppes under different grazing conditions. Oikos, 56:364-370.

Vitousek, P.M. 1982. Nutrient cycling and nutrient use efficiency. American Naturalist, 119:553-572.

Walter, H. 1977. Zonas de vegetación y clima. Ediciones Omega. Barcelona. pp: 158-184.

Webb, W.L., Lauenroth, W.K., Szarek, S.R. y R.S. Kinerson. 1983. Primary production and abiotic controls in forests, grasslands, and desert ecosystems in the United States. Ecology, 64 (1): 134-151.

Webb, W.L., Szarek, S.R., Lauenroth, W.K., Kinerson, R.S. y M. Smith. 1978. Primary productivity and water use in native forest, grassland and desert ecosystems. Ecology 59 (6): 1239-1247.

Weisberg, S. 1980. Applied linear regresion. J. Wiley, New York.

Wieder, R.K. y G.E. Lang. 1982. A critique of the analytical methods used in examining decomposition data obtained from litter bags. Ecology, 63:1636-1642.

Wilson, A.M. y K. Thompson. 1989. A comparative study of reproductive allocation in 40 British grasses. Functional Ecology 3:297-302.

Woodmansee, R.G. y D.A. Duncan. 1980. Nitrogen and Phosphorus Dynamics and Budgets in Annual Grasslands. Ecology, 61 (4):893-904.

Woodmansee, R.G., Vallis, L. y J.J. Moott. 1981. Grassland Nitrogen. En: Clark, F.E. y T. Rosswall (Eds.). Terrestrial Nitrogen Cycles. Ecol. Bull. (Stockholm) 33: 443-462. 